Portland State University

PDXScholar

Fall 10-21-2016

\title{
The Village Market: New Columbia Goes Shopping for Food Justice
}

Jane Therese Waddell

Portland State University

Follow this and additional works at: https://pdxscholar.library.pdx.edu/open_access_etds

Part of the Food Security Commons, and the International and Community Nutrition Commons Let us know how access to this document benefits you.

Recommended Citation

Waddell, Jane Therese, "The Village Market: New Columbia Goes Shopping for Food Justice" (2016). Dissertations and Theses. Paper 3288.

https://doi.org/10.15760/etd.3279

This Dissertation is brought to you for free and open access. It has been accepted for inclusion in Dissertations and Theses by an authorized administrator of PDXScholar. Please contact us if we can make this document more accessible: pdxscholar@pdx.edu. 
The Village Market:

New Columbia Goes Shopping for Food Justice

\author{
by \\ Jane Therese Waddell \\ requirements for the degree of \\ Doctor of Philosophy \\ in \\ Urban Studies

\section{Dissertation Committee: \\ Karen J. Gibson, Chair \\ Nathan McClintock \\ Maude Hines \\ Siobhan C. Maty}

A dissertation submitted in partial fulfillment of the

Portland State University

2016 
(C) 2016 Jane Therese Waddell 


\begin{abstract}
The Village Market is a nonprofit Healthy Corner Store that has been open since May of 2011 in the mixed-use, mixed-income New Columbia housing development in Portland, Oregon's Portsmouth neighborhood. The venture began as a "community-led" effort in partnership with Janus Youth Programs and Home Forward. The project was conceived after a private enterprise in the small grocery space designed into the development failed, leaving the neighborhood without easy access to healthy foods. This dissertation is a case study of the development process, the operation of the market, and the degree to which it addresses food justice and health equity concerns, among others, of residents. It is a case study of the Healthy Corner Store movement that uses food regime theory and political economy perspectives to critically examine the translation of Healthy Corner Store movement theory into practice, highlighting the perspectives of New Columbia residents on the endeavor. It explores the transition of the store from a community-led project to a management-led social enterprise, and the impacts of that approach on local autonomy, food justice, health equity as well as its successes and shortcomings. The store's situation in a mixed-income community meant that it had a particularly diverse set of expectations to navigate, and the changes to the store over time reflected Village Market's growing understanding of the implications of that situation but also a limited capacity to accommodate residents' differing tastes and the price sensitivity that many of them exhibited in their shopping habits.
\end{abstract}




\section{Acknowledgements}

It has now been some years since I embarked on a quest for a "right livelihood" that took me back to school. I was very much following my nose, and went down many rabbit holes in the process. I probably took enough credits to fulfill a second master's degree as I figured out where I did and didn't fit. While it is by no means complete, my journey thus far has benefitted greatly from the contributions of some wonderful people.

A few individuals helped me discover critical pieces of the jigsaw. I am particularly beholden to Claire Strawn and Priya Kandaswamy, in whose courses I finally found what I had been looking for but didn't yet have words to articulate. Sy Adler and Sheila Martin gave me much to consider with respect to how my interests related to disciplinary boundaries. My dear friends and colleagues, Ron Pate and Marianne Ryder, offered invaluable intellectual companionship that helped me see this whole project through to completion.

Initial committee members Ellen Basset and Barry Messer offered insights into my proposal that helped me refine my research questions and temper my expectations. Enduring committee members Siobhan Maty and Maude Hines encouraged my work, helped me stretch outside my comfort zone, and provided thoughtful feedback. Karen Gibson was a wonderful chair and editor who encouraged me to find my own voice. Special thanks go to Nathan McClintock, my pinch-hitting committee member, for his willingness to come in relatively late in the game as well as for his meticulous editing.

Robert Ingram, Carolyn Parsons, Charles Robertson, and Therese Lugano all played critical roles in this project, helping me to better understand the community I was researching (and the communities within it) and connecting me with people to talk with. I 
must also thank everyone who agreed to be interviewed for sharing their perspectives with me. I learned so much from you, and I hope I represented you faithfully.

This project attuned me to the judgment entwined in our beliefs about food and nutrition. My fearless leader at Clackamas County Extension, Kelly Streit, provided me an example of nutrition work done with empathy and participant direction through her Plot to Plate program. Thanks to her and all of my fellow Master Food Preservers/Family Food Educators past and present for giving me much food for thought.

To my friends and family, I am grateful for all you did to help me on my path. The Menze and Ude clans have cheered me on in all my pursuits. Nathalie Weicker had a knack for calling me just when I needed to talk. Diane Yensen enticed me out for many a row and run that kept me moving forward even when I felt stuck. Coach Lisa Schlenker taught me to push myself beyond what I thought were my limits on the water. It gave me the confidence to take on such an ambitious project on land. Bill McMillen issued me a much-needed pep talk when things looked pretty bleak and reminded me that failure was not an option. And, through her jewelry studio, Cindy Proctor provided a welcome respite from the drudgery of the research process and became a friend and mentor. I don't think I could have gotten through all that transcription without the creative outlet I found there.

Two special men have made all the difference. My husband Ed was an unwavering source of support along the way, and most importantly, knew how to make me laugh when I really needed it. My father, Robert J. Waddell, has encouraged me in all my endeavors for as long as I can remember. Words cannot express how much I love you both. 


\section{Table of Contents}

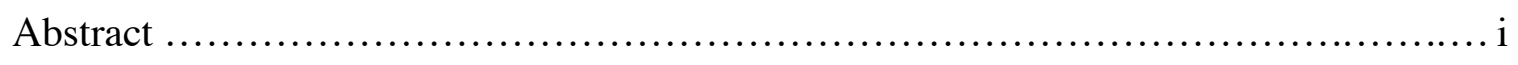

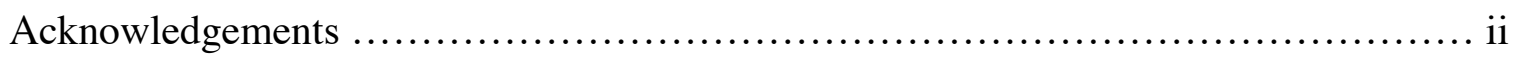

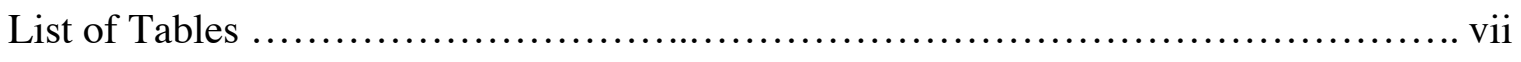

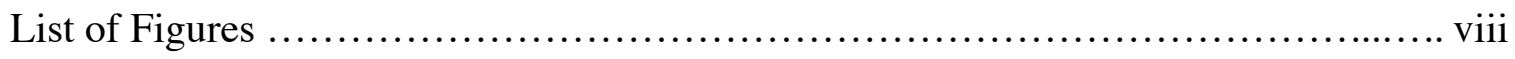

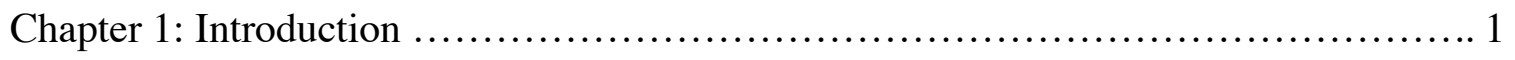

Research Problem and Context ................................................ 1

Theoretical Orientation ....................................................... 3

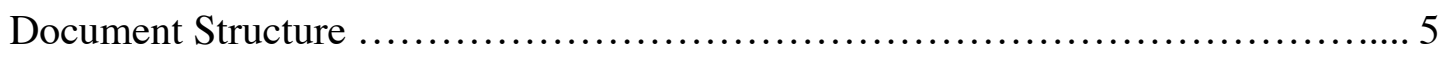

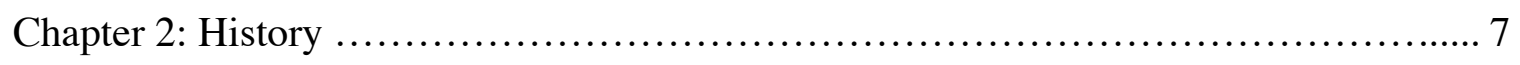

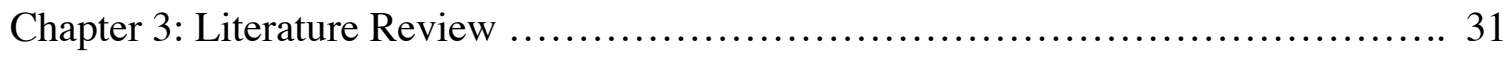

Mixed-Income Communities ............................................... 34

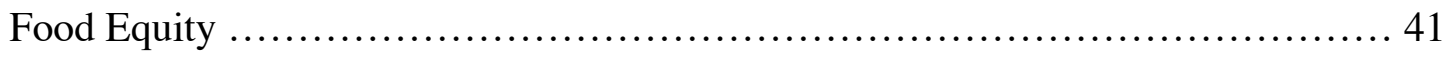

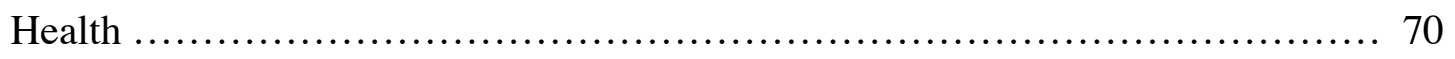

The Social Economy as Economic Development ............................ 90

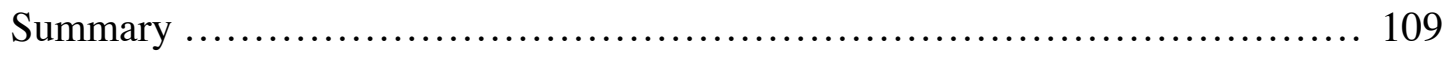

Chapter 4: Research Design and Methods .................................... 113

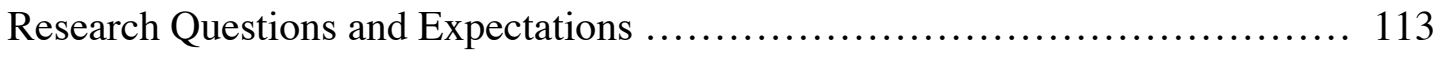

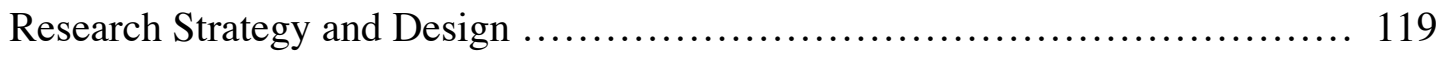

Chapter 5: Varied Perspectives on Food and Health ............................ 136

The Healthy Corner Store Movement ...................................... 136

The Village Market ........................................................ 146

Resident Non-Participants .............................................. 166

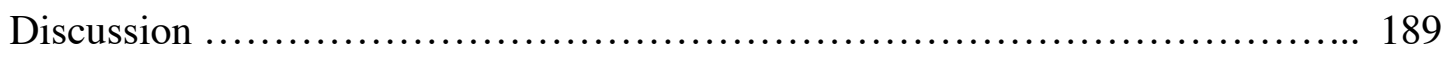


Chapter 6: The Nonprofit Dimension ..................................... 195

Village Market Outcomes ............................................ 197

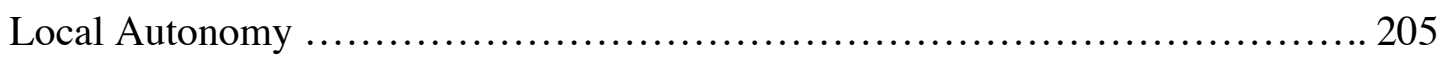

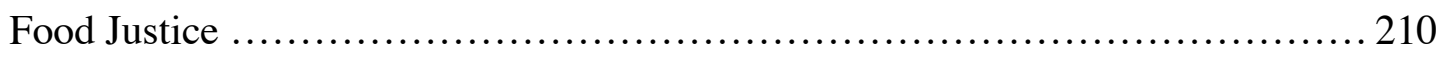

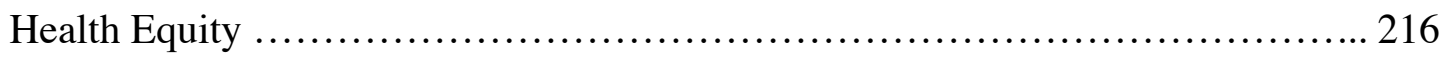

Discussion ............................................................ 220

Chapter 7: Mixing Incomes, Ethnicities, and Ages ......................... 227

Subsidized Senior Renters ......................................... 227

Subsidized Renters ................................................... 231

Market-Rate Residents and Neighbors .................................. 237

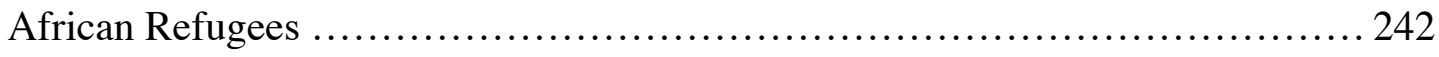

Latin American Immigrants \& Refugees ................................ 243

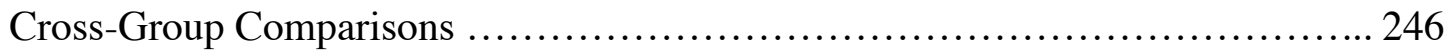

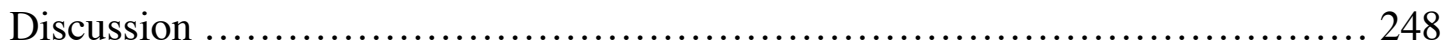

Chapter 8: Findings, Conclusions and Limitations ........................... 258

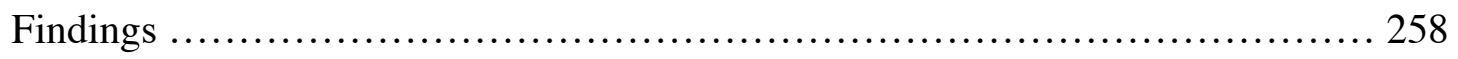

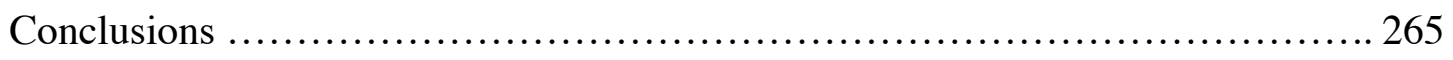

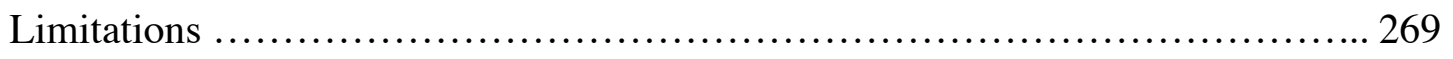

Contributions to Scholarship, Policy, and Practice ......................... 271

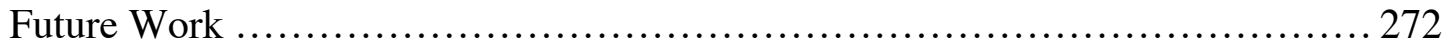

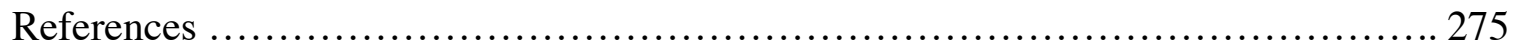

Appendix A: SAMPLE INTERVIEW QUESTIONS ........................ 316

Appendix B: FOCUS GROUP OUTLINE - GENERAL ....................... 318

Appendix C: FOCUS GROUP OUTLINE - IMMIGRANT \& REFUGEE GROUPS . 320 
Appendix D: FOOD REGIMES AND FOOD MOVEMENTS TYPOLOGY ......... 321 


\section{List of Tables}

Table 1: Comparison of Census Tracts 39.01 and 40.01 Pre and Post Redevelopment .. 12

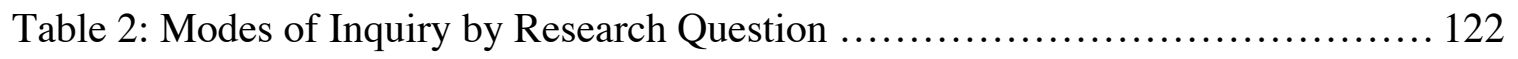




\section{List of Figures}

Figure 1: High Poverty Hot Spots in North Portland $\ldots \ldots \ldots \ldots \ldots \ldots \ldots \ldots \ldots \ldots \ldots \ldots \ldots$

Figure 2: Half Mile Radius around the Village Market ........................ 19 


\section{Chapter 1: Introduction}

\section{Research Problem and Context}

During the 1960s and 1970s, around the time when many whites left cities for the suburbs, grocery stores followed, leaving central cities with very few full service grocery stores (Nayga \& Weinberg, 1999). Low-income communities both urban and rural were often left with smaller, more expensive markets that had relatively lower quality and selection than full-service grocery stores (Nayga \& Weinberg, 1999; Shaffer, 2002). As a result, these populations often have greater difficulty accessing healthy food than their suburban counterparts. Areas without convenient access to full-service grocery stores became known as "food deserts." Food deserts are regarded as particularly problematic for seniors and those without access to cars (Nayga \& Weinberg, 1999; Flournoy \& Treuhaft, 2005; Treuhaft \& Karpyn, 2009). Disparities in food access are implicated in poor eating habits, and improving access to healthy food has become a particular concern for some scholars and policymakers interested in increasing health equity (Shaffer, 2002; Winne, 2004; Flournoy \& Treuhaft, 2005; Public Health Law and Policy [PHLP], 2009). Widespread concern over increased rates of obesity and Type 2 diabetes in the U.S. has rendered the dearth of full-service grocery stores in low-income communities, urban and rural, much more visible to public health advocates, policymakers, nonprofit organizations, and academics. Scholarly and practical debates over food deserts and what to do about them has ensued. One strategy has been to enlist the corner stores that proliferate in these communities to improve their selection of goods. Most Healthy Corner Stores, as such enhanced stores are called, are small markets whose owners have agreed to increase their offerings of affordable, healthy foods, often in exchange for 
material and technical support as they make this transition (PHLP, 2009). Academic research on these types of stores has focused on the perspectives of storeowners (Song et al., 2010), changes to the food environment (Gittelsohn et al., 2007), logistical challenges (Song et al., 2009; Gittelsohn et al., 2010), or behavioral changes (Gittelsohn et al., 2010). Much of it is approached from a positivist methodological paradigm. What is largely missing are in-depth, interpretive accounts of the perspectives of people living in the communities where these stores operate, and a more holistic look at the food, health, and other concerns that they have. Also absent is research that considers Healthy Corner Stores from a critical perspective. Health equity concerns in this arena rarely encompass a broader critique of systemic socioeconomic inequality. They are generally focused on diet quality and the improved access and nutrition awareness they see as necessary for the requisite behavior changes.

The research described herein is a critical case study of the effort to build and operate a small grocery store in an area of North Portland that is considered a "food desert." The Village Market is a nonprofit Healthy Corner Store planned and created with community involvement. This case study uses a critical, interpretive approach to examine Village Market as a food justice and health equity project. One question examined is how this store makes a difference in people's daily lives, particularly as relates to their ability to tend to their essential food needs. Another is the degree to which this project has been shaped by the involvement of well-meaning, white, middle class folks (including myself) who have been involved in many of its dimensions, as well as by the influence of larger social discourses that advance particular visions of food justice and health equity. The nonprofit approach is one aspect of the store that motivated in-depth examination for 
such influence, as constraints stipulated by funding grantors and reliance on volunteers are part and parcel of the nonprofit modus operandi that both create opportunities for influence to occur. The products in the store itself are another dimension considered. The 1700 square feet of shelf space means that there are significant constraints on the range of products that it can stock, inspiring questions about whether and how such a store can serve the diverse population living nearby. Because New Columbia is home to residents ranging in affluence from public housing renters to market-rate homeowners and also includes many immigrant and refugee populations, the store provided an opportunity to consider in a concrete way how closely neighbors' tastes align and what that implies for mixed-income communities in general.

\section{Theoretical and Epistemological Orientation}

My theoretical perspective on this project is influenced by scholarship that argues that our social world is shaped in ways both subtle and overt by voices of those in positions of power (Gordon, 1997), and that race (Omi \& Winant, 1986) and gender (Glenn, 1999) have been socially constructed in ways that obscure the privilege that members of dominant groups enjoy. This privilege has infused our social structures (Brown, 1992; Harris, 1993) in ways that are harmful to many subordinate groups, but particularly so to people of color (Gilmore, 2002). While race as a construct has social origins, racism has produced physical outcomes, manifesting very tangibly in health disparities (Gravlee, 2009), yet these disparities are commonly attributed to behavioral rather than social causes. Failure to meaningfully include subordinated 'others' in social dialogues effectively reinforces privilege while at the same time masking it (Scott, 1986). My intent is for this research to inquire into the ways that power and privilege have 
shaped the Healthy Corner Store movement by looking at this store and how it departs from the usual approach, asking both participants and community members at large for their views on the project, and interpreting the meanings of this change in model.

Epistemologically, my research approach was guided by the belief that some perspectives are especially valuable for considering how power manifests in everyday life. This begins with questioning the notion of objectivity. Donna Haraway argues that rather than accepting a disembodied objectivity in the pursuit of science, we must recognize that knowledge is situated in and mediated through a physical body (1988). Moreover, "“subjugated' standpoints are preferred because they seem to promise more adequate, sustained, objective, transforming accounts of the world" (584). Dorothy Smith notes how "relations of ruling" are embedded in the discourses that shape our institutional frameworks and how the standpoints of women explored through an investigation of everyday life are useful for revealing the gendered subtexts of those discourses and the cultures they create (1987). Works by Patricia Hill Collins (1986) and Gloria Anzaldua (1999) helped me consider how this standpoint epistemology extended to race, class and other dimensions of difference as well as their intersections. Guided by Nancy Naples (2003), I consciously adopted a materialist feminist framework in order to draw out knowledges that I felt were absent from policy-level discussions about food and health, specifically those stemming from the everyday lives of the socially and economically diverse population of the neighborhood surrounding the store. Liberating my own consciousness was an important part of this entire project, and remains an ongoing process (Sandoval, 2000). I made a particular effort to seek out voices that were 
absent from project participation in a way that was mindful of my own privileges (Lugones \& Spelman, 1983) and incorporated those voices into the story of the store.

That story was used to consider the benefits and limitations of the Village Market project, using selected academic literatures to guide the inquiry. These literatures have been assembled according to subjects that emerged from my participation in the project, and reflect both my perspective as a researcher and the social context in which I was immersed. This is consistent with a second-generation grounded theory approach to research (Charmaz, 2006) and complements the extended case method I also employed (Burawoy, 1991). More particularly, I share the constructivist grounded theory belief that both participants' actions and my own are socially constructed, and that therefore the data produced in the course of this study was constructed mutually (Charmaz, 2009). My hope is that this critical, interpretive approach and the focus on residents' perspectives will encourage those who engage in this movement to consider whether they are denying the complex personhood (Gordon, 1997) of the people whose lives they are seeking to improve and draw attention to the need to address the underlying problems, as well as the immediate concerns.

\section{Document Structure}

Chapter 2 of this study begins with a scan of some Portland history that is relevant to the research site and continues with a more in-depth examination of the events that unfolded as the Village Market project took shape, establishing both the character of the organization behind it and its disposition as a venture. Chapter 3 provides a review of the literatures on mixed income communities, the food and health literatures that relate to the market's aspirations and outcomes, and the social economy. The research questions and 
methodological approach are presented in Chapter 4. Chapters 5 through 7 explore the research questions. Chapter 5 discusses the perspectives of participants in the store project on food justice and health equity, and how they compare to those of both the Healthy Corner Store movement and community members who were not involved in the store. In Chapter 6, the nonprofit dimension of the project is explored more critically for its influence on the store's outcomes generally, but also more specifically on local autonomy, food justice, and health equity. Chapter 7 delves into the impact that Village Market's situation in a mixed-income community has had on its operations and the implications this has for the advocacy of mixed-income communities. The final chapter, Chapter 8, discusses the implications of the findings and offers suggestions for future research. 


\section{Chapter 2: History}

The Village Market is situated in North Portland's Portsmouth neighborhood, on the now re-developed site where Oregon's largest public housing project, Columbia Villa was located. Columbia Villa was a suburban-style development of 164 one and two story wood-framed buildings on 82 acres of curvilinear streets (Blake, Abbott, \& Lindberg, 1990) that at its peak provided 462 units of housing (Gibson, 2007b). The buildings were constructed in 1942-3 during the boom Portland experienced as defense workers moved here by the thousands to build ships for the war effort. It was well regarded as a place to live through the early 1960s, but by the mid 1970s, not long after African Americans were allowed to move in (Becker, 2015), the development acquired a stigma (Gibson, 2007b). An influx of gang members in the mid 1980s led to problems with drugs and violence and the first gang-related drive-by shooting in Oregon (Curl, 2003). A comprehensive intervention strategy was successful in reducing crime in the neighborhood, but the stigma lingered (Gibson, 2007b). By the early 2000s, infrastructure was in poor condition (ibid). In June of 2001, the Housing Authority of Portland (now known as Home Forward) applied for HOPE VI funding from the U.S. Department of Housing and Urban Development to redevelop Columbia Villa. They worked with residents and citizens from the larger Portsmouth neighborhood for a year to develop a plan for the project, and were successful in their application (Portland, 2002). At the time of its redevelopment, Columbia Villa was the most diverse neighborhood in the state and had 37\% non-Hispanic white residents, roughly one third African American residents, and fourteen different languages spoken (Gibson, 2007b). In spite of the stigma and the declining state of the buildings, two thirds of the population did not want to move. After 
relocation, many residents reported missing the natural setting of "the Villa," and adults as well as children, particularly African Americans, missed the close relationships they had formed (ibid). As sections of the redevelopment were completed, residents were gradually brought back. This began in May of 2005, and by late 2006, everyone who was able to return, about $30 \%$ of former residents, was back (ibid).

A major redevelopment goal was to make the new development more integrated with the rest of the Portsmouth neighborhood that surrounded it (Portland, 2002). This intent manifested in physical as well as social forms. The curvilinear streets were reconfigured to connect with the grid of the surrounding neighborhood and a "village square" was created so that New Columbia would be able to have a thriving Main Street to draw in residents from the larger Portsmouth neighborhood. Space for a small grocery was built into the development to anchor that Main Street activity. Populations were realigned as well as the streets. New Columbia included market-rate and low-income home ownership options and market-rate rentals in addition to Section 8, public housing and affordable rentals. Improving the prospects for people to connect across social boundaries was part of the social project. In addition to an influx of wealthier residents, nearly 100 of the poorest residents were reportedly going to be permanently relocated rather than be allowed to return $(\mathrm{Curl}, 2003)$ because of the loss of 92 units of public housing.

The relocation of Columbia Villa residents came at a time when many North and Northeast Portland neighborhoods, historically where Portland's African American community was concentrated, were experiencing gentrification. When residents were initially given notice to vacate Columbia Villa, two thirds of them wanted to remain in 
North Portland. Although Home Forward put a great deal of effort into encouraging landlords to accept Section 8 vouchers, they were still not able to place a third of residents in their first choice location, and the housing situation became even tighter the following year (Gibson, 2007b). Gentrification in North and Northeast Portland followed a long history of successive displacements of residents and businesses by urban renewal, disinvestment, and redlining that substantially weakened the social fabric of African American communities and left many residents embittered (Gibson, 2007a; Hosford, 2009). So, in addition to the changes happening as Columbia Villa morphed into New Columbia, the community surrounding it was also becoming more white and more affluent. These changes were uneven, impacting some neighborhoods more than others. Several community development corporations (CDCs) had been actively developing affordable housing in Inner North and Northeast Portland. Their efforts further primed their neighborhoods for transition (Brown, 2011). Although the housing stock the CDCs created was preserved, the changing demographics meant that many churches and businesses that were part of the daily lives of residents were struggling as their customers and congregants moved further east.

Census data from 2000 and 2010, and the most recent American Community Survey for the two tracts that encompass New Columbia appear in Table 1. Tract 40.01 contains most of New Columbia, including the Village Market. Tract 39.01 contains the remainder of the development and also includes the Tamarack apartments, a public housing complex also owned by Home Forward. I provide the data for both tracts both because it is at the tract level that SNAP acceptance is tracked and because the half mile radius surrounding the store includes the vast majority of tract 40.01 and much of 39.01 . 
Tract 39.01, however, is much more affluent. A recent report describing Portland's "High Poverty Hotspots" identified tract 40.01 and the tract in the St. John's neighborhood to the west of it as areas of concern (see Figure 1 for their map of the area) (Oregon Department of Human Services, 2015). The way the U. S. Census treats race and ethnicity has been changing in an attempt to better reflect the growing diversity of the country. The 1980 census was the first to include a question on Spanish/Hispanic descent on the short form (Gauthier, 2002). Beginning in 2000, individuals could select multiple race categories to describe themselves. While this change better allows the census to capture the lived realities of the many Americans with mixed heritage, it makes comparing data across time a little more challenging. Although I did not use any U.S. Census data from before 2000 directly, I chose to use the "single race" category for White and Black categories and list multi-racial individuals separately in order to maintain some comparability to historical references of racial composition of the neighborhood that would reflect prior censuses.

The redevelopment of Columbia Villa replaced the 462 public housing units with 232 owned homes, 186 affordable rental units, 66 subsidized senior apartments, and 370 units of public housing, 72 of which were project-based Section 8 (Housing Authority of Portland, 2007). This was a loss of 92 units of public housing that were to be replaced at other sites in the Portland area (ibid). While this loss represented $20 \%$ of the public housing units at Columbia Villa, nationally, HOPE VI redevelopments resulted in losses of almost half of their total public housing units or approximately $22 \%$ of their occupied units (Popkin et al., 2004). Affordable homeownership opportunities at New Columbia constituted 55 of the 226 homes, and just under half (47\%) of the initial homeowners 


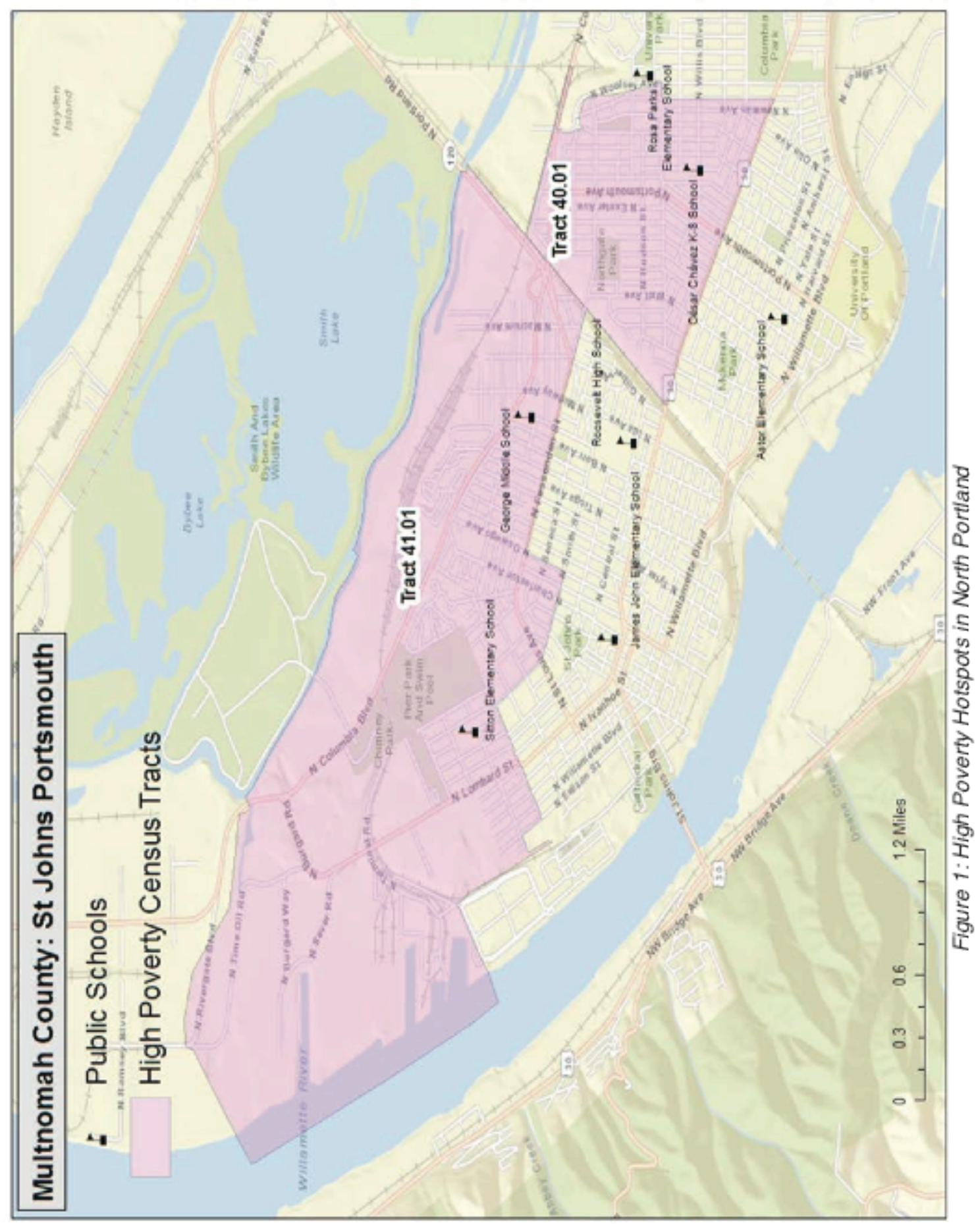




\begin{tabular}{|l|l|l|l|l|l|l|}
\hline & \multicolumn{2}{|c|}{$1999^{1}$} & \multicolumn{3}{c|}{$2010^{2}$} & \multicolumn{2}{c|}{$2014^{3}$} \\
\hline Tract & 39.01 & 40.01 & 39.01 & 40.01 & 39.01 & 40.01 \\
\hline$\%$ White alone & 55.0 & 52.4 & 56.2 & 46.0 & 58.9 & 44.5 \\
\hline$\%$ Black alone & $19.1^{*}$ & $12.8 *$ & 15.1 & 18.7 & 16.3 & 20.7 \\
\hline$\%$ Hispanic & 12.5 & 20.0 & 16.3 & 23.6 & 14.4 & 21.6 \\
\hline$\%$ Multi-racial & 6.7 & 6.7 & 7.8 & 6.9 & 5.0 & 5.9 \\
\hline $\begin{array}{l}\text { \% Below Poverty } \\
\text { (households) }\end{array}$ & 14.1 & 25.0 & 19.0 & 30.6 & 16.4 & 43.1 \\
\hline $\begin{array}{l}\text { \% SNAP acceptance } \\
\text { (households) }\end{array}$ & N/A & N/A & 19.7 & 36.4 & 23.6 & 48.2 \\
\hline
\end{tabular}

Table 1: Comparison of Census Tracts 39.01 and 40.01 Pre and Post Redevelopment

${ }^{1} 2000$ U.S. Census, Summary File 1, Summary File 3 (for poverty data)

${ }^{2} 2010$ U.S. Census, Summary File 1, 2006-2010 ACS Survey 5-Year Estimates (for poverty and SNAP data)

${ }^{3}$ U.S. Census, 2010-2014 ACS Survey 5-Year Estimates

* the 2000 U.S. Census did not have individual estimates for the non-Hispanic Black population, only household estimates. These percentages are for the Black population claiming a single race.

were people of color (ibid). The social diversity of the previous neighborhood was preserved and the economic diversity increased. Just after redevelopment, households in New Columbia that were Section 8-based, affordable rentals or public housing were 52\% black (inclusive of both African and African American households), 31.3\% non-Hispanic white, $13 \%$ Hispanic and $1.3 \%$ multi-racial (Collier, 2016). Home Forward does not track demographic information on the market-rate properties. Bringing so many new people together in a new space was not without its challenges. While Home Forward put a great deal of effort into community-building activities, tensions emerged, perhaps in part due to 
the different restrictions placed on renters versus homeowners (Arbuthnot \& Wilhelm, 2009).

Demographic changes in inner North and Northeast Portland shifted both racial and economic characteristics of residents as gentrification advanced in Portland's central core (Hannah-Jones, 2011). These changes were having an impact on restaurants, social institutions, and stores like Big City Market, a small produce-centric grocery store that had long provided soul food staples to the Humboldt neighborhood a little further to the east of New Columbia's Portsmouth neighborhood. It was Big City's owner, Hugh Gray, who was first enlisted to fill the grocery space that Home Forward had built into New Columbia in late 2006 (Johns, 2007). The New Columbia branch of the store was dubbed “Big City Produce.” A branch of a local coffee roaster, AJ Java, occupied a second retail space in New Columbia. Gray closed his original Big City Market store in 2007 due to financial difficulties. It hadn't been profitable for a few years, and he could no longer service his debt (Budnick, 2007). His difficulties may have been reflective of Portland's growing identity as a foodie town and his "old grocery guy" ways and the implications of gentrification for both. Two employees bought the store and re-opened it after just a day of closure, renaming it Cherry Sprout Produce. The new owners found ways to negotiate a balance between providing the foods that long time customers wanted and stocking things that would appeal to the residents new to the neighborhood. They made some adjustments to their ordering practices and moved into positive financial territory not long after they transitioned (Nicols, June 9, 2014, interview). The New Columbia branch of Big City, although it outlasted the original, closed in 2009, and AJ Java closed as well. Although I heard numerous stories offering explanations for why Big City Produce 
closed, the larger economic context presumably figured into the difficulties both businesses faced. Portland as a city and Oregon as a whole were hit particularly hard by the Great Recession (Sum \& Khatiwada, 2009; Manning, 2010). Nonetheless, the Portsmouth neighborhood plan had stated goals to "encourage businesses that provide affordable, healthy food to locate in or near the neighborhood" (Portland, 2002), and planners at Home Forward decided to try again to bring in a healthy neighborhood store (Gilles, 2014). The organization they turned to was Village Gardens.

Village Gardens, the parent organization of the Village Market, is a nonprofit that operates programs intended to empower youth and adult community leaders in the New Columbia and St. Johns Woods communities. They began in 2001 with the St. Johns Woods Garden Project. The project was instigated by community members as a positive response to some negative activity going on there that included a midday shooting on the playground, capped off by a Willamette Week article that labeled it the worst apartment complex in the Metro area (Village Gardens staff member, January 14, 2014, interview). They wanted some positive activities for youth, and their answer came in the form of a garden project that yielded FoodWorks, a youth-led entrepreneurship program, a gardening club for younger children, and another garden for families. In 2005, the garden at St. John's Woods was replicated at the New Columbia site, and FoodWorks expanded to a one-acre certified organic farm on government-owned land on nearby Sauvie Island in 2005 (Village Gardens, 2016). So, at the time Village Gardens was approached about opening a grocery in New Columbia, they had been working with both youth and adults in the neighborhood around food for years. 
Janus Youth, the parent organization for Village Gardens, is a nonprofit that started in 1972 and now operates over 40 programs in Oregon and Washington for youth struggling with homelessness and addiction. It has become one of the largest nonprofits in the Pacific Northwest. Leaders at Janus Youth were skeptical about opening a grocery in the midst of a recession. Initial meetings among Village Gardens participants and staff showed that they, too, were reticent. The organization was already in a state of flux. The founding program director had recently handed the reins over to her successor, three large grants had come through that stretched the organization in other new directions, and many of the staff had been there for six months or less (Village Gardens staff member, November 20,2014, interview). An initial straw poll over whether to take on the grocery store project was $75 \%$ against because it wasn't seen as a good time for Village Gardens to take it on, although there was a great deal of excitement at the community level over the prospect of launching a store (Village Gardens staff member, October 19, 2015, interview). The promise of addressing previously identified goals to provide employment opportunities, connect youth and adult program leaders, and establish a year-round presence in the community combined with pressure from Home Forward to melt that resistance. Once the group began researching the initial questions they identified as critical to moving forward, the project had generated its own momentum. Buoyed by the successes of their other programs, they saw its potential: "No one out there had done it, so we look around, and we're like, we have no idea if this is going to work, but if it did, wouldn't it be so phenomenal?" (Village Gardens staff member, November 20, 2014, interview). They enlisted some help to put together a business plan, and because of the 
scale of the Village Market project and the many other new efforts they were already engaged in, decided to hire a project coordinator.

The coordinator came onto the project in February 2010, after careful screening by community members on the Village Gardens Leadership Team. He jumped right in and organized participants into four committees to look into various aspects of the store: inventory, staffing, marketing, and store layout. He trained them in consensus decisionmaking. Many participants in the store were also Community Health Workers, and they had an additional 40 hours of training through the Community Capacitation Center to develop leadership, facilitation, and communication skills, and gain education around basic health concerns like mental health, chronic diseases and the roles that diet and exercise play in health. They learned about popular education as a means of teaching in a more engaging and egalitarian manner, and had a session on the social determinants of health. Participants had a tremendous amount of energy, and there were store visits, vendor visits, and an initial survey of community members to find out what they wanted in the store. Personalities clashed and arguments flared as people got to know each other and learned how to work together. Some dust got kicked up, but much good work got done.

It was early in 2010 that I first heard of the project, and I finally met the project coordinator and some others involved in the project in April 2010 at the Coalition for a Livable Future Summit where the founding Village Gardens director was doing a "Beyond White Guilt" workshop that I attended. Several African American community members came in towards the end of the session and were both singing her praises and sharing their excitement over the anti-oppression work they were doing together. She 
clearly had gained their love and respect. I learned later that she took particular care to emphasize community leadership. This was evident in how hiring decisions were made within the organization. One staff member hired during her leadership described the process:

I really equate it to a presidential debate ... where, um, went in ... and there were 4 candidates, so all of us were applicants and applying for the job, all sitting in a row, and around this large table were about 20 community members. We had a minute to answer the question, and then the next candidate got the same question. It was super-intense, and they were really strict on time. So, um, I made it through the first round, got into the second round. It was similar in the sense that a lot of community members were there at the interview, but this time it was just me. So there weren't other candidates there in the room, which was nice ... had another interview with them, and then had a one-on-one with the program director at the time ... I passed all the tests. And I tell everybody this, that when I was selected, it really felt like I won the lottery. I was just so blown away by the engagement in community ... that was taking place, and just the people that were invested and really had a say in who was going to be the next person hired (Village Gardens staff member, January 14, 2014, interview).

This emphasis on the decision-making power resting in the community was also reflected in terminology they used around staff who were not residents of either community. They were referred to as "invited staff" to emphasize that they were there serving at the will of 
the community members. Village Gardens had created a subculture within their larger organization that strove to equalize power and for the most part had free reign over their programs.

In the context of the Village Market, which was a much larger project, however, there was greater oversight by the parent organization. The board of Janus Youth Programs provided guidance throughout the creation of the business plan and the initial planning phase as community members developed their ideas around the store layout, features, and products. It was the Janus board whose approval they needed to proceed beyond the investigative phase and on to implementation. At a meeting in June 2010, community leaders, together with a grocery consultant they had brought in, presented their case to the Janus board. They had mapped out the half-mile radius from the store, estimated income, SNAP allotments, and the percentage of residents who owned cars and successfully convinced the board that the market might be fiscally viable and was worth attempting (see Figure 2). The search for grant funding began. Funders, however, didn't catch the vision for the store. They were more focused on whether the group was capable of operating a business. A planned opening day of July 15, 2010 came and went as funding requests were denied. The leadership team kept at it, and support eventually began to trickle in. Grand Central Bakery, a local artisan bread company, offered daily delivery of free bread for their deli sandwiches. They got a letter of support from one of the county commissioners to add to their grant applications. Some smaller grants came through in mid-November, and several other prospects looked promising. A few of these finally came through in December, and the final stages of the project were finally set in motion. All told, the Village Market raised more than $\$ 800,000$ in grant funds 


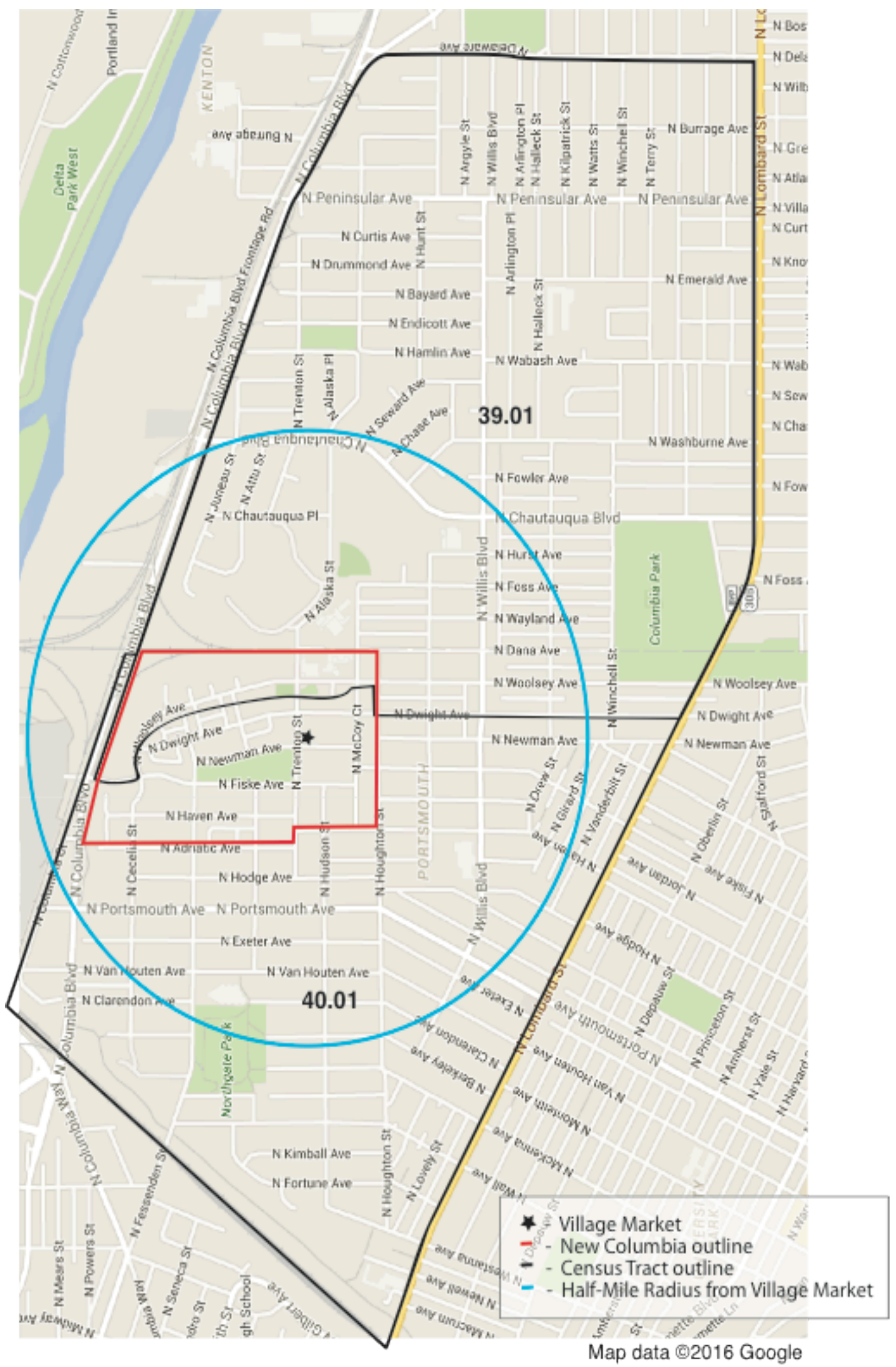

Figure 2: Half-Mile Radius around the Village Market 
(Edgington, 2012). The leadership team began completing some of the physical store projects that had been put on hold during the funding limbo and began looking for a general manager (GM).

They soon hired their first GM, a mid-level manager from a local natural foods chain. The project proved to be too demanding in terms of community dynamics as well as logistics, and an interim manager was brought in to help get the store open after the first GM left. Some discrepancy between the store's aspirations and its realities began to emerge at this point. The grocery consultant they had been working with came from a traditional grocery background and had a long history of working with independent grocers. He served on the board of Unified Grocers, a wholesale grocer cooperatively owned by independent retailers. The interim manager came from a local/organic/natural foods background and had extensive experience in collectively managed member-owned cooperatives. The two had very different perspectives, and the tension between them illustrated an essential tension in the store, both in its operations and in its food. The consensus-based decision-making processes that had been employed throughout the development process gave way to a more hierarchical one in the management of the store. In terms of its food, the sensibilities of Village Gardens participants embraced fresh, local, and organic, while the community at large was very much divided between residents sharing those values and those more oriented toward the standard American diet, albeit with some allowances for the multiplicity of cultures and income levels around both of those camps. Initial objectives for the Village Market focused on healthy foods. They were to stock some organic produce, products chosen to minimize trans fats and high fructose corn syrup, and halal foods like goat and lamb for the Muslim 
community (Law, 2011). But items from Unified Grocer's list of the top 100 sellers for small stores made it on the shelves as well. When the store opened, they had cake mixes and quinoa, Top Ramen and tofu, but a limited selection of sodas and chips. Prices were uneven. A gallon of milk was \$2.69 on opening day (Koffman, 2011), but organic kale was $\$ 3.25 /$ bunch. The prices prompted some unwanted attention. Much to the chagrin of paid staff members who had been working into the wee hours just to get the place set up and functional for the big day, one of the active resident volunteers who had not pursued employment at the store was buzzing about telling customers with authority that prices were going to come down. In some sense, cultivating community stakeholders in the store created some difficulties as the grocery store project transitioned into a social enterprise.

As a business, the nonprofit aspect of the store was not easily discernible to customers who hadn't been involved in the process. It was a store. You went in, grabbed what you wanted, paid for it, and left. Village Market staff were busy learning how to run a grocery, and they didn't have the capacity to examine the larger question of what it meant to be a nonprofit grocery for the first year or so. An advisory council of community members that was formed just before the store opened offered the main venue for continued community involvement with the store. One of the things the committee did early on was to gather comparison data and advocate for lower prices. Strong personalities, inconsistency in leadership and attendance, and difficulty figuring out what work the committee should be charged with led to that group fizzling out. Staff didn't have the time or energy to provide strong facilitation and didn't find the suggestions of people so removed from day-to-day store operations to be particularly helpful or 
welcome. Other volunteer efforts undertaken in the context of the store withered as well. One manager tried to have weekly volunteer nights and a community member spearheaded a volunteer cooking crew to cook up soups using wilting produce. As an organization, Village Gardens was not practiced in creating programs to draw in outside volunteers - their programs are typically run by and for their participants - and these attempts reflected a limited understanding of who participates in such programs and why. At the orientation for the volunteer nights, the manager admitted that he didn't volunteer himself, and it was obvious that beyond trying to make it fun and social, he didn't really grasp what motivated people to volunteer. Building consistent volunteer efforts proved challenging for the Village Market, but no more so than staffing the store.

When the store first opened in May of 2011, they had five clerks from the neighborhood and six people from Seniors Make Sense working there (Koffman, 2011), plus four assistant managers also from the community. The four assistant managers were full-time, the other 11 were part-time (Curtis, 2011). One of the assistant managers had produce expertise and others had food industry experience, but overall there was very little specific grocery experience among staff. Training had been minimal. Although they had been assured that a manager with grocery expertise would be hired, the fourth manager, hired in the summer of 2011, had none. A candidate with good powers of persuasion was able to convince them that he could do the job even though he had no grocery experience, and many people involved in the hiring process didn't have the knowledge they needed to see through his claims. Some community members did, and put his application in the 'no' pile, but staff members moved it back to the 'yes' pile, and ultimately he was selected. This, together with inadequate training, resulted in 
inconsistency in the store. One person would bring back a bad watermelon and get a refund, but another person would be denied the same. A sandwich made by one person staffing the deli would be different than one made by someone else. There were frequent phone calls to the store by customers inquiring about who was working the deli that day because people had their preferred sandwich-makers.

Although the manager was an intelligent man with good business acumen, his efforts to meet what were extremely ambitious goals with what turned out to be a relatively modest level of funding fell short. He made strides learning the business and put in a tremendous amount of effort to do so, but the demands of the position took their toll on his less-developed people skills. He was given financial targets to reach staffingwise that led to unmet hiring commitments to subsidized workforce organizations and undermined staff morale. By the fall of 2012, the deli that had been very popular amongst residents and workers in the neighborhood was closed due to insufficient staffing and employees were disgruntled and on edge. Funds were being embezzled. While apparently employee theft is common in the grocery business, I think it is notable that it occurred in this one. One Village Gardens staffer acknowledged that store employees didn't get the support they needed:

And we asked so much of folks. We didn't have anyone to help train them, we threw them in, um, and we said, by the way, now you're your friend and neighbors' boss, and you are the gatekeeper to this incredible resource of money and products, and all this stuff ... it was just a lot to ask of people ... without a leadership support that was ... really in place. And solid. (November 20, 2014, interview). 
Inexperience in the grocery business meant that for the first few years, systems didn't get properly developed and the details that make a store run smoothly and efficiently were not getting tended to.

The grocery business itself proved to be more challenging than expected, and grant funds didn't go as far as was hoped. The higher prices that smaller stores pay for inventory significantly impacts the prices they charge, and New Columbia residents demonstrated extreme price sensitivity. Demand for produce didn't meet expectations, and the cost of keeping a 30' cooler stocked and fresh was a real challenge, especially after the Assistant Manager with produce expertise moved away. Once they learned how sensitive the community was to price, store management scaled back their expectations of being able to sell much organic produce in the store (Swart, 2012), but by the fall of 2012, the losses had taken their toll. The threat of closure led to a re-figuring of staff positions and a reconsideration of the larger store project, including some of the values they had ascribed to. Instead of replacing the manager that left, two staff members from other Village Gardens programs took on the task of revamping the store. One worked on the prepared foods aspect of the store, the other on the general systems and processes. Never again would there be eight cases of 16 oz cups cached and forgotten in various cubbies around the store! They were able to consult with Lisa Sedlar, a local grocery whiz who had just opened a small high-end grocery called Green Zebra nearby. She helped fine-tune the business aspect and had her chef give the prepared foods team instruction in making sandwiches and other deli items. The changes got noticed. People who had stopped coming when the deli closed began to filter back in. The store got a physical reset as tall shelves were shortened to improve interior visibility. The product 
mix changed significantly, too. Initial product selections and omissions that seemed personal and arbitrary were amended so that the store stocked Coke as well as Pepsi. A suggestion box was put on the counter, and products were brought in accordingly. FritoLay snacks were added to accompany the Kettle Chips that were already there. The store turned a corner and managed to secure an additional federal grant (Gilles, 2014). With that and some continued assistance from local government in the fall of 2013 , they have been able to keep the doors open, but as of the fall of 2015 have not yet had a profitable month. However, management indicated that profitability is not necessarily their goal.

While many of the Village Market's early struggles with their venture are certainly attributable to their lack of grocery experience, the present day realities of the grocery business present significant obstacles to operating any small grocery, especially one without higher margin items like alcohol and cigarettes. Margins are thin industrywide and stores need volume to be successful. Regular size stores are typically in the red for the first 5 years and are expensive to open (Griffin, 2013). According to the Food Marketing Institute, a research and lobbying group for the industry, earnings are typically $\$ .02$ per dollar spent for food stores (ibid). Once dominated by small stores with personal service, the grocery industry has undergone tremendous change in the last century. This began with the advent of chains of small footprint stores, like the Great Atlantic and Pacific Tea Company, popularly known as A\&P. The chain gained economic power and was able to use it to bargain away the broker fees that independent grocers were subject to. This led to other changes, like its experimentation with all-in-one stores. The success of that format led to A\&P's further market dominance, aided by vertically integrated supply chains of factories, warehouses, and trucks (Ellickson, 2011). This produced a 
backlash of anti-chain sentiment. A\&P was the original Wal-Mart. Legislation was enacted to try to equalize the prices that independent stores paid, but enforcement of the provisions of the Robinson-Patman Act of 1936 has waxed and waned. Some independents dealt with the situation by forming wholesale cooperatives, like the Unified Grocers cooperative that sources many of Village Market's grocery items. Wal-Mart's entry into the grocery business has produced a similar impact to that of A\&P on independent stores, and the bankruptcy of many small chains has been attributed to their presence (ibid). Changes in the grocery industry have rippled throughout the economy. The advent of cheap food meant that people could subsist on less income, making possible the lowering of wages everywhere else (Wrigley, 1999).

While nostalgia for days of mom and pop markets and dreams of 20 minute neighborhoods make the creation of small but nutritionally complete grocery stores like the Village Market appealing, the realities of the industry raise questions over who such stores can serve. Green Zebra, occupying a space that was a Safeway in the 1950s, had its first profitable month in November 2014, about a year after they opened (Marum, 2014). Their success may be attributable to the gentrifying neighborhood as well as the skill of the owner, as seems to be the case with Cherry Sprout. Cherry Sprout implemented changes to better track inventory and manage vendor relations, but management indicated that serving customers with more money to spend has contributed to their success (Nichols, June 19, 2014, interview). They continue to work really hard to please their long-time clientele, too, taking care that their greens are trimmed and fresh even though they make less margin on them because they want to demonstrate their commitment. Nichols said that $25-30 \%$ of their produce business is yams and greens, and they'll sell 
400 cases of greens at holiday time. But while Cherry Sprout fills a valuable market niche for African Americans, those shoppers often contain their purchases at the store to greens, yams, and specialty meats. There may be many reasons for this, but one explanation is price. While their relationships with small vendors mean that they occasionally get random deals on things (Budnick, 2007), the notion that smaller stores may be in a better position to compete with large chains in a climate of rising food and gas prices (Shum, 2008) seems questionable where low-income shoppers are concerned. My interviews with New Columbia residents who mentioned Cherry Sprout to me suggested that price is indeed a significant factor in where they shop. They simply need to shop at big stores that have lower prices in order to make their food budgets work, even if it means a long bus ride or car ride. The prospects for Village Market achieving financial independence may rest on the degree to which they can draw in more affluent customers as Cherry Sprout and Green Zebra have done, or develop further capacity to reduce their costs. They have at times been able to affordably source produce from their FoodWorks program, so they have some resources that other businesses do not. They may also be able to further leverage their nonprofit status with vendors, but that prospect remains largely untapped. Claims that its status as a nonprofit would allow Village Market to make prices more affordable than other small groceries (Waldroupe, 2011) remain in doubt. Many residents of New Columbia have seen their food budgets decline in the period that the Village Market has been open, and for the store to be useful for more than emergency use or snacks to the least affluent residents, greater effort in this direction seems necessary. 
Any discussion of the store's prospects must also consider the larger economic context. For the fiscal year that ended in June 2011, the first full month the market was open, demand for food boxes was up $12 \%$ over the previous year and food stamp participation rose steadily from July 2008 to August 2011, climbing 60\% in spite of a peak in unemployment in June 2009 (Read, 2011). The Great Recession was maintaining its tight grip on Oregon. Department of Agriculture statistics showed that the state had the highest rate of child food insecurity in the country at the time (Sarasohn, 2011). Further, Oregon's economic recovery from the economic downturn has been uneven across time and population. Although there was some improvement statewide in very low food security and also a small decrease in households experiencing food insecurity at any point in 2009-2011 (Budnick, 2012), both indicators increased in the following 2-year period. Very low food security (food insecurity with hunger) increased to $6.3 \%$ for the 2012-2014 period, and low food security (food insecurity without hunger) also rose to 16.1\% for that period (Oregon Center for Public Policy, 2015). The "recovery" from 2009 to 2012 left the incomes of the bottom 40\% lower by 6\% nationwide (Krugman, 2013), and Oregon was no exception. Statistics from the Oregon Center for Public Policy estimated that $7.9 \%$ of Oregon's population was living in deep poverty in 2012, a level of income half that of poverty, whereas that level had been 6.3\% in 2009 (Street Roots, 2013).

This hardship was sustained at a time when available resources were shrinking. While they were struggling to meet record demand in 2012, The Oregon Food Bank expected a 6 million pound decrease in the amount of food they would get from the federal government for 2013 (Sarasohn, 2012). The federal Women, Infants, and 
Children program (WIC) program was also getting cut $\$ 500$ million at the federal level and additional cuts were being planned to block grant programs that funded hunger relief (ibid). Debates over SNAP (food stamps), among other provisions, meant that the 2012 Farm Bill didn't get passed until February of 2014 and included $\$ 8$ billion in cuts to food stamps over 10 years (Nixon, 2014). Cuts to the program in Oregon began in the fall of 2013, when economic stimulus money that had been directed to the program expired. Individuals lost \$11 a month, and families of four \$36 (Myers, 2013). Cuts to food stamps and a late Thanksgiving meant there was an especially high demand for holiday food boxes that year (Zheng, 2013). Neither have things improved since then. While Oregon's economy grew by 3.5\% from August 2014 to August 2015 (Young, 2015), more Oregonians were living in poverty in 2014 (16.9\%) than were during the recession (13.4\%-14.3\% in 2008 and 2009, respectively) (Oregon Center for Public Policy, 2015). As people across the state struggled, so did those in the neighborhood and for many New Columbia residents the Village Market was not viewed as an affordable place to shop. Prices did show some movement in the right direction, however. By fall of 2011 , produce prices at least for some things in the store were more competitive: garlic was 3 heads for $\$ 1$, collard greens $\$ 1 /$ bunch, and kale $\$ .75 /$ bunch. For a time, the store made a commitment to pricing greens at $\$ 1 /$ bunch even though they sometimes lost money on them, but they ultimately abandoned this practice. Nearly all of the residents I spoke with over the four years I conducted interviews mentioned their prices as being at least something of a barrier to them doing much shopping there. The store's ability to get a sufficient volume of customers may have contributed to their financial woes, as nearby violence nearby may have deterred shoppers. Shootings near the store's location, one in 
2010 before the store opened, and another the summer it did open led to increased patrol of the neighborhood (Anderson, 2012) but may have made people from the surrounding neighborhoods reluctant to venture over to "The Villa."

In a larger context of deepening inequality and shrinking federal supports, the Village Market has a difficult path to tread. Their balance sheet has been moving in a positive direction and residents are happy with the changes they have seen since they opened. Whether they are enough to make the store viable without significant support remains to be seen. Their average transaction remains quite low, between $\$ 3$ and $\$ 4$, which means that most people shopping there are coming in for one or two items. What they need in order to move into the black, however, is for more people to regularly come in and spend \$20-\$30 at a time (Village Gardens staff member, October 19, 2015, interview). They continue to try new things, and have experimented with a volunteer program incentivized with discounts, a senior discount day, and discounts on fresh produce and other "healthy" foods made possible through grant funds. So, they are beginning to explore how to use their nonprofit status toward affordability goals. They also have a paid prepared foods manager stocking a grab and go cooler and have recently started an incubator program to help community members launch food enterprises. Still, drawing people from outside New Columbia into the store may be an important piece of getting them into stable financial territory (Village Gardens staff, October 19, 2015, interview). While the store may not be affordable for extensive use to many New Columbia residents, it does provide a welcome convenience. Its value as a food justice, health equity, and social economy project is more complex, and a review of recent literature on these topics is required to fully consider it. 


\section{Chapter 3: Literature Review}

My early observations of the Village Market project indicated that it would make a compelling research case for a number of reasons. First, it was the only Healthy Corner Store to be done from the ground up with community involvement. Most corner store programs involved some combination of increased fresh produce options, expanded healthy options (e.g. low-fat dairy, whole grain products), and nutrition information. The Village Market planned to limit unhealthy offerings and organize the shelves in such a way as to put health promotion above profit-making. These aspirations seemed to have potential to alienate some potential customers, so one of my research questions focused on investigating the Village Market as a food justice and health equity project. Second, it was to be done as a nonprofit social enterprise. The consensus-based processes and the anti-oppression philosophies of the organization led me to hope that there might be some transformational outcomes from the project, so another of my research questions sought to assess the way that this organization used its nonprofit status to implement a small grocery. And finally, the situation of the store in a mixed-income community meant that it was a very tangible way to explore the needs and tastes of a diversity of residents, shared and not.

While many arenas could be drawn into an exploration of these research questions, this literature review focused on discussions in four broad categories. The first section reviews the debates over the formation of mixed-income communities, which provides a necessary backdrop for the project as a whole. Proponents offer them as a solution to poverty concentration, but critics argue that this approach is based on faulty assumptions of social processes and may be politically motivated. As residents of a 
mixed-income community, New Columbia residents are on the front lines of current poverty de-concentration efforts. The operation of this store revealed substantive differences among community members in addition to some of the shared needs that were anticipated, and the research on other HOPE VI developments offers insights as to why this might be the case.

The next section considers a variety of perspectives on the food dimension of poverty and inequality. Food is essential for survival, and its availability strikes at the heart of inequality issues. The food deserts literature discusses one dimension of food access issues, food insecurity literature another. The Healthy Corner Store literature provides perspective on a modestly reformist avenue for alleviating such disparities, the food justice and food sovereignty literatures discuss efforts that seek deeper food system change. Literature on food regimes provides a political economy frame with which to consider these varied perspectives on the food system, and a final segment of the food literature reviewed considers food through the lens of class. As a grocery store, the Village Market is filling the sort of void in the neighborhood food geography that is the subject of the food deserts literature. But, those who planned the store also strove to address other food-related problems, some behavior and lifestyle oriented, others tied to knowledge, skills, and costs that extend into the arena of the literatures on food security and food justice. Through their choices of problems to address, Village Market team members defined what food justice meant for them, and the market's outcomes have reflected how well their concept matched up with that of others in the community. Participants in the Village Market's launch failed to recognize the degree to which food 
tastes and purchasing decisions are shaped by class and other social factors, perhaps in part because the food deserts policy approach largely ignores them.

The third section discusses the debates over the health implications of social and economic inequity. Research on obesity and diabetes reveals that these public health concerns are more complex than popular discussion admits, and juxtaposing these debates with research on the social determinants of health (SDOH) brings attention to systemic social inequalities beyond the individual behaviors that are so often emphasized. Emerging perspectives on nutrition and dietetics offer possibilities for approaching the subject in more culturally relevant ways, and that literature as well as research on community health workers provides some means of interpreting efforts undertaken in the context of the Village Market. Village Market participants were aware of health disparities, particularly for chronic diseases like obesity and diabetes, and wanted to use their Healthy Corner Store to make their community healthier, although they varied in the degrees of their engagement around health. Their approach to the store reflected a limited critique of both the current food system and inequality, but tried to engage more deeply with these issues than the current Healthy Corner Store movement does. The literatures on food regimes and the social determinants of health help assess the level of consciousness and mobilization in the community around food and health issues.

The final section examines perspectives on the social economy and its potential for economic development and social change. Some view nonprofits as valuable for their contributions to social capital as well as for the niches their activities fill, whereas critics point out the way the nonprofit industrial complex directs these activities away from revolutionary change. As a community-led nonprofit, the Village Market forged new 
ground for Healthy Corner Stores. Literature on the social economy and community development aid interpretation of the social and economic outcomes that arose from this endeavor. The selection of these bodies of literature has been an evolutionary process. As is typical of the extended case approach, I began with participant observation, and have "shopped" for theory as circumstances unfolded (Burawoy, 1991). This extended case approach aims to elicit theoretical implications from participant observation data (ibid), and is one method used for "new" critical ethnography (Foley \& Valenzuela, 2008). The theories incorporated into my literature review thus reflect my current understanding of the project.

\section{Mixed-Income Communities}

The neighborhood context figures prominently both in the motivation behind the creation of the store and the circumstances in which it operates. The New Columbia neighborhood is a product of the federal HOPE VI program that sought to revitalize dilapidated public housing developments, replacing what were often high-rise developments with low-density, mixed-use, mixed-income developments. In the case of New Columbia, both the income mix of residents and the neighborhood design changed with the redevelopment, although the former Columbia Villa was already a low-density development. The New Urbanist development there today is described as being more connected with the surrounding street grid and has fewer public housing units, but offers a greater range of housing options, from public housing units to subsidized Section 8 rentals to market-rate and affordable home ownership units (Housing Authority of Portland, 2007). 
A national policy for public housing initially emerged in the U.S. in the 1930s following the Great Depression, but rather than intended as a part of a safety net, housing was allocated only to the "deserving” poor (Bratt, 1986; Owens, 2012; Burns, 2013). These restrictions were relaxed in the 1950s, when selection began to focus on the neediest families, but racial segregation was part of the reality, if not the letter of public policy, even after the Civil Rights Act of 1964 legally desegregated housing projects (Bratt, 1986). Housing was typically constructed in poor, often minority neighborhoods and in undesirable locations (Burns, 2013). By the late 20th century, patterns of concentrated poverty around public housing had developed (Massey \& Denton, 1993). According to HUD figures, almost $80 \%$ of public housing residents lived in poverty in the mid-1990s (Vale, 1999).

Neighborhoods with high concentrations of poor residents generated much concern over the negative circumstances that were observed to proliferate in them (Wilson, 1987; Jargowsky, 1997; Parker \& Pruitt, 2000). As a result, dispersal as a policy approach re-emerged in the 1990s (Goetz, 2003) and was a stipulation of receipt of HOPE VI funds. HOPE VI followed on the dispersal mandates first enacted via the Gautreaux program that emerged out of complaints over the Chicago Housing Authority's practice of building public housing in poverty-dense minority neighborhoods (Owens, 2012; Goetz, 2015). Moving To Opportunity (MTO), a program that allowed public housing residents to move to lower poverty neighborhoods via vouchers, was modeled on Gautreaux (Goetz, 2015; Khare, Joseph \& Chaskin, 2015). Poverty deconcentration was argued to be capable of breaking the cycle of poverty, if done via careful market management and in pursuit of racial equality (Massey, 2006), but no 
criteria were established for racial integration (Khare et al., 2015). Neither Gautreaux nor MTO produced benefits in terms of wages, welfare independence, or improved successes for children, although participants did experience positive mental health outcomes (Burns, 2013). These poverty de-concentration strategies were not based on empirical evidence from existing mixed-income communities, however, but rather on literature (Tach, 2010).

The argument for the creation of mixed-income communities includes four propositions based on theoretical explanations for poverty (Joseph, Chaskin, \& Webber, 2007). One proposition draws on social networks theories that argue that social interactions between those of different income levels can build familiarity and lead to information exchange and access to resources that will benefit poor people (e.g. employment). A second proposition supposes that as new networks of relations form, social control over delinquent behaviors will increase and those behaviors will change. A third claims that social modeling will lead to improved behaviors as poor people learn the middle class culture of work and social responsibility. Finally, political economy perspectives argue that with more residents of greater means, mixed-income communities will be able to garner better services and infrastructure than poor communities could.

These four propositions generally characterize the poor as deficient, but critiques of the mixed-income approach offer other perspectives. Arguments for dispersal have been criticized for emphasizing the need for role models rather than economic opportunity (Crump, 2002). Assumptions that the poor are more in need of bridging social capital than bonds with similarly situated friends and neighbors are also questioned (Greenbaum, 2008). The assimilation/dispersal argument can also be interpreted along 
political rather than paternalistic lines. While dispersal via redevelopment may be yet another example of the state treating minority populations like objects (Keating, 2000), it may be also be a tactic to reduce the political threat of organizing amongst the poor (Imbroscio, 2008). Perspectives that critique policies advancing mixed-income communities as state-sponsored gentrification and colonization have emerged. The displacement of low-income residents to make room for wealthier neighbors is argued to be an unbalanced approach targeting poor communities, couched in neutral language advocating "mixing" and "diversity" in order to mask the class conflict at work (Bridge, Butler, \& Lees, 2011). HOPE VI is argued to be not simply a means of creating better housing, but for making the neighborhoods in which it is deployed safe for investment and development (Fraser, Burns, Bazuin, \& Oakley, 2012). Others question whether a market-based approach to creating housing for the poor is capable of meeting their needs (Joseph et al., 2007). Mixed-income communities may not be able to provide the safety that is so prominently discussed. Even in environments where crime or violence was common, social ties in housing projects gave some people a greater sense of safety than did relocation to a new, "safer" neighborhood (Clampet-Lundquist, 2010). Residents considered this very neighborhood to be safe, desirable and to have a strong sense of community before it was redeveloped (Gibson, 2007b), challenging assimilationist assumptions.

Evidence from HOPE VI projects shows mixed outcomes in terms of resident satisfaction with the new communities, although residents are generally happy with the physical settings. Expectations of community change among residents and key informants in Chicago were modest and focused on shared instrumental goals and 
informal interaction rather than deep solidarity (Chaskin \& Joseph, 2010), while those at a Texas site were more optimistic (Jourdan, Van Zandt, \& Tarlton, 2013). Initial findings showed that residents of Chicago HOPE VI projects were pleased with the physical environment (Joseph, 2008; Jourdan et al, 2013), but later work found that while public housing residents remained reasonably satisfied, other renters and owners were more critical (Joseph \& Chaskin, 2010). Many residents of all housing tenures at a New Orleans development expressed a desire to live somewhere else. Market-rate renters were constrained by leases, public housing residents were marginalized but had no other option, homeowners were constrained by negative equity in their homes (Owens, 2012). The ability of mixed-income developments to foster cross-class ties has been questioned as research on HOPE VI sites accrues. 'Othering' of low-income renters by homeowners was a particular problem at several sites (Chaskin \& Joseph, 2010; Fraser et al., 2012; Burns, 2013; Chaskin, Sichling, \& Joseph, 2013; Khare et al., 2015). This was particularly apparent in contested views over the appropriate use of space (Arbuthnot \& Wilhelm, 2009; Fraser et al., 2012; August, 2014; Khare et al., 2015), evidence of the dearth of tolerance in many cities (Bannister \& Kearns, 2013). Having a diverse community provided learning opportunities that were considered beneficial by both lowincome residents and market-rate owners alike, but relational distance and deeper levels of tension were also acknowledged (Joseph \& Chaskin, 2010). The NewHolly HOPE VI project in Seattle showed little overlap in relationships between homeowners and public housing renters, even though both groups were more likely to attend community events than subsidized renters (Kleit, 2005). In NewHolly, people tended to know and interact with others like themselves (ibid). Early evidence from Chicago showed similar social 
isolation (Joseph, 2008) and at other HOPE VI locations residents were reluctant to form bonds even within social groups (Burns, 2013). Other research noted that in areas where different classes do interact, there is often friction (Tach, 2010), especially around the activities of idle youth (Burns, 2013; Chaskin et al., 2013). At HOPE VI sites that were primarily African-American, low-income black public housing residents were marginalized by both nonblack and higher-income black neighbors (Burns, 2013; Khare et al., 2015). At a HOPE VI project in Boston, management practices and policies encouraged social distance and structured social life (Graves, 2010). Neither does increased self-sufficiency through employment actually appear to be happening for HOPE VI families (Levy \& Woolley, 2007). Poor health was found to be a major barrier to work (Levy \& Woolley, 2007; Manjarrez, Popkin, \& Guernsey, 2007). Overall, little evidence supports claims that social interaction among different income levels happens (Joseph et al., 2007; Kleit \& Carnegie, 2011; Owens, 2012; Burns, 2013; Khare et al., 2015).

Propositions for increased social control have proven to be more accurate, although not always through equitable processes. Public housing residents were generally expected to adopt white middle class behavioral norms as part of their residence in the new environments (Arbuthnot \& Wilhelm, 2009; Owens, 2012; Burns, 2013; August, 2014; Khare et al., 2015). At many developments, homeowners lobbied successfully for increased surveillance and police presence, often using their homeowners association to do so (Fraser et al., 2012; Burns, 2013; August, 2014; Chaskin \& Greenberg, 2015). These sorts of measures left many residents feeling frustrated and uncomfortable in their new surroundings (Arbuthnot \& Wilhelm, 2009; August, 2014; Khare et al., 2015). The 
tension these efforts created were implicated in the way public housing residents at one HOPE VI site mostly just kept to themselves, generally avoiding socializing at all, and citing suspicion and distrust of neighbors (Burns, 2013). That site contrasted markedly with a nearby traditional public housing community where neighbors watched out for each other and helped each other out. So, there is some evidence that increased social control may come at a cost of closely-knit ties with similarly situated neighbors. In New Orleans, some HOPE VI residents were more guarded, while others did engage around community advocacy and built connections with neighbors (Owens, 2012). A study of Boston HOPE VI residents showed that improved local institutions and facilities, attachment to place, and feelings of security were more associated with social capital than the socioeconomic mix of the neighborhood (Curley, 2010).

This project uses the experiences and views of current New Columbia residents on the store to gain insight into the mixed-income aspect of the community as a whole. Support of the social control thesis emerged at this HOPE VI site as well. Lease requirements indicated the imposition of norms that accord with white middle-class values, and the store showed some similar influences. The nonprofit approach was arguably an avenue for this influence to occur in the context of the store. It was present to some extent in who took enough interest to participate in the store development process and was reflected in the products that the store chose to carry. Despite intent to make the Village Market a store that would serve everyone in the community and inclusion of the surrounding neighborhood in store projections, it isn't at all clear that many people from outside New Columbia shop there. Evidence also suggests that better off residents in mixed-income communities are more likely to shop in higher end grocery stores and 
establish other patterns of "micro-segregation," particularly in areas that are marked by visible differences like race or housing type (Tach, 2010). By looking at income mixing through the lens of a store, this study contributes a unique and material way to assess the extent to which needs and wants of the diversity of New Columbia residents are shared.

\section{Food Equity}

The Village Market project invites engagement with a diverse array of food literatures, particularly as they relate to the problem of having access to sufficient acceptable food. Included here are those that address social justice concerns about food, and I begin by reviewing some essential terms that have emerged from policy and practice. Food deserts and Healthy Corner Stores relate directly to the project, and were a recurring subject in meetings and discussions in which I participated. Hunger and the threat of hunger have been more subtly present, invoked in discussions of food stamps and Women, Infant, and Children nutrition program (WIC) vouchers. Attendance at two local conferences by me and several project participants inspired discussions of food justice and how the Village Market sought to improve it. Food regime theory ties these subjects together and provides a basis for considering the possible outcomes of this endeavor. Work in the areas of critical dietetics and the class contours of food provided ideas I could use to consider the differences in taste and health interest that New Columbia residents had with respect to their foods of choice.

\section{Terminology}

Recognition that the food needs of many populations in the U.S. remain unmet has drawn new attention from academics and renewed interest in food issues among policymakers as well as those in the nonprofit sector. Activism around food issues is 
equally vibrant, and a variety of terms have come into use to refer to the concerns that have surfaced. Food insecurity is used by government agencies to indicate the degree to which there is sufficient food of acceptable quality obtainable in socially acceptable ways, and may occur at multiple levels, individual, household, community, or nationwide (Chilton \& Rose, 2009). It was formerly described as being accompanied by moderate or severe hunger (Cook, 2002), but 'hunger' was removed from these definitions in 2006 (Chilton \& Rose, 2009). Food security often refers to a place-based ability to address household food insecurity and to produce sufficient quantities of the food the population there requires, combining distribution issues with economic development ones (Winne, 2004). More recently, however, both food insecurity and food security have been used by policymakers concerned with the condition formerly known as hunger, and families are now categorized as being "food secure" or having 'low food security' or "very low food security' (Nord, Coleman-Jensen, Andrews, \& Carlson, 2010). Food justice is used to articulate a right to food that often brings with it a critique of the corporate global food system, particularly for its labor practices (Wekerle, 2004; Liu \& Apollon, 2011). Food sovereignty further critiques the role of corporations in the global food system, but focuses more broadly on the right of each nation to produce its own food in its own territory, although it can be applied to peoples within a nation as well (Alkon \& Norgaard, 2009; Patel, 2009). Each term provides a different lens through which to view the problem of food insufficiency, and each carries a different political orientation.

\section{Food Deserts}

One concern that has gained momentum in the last decade has been the lack of physical access that some communities have to retailers with food of a particular quality. 
Areas lacking proximity to full service grocery stores are commonly referred to as "food deserts," and discussions surrounding them has drawn attention to barriers that many low-income, urban, rural, or minority communities confront with respect to maintaining a healthy diet (Caraher, Dixon, Lang, \& Carr-Hill, 1998; Vasquez, Lanza, HennesseyLavery, Halpin, \& Minkler, 2007; PHLP, 2009; Walker, Keane, \& Burke, 2010). Debates followed about what constituted a food desert and which methods were the best means of identifying them (Walker et al., 2010). The supply side argument inherent in the definition was soon accompanied by demand side arguments about equitable food access, as well as racial and ethnic disparities in that access (ibid).

Strictly as defined, the "food desert" problem focuses solely on the supply side of the food quality aspect of food access. It both feeds and reflects concerns over increases in obesity and diabetes in the U.S. and is intertwined with particular ideas about health equity. Literature inspired by supply side concerns focuses on the link between food environments and health. Much of this literature looks at whether behavior changes are enabled by the provision of healthier options (Wrigley, Warm, Margetts, \& Whelan, 2002; Pearson, Russell, Campbell, \& Barker, 2005; Walker et al., 2010), although nutrition education is also sometimes part of the "treatment." The associations among food environment, diet quality, and rates of obesity and diabetes have been interpreted as signifying a grocery store crisis (Treuhaft \& Karpyn, 2009; Bodor, Rice, Farley, Swalm, \& Rose, 2010) and a perspective of food justice as an inability to eat properly because of insufficient food infrastructure has emerged. But the veracity of the claim that living in food deserts promotes negative health outcomes is questionable (Holsten, 2009; Lee, 2012; Budzynska et al., 2013), as is the link between living in a food desert and poor diet 
(An \& Sturm, 2012). People living in low-income neighborhoods often shop outside of the area (Hillier et al., 2011; Zenk et al., 2011; LeDoux \& Vojnovic, 2013; GhoshDastidar et al., 2014; Shannon, 2014). Temporal considerations of healthy food access like the week of the month, traffic congestion, transit schedules, store hours and seasonality may also impact the difficulty of getting to healthy food (Widener, Metcalf, \& Bar-Yam, 2011; Widener \& Shannon, 2014). Problematizing neighborhoods for their lack of proximity to a full-service grocery store may be defining food access difficulties in ways that ensure intervention failure.

Nonetheless, the food desert metaphor captured the imagination of policymakers and planners alike (Pothukuchi, 2004; Winne, 2004; Food Trust, 2014) and strategies to address them include the development of new grocery stores, the improvement of existing small stores, and starting and maintaining farmers markets, among others (Flournoy \& Treuhaft, 2005). Drawing major grocery store chains to low-income areas is difficult on a number of fronts: perceived lack of profit potential, site procurement, and financing. Working with existing smaller stores is considered an easier solution (ibid). Improved small stores have been dubbed 'Healthy Corner Stores,' and initiatives across the country partner with store owners to increase the fresh food options available in their stores (Flournoy \& Treuhaft, 2005; PHLP, 2009). A national Healthy Corner Store Network formed to share information, and has 600 individual and organizational members nationwide (Healthy Corner Store Network, 2015). They refer to themselves as the Healthy Corner Store movement, and they are discussed in the following section. The naïveté of this theorization of food deserts has come to light as evidence on the value of intervention has proved ambiguous. While a British study (Wrigley et al., 2002) found a 
significant increase in fruit and vegetable consumption among those with the worst diets in a low-income, underserved market once a new full-service grocery was introduced, domestic research found that the addition of grocery stores did not impact diet for the target population (Cummins, Pettigrew, Higgins, Findlay, \& Sparks, 2005; Cummins, Flint, \& Matthews, 2014) or that diet change that occurred was not attributable to the presence of a new store (Caspi, Kawachi, Subramanian, Adamiewicz, \& Sorenson, 2012). However, the limited impact of a new supermarket in Philadelphia on fruit and vegetable intake and BMI may be due in part to the shortness of the follow-up period of 6 months (Cummins et al., 2014). Few survey respondents (26.7\%) adopted the new store as their primary store, and only $51.4 \%$ used it at all even though the site is community owned and operated and residents indicated interest in having a new supermarket built over using it for residential development (ibid).

The food desert designation has born some criticism for what it doesn't "see" (Short, Guthman, \& Raskin, 2007) as well as the other barriers it obscures (Shaw, 2006) and consideration of the demand side of the food access problem has ensued. Demand may involve having the resources to purchase healthier food, but it may also be interest in eating said food. Regardless, the research in this vein does not point to any simple solution, either. While some work shows that income is a prominent factor in increasing fruit and vegetable consumption (Gill, 2014), other research finds the overall effect of income to be small compared to other factors like race, gender, living with a partner and education (Boukouvalas, Shankar, \& Traill, 2009). Income may not be the only factor influencing the food budget, however, because bodies' food needs are not uniform. Appetites differ along with activity levels and metabolisms. Evidence does support that 
shopping at lower price stores correlates with higher rates of obesity (Drewnowski, Aggarwal, Hurvitz, Monsivais, \& Moudon, 2012; Ghosh-Dastidar et al., 2014).

While demand in terms of income seems to be something of a factor in ability to access healthy foods, the demand in terms of desire seems uneven, and a product of something more than nutrition knowledge. The presence of children at home may have a negative impact on produce consumption (Gill, 2014), and interest in fruits and vegetables among those who already consume few of them is low (Boukouvalas et al., 2009; Gill, 2014). While nutrition education has been effective in some cases (Wedick et al., 2015), in others it has had more modest impact (Cortes, Millan-Ferro, Schneider, Vega, \& Caballero, 2013), although the Latino families in the latter study did express interest in recommendations for ways to eat healthier on their budgets. African Americans living in Philadelphia who were found to have poor diets also had sufficient command of nutrition principles to eat healthily (Lucan, Barg, Karasz, Palmer, \& Long, 2012), so there are other factors at work in food selection. The ambiguity of these findings suggests that food choice is under-theorized in the food desert concept. Indeed, French sociologist Pierre Bourdieu conducted research in the 1960s that revealed marked differences in tastes by class that has born up well over the decades since, yet is ignored by the food desert literature. Bourdieu's work and subsequent research on food and class will be reviewed in a later section.

Deeper criticisms of food desert theorization and scholarship have emerged as other founding assumptions about residents have been questioned as well. The portrayal of residents as passive victims of their environments has provoked a call for participatory research methods (Walker, Block, \& Kawachi, 2012; Shannon, 2014) and qualitative 
studies to give residents voice and dimension (Walker et al., 2010; Cannuscio, Hillier, Karpyn, \& Glanz, 2014). Critiques have been leveled at the food desert scholarship that focuses on the technology of identifying and solving "food deserts" rather than furthering a broader understanding of the mechanisms that create them (Shannon, 2014). Similarly, the need to study the larger global retail landscape in order to understand the complexity of institutional and local geographic factors that constrain individual action has been identified (Donald, 2013). The loss of a store that was incentivized to open in New Haven, CT in spite of its value to residents prompted questions about the value of intervention in the location decisions of supermarkets and an argument that supermarkets need to be considered as the problem (Russell \& Heidkamp, 2011). Russell and Heidkamp consider them a weakness in the food supply system in which their monopoly power dominates food supply chains - "food deserts" are merely the symptom (ibid). One disagreement that has emerged is over a social ecology approach to food deserts. Jerry Shannon associates social ecology with the food desert research that conceives the resident organism to be a passive recipient of an environment in which he is trapped, whereas Carolyn Cannuscio sees social ecology as a new direction for food desert research to go and a way to theorize such residents as having mobile bodies that can navigate this environment and leave as they need to in order to meet their needs. What they share is a belief that the people living in neighborhoods that have been labeled as "food deserts" should be treated as fully human subjects, which much of the food desert research has failed to do.

As scholarship on "food deserts" has developed, questions about the terminology have arisen that reflect a differing politics to the problem of food access. Many scholars 
find that it inaccurately captures the phenomenon they're studying, and "food swamps" is preferred by those who find the prominence of convenience stores and fast food outlets resulting in a low quality diet to be most salient (Rummo et al., 2015). "Food mirages" is preferred by those who find the "conventional approach to food desert identification" reductive for its assumption that full-service grocery stores have been equated with healthy, affordable food and distance to the nearest grocery store has been equated with access (Breyer \& Voss-Andreae, 2013). But neighborhood residents object to having their communities labeled and disparaged by outsiders altogether (Barcega, 2013). "Food apartheid" is used by those who seek to engage with the larger pursuit of food justice, particularly as it pertains to the history of colonialism and exploitation within the food system (Sbicca, 2012). I find the act of labeling to be more troubling for the epistemological violence it commits than the aptness of whatever term is chosen, so I will accent the term with quotation marks where appropriate to draw attention to act of labeling that it includes. Arguments that spatial stigmatization is a contributing factor in health inequality have recently emerged (Keene \& Padilla, 2014).

The New Columbia neighborhood is more than two miles from a full service grocery, and many residents are without cars. This prompted the labeling of the community as a "food desert" (Sparks, Bania, \& Leete, 2009). The Village Market is attempting to fill the perceived gap. Most participants wanted to have easier access to better quality foods, and several cited specific concerns about the amount of candy and junk food that neighborhood kids consumed when Big City Produce occupied the space, but the store also had potential to fill other identified social and economic needs as well. Although early food deserts literature equivocated food access to full size grocery stores 
and objectified the poor and minority populations that typically live in "food deserts," more recent scholarship draws attention to the complexity of food access and the privilege that infused the characterization of such neighborhoods as problematic. Because these studies more accurately capture the complexity of food procurement and offer some perspective from people living in such environments, they gave me something to compare my findings to. This study extends their work by providing an in-depth exploration of the views of a diversity of New Columbia residents and neighbors on the Village Market.

\section{Healthy Corner Stores}

The scholarly literature on the Healthy Corner Store movement is somewhat sparse, with much of the domestic research based in the northeastern U.S., where the movement originated. One study that evaluated Healthy Corner Stores and supermarkets in Baltimore (Song et al., 2009) found some support for them as avenues for improving access to healthy, nutritious food. Studies have focused on the perspectives of storeowners (Song et al., 2010), the food environment (Gittelsohn et al., 2007; Song et al., 2009; Cavanaugh, Mallya, Brensinger, Tierney, \& Glanz, 2013; Cavanaugh et al., 2014; Martin et al., 2014), the potential for implementation in a particular area (O'Malley, Gustat, Rice, \& Johnson, 2013), the logistical intricacies (Gittelsohn et al., 2010; Ortega, Albert et al. 2015), or behavioral changes (Gittelsohn et al., 2010; Dannefer, Williams, Baronberg, \& Silver, 2012), but have yet to offer community perspectives on such stores. Evidence of the desired behavior change has been slim (Song et al., 2009; Gittelsohn et al., 2010; Dannefer et al., 2012). Overall, the literature discussing store interventions is substantially behavior focused, with an interest in addressing obesity and diabetes 
through improving eating habits. Emphasis is placed on enabling individual behaviors, yet the individuals are, with a few notable exceptions (Walker et al., 2010; Martin et al., 2012; Walker et al., 2012; Cannuscio et al., 2014), thinly depicted, represented only through recalls of shopping purchases or store receipts. As with research on the addition of larger stores, evidence of the usefulness of this sort of intervention is spotty, and one reason for this that is hinted at in HCSN materials is price.

Price is a significant barrier to people being able to shop at corner stores. Customers at corner stores in Hartford, CT generally did the bulk at their shopping at medium-size stores that had custom brands and lower prices, and used the corner stores for staples like bread and milk and snacks (Martin et al., 2012). Weatherspoon et al. examined sales receipts from a small nonprofit grocer in Detroit, and found that while price negatively impacted demand for fruit in general, some fruits were luxury goods and purchased to a greater extent when ability to do so increased (Weatherspoon et al., 2013). A follow-up study revealed that while price and availability were also important for vegetables, other factors likely impacted vegetable choices as well as overall demand (Weatherspoon, Oehmke, Dembele, \& Weatherspoon, 2014). Fresh lettuce, tomatoes, and peppers were the most frequently purchased vegetables and vegetables were purchased at a much lower rate than fruit. A companion study revealed that inability to cook or store produce was an issue for $48 \%$ of interviewees (Weatherspoon et al., 2014), indicating that access to competitively-priced, quality vegetables may not be enough to encourage greater consumption of vegetables, particularly those requiring greater effort to prepare. SNAP recipients in Hartford, CT were more likely to buy fruit (Martin et al., 2012). Selection has also been raised as an issue. The same study showed that greater selection 
of fruits and vegetables made customers more willing to buy them both. A study done in an ethnically diverse, low-income neighborhood of Madison, WI showed that a small ethnic grocer was able to be price competitive and provide a wide range of foods to please price-savvy African, African American, Southeast Asian, Latino and white residents alike (Walton, 2014). It has become what Walton terms a "vital" place that contributes to community health through facilitating healthy behaviors like healthy eating, physical activity, or social interaction.

Policy-oriented, government agency-sponsored research on Healthy Corner Stores exists as well, but is more focused on the logistical dimension of making such stores happen. Reports on the success of Healthy Corner Stores thus far show a mixed picture. One case in Oakland, California demonstrated some of the challenges of this approach. This market used subsidies to provide infrastructure and technical assistance, but also relied heavily on the involvement of a committed local produce vendor for his expertise in getting the corner store set up to carry produce as well as a committed owner (Bolen \& Hecht, 2003). A 2007 study of seven stores in California found that three of the four stores no longer receiving support stopped stocking much produce (PHLP, 2009). Reasons for abandonment of the program included lack of demand, competition from other stores, and change of ownership (ibid), raising questions about when and where this approach is viable. Other efforts appear to have been more successful. Hartford's Healthy Food Retail Program began in 2006 with six stores in a city with just one full service grocery, and had forty participating stores that each year increased the percentage of their shelf space dedicated to healthy foods (Hartford Food System, 2008). Researchers from the project did not find any significant differences in the healthiness of store offerings 
between participating stores and control stores on average, which they attribute to staffing resources insufficient to meet program goals (Ferris \& Martin, 2010). The committed involvement of store owners is seen as critical to the success of this approach, and interviews with owners/managers of six stores in California indicated low interest in starting such a program (PHLP, 2009). Thus, the Healthy Corner Store model as conceived has some barriers to successful, long-term viability.

Most policy implementations of Healthy Corner Stores involve incentives to existing store owners to provide some fresh produce and nutrition information (Hartford Food System, 2008; PHLP, 2009). Systemic critiques are not completely absent from these interventions, however. The Good Neighbor Program in the Bayview Hunter's Point neighborhood in San Francisco makes the connection between corner stores and tobacco companies through the Nabisco snack foods they sell, and have created a program that both increases availability of produce and reduces alcohol and tobacco advertising (Literacy for Justice, 2011). Still, the focus on individual consumer behavior remains evident in the framing of the problem they are seeking to solve. Within this movement, current population health and food issues have been attributed to behaviors, and health equity has been framed as individual problem.

The Village Market has a small footprint, but from the beginning was planned as a full service grocery. So, it has a very different operational model than a typical corner store. The Village Market is also unique among Healthy Corner Stores in that it was built from the ground up and formed as a nonprofit. Other interventions have been retrofits to existing stores using incentives to owners. By typical standards, then, the Village Market isn't exactly a Healthy Corner Store, although it does take a small store approach to the 
"food desert" problem that the HCSN promotes. Village Market stocks a variety of whole grains, produce and other healthier products that HCSN interventions attempt to bring to their stores. Further, by referring to their store as a Healthy Corner Store, the creators of the Village Market engage with this policy approach and the literature it has spawned.

\section{Food Insecurity}

Within the realm of food equity as well as the larger framework of social inequalities, the subject of food insecurity is also relevant to this project, although it is not explicitly within the purview of the Healthy Corner Store movement. Nationally, rates of food insecurity fell from 2011 to 2014, with the percentage of households being food insecure at some point during the year dropping from $14.9 \%$ to $14 \%$ over that time period (Coleman-Jensen, Rabbitt, Gregory, \& Singh, 2015). The rate of households experiencing very low food security (hunger) was $5.6 \%$ in 2013 , essentially unchanged from the rates of 2011 and 2012, and $10.8 \%$ of children experienced food insecurity (ibid). Oregon has a particularly troubled history of problems with hunger and food insecurity. Despite progress made from 2000-2005 through the expansion of the Food Stamp Program/Supplemental Nutrition Program (Oregon Food Bank, 2008), hunger resurfaced in 2006. Oregon remains one of the more food insecure states in the country with an average household rate of $16.1 \%$ from 2012-2014, up from averages of $11.9 \%$ from 2002-2004 and 13.6\% from 2009-2011 (Coleman-Jensen et al., 2015). So Oregon fared worse than the rest of the nation in terms of food security following the Great Recession. Recent improvement in Oregon's rank nationally with respect to hunger was based on other states losing more ground rather than Oregon improving (Seaberry, 2014). 
Food insecurity patterns differ by race, gender, and location and are the result of many factors. Nationally, 2014 USDA figures show that households headed by single women $(35.3 \%)$ and single men $(21.7 \%)$ had higher rates of food insecurity than the national average of 14\% (Coleman-Jensen et al., 2015). Non-Hispanic black and Hispanic households are much more vulnerable to food insecurity than non-Hispanic white households of similar income levels (ibid). Households with children (19.2\%), those with non-Hispanic black (26.1\%) and Hispanic heads (22.4\%) also had higher food insecurity rates than the national average in 2014 (ibid). Similar patterns emerged in the data for very low food security in 2014 (ibid). Somali refugees resettled in the U.S. have a very high overall rate of food insecurity $(67 \%)$ that reflect particular difficulties among recent arrivals (Dharod, Croom, \& Sady, 2013). Food insecurity is also influenced by a complex array of environmental factors ranging from mental and physical health to household facilities to cultural obligations (Gorton, Bullen, \& Mhurchu, 2009), so it shouldn't be considered solely as a lack of financial wherewithal. Common factors contributing to food insecurity for both urban and rural Oregonians include financial fallout from injuries and illness, un- and under-employment, and past mistakes (DeMarco, Thorburn, \& Kue, 2009).

Food insecurity has a number of troubling consequences for mental and physical health. Children are particularly at risk, both of general ill health and of hospitalization as infants and toddlers (Cook et al., 2004), as well as of behavioral, emotional, and academic problems when they are of school age (Cook \& Frank, 2008; Kimbro \& Denney, 2015). Food insecurity among young adults is associated with difficulties with education, housing, and substance use (Baer, Scherer, Fleeger, \& Hassan, 2015). It 
appears to have a bidirectional causal relationship with depression (Huddleston-Casas, Charnigo, \& Simmons, 2008), so it both produces and is a product of poor mental health. Adults experiencing food insecurity are more likely to characterize their health as poor or fair and score lower on scales measuring physical and mental health (Stuff et al., 2004; Tarasuk, Mitchell, McLaren, \& McIntyre, 2013). Food insecurity is implicated in poor sleep duration for women and difficulty getting to sleep for men (Ding, Keiley, Garza, Duffy, \& Zizza, 2015). Insulin resistance, with differing impacts according to gender and BMI, is another outcome (Liu et al., 2015). In Mexican-American women, food insecurity is significantly associated with overweight and obesity, but this relationship does not hold for Mexican-American men or other Hispanic groups (Smith, ColonRamos, Pinard, \& Yaroch, 2015). There are also particular risks for older adults who have restricted abilities or mobility (Cook \& Frank, 2008). Copious attention has been focused on obesity, but food insecurity is also a significant problem.

The food insecurity literature is included here to raise awareness of the depth and history of this problem in Oregon and to highlight the health risks that it entails. New Columbia's population is significantly represented by groups most at risk, so residents may be struggling with health consequences as a result of food insecurity. The Village Market did not engage very deeply with food insecurity, but hoped to provide high quality food at warehouse grocery store prices. They planned to do this by procuring better deals because of their nonprofit status and by keeping overhead costs low through volunteer labor. This study sought to explore how well the Village Market managed to address the food needs of a population vulnerable to food insecurity, and what the implications are for the Healthy Corner Store model. 
Food Justice and Food Sovereignty

Whereas the problems of food insecurity and "food deserts" observe some symptoms of the inadequacy of our current food system, food justice and food sovereignty introduce the idea that fundamental human rights are being violated through its operations. The U.S. food system has a long history of inequity, and food justice is about finding ways to grow, produce, and distribute food differently as part of a larger effort to address social justice aims of better job security, wages, and, of course, good food (Gottlieb \& Joshi, 2010). An alternative food movement that arose in response to the agro-industrial complex was criticized for its whiteness and affluence (Slocum, 2007; Breeze Harper, 2010; Guthman, 2011; Ramirez, 2015) and the food justice movement emerged from that critique (Guthman, 2015). A food justice orientation helps construct representations of food insecure or hungry people as active agents rather than passive indigents in need of sympathy or aid (Saul \& Curtis, 2013; Sbicca, 2014). It suggests alternate pathways to solving food equity problems from the charitable approaches that often address food insecurity or the market-based solutions like the Healthy Corner Stores that seek to improve healthy food access in "food deserts" (Alkon \&Agyeman, 2011; Sbicca, 2012; Figueroa, 2015; Ramirez, 2015). Food justice and food sovereignty frame food inequity as resulting from powerful forces that must be resisted (Alkon \& Norgaard, 2009; Alkon \& Agyeman, 2011; Shiva, 2011; Figueroa, 2015). However, even within these more politicized orientations, perspectives vary with respect to the degree of change sought.

On one end of the food justice spectrum are mildly reformist efforts to address perceived food system inadequacies. The food desert and Healthy Corner Store literatures 
discuss the question of access to healthy food primarily through geographic proximity and to a lesser extent, price. Although community gardens have existed in the U.S. since the late 19th century, current era efforts are often positioned as venues for individual transformation and organized by non-state and quasi-state actors and less often as the social movement-inspired efforts of previous generations of community gardens (Pudup, 2008). Many food justice efforts incorporate ecological sustainability goals (Wekerle, 2004; Mares \& Pena, 2011; Morales, 2011; Bradley \& Galt, 2014; Ramirez, 2015). Urban agriculture projects are springing up across the continent and offer opportunities for increasing food sovereignty as well as sustainability, although they are not without their hierarchies and hegemonies (Pudup, 2008; Colasanti, Hamm, \& Litjens, 2012; Heynen, Kurtz, \& Trauger, 2012; Ghose \& Pettygrove, 2014; McClintock, 2014; Miewald \& McCann, 2014; Ramirez, 2015). Indeed, food justice projects can exhibit the paternalism that is often present when policymakers concern themselves with the problems facing poor and minority populations (O'Connor, 2002; Goldberg, 2013), just as they are capable of expressing deeper social justice goals. The recognition of institutional racism in the food system is essential to some understandings of food justice (Alkon \& Agyeman, 2011; Figueroa, 2015; Ramirez, 2015). For this segment of the food justice movement, confronting racism and sexism, enacting corporate and institutional reform, and developing food sovereignty are important paths to a just sustainability. Inequalities by race, class and gender in the U.S. are intertwined with the food system. From the theft of land and food sources from Native Americans (Haman et al., 2010; Norgaard, Reed, \& Van Horn, 2011) to the forced labor of slavery and sharecropping or tenant farming (Green, Green, \& Kleiner, 2011; Figueroa, 2015; 
Ramirez, 2015) to the tyranny of home kitchens (DeVault, 1991; Koch, 2012; Sachs \& Patel-Campillo, 2014), for many people food invokes memories of colonization and subjugation. Motivation to decolonize the diet adds a further political dimension to adopting a vegetarian or vegan diet for women of color (Breeze Harper, 2010). Scholars also see potential for food justice work to integrate with \#BlackLivesMatter mobilizations or other such radicalizing influences to maintain the push for social justice in the food system (Brent, Schiavoni, \& Alonso-Fradejas, 2015), although groups must be wary of the threat that foundations present to maintaining that radical stance through their funding requirements (Lethabo King \& Osayande, 2007; Guthman, 2008; Sbicca, 2012). The need to eliminate disparities in the benefits and risks of food production from cultivation to consumption and incorporate workers rights into the debate on food justice is another important issue to address (Liu \& Apollon, 2011). In addition to reforming food production, finding ways to value women's social reproductive work around food without reinforcing the gender division of labor is another worthy objective that gets little attention. This project could involve re-imagining heteronormative household models and seeding projects like community kitchens and shared food preparation that can help redistribute that burden, perhaps by involving more men and boys in food prep and more radically ensuring that all people have time and resources to provide and prepare adequate food for their families (Bowen, Elliott, \& Brenton, 2014; Sachs \& PatelCampillo, 2014). Efforts in this direction around the turn of the 20th century gained little traction (Turner, 2014) and expectations that mothers will give selflessly of their time and energy remain an ironic counterweight to the "rational market" that is considered our “real” economic system (Hays, 1996). 
Wresting the food system from the control of large corporations is another component of food justice and food sovereignty that has inspired much discussion, as both the profit motive in the food industry (Winson, 2004) and the nature of agricultural subsidies have been cited as particularly profound influences on the dietary habits of Americans (Pollan, 2006). This has inspired some to argue for re-regulation of commodity markets and addressing the domination of the global food system by supermarkets so that it will be fair to both farmers and consumers and protect the indigenous food production of all nations (Rosset, 2008; Akram-Lodhi, 2013). To members of the West Oakland Food Collaborative, challenging corporate power means combatting institutional racism by supporting black farmers and local stores over the chain stores that abandoned their neighborhoods and pay poorly (Alkon \& Norgaard, 2009).

Food sovereignty demands democratic control over food systems by their stakeholders. Vandana Shiva argues against patents on seeds as part of her quest for a people's food system (Shiva, 2011). The Karuk Tribe of California sees food justice as intertwined with environmental justice and their rights to a free-flowing river and the food that it once provided them with, incorporating elements of food sovereignty (Alkon \& Norgaard, 2009). For members of marginalized communities, self-reliance is a powerful motivation to engage in food work, particularly in light of the fact that the food system has often been a means of their exploitation. Two Black Nationalist groups in Georgia, one Christian, one Muslim, organize around race and religion to try to take care of their own and heal current and historical trauma through food cultivation (McCutcheon, 2011). A black-led food organization in a historically black but gentrifying 
Seattle neighborhood seeks to help their remaining community members thrive in place through their farming endeavor while understanding the historical oppression that such work invokes (Ramirez, 2015). Dig Deep Farms in Oakland, CA tries to provide good jobs to youth with criminal pasts in order to invest in the future of the community (Bradley \& Galt, 2014).

Although the food justice movement attempts to address issues of equity in the realm of food, its conception of what equity entails remains constrained. While the movement originated in a critique of the alternative food movement, it concerns itself most with the availability and affordability of that same alternative food to low-income people and people of color (Guthman, 2015). It invokes the same alternative healthy eating discourse that espouses the value of fresh, local and organic food (Beagan et al., 2015). While the food justice movement makes attempts to incorporate elements of race and class inclusivity, its focus on local and organic may hamper its ability to achieve justice (Guthman, 2015). Gender is another dimension of difference that has been underconsidered in the realm of food justice (Sachs \& Patel-Campillo, 2014).

Food justice articulates a vision of communities being able to produce and consume "good" food, and food justice scholarship thus far has focused on sketching the landscape of what that may entail. What is conceived of as good starts with the local and organic products of small farms that the alternative food movement espouses and adds elements of racial, economic, and environmental equity, although critics argue that its project has limitations in these directions that may hinder its potential for achieving the justice it claims to seek. But "good" food is first and foremost healthy food. This case seeks to explore what "good" food is from the perspectives of residents of New Columbia 
to glean what they might consider food justice to be. Through its operation, the Village Market has sought to address a number of issues that fall into the realm of food justice. The project touches on issues of food enterprise, the quality of food that is accessible to neighborhood residents, food literacy, and community control over food access. A vision of health equity is woven throughout. While the Healthy Corner Store movement largely concerns itself with improving physical access (and some nutrition education), the Village Market took a community-infused approach to their provisioning problem, incorporating some limited food sovereignty goals. So, the Village Market sought to advance food justice further than the Healthy Corner Store Network's objectives typically involve. This research provides a basis for critiquing the assumptions held by both the Village Market and the food justice movement about what constitutes "good" food. Food Regimes

Food regime theory provides a useful framework for looking at the Village Market project, the context of the larger Healthy Corner Store movement, and how they both fit within the U.S. food system. A food regime is a 'rule-governed structure of production and consumption of food on a world scale' (Holt-Gimenez \& Shattuck, 2011). Food regimes have been used as a way to characterize the influences of power on society through food and agriculture (Campbell \& Dixon, 2009). They have been applied to the evaluation of food movements with respect to recent global food crises (Holt-Gimenez \& Shattuck, 2011). In this usage, food regimes are used to characterize responses to dissatisfaction with the current food system with respect to their potential to transform it (see Appendix D). Corporate food regimes are positioned as politically conservative, and food movements more progressive. This typology places food concerns on a continuum 
of political engagement from accommodative to transformative, with food enterprise at the least critical end of the spectrum, followed by food security, then food justice and finally food sovereignty. A corporate food regime may be neoliberal, in which corporate food production is emphasized and liberal trade practices are encouraged, or reformist, in which some measures are taken to moderate some of the perceived excesses of the neoliberal approach. Discussion in reformist regimes is focused on food security. Food movements may be characterized as progressive, in which empowerment is emphasized and business models that improve workers wages and production practices are pursued, or radical, in which land and water rights reforms are demanded as democratization of the food system is sought. The former type of movement is concerned with food justice, the latter with food sovereignty.

This typology guides my inquiry into the Village Market project and what it means for those in the community, as well as for the larger significance of this project for the Healthy Corner Store movement. The focus of the Healthy Corner Store movement on the obesity and diabetes issues, their interpretation of them as individual behavior problems, and their failure to incorporate food insecurity is reflective of the position of the movement within the neoliberal food regime. Their usage of the term "movement" portrays the planning and policy-making they do as activism, and invites comparison with other food justice theories and movements. This case will provide grounds for critiquing the Healthy Corner Store movement by considering the larger political economy of food as it is experienced and perceived by people living in the New Columbia community and relating how this store does and does not address their needs.

\section{Critical Dietetics/Nutrition}


The difficulty of taking up the healthy food mantle as part of food justice work is that the field of nutrition in the U.S. is itself reductive and paternalistic both in its pedagogy and its practice. The dietetics curriculum privileges science courses in lecture format over seminars that provide a broader understanding of our social structures (Clarke, 2011). Curricula fail to expose students to other ways of thinking about food and other ways of being that differ in the value they place on health (ibid). The privileging of Western epistemology in the field is very limiting in the types of advice and education that dietitians are trained to give, which becomes problematic when practitioners work with people from differing religious and cultural traditions. Moral arguments about food are traced intellectually to Greek notions of dietetics as a critical component of one's moral practice that was required in order to properly claim citizenship (Coveney, 2011). Self-mastery over practices that gave pleasure were particularly important, and good health was equated with moral uprightness (ibid). The association of pleasure and indulgence in food with sin was part of early Christian beliefs as well, and carried forth by sects like the 7th Day Adventists that view eating, healing, and piety as one and the same (ibid). But post-Enlightenment, human science came to dominate religion and the moral messages about food were translated into those terms, using nutritional science as a basis for which to judge diet (ibid). So nutritionism carries moral imperatives through the language of science that ignores the sensual qualities of food.

Critical perspectives are emerging in these fields, but slowly. Jacqui Gingras argues that the field of dietetics "has yet to take up race, class, and gender through an examination of how our own blinding whiteness, privilege, and female gender aid in a dietetic performativity that can be described as apolitical and objective, but which is only 
a marker for unexamined complicity and perpetuation of healthism, food insecurity, and abject food politics" $(2008$, p. 7). She provides an example of what a different dietetics education might look like through a "sacra conversazione", a conversation to explore multiple views in a personal way that may help model other pedagogical approaches in a field where "othering" the client is the norm. This is particularly problematic because of the lack of African American dieticians due to institutional racism, so African Americans are often getting dietary advice from white practitioners who have no grounding in communities of color (White, 2012). White echos Kumanyika's calls for an African American definition of healthy eating, fitness, and body size that comes out of their own historical and cultural context (Kumanyika, 2002), but argues that pedagogical approaches within the academy as well as in dietetic practice need to be reworked in order to make their knowledge more relevant to African American students and clients alike. Tamara Beauboeuf-Lafontant (2013) argues that stress and emotional eating are a significant part of the weight discrepancy of black women relative to other racial and ethnic groups because black women are encouraged, through the equation of strength with adult feminine goodness among African Americans, in the self-sacrifice and selfsilencing that are essential components of that strength (ibid). In a society where the emotional wellbeing of Black women is largely ignored, food becomes a means of coping and self-silencing in the midst of stressful work/school/life environments. Additionally, being overweight provides a measure of protection against sexual abuse. She sees overeating as a tension between being human but having to appear to be strong, and that the real solution is to address the overwork, undervaluing of "the mules of the world" and the denial of their humanity (ibid, 53). 
Food scholars and professionals have also begun to ask what a postcolonial feminist nutrition practice might entail. They argue that it would begin with recognition of the multiplicity of practices of healthy eating instead of the universal standard issued by the USDA (Hayes-Conroy \& Hayes-Conroy, 2013). Nutrition messages are dumbed down for non-white target audiences who are considered incapable of keeping themselves healthy without nutrition education (ibid). They see these essentialist notions of food dangerous because they obscure diversity and discrepancy. One avenue the HayesConroys pursue is Sandra Harding's “strong objectivity” (Harding, 1993). By listening to the life experiences of those who are marginalized or oppressed by the universal core nutrition the partiality of what we know about what to eat and the situatedness of nutritional knowledge is revealed. Other scholars with similar intent suggest dialogue with Indigenous and non-western epistemologies as avenues for dietary decolonization that can help destabilize the whiteness of work done around health and food (Gord, 2011).

The literature on critical dietetics and nutrition acknowledges the failure of mainstream nutrition education to resonate across race and class divisions in our society because of the way it reduces food to its nutritional content to the exclusion of its many other roles. As I listened to New Columbia residents talk about food, I realized that we really need a different approach to fostering healthy relationships with food. This scholarship is very much emerging, but has potential to loosen the stranglehold that expert-driven nutrition science knowledge has on our concept of healthy eating. The Community Capacitation Center that trained the community health workers at Village Gardens has recently developed a popular education curriculum that seeks to do the same. 
However, in the context of the Village Market, more traditional understandings of nutrition predominated. This study underscores the limitations of this approach.

\section{Food and Class}

As interest in food as an academic topic has blossomed, scholarship has begun to address the ways that food tastes, habits, and practices differ among social groups. Much of this research has focused on ethnic groups or middle and upper classes, and scholars note the absence of qualitative social science research on the perspectives of poor people with respect to food in the U.S. (Alkon et al., 2013). One recent review of literature referencing the class differences Pierre Bourdieu articulates in the realm of food and eating in Distinction: A Social Critique of the Judgment of Taste was conducted by one of the principal early scholars of healthy corner stores (Sato, Gittelsohn, Unsain, Roble, \& Scagliusi, 2016). The 38 studies reviewed were in English, Spanish, Portuguese, and French, and only 3 of the empirical studies were in a U.S. context. Many of these articles were focused on specific locales or populations (women, prisoners, elites, British football players, diabetics), but several did investigate the relationships among gender, class, and food practices. Although Bourdieusian frameworks are frequently chosen to investigate class and food, others have proposed using Giddens' structuration theory as a means of studying food choice patterns as a means of understanding why nutrition education approaches have failed to change behaviors of target populations (Delormier, Frohlich, \& Potvin, 2009). Ethnographic approaches have sought to counter the characterization of the urban poor as deficient with respect to their food practices by examining their daily lives (Alkon et al., 2013). 
Research connecting food and class revealed patterns of shopping and eating habits by class that were similar across multiple nations. A number of studies showed that high-income shoppers were focused on quality and health, and adoption of healthy eating habits was a way of claiming social status, or in Bourdieu's terminology, symbolic capital (Wills, Backett-Milburn, Roberts, \& Lawton, 2011; Koch, 2012; Beagan, Power, \& Chapman, 2015; Beagan, Chapman, \& Power, 2016). There are gendered dimensions to this health interest, however, as many men resist healthy food habits (Tomlinson, 2003; Tivadar \& Luthar, 2005; Beagan et al., 2015). Higher-income Canadians distanced themselves from those who ate convenience foods or "junk" (Beagan et al., 2016), but low-income families did so as well to distance themselves from the "other" poor even if it was merely through discourse and not actual practice (Beagan et al., 2015; Chen, 2016). Sharon Hays' (1996) notion of "intensive mothering" is one indication of the way food has become a status symbol that spilled over into ideal mothering practices that involve spending much time and money on food and its preparation (Chen, 2016). "Ethical eating" in terms of choosing organic, local, and environmentally responsible consumption was also a way of claiming class status in some places (Johnston, Rodney, \& Szabo, 2012; Paddock, 2014; Beagan et al., 2015). Morals around eating were present but differently expressed for low-income Torontonians whose incomes prevented them from attaining the ethical eating standards of their wealthier counterparts (Johnston, Szabo, \& Rodney, 2011). Elsewhere in Canada, however, it was the downwardly mobile and not the elite who were interested in local and organic (Beagan et al., 2015). As they were in Wales, elites were more likely to claim omnivorousness as a means of claiming "distinction" (Paddock, 2014; Beagan et al., 2015). For high-income shoppers, trips to the 
grocery store were found to be acts of creativity that were pleasurable (Beagan et al., 2016).

Lower-income shoppers dealt with constraints that made grocery shopping a very different experience for them. It involved skilled shopping, scrutinizing sales flyers, clipping coupons, and visiting multiple stores to get the best prices on the things they needed (Alkon et al., 2013; Beagan, Chapman et al., 2016). Shopping was a chore, and while they did more cooking, it also was work rather than pleasure (Nie \& Zepeda, 2011; Beagan et al., 2015; Beagan et al., 2016). They tended to be more conservative in their shopping so as not to waste money on food that wouldn't be appreciated (Nie \& Zepeda, 2011). Freshness and quality were important to low-income shoppers and in many cases research indicated an interest in healthy eating on a par with wealthier populations in spite of reduced ability to practice it (Nie \& Zepeda, 2011; Zachary, Palmer, Beckham, \& Surkan, 2013; Beagan et al., 2015; Nevarez, Tobin, \& Walternaurer, 2016). In some cases interest in healthy eating was a way of maintaining connection to a cultural identity, as it was for Latin American immigrants in San Francisco (Martinez, 2016). "Comiendo bien," or eating well, is an important part of practicing health and being a good mother for these families, sharing a belief in the responsibility of the mother for the health of the family of the "intensive mothering" ideology that informs the norms and expectations of mothers in the U.S. (Hays, 1996; Chen, 2016). Poor mothers emphasize the act of provisioning over the selection of foods for quality in part because making ends meet is such a challenge (Chen, 2016). Treats are a way to express love and to try to create a "normal" childhood in ways that are within their means, and a means of achieving social acceptance by peers. 
Certain foods and types of foods had more significance as markers of class. Bourdieu's notions of the tastes of necessity and the tastes of luxury are useful here (Bourdieu, 1984). "Taste of necessity" refers to foods that meet basic subsistence needs effectively, and thus more important when getting enough food is a challenge. Foods that are harder to access either through expense or in being an acquired taste have a "taste of luxury." While Bourdieu found that lower-class households preferred cheaper, heavier, and fattier foods and upper classes preferred lighter and more refined foods, more recent work has emphasized that different foods represent the taste of luxury to different social groups. Meat is one food that has symbolic importance to low-income eaters (Gross \& Rosenberger, 2010; Alkon et al., 2013; Chen, 2016). Eating out in any capacity represents a taste of luxury to the most marginalized eaters (Gross \& Rosenberger, 2010; Chen, 2016). Foods have class connotations, so some foods (e.g. simple and plain foods, processed meats, convenience foods, powdered milk, margarine, fast food, junk food, soda) are associated with lower classes whereas other foods (e.g. local, organic, specialty foods, particular brands, "authentic" foods) are indicative of higher status (Wills et al., 2011; Paddock, 2014; Beagan et al., 2015). In Wales, lower-income residents felt excluded by "middle class spaces" like the farmers market, whose abundance of ready-toeat items were beyond their means (Paddock, 2014). The discursive privileging of certain ways of eating that are associated with higher classes is a way to shame and judge members of lower classes, a form of neoliberal governance much in evidence in North America (Johnston et al., 2011; Beagan et al., 2016). Indeed, scholarship indicates that taste in food was at times used to designate differences in class that could not be discerned through type of labor performed (manual or intellectual) or income generated 
and issue judgements accordingly (Biltekoff, 2013). In the U.S., defining a good diet has been a social, moral, and political act (ibid).

Scholarship on the relationship between class and food in the U.S. is quite scarce at this point, but what there is indicates division in both tastes and habits. More studies have been conducted in Canada that reveal similar divisions and also indicate judgment around those differences that privileges more affluent tastes. While it is reasonable to conclude that such "distinction" occurs here as well, I have found just a small body of research that documents it (Biltekoff, 2013; Turner, 2014). Beagan et al (2015) took an ethnographic approach to investigating food tastes and habits among a socially and economically diverse population and adds to the evidence depicting differences among residents as well as their use of distinction to align themselves with or distance themselves from others. The Village Market did so unconsciously in the foods that they included and omitted, and this case documents the store's struggles around food and class.

\section{Health}

Two prominent public health concerns that motivate the Healthy Corner Store movement are the national rates of obesity and diabetes, and the patterns that have emerged with respect to gender, race, ethnicity and socioeconomic position for each of these conditions. Discussions of such chronic, non-communicable diseases are often intertwined with diet and lifestyle concerns. But they are also of particular interest for those pursuing greater health equity because they are more complex than is generally understood. In addition to the physiology and epidemiology of obesity and diabetes, 
perspectives on health equity place these issues in a larger context that intersects with the food regime/food movement typology.

\section{Obesity}

The position of the Healthy Corner Store movement in relation to public health discourses on obesity and diabetes invites an inspection of the literatures on those two health conditions. While concern over an obesity "epidemic" galvanized public figures from Jamie Oliver to Michelle Obama and prompted calls for healthier diets and more exercise, the literature on obesity paints a more nuanced picture of the factors that contribute to the increased levels of obesity in the U.S. (and elsewhere) as well as the risks that it poses.

Much of the research on obesity uses the same measurement, and because this measurement is acknowledged to be crude, it is important to keep this in mind when reviewing current research. Body mass index is the ratio of weight to the square of height. Body mass index (BMI) is used in most research as a proxy for adiposity (fatness) and is acknowledged to be especially problematic across sex, racial, and ethnic groups that tend to have different body compositions (Flegal, Carroll, Ogden, \& Curtin, 2010). Furthermore, the categories of overweight, obesity, and severe obesity take a continuous measurement (BMI) and make it discrete. Overweight is defined as a BMI between 25 and 30 , obesity is a BMI of 30 or more, and severe obesity as a BMI of 35 or more. So a person who has a BMI of 30.1 is categorically obese, as is someone with a BMI of 34.8. In a large sample study, nearly half of the subjects identified as obese by the BMI measure were metabolically healthy (Ortega et al., 2013). Some argue that the use of such categorical standards has exaggerated the import of what amounts to slight increases in 
average weight (Campos, Saguy, Ernsberger, Oliver, \& Gaesser, 2006), while others counter that a small increase in average weight over a large national population is significant (Kim, 2006). The important takeaway is that when the word "obesity" is used in medical research, it is a crude approximation of adiposity.

By this admittedly crude measure, rates of obesity and extreme obesity increased significantly in the U.S. among adults of all sex, race, and ethnic groups measured between 1980 and 2008 (Ogden \& Carroll, 2010; Ljungvall \& Zimmerman, 2012). Obesity doubled among adults between 1980 and 2002, and overweight among children between 6 and 19 has tripled over that time period (Ogden et al., 2006). More recently, obesity among women has leveled off (Wang, Beydoun, Liang, Caballero, \& Kumanyika, 2008), and there is indication that it may possibly be doing so for men as well (Flegal et al., 2010). There has been no significant change in overall obesity prevalence in youth or adults from 2003-2004 to 2011-2012, although there was a significant decrease in obesity for 2-5 year old children and a significant increase in obesity for women 60 and older (Ogden, Carroll, Kit, \& Flegal, 2014). Nonetheless, overall levels (36.1\% for women, $33.5 \%$ for men) are still considered to be too high by some, and there remain significant differences between rates of obesity in non-Hispanic whites and other groups (nonHispanic black men and women, Mexican American women) (Flegal et al., 2010; Ogden et al., 2014). The racial/ethnic differences in obesity rates are particularly pronounced among women, and racial differences in obesity for both men and women appear to be more complex than linear correlations with SES where low-income people are more susceptible to obesity (Wang \& Beydoun, 2007). Low income is associated with more severe overweight and obesity (Jolliffe, 2011), as is low educational attainment. 
Achieving a college degree is significant, as groups with at least that much education converged to a lower level of obesity than those with less than a college degree (An, 2015). Severe obesity is much more prevalent among women, people of middle age, and non-Hispanic black adults (Ogden et al., 2014). Research indicates an increase at the U.S. population level over the past 30 years, and the trend spans the globe (Wang \& Lobstein, 2006; Stevens et al., 2012; Ng et al., 2014).

Interpretations of this research and the threat obesity poses differ considerably. Some academics and health practitioners are alarmed by the increase in obesity over the past few decades because of its association with other disease (Stein \& Colditz, 2004; Kim, 2006; Bean, 2008; Westley \& May, 2013), the expected economic impacts resulting from increased health care costs (Stein \& Colditz, 2004; Wang et al., 2008; Cawley, 2015), and the difficulty of successful intervention for adolescents and adults (Apovian, 2016). Some simply focus on the disparities by race, income, and education as the motivation for action (May, Freedman, Sherry, \& Blanck, 2013). They view obesity as a disease reaching epidemic proportions that requires intervention.

The prevailing wisdom is that obesity is created by an excess of calories consumed relative to calories burned, what is referred to as the "energy balance" model (Guthman, 2011). People's dietary habits, physical activity and the role of food environments in shaping them have engaged readers (Schlosser, 2001; Pollan, 2009), scholars (Bell et al., 2011; Zenk et al., 2011; Lee, 2012), policy makers (Treuhaft \& Karpyn, 2009; The White House Office of Communications, 2010), and activists (Shannon, 2014) alike. Most research on "food deserts" and the grocery store interventions falls into this category, but scholars have also focused on how the evolution 
of humans to store fat is maladaptive to the modern world (Wells, 2006; Bellisari, 2008), how our diets have changed over the last 50 years (Woodward-Lopez, Kao, \& Ritchie, 2010; Carlson \& Frazao, 2014), and how the stressful conditions of low-wage work present difficulties with eating properly and having time to exercise (Nobrega et al., 2016). The influence of contextual environmental factors like weather patterns (von Hippel \& Benson, 2014), urbanization (Voss, Masuoka, Webber, Scher, \& Atkins, 2013), elevation (ibid), and migration (Florez, Dubowitz, Saito, Borges, \& Breslau, 2012) have also been explored. While there are most certainly places where accessing affordable, fresh food is a problem and there are injustices implicated in that circumstance, the data does not really match the energy balance explanation of the obesity "epidemic." The increase in obesity and severe obesity has happened across the entire U.S. population (Ljungvall \& Zimmerman, 2012). Some differences in prevalence according to race, education, and income that existed before the trend started have remained, and some of them even increased, but the trend holds across the entire U.S. population, and, moreover, has spread worldwide.

At the same time as the energy balance model has been getting a great deal of attention, more nuanced understandings of obesity have emerged. Concerns about diet beyond the caloric content have been raised. The nutritional content of our agricultural products has been cited as a concern, because a decline in soil fertility has led to nutrientdeficient food (Thomas, 2003; Marler \& Wallin, 2006). Properties of different types of nutrients impact biological processes (Stenvinkel, 2015) and the addition of some foods to our diets in great quantity, like high fructose corn syrup (ibid) and unfermented soy products (Roccisano \& Henneberg, 2012) are implicated in the obesity problem. Some 
argue that composition of the diet is part of it as well. We evolved to be able to extract energy from protein, so the combination of carbohydrate and protein means that carbohydrates get used as energy because they digest more quickly, whereas meats become excess energy and get stored as fat. Some attribute the lower prevalence of overweight and obesity of vegetarians relative to those who consume both meat and carbohydrate to this evolutionary attribute (Henneberg \& Grantham, 2014). A similar argument is used to justify Paleo diets that eschew cultivated foods like beans, grains, and dairy but encourage meat and vegetable consumption (Pitt, 2016). Anthropological perspectives are also used to argue that storing fat is how the body manages times of uncertainty, and suggest that climate change, through its impact on ecological volatility (Wells, 2012), is potentially part of the increase in obesity as well. This "thrifty metabolism" may also explain how food insecurity leads to obesity, as has been observed in general (Dinour, Bergen, \& Yeh, 2007), but is particularly a problem for Mexican American women (Smith et al., 2015). A recent study of Canadian women revealed a vicious cycle entangling poverty, stress, weight gain, and illness (Papan \& Clow, 2015).

Explanations that go beyond diet are also present. Obesity has neurobiological pathways that are expressed through appetite (Jauch-Chara \& Oltmanns, 2014). Psychosocial stress has been found to play a role in obesity for subordinate individuals (Wells, 2012) for Mexican men (Ortega-Montiel et al., 2015), Mexican-American women (Smith et al., 2015) and Canadian women (Chen \& Qian, 2012), although a recent scan of the literature indicates that research findings are still inconsistent, possibly due to methodological differences (Rodriguez et al., 2015). Evidence of a relationship between obesity and increased activity along the hypythalmic-pituitary-adrenal (HPA) axis, the 
pathway through which stress influences cortisol levels, supports the claim that stress negatively impacts abdominal obesity (ibid). Adequate sleep also seems to be important for weight management (Tremblay \& Chaput, 2012). So, stressful modern lifestyles seem to encourage weight gain. Toxins may also play a part. Persistent organic pollutants (POPs) are thought to be endocrine disruptors, culprits that may become more concentrated in the blood and therefore more harmful with weight loss. In this scenario, fat tissue provides health benefits by keeping these toxins out of the blood stream (Tremblay \& Chaput, 2012), so obesity is not necessarily pathological (Wells, 2012). In fact, fat tissue is not the passive repository that it is often understood to be, but rather plays an active part of managing the body's energy expenditures, and is, in effect, a risk management system that adapts to the local environment (ibid).

The obesity phenomenon is further complicated by the fact that obesogenic impacts are not limited to individuals exposed to environmental stressors. Endocrine disruptors found in plastics (like BPA) caused obesity in rats that was transmitted across generations (Manikkam, Tracey, Guerrero-Bosagna, \& Skinner, 2013). Epigenetic research focuses on the mechanisms by which genotype expression is altered by various factors, and offers an explanation for how trauma, social or environmental, shapes biology. This research is in its early stages and hasn't yet identified many specific mechanisms or included a diversity of populations (Goni, Milagro, Cuervo, \& Martinez, 2014; Waterland, 2014; Houde et al., 2015), but one “on/off switch” for weight gain has recently been identified (Dalgaard et al., 2016). Factors that activate it are still being explored, but there are a variety of epigenetic changes that are associated with obesity 
(Goni et al., 2014; Houde et al., 2015). For instance, epigenetic differences correlate to how satisfying food is and how hungry you are (Gardner, Sapienza, \& Fisher, 2015).

The many and varied pathways that seem to influence obesity, along with the way the definition of the problem has framed the study of its causes and consequences has raised concerns by more critically-minded scholars. They see the "problem closure," the way that the definition of the problem indicates the solution, as evidence of neoliberal governmentality (Guthman, 2011), an attempt to put the onus of health on the individual through their exercise of rights and responsibilities of citizenship. More measured responses question whether the use of words like "disease" and "epidemic" are appropriate, or merely serve to sensationalize the issue (Flegal, 2006; Chiolero \& Paccaud, 2009; Puhl, Peterson, \& Luedicke, 2013) at the expense of generating solutions (Moffat 2010). The health risks of obesity have been called into question (Guthman, 2011; Henneberg \& Grantham, 2014). BMI, obesity, and mortality have a "U”-shaped relationship, so that at some levels, obesity is beneficial (Chiolero \& Paccaud, 2009). A review of 141 international studies looking at hazard ratios of all-cause mortality for obesity and overweight relative to normal weight showed that Grade 1 obesity (BMI $>=30$ but $<35$ ) was not associated with higher all-cause mortality, overweight (BMI $>=25$ but $<30$ ) was associated with significantly lower all-cause mortality, while Grades 2 and 3 obesity were associated with significantly higher all-cause mortality than normal weight (Flegal, Kit, Orpana, \& Graubard, 2013). Motives for accentuating obesity’s health risks are questioned because health knowledge is a product of powerful corporate interests, and the politics of the process through which the obesity standards are defined involves research funded by pharmaceutical companies and the weight-loss industry 
(Campos et al., 2006). Some have noted the influence of the current food regime in the production of obesity, both physically as a result of profit-seeking in the food industry (Winson, 2004) and psychologically in the perception of obesity as a problem (Orbach, 2006; Guthman, 2011). Because the origins and impacts of increases in average weight are poorly understood, the use of obesity as a public health indicator is problematic.

Concerns over how obesity discourse reflects societal attitudes toward fat are raised as well, particularly for the body image issues it creates for women (Orbach, 2006). There is evidence that dissatisfaction with one's weight independently impacts one's physical and mental health negatively (Muennig, Jia, Lee, \& Lubetkin, 2008), as does perceived weight discrimination (Schafer \& Ferraro, 2011). Use of stigmatizing language like "fat" and "obese" were least motivating for weight loss to women of all weights, indicating that use of those terms may be harmful to emotional and physical health (Puhl et al., 2013). Some have suggested that a focus on lifestyle would be more meaningful (Blair \& La Monte, 2006; Campos et al., 2006). Others call more generally for different approaches to health and health inequality (Guthman, 2011). So, while obesity may be an indicator of the presence of some health concerns, research indicates that much remains in dispute and that the hype over the obesity "epidemic" may serve to reinforce the social stigma experienced by those with higher BMIs, and actually create health problems that are the real subject of concern. Momentum around a "health at every size" paradigm has been offered as a different approach to the health concerns that weight carries along with it (Penney \& Kirk, 2015).

In spite of the great fervor with which the alarm over the obesity "epidemic" has been sounded, a great deal of evidence supports that the threat it poses is significantly 
overstated and that its presumed causes of inadequate activity relative to calories consumed are oversimplified. The increases in weight across the entire U.S. population and across the globe indicate otherwise, as does research that documents a complexity of factors play roles in obesity, including stress, sleep, exposure to endocrine disruptors and possibly even climate change. New research in epigenetics offers mechanisms that explain how these changes occur and are transmitted across generations. The important takeaway from this work is that obesity is not simply a product of behavioral excess and that the way we stigmatize fat is problematic, particularly because we don't have a good grasp of the extent to which it presents a health risk. It may actually be protective. This research uses this broader understanding of obesity to critically evaluate the Village Market as a health equity project in which obesity was a commonly-cited cause of concern.

\section{Type 2 Diabetes}

Type 1 diabetes, previously known as juvenile diabetes, is a condition where the pancreas produces little insulin, which makes it hard for the body to metabolize sugars and starches. It occurs in a small, but increasing, percentage of the population for reasons that are not yet understood (Vehik \& Dabelea, 2011). Diabetes mellitus (Type 2 diabetes, hereafter diabetes) is also impaired ability to metabolize glucose, but may be the result of decreased sensitivity or a compromised ability to produce insulin. Because Type 2 diabetes comprises approximately 90\% of diabetes cases worldwide (McKenna, 2012), literature reviewed was restricted to that which discussed Type 2 diabetes.

Like obesity, diabetes is a public health concern receiving attention for its increase worldwide (Herman \& Zimmet, 2012; Canale et al., 2013; Hill et al., 2013). It 
parallels the rise of obesity, which is a risk factor for the disease (Abraham, Pencina, Pencino, \& Fox, 2015). In Framingham Heart Study participants, risk of diabetes increased in the 1980s and 1990s but stabilized in the 2000s in spite of continued increase in mean BMI (ibid). The condition is now appearing in children whereas it previously was almost exclusively in adults (Hussain, Claussen, Ramachandran, \& Williams, 2007). Diabetes prevalence in adults rose significantly from the 1988-1994 NHANES survey (9.8\%) to the $2007-2008$ one $(12.5 \%)$, increasing in all age groups, among both men and women, but particularly for non-Hispanic blacks (16.3\% to 22.6\%) (Menke, Casagrande, Geiss, \& Cowie, 2015). Overall, approximately $12.4 \%$ of the adult U.S. population is estimated to have diabetes (diagnosed or not), and another $38 \%$ are considered prediabetic (ibid). Diabetes is disproportionately prevalent in minority groups and lowincome populations. Compared to the age-standardized weighted rates of diabetes in nonHispanic whites (9.5\%), those of non-Hispanic blacks (20.6\%) and Mexican Americans $(20.6 \%)$ were more than double, and for the lowest tertile by poverty income ratio, diabetes rates were $17.8 \%$ compared to that of the middle income $(11.5 \%)$ and highest income (8\%) tertiles, respectively (ibid). Unadjusted rates for diabetes were high for nonHispanic Asians (20.6\%) and all Hispanics (22.6\%) as well, but adjusted rates were not reported for these groups (ibid). Rates of diabetes vary among Hispanic/Latino populations living in the U.S. by country, with Mexican Americans having the highest prevalence (Schneiderman et al., 2014). South Asians (those from Nepal, India, Bangladesh, Pakistan, and Sri Lanka) living in America (23\%) have much higher rates of diabetes than Chinese Americans (13\%) (Kanaya et al., 2014). Pima Indians have historically had the highest reported prevalence of the disease (Ravussin, Valencia, 
Esparza, Bennett, \& Schulz, 1994), and across all Native American groups, diabetes was the 4th highest cause of death for men and the 3rd highest for women (Espey et al., 2014). While increases in diabetes appear to have stabilized, they remain high (Herman \& Rothberg, 2015). In Oregon in 2012, $13.4 \%$ of African Americans had diabetes, while $6.2 \%$ of the white population did (Urban League of Portland, 2015). Those rates are below national averages, but the disparity remains concerning.

Again, like obesity, diabetes is frequently portrayed in print media as being a product of behavioral excess, but is more complex in origin and mechanism (Gollust \& Lantz, 2009). Type 2 diabetes starts at lower BMI in Asians (Chan et al., 2009), and can take a form that is neither type 1 nor type 2 among those of African descent (Sobngwi, Mauvais-Jarvis, Vexiau, Mbanya, \& Gautier, 2002). Native Americans and non-Hispanic blacks have different patterns than non-Hispanic whites (Hussain et al., 2007). Various life circumstances that have been linked to increased diabetes risk include job strain (Nyberg et al., 2014), low and very low birth weight independent of BMI (Ruiz-Varvaez et al. 2014), food insecurity (Berkowitz, Baggett, Wexler, Khuskey, \& Wee, 2013; Berkowitz, Gao, \& Tucker, 2014), and poor sleep quality (Mahmood et al., 2013). All of these can be stress-induced, and indeed, psychosocial stress has been found to accelerate progression for those with pre-diabetes (Virtanen et al., 2014). Diabetes and depression have a well-established correlation as well, although causality has not been ascertained in either direction (Roy \& Lloyd, 2012). Depression was identified as a diabetes risk factor for those with less than a high school education that is particularly pronounced in women (Carnethon, Kinder, Fair, Stafford, \& Fortmann, 2003). Stress has been recognized as a factor in diseases like diabetes for some time (McEwen, 2012), and some more specific 
mechanisms for how it manifests biologically have become known as research has progressed (Peckett, Wright, \& Riddell, 2011; Beaudry \& Riddell, 2012). Research on social support in Hispanic communities is sparse, but evidence suggests that the importance of social relationships in that culture may explain their lower morbidity and mortality from cardiovascular disease in spite of elevated rates of obesity and diabetes (Gallo et al., 2015). A recent study showed that higher social support was protective against development of diabetes among Latinos (ibid). As with the case of obesity research, epigenetics has provided new explanations for how diabetes becomes established in different groups that is then transmitted to offspring (Nilsson et al., 2014; Olsson et al., 2014; Ma, Tutino, Lillycrop, Hanson, \& Tam, 2015; Raciti et al., 2015). Exposure to more established disease vectors may also play a role in diabetes risk, as research shows a correlation with a bacterium that has been linked to other diseases (Rayner, Talley, \& Horowitz, 2012; Vafaelmanesh, Parham, \& Bagherzadeh, 2015). In spite of much evidence that diabetes is much more complex than commonly understood, interventions are often focused on individual behaviors as both the cause and treatment (Hussain et al., 2007).

The conventional wisdom about obesity has infused approaches to preventing and managing diabetes, in part because the doubling of obesity among U.S. adults and the tripling of overweight among U.S. youth between 1980 and 2002 has been pointed to as the foremost culprit in the rise in type 2 diabetes (Liburd \& Vinicor, 2003; Hussain et al., 2007). So healthy eating and active living are prominent in the interventions studied. Regular, sustained physical exercise is protective (Hussain et al., 2007). Having fewer lifestyle risk factors (overweight, inactivity, diet, smoking, alcohol use) translates to 
reduced risk of diabetes mellitus incidence in older adults (Mozaffarian et al., 2009) and Native Americans (Fretts et al., 2014). Traditional lifestyles seem to be protective for the Pima Indians (Ravussin et al., 1994; Schulz et al., 2006) and for aboriginal Canadians (Haman et al., 2010). Lifestyle interventions were similarly successful in reducing the onset of diabetes in obese children from multi-ethnic backgrounds with pre-diabetes (Savoye et al., 2014). Eating breakfast helps metabolic health and decreases risk of obesity and diabetes in young adults, and the quality of the breakfast doesn't seem to matter (Odegaard et al., 2013). Addressing diabetes through weight management is common, and sustained weight loss in adults is predictive of reduced risk of diabetes (Delahanty et al., 2014; Gallagher, Heshka et al. 2014). Weight management approaches are tricky, however, because weight cycling appears to increase diabetes risk (Delahanty et al., 2014) and community-based interventions seem to have limited success in duplicating clinical interventions (Kahn \& Davidson, 2014). Dietary factors beyond weight may play a role as well, as by-products of certain gut microbia are associated with lower incidence of diabetes development, suggesting that a diet of whole grains, fruits, and leafy green vegetables is beneficial for diabetes prevention (Sun et al., 2014). Coffee, caffeinated or not, also appears to reduce risk of diabetes (Ding, Bhupathiraju, Chen, van Dam, \& Hu, 2014), as does curcumin, a compound found in turmeric (Zhang, Fu, Gao, \& Liu, 2013).

The wealth of evidence that lifestyle, particularly diet and exercise, can influence the emergence and the successful management of diabetes should not be taken as indication that such intervention is universally seen to be sufficient. Lifestyle is an acknowledged social product, and the socioeconomic forces that shape our environments 
and our habits is recognized as a problem, particularly because of the higher burden of risk placed on racial and ethnic minorities, women, urbanites, older adults, and the poor (Liburd \& Vinicor, 2003). Denial of traditional lifestyles to Native peoples is noted to be a product of racism (Alkon \& Norgaard, 2009), but the viability of reintroducing "off the land" foods that may carry their own risks due to their contamination given the "enclosure" of the lands that yield them remains suspect (Haman et al., 2010). Still, many scholars argue for remediation of the socio-environmental factors that deny various populations equal access to healthy food and lifestyles (Chaufan, Constantino, \& Davis, 2012; Mitchell, 2012; AlHasan \& Eberth, 2016). It is this conception of health equity that motivates Healthy Corner Stores as an intervention.

Despite the growing evidence that type 2 diabetes is markedly shaped by inequality both through lifestyle and otherwise, interventions are often focused downstream, aiming at high risk individuals, or midstream, targeting high risk populations, but rarely upstream (Hussain et al., 2007). Upstream interventions that address the social and political economic contexts are desirable (Liburd \& Vinicor, 2003), but media coverage of the disease frames it in such a way as to emphasize diabetes as an individual problem rather than as a social or sociological problem (Rock, 2005; Gollust \& Lantz, 2009). A series in our local newspaper written by a popular Portland chef who used diet and exercise to successfully reverse his case of the disease illustrates this beautifully (Gordon, 2012). The implication is that if he was able to reverse his diabetes through taming his dietary excesses and exercising more, everyone else can do the same. 
Overall, the research on diabetes indicates that it is much more complicated than the conventional wisdom. Like obesity, it has increased worldwide, and has race and class disparities in terms of the bodies in which it is more likely to occur. But also like obesity, it is not simply a product of poor diet and weight gain. Low birth weight, stress, depression, weight cycling and potentially even exposure to certain bacteria may induce Type 2 diabetes. While lifestyle factors do figure into the mix, lifestyle is also shaped by social and economic position. Social support and certain gut microbia seem to have protective potential. Research into this case is informed by this more complete understanding of diabetes in order to assess the Village Market's approach to health equity and its limitations.

\section{Health Equity}

While deeper systemic critiques of inequality as it impacts health are evident in the literature, the health equity language is decidedly less politically charged than that of the food justice movement. "Social determinants of health" is one phrase that is often applied, but has not gained traction in the U.S. as it has elsewhere (Kim, Kumanyika, Shive, Igweatu, \& Kim, 2010; Krieger, 2013). It is more prevalent in the UK where the term first took hold.

Michael Marmot and Richard Wilkinson popularized the term to describe the way health follows a social gradient. Those higher on the social ladder attain better health, experience lower rates of disease, and live longer (Marmot and Wilkinson, 1999). Stress is theorized as a significant factor in this gradient, and early childhood development figures prominently in later health (ibid). It is used to emphasize the historical trauma that continues to impact African American (Kim et al., 2010) and Native American health 
today (Goodkind, Hess, Gorman, \& Parker, 2012; Mitchell, 2012) and the social stigma of being "other" (Krieger, Kosheleva, Waterman, Chen, \& Koenen, 2011; Abdulrahim, James, Yamout, \& Baker, 2012) that manifests in the body (Gravlee, 2009). It is implicit in the notion of "allostatic load" that is used to characterize how chronic stress burdens the brain and body and leads to disease, how the social environment "gets under the skin" (McEwen, 2012), and developments in epigenetics provide some explanation for how this can happen biologically. Research in epigenetics validates the work of those who argued that that environmental, social, psychological, and biological factors all influence health, and that phenomena like power, racism, discrimination, and segregation become determinants of health (James, Strogatz, Wing, \& Ramsey, 1987; McEwen \& Seeman, 1999; Sampson, 2003; Everson-Rose \& Lewis, 2005; Juster, McEwen, \& Lupien, 2009). The good news is that intervention helps. The plasticity of the brain means that although previous damage cannot be undone, compensation is possible, resilience can be enhanced, and lost plasticity may even be restorable (McEwen, Gray, \& Nasca, 2015). So interventions that are aimed at improving mental health (Goodkind et al., 2012) or simply trying to be culturally relevant (Sanderson et al., 2012) may prove to be biologically restorative.

The social determinants of health perspective offers a way to look at social and economic inequality that goes beyond the ability to access amenities, but rather how certain bodies may become marked for life. Indeed, socioeconomic position has been shown to be a fundamental cause of disease to such an extent that our social structures themselves are argued to be a necessary focus over individual behaviors (Link \& Phelan, 1995; Subramanian, Belli, \& Kawachi, 2002; Isaacs \& Schroeder, 2004). The evidence is 
particularly compelling with respect to diabetes. Childhood socioeconomic position impacts the development of type 2 diabetes among both non-Hispanic black and nonHispanic white respondents (Maty, James, \& Kaplan, 2010). For adults, socioeconomic position is significantly inversely related to diabetes for non-Hispanic black and nonHispanic white women when measured as income/poverty (PIR), though the PIR at which diabetes prevalence became significant for non-Hispanic black women was lower (twice poverty versus 5 times poverty) (Robbins, Vaccarino, Zhang, \& Kasl, 2001). This relationship did not hold for men (ibid), and other evidence suggests that low education and blue-collar occupation may in fact be protective for non-Hispanic black men (Maty et al., 2010). Educational attainment is protective for non-Hispanic white women, but not for non-Hispanic black women (Robbins et al., 2001) and cumulative socioeconomic position was inversely related with diabetes risk in white women (Smith et al., 2011). Body size, physical activity, caloric and fat intake, alcohol use, and tobacco use failed to explain most of the differences in diabetes prevalence among low SES non-Hispanic black and non-Hispanic white women (Robbins et al., 2001). The pronounced gap in mortality by race and the lack of behavioral explanation brings to mind Ruth Wilson Gilmore's definition of racism as "the state sanctioned and/or extra-legal production and exploitation of group-differentiated vulnerabilities to premature death" (Gilmore, 2002).

In the U.S., "social determinants of health" as Marmot and Wilkinson define it has largely failed to catch the attention of the larger public. Intervention remains focused on individual behaviors. The term has been used to refer to the "indirect" health disparities that result from unequal access to healthy lifestyles (Chaufan et al., 2012; Hill et al., 2013) although the argument that inequality itself is the root cause is present as 
well (Center for Disease Control, 2016; Marx, 2016). Research funding in the U.S. has been directed toward genetic understandings of biology rather than social ones even for social inequalities in health (Krieger, 2013). So just as poverty research was directed along individual, behavior-oriented lines along with the neoliberal turn (O'Connor, 2002), similarly has scholarship on health equity. The research on "food deserts" that motivates the Healthy Corner Store movement reflects this, and limits the scope of its inquiry into health equity accordingly.

Social determinants of health research documents disparities in how disease manifests along a social gradient. There are health costs that come with being "other." This happens not only through the reduced access to health lifestyles that is often meant by the use of the phrase "social determinants of health," but also through the allostatic load that difference and exclusion imposes on people. However, brain plasticity offers hope that efforts to address oppression may undo some of this damage as it can certainly minimize future damage. Egalitarian and democratic practices, then, should be understood as productive of health. This research explores the Village Market as a health equity project through the lens of social determinants of health, so not only is access to healthy food through the store important, but so, too, are social relationships nurtured and democratic processes observed.

\section{Community Health Workers}

Community health workers (CHWs) are trained lay health workers that help with education and outreach in underserved communities. They are often used to help support people who experience difficulties accessing medical services because of language or cultural barriers. Becoming a CHW typically involves a specialized training and work has 
historically been located in nonprofit or public health settings, although CHWs are increasingly employed in for-profit health settings (Koch, 1998). CHW projects vary in their approaches, with some emphasizing the community engagement and participation that reflect a SDOH perspective rather than delivery of "off the shelf" health promotion packages (Warr, Mann, \& Kelaher, 2013). Others use CHWs more procedurally to deliver program materials in a culturally sensitive way, but remain focused on the centrality of delivering the technical health information that recipients "need" to modify their behaviors (Palmas et al., 2012; Perez-Escamilla et al., 2015). The social action approach is increasingly undermined by bureaucratization and professionalization (Warr et al., 2013). A study of six Neighbourhood Renewal (NR) locations in Victoria, Australia found that cooperative "bottom up" approaches and procedural "top down" approaches to health promotion could be successfully married in ways that worked in socio-economically disadvantaged circumstances, but the work styles of health promotion professionals significantly influenced how their ideas were received.

Scholarship on community health workers indicates that programs differ in the degree of agency they seek to activate within the workers themselves and the communities they work in. A study of the Poder es Salud/Power for Health (PES/PFH) project in Portland offers an example of a more progressive project. The primary goal of that project was to address health disparities in African American and Latino communities by building community capacity to work together to address the root causes of those disparities (Wiggins et al., 2009). Training involved an 80-hour curriculum, and the PES/PFH training sought to build leadership/organizing skills, focusing on the use of popular education (Farquhar, Wiggins, Michael, Luhr, \& Jordan, 2009). The training that 
the Village Gardens CHWs participated in involved 40 hours of classroom work on topics Village Gardens staff selected from the same training organization. This organization uses popular education extensively and ascribes to a SDOH philosophy, although their interpretation of SDOH focuses on systemic barriers to healthy lifestyles. If the folks who participated in opening the Village Market recognized the existence of inequalities as a cause of health disparities beyond the unequal access they allow to healthy behaviors, it wasn't evident to me. They were very concerned about the chronic diseases discussed above, but mostly discussed diet and exercise as interventions. However, one approach they proposed was to create a community-based wellness program that the store would support through nutrition education efforts and discount programs. The idea for the wellness program came out of one of the committees planning the store, and planned to involve community health workers supporting people as they work to adopt healthier lifestyles. The social support that such a program could offer might have helped address deeper social determinants of health, but it has not yet been implemented.

\section{The Social Economy as Economic Development}

A final arena of literature speaks to the economic dimension of this project. Having a grocery store was reportedly a particular need identified by residents of the former Columbia Villa. Many residents at New Columbia are car-less, and do their grocery shopping by bus at stores some distance away. The community itself is a socially engineered environment with a racially, ethnically, and generationally diverse population that is also more economically diverse than the one that inhabited the previous development. As such, the literatures discussing disinvestment in inner-city minority 
communities are not as directly applicable. The New Columbia neighborhood is also not "central city" but more suburban in its configuration, and although two bus lines run down the main thoroughfare, the distance to commercial outlets reflects a more cardependent lifestyle. However, it is worth noting for the purposes of this project that failure of the capitalist market to establish full service grocery stores in poor, urban communities of color is what inspired the food deserts literature reviewed earlier. While ideally markets are managed so that they benefit citizens, in reality they distribute resources unevenly and, depending on cyclical changes in influence, may skew distribution toward the wealthy and reinforce class divisions (Massey, 2006). Such is the case with grocery stores in this area of North Portland, and as a remedy, space for a grocery store was designed into the ground floor of a mixed-use building on the main street running through the community. The first attempt to create a grocery in this space involved having a local entrepreneur open an offshoot of his small, affordable, producecentric grocery there. It lasted less than three years even with subsidies. After this publicprivate partnership failed, the idea of creating a nonprofit market with neighborhood residents emerged as the chosen solution. Both "natural" market forces and subsidized market intervention failed to yield a viable grocery, so HAP (now Home Forward), recruited Village Gardens to create one, not as a traditional for-profit venture, but instead as a nonprofit.

\section{Social Economy}

The social economy is used to refer to the universe of activities to satisfy human needs that are neither done by for-profit enterprises nor by the state (Mertens, 1999; Moulaert \& Ailenei, 2005). It is also referred to as the third sector, the solidarity 
economy, and in the U.S., the nonprofit sector or voluntary sector. Another more generic term is civil society (Muukkonen, 2009). Muukkonen notes that the different terms derive from different metaphors that reflect cultural and disciplinary differences, and even the individual terms have different meanings based on how the basic social institutions are framed. For example, civil society means something different if the main institutions are the state and the family versus the state and the market, so it is framed differently by Marxists, liberals, and the church. She finds that in the U.S., civil society is generally equated with the formal nonprofit sector, and is hence an economic sphere, whereas elsewhere it is defined more broadly (ibid). Likewise is the social economy an economic sphere, and its meanings are equally varied. The range of meanings has been apparent in policy debates in Quebec, where three different perspectives on the social economy were in contest (Graefe, 2006). The perspectives that dominated in that context were those that flanked neoliberalism by aiming to address some of its exclusions or sought to roll-out new institutions to further it, rather than those that sought to countervail it. It is important to keep the terminological multiplicity in mind, because much social economy research is done in areas outside the U.S., where the political and economic contexts differ, so the language used must be interpreted cautiously. In the context of this project social economy will be used to refer to the activities of the nonprofit sector and solidarity economy will be used for instances in which activities are more explicitly political.

The disposition of the social and solidarity economies with respect to market forces motivates some explication of the term 'neoliberalism.' It is characterized as a "a theory of political economic practices that proposes that human well-being can best be advanced by liberating individual entrepreneurial freedoms and skills within an 
institutional framework characterized by strong private property rights, free markets, and free trade" (Harvey, 2005) (2). The advancement of the market and rollback of the state is a recognized part of neoliberalism, although it is useful to consider it a variegated process rather than a clearly defined state (Agyeman \& McEntee, 2014), in which case the term neoliberalization is more appropriate (Guthman, 2008). Neo-Foucauldian usages of neoliberalism employ his concept of governmentality to draw attention to the ways that thought and behavior is directed toward use of market logics by a variety of exertions of power that shape perception and knowledge (ibid). All three terms have relevance to the social economy, but perspectives that neoliberalism is not totalizing, but rather partial and contested through the multitude of non-market and alternative market activities that people engage in daily (Gibson-Graham, 2006), are important to bear in mind as well.

The social economy has waxed and waned over time. Increases in social economy activities have been linked to emerging crises (Tomas Carpi, 1997; Moulaert \& Ailenei, 2005). In the U.S., the rise of the nonprofit sector has been connected to the increase in contracting out of administrative and social service functions by the government because contending political camps could not agree on the size and role of government, using the social economy to create a shadow state (Wolch, 1990; Mertens, 1999; Morgan \& Campbell, 2010). This has meant that in the U.S. the social economy is dominated by groups working in the general interest. These are organizations in which the dominant group making decisions is operating for the benefit of a different group, and possibly for the whole of society (Mertens, 1999). In Europe, where government agencies provide more social services, the social economy consists more of organizations focused on mutual interest (ibid). 
The social economy is marked by two key differences with the market economy. First, organizations that fit in the social economy are generally distinguished by their ideas of ownership and their allocation of profit. Whereas capitalist enterprises direct their surpluses to investors, those in the social economy allocate surpluses to other beneficiaries (Mertens, 1999). Redistribution of surplus may be implicit, such as is the case when outputs are sold at prices below the market rate or when inputs are purchased at above market prices, or it may be explicit in the form of bonuses or dividends (ibid). In the case of social enterprise, surplus may be reinvested in social programs or put toward operational costs (Alter, 2007). A second distinction comes in the character of involvement. Work done in the social economy is considered to be more participatory and democratic, less hierarchical (Tomas Carpi, 1997; Lukkarinen, 2005; Ben-Ner \& Ren, 2015). Through this quality of involvement and membership, such organizations provide a means of influence on economic activity that differs from the voice and exit options provided by the state and the market, respectively (Tomas Carpi, 1997).

Proponents see the social economy as a valuable tool for local development, particularly where marginalized groups are concerned, because of its greater consideration of equity and other ethical dimensions, its participatory and democratic nature, and its provision of jobs (Tomas Carpi, 1997; Lukkarinen, 2005). It is also cited as a source of innovation (Mertens, 1999), and a potential means of providing local respite from the forces of globalization and a means of resisting neoliberalism (DeFilippis, 2004; Hadjimichalis \& Hudson, 2007). Properly governed and funded, local nonprofit actors have the ability to tailor their programs to their community needs and apply creative solutions to complex problems (Saul \& Curtis, 2013). The social economy 
may have the potential to encourage the evolution of thought within the market economy such that the social responsibility of economic actors becomes de rigueur (Golob, Podnar, \& Lah, 2009). The social context has great bearing on the character of the social economy, however, and this context can be supportive of social goals (e.g. building on energies of social movements) or deleterious to them (e.g. adopting capitalist sector logics like hierarchy, rigidity, and specialization) (Tomas Carpi, 1997).

Critics see problems associated with the growth of the social economy. Use of nonprofits for social welfare service provision translates into those services being influenced by the nature and extent of local voluntarism, and thus variation by geography (Wolch, 1990). Nonprofits are constrained by the norms of the public sector agencies with whom they work, but still see themselves as accountable to the populations they serve, thus creating a contradiction that they must navigate internally (Trudeau, 2008). The professionalization that comes with taking on such contractual obligations often changes organizations and the ways they relate to their communities and their clients (Carey, Braunack-Mayer, \& Barraket, 2009). Changes in the nonprofit sector that have led to greater adoption of business-like practices have prompted much scholarly inquiry to understand the causes, processes, and effects of this shift (Maier, Meyer, \& Steinbereithner, 2016). Questions have arisen over whether the nonprofit sector in the U.S. constrains and represses the development of radical movements (Wolch, 1990), ultimately reinforcing the hierarchical, patriarchal, and white supremacist state (Lethabo King \& Osayande, 2007; Rodriguez, 2007). Ford Foundation funding, for example, was dispensed in order to diffuse tension among black militant organizations in the late 1960s, directing Black Power proponents toward black capitalism, which ultimately reinforced 
American corporate capitalism (Blaustein \& Faux, 1972; Allen, 2007). Substantial funding for nonprofits is obtained through tax code provisions that allow individuals to avoid paying taxes through charitable donation and through estate tax laws that allow individuals to avoid the $50 \%$ estate tax through foundation establishment (Ahn, 2007). So, foundations are often funded through lost taxes. Still, some argue that the form itself is not the crux of the problem, and can indeed be used effectively for political mobilization (Majic, 2011) that can counter neoliberalism (Roy, 2011). Because no incorruptible form exists, it is important to focus on an organization's ultimate objective of liberation so as not to get swept up in tangential activities to secure its survival (Gilmore, 2007). Making time for reflection, evaluation, and political discussion is suggested as a way to maintain organizational focus in the face of bureaucratization and neoliberalization (Perez, 2007; Woolford \& Curran, 2012).

Research critical of the social economy often emphasizes the way that nonprofits are used to fill the void left by the decline of the welfare state as part of the "shadow state" (Wolch, 1990) or to support feel-good projects that ultimately reinforce the systemic inequalities that are at the root of many of our social problems. Nonprofit organizations are an avenue for executing "roll-out" neoliberalism, the political and institutional infrastructural adaptations that address the failings of the neoliberal project (Peck \& Tickell, 2002). This is particularly so in the U.S., where the nonprofit sector is often used to benefit others. But it is also a tool that can help communities develop their own capacities provided they can find the funding for their projects. Nonprofits that can foster reflexivity have better capacity to withstand attempts by external forces to influence them. This case examines the ability of New Columbia residents, through 
Village Gardens, to create a store that reflects the needs and wants of a full spectrum of community members and maintain participatory and democratic practices in the context of a nonprofit sector where focus often strays.

\section{Social Enterprise}

Social enterprise is a subset of the social economy that has arisen in recent decades to address social ills through income-generating activities. Its rise has been attributed to a combination of the ceding of many services by governments to the nonprofit sector as well as to the application of entrepreneurial thinking to social welfare concerns (Cooney \& Willams Shanks, 2010). Some scholars argue that because nonprofits have engaged in revenue generation for quite some time, the phenomenon isn't as new as the social and economic context in which it has been touted with renewed zeal (Sepulveda, 2015). Nevertheless, the terminology is newly emerged. As with the social economy literature, definitional differences between the U.S. and Europe make comparison of social enterprises across geographies difficult (Young \& Lecy, 2014). In the U.S., social enterprise often refers to revenue generating activities undertaken by nonprofit organizations (ibid), but may also be applied to the growing interest in fostering socially conscious business practices (Alter, 2007). Business schools have particularly embraced the latter form of social enterprise (Massetti, 2012; Smith, Gonin, \& Besharov, 2013). Social enterprises are considered hybrid organizations, combining social and economic goals that are perceived to be conflicting (Gidron \& Hasenfeld, 2012). Still, cooperatives also incorporate dual goals (Levi \& Davis, 2008), and they have a long, if unsung, history in the U.S (Fairbairn, 2004). It should be noted that because social enterprises often aspire to bring private sector discipline and innovation to their 
operations, they may differ from other nonprofit organizations. For social enterprise, efficiency may trump democracy. The Village Market is a nonprofit that secured operational funding through grants to launch it and sustain it for the first few years, after which time it was intended to be self-sufficient. So, it started off as a nonprofit, and became a social enterprise. For that reason, specific social enterprise cases discussed herein will be drawn from those that are nonprofits engaging in some type of income generating activity as a means of fulfilling a social need, whether in the pursuit of selfsufficiency or to address a market failure.

Social enterprises have different planning and start-up requirements relative to both businesses and nonprofits. They are typically funded through a combination of philanthropic, public, and commercial sources and often involve some "sweat equity" in their start-up (Young, 2012). Organizational planning involves not just a business plan, but also plans for the social and power dimensions of the organization, and finding a combination of finance, governance, and legal status that helps the social enterprise persist is part of that planning process (Social Enterprise Alliance, 2010).

Communication is important in the realm of social enterprise, especially because of the dual goals. In the context of human resource management, it is helpful to create a psychological contract to reflect the expectations that different stakeholders have of each other (ibid).

Credibility and legitimacy are often problems for social enterprises because their hybrid nature confuses people. Finding ways to manage perceptions and present a coherent logic is important for success (Galaskiewicz \& Barringer, 2012). Pursuing social enterprise within an existing nonprofit can particularly lead to confusion among 
stakeholders (Smith, Knapp, Barr, Stevens, \& Cannatelli, 2010) and decreased funding from individual donors, especially if the enterprise is not well aligned with the mission (Smith, Cronley, \& Barr, 2012). Contradictory purposes create identity difficulties for employees as well as donors. Nonprofits that added social enterprises after their "conception," especially those doing social service provision, struggled with identity to a much greater extent than those that started with the social enterprise (Smith et al., 2010). Organizations pursued "identity marketing" as a means of managing perceptions of internal and external stakeholders (ibid). A case study of 6 British social enterprises found that while they all espoused strong social values, they drew their legitimacy from conventional institutional structures (Nicolopoulou et al., 2015).

The prevailing opinion is that managing social enterprise requires balancing competing logics. Four ways these contradictory elements are typically handled are: the social mission gets co-opted; the competing logics are compartmentalized into different organizational units; structures of governance are developed to reinforce shared objectives and build cooperation; shared identities are creatively forged out of both logics (Gidron \& Hasenfeld, 2012). Paradoxical thinking is suggested as a useful skill for social enterprise management (Smith, Besharov, Wessels, \& Chertok, 2012). Paradoxical thinking involves finding new ways to act that embrace complexity and contradiction within the organization. However, the balancing act may not be as difficult as generally believed. Analysis of British and Japanese social enterprises suggested that the social and business dimensions of social enterprise were linked such that success in one dimension supported success in the other, so approaching the enterprise strategically can enhance performance in both dimensions (Liu, Takeda, \& Ko. 2012). 
Nevertheless, risks associated with respect to maintaining social purpose exist.

The more exposed organizations are to market logics, the greater the risk of subordinating the social mission, and when an organization is in a field full of market-oriented competitors, it is embedded in the market (Garrow \& Hasenfeld, 2012). In the context of work integration social enterprises, this resulted in the commodification of clients/workers as they were hired according to the needs of the enterprise, dismissed for not being productive or violating work norms, and their work experiences were dictated by the needs of the business (ibid). The simultaneous construction of clients as both workers and clients reinforced neoliberalism by blurring the distinction between the market and the welfare state, undermining the social rights that are part of the latter (Garrow \& Hasenfeld, 2014). Hierarchical decision-making is more effective for service delivery, but taking a narrow employment and service delivery approach to addressing disadvantage risks undermining the potential of social enterprise to pursue empowerment and social inclusion (Teasdale, 2010).

Some practices are protective of the pursuit of social mission. Supporting a learning culture, one where it is understood that no one knows best and humility is a virtue, is valuable to social enterprise, as is sensitivity to power dynamics (Frankel \& Bromberger, 2013). In Latin American case studies of civil service organizations and businesses, success in social enterprise generally required implementation by its beneficiaries, and problems resulted when they were disconnected from their grassroots (Social Enterprise Knowledge Network, 2006). Paternalism was detrimental to long-term success, and creating a participatory culture helped sustain development of the organization (ibid). Organizations perform better when there is cohesion around the 
social mission (ibid). Being able to identify, understand, and engage stakeholders also contributes to performance (ibid). Participation of employees in decision-making and ability to express their views both fostered greater commitment to the social enterprises (Ohana, Meyer, \& Swaton, 2012).

The research on social enterprise draws significantly from business school approaches that are interested in defining best practices and creating tools to assess success, like social return on investment (SROI). This case took a qualitative, ethnographic approach, so research on SROI was less of interest, although many of the best practices give insight into the struggles the Village Market encountered. The practice of planning for social and power dimensions of the Village Market instead of just the business activity might have been helpful. Literature that discusses the challenge of balancing competing logics with paradoxical thinking and the confusing nature of hybridity similarly reflect the Village Market's experience. Equally relevant is the discussion of when hierarchical decision-making is beneficial and steps that help keep staff engaged. This research corroborates some of these previous findings, although the scope and scale of the enterprise relative to the experience of the organization means that my findings in this arena may not be particularly illuminating for experts in the field.

\section{Community Development Corporations as Social Economy Actors}

Although efforts to improve the economic circumstances of neighborhoods have a much longer history, the modern era of community economic development began in the 1960s as a result of the Lyndon B. Johnson's "War on Poverty" (Halpern, 1995). The Community Action Program in the newly formed Office of Economic Opportunity (OEO) began as a means of fostering organizing and activism particularly in low-income 
black communities, but shifted its focus toward economic development within three years (DeFilippis, 2004). This shift in focus led to OEO's Special Impact Program (SIP) that was intended to help local groups pursue economic development projects. SIP was further enhanced by the passage of the Federal Community Self-Determination Act of 1969 that led to a substantial increase in the number of Community Development Corporations (CDCs) being formed. Early CDCs tried to create a more equitable marketplace by taking on neighborhood projects that ranged in size (Halpern, 1995). During this era, the rise of the "black power" movement sought greater community control over social and economic aspects of life in black neighborhoods (DeFilippis, 2004). The Nixon administration placed greater emphasis on individual entrepreneurial approaches, and the Small Business Administration was recruited to increase access to black capitalists, resulting in the formation of Minority Enterprise Small Business Investment Companies (MESBICS) (Blaustein \& Faux, 1972). These efforts reflected Nixon's lack of interest in actual progress and left many entrepreneurs saddled with high interest rates on debt and subject to the whims of the sponsoring enterprise, but provided a superficial engagement with debates over "black capitalism" that emerged between Booker T. Washington, who advocated for creating black-owned institutions and businesses as a means of dispelling racism, and W. E. B. Dubois who felt that this placed the onus on blacks themselves (ibid). The quest for black power was disciplined through the provision of opportunities for black capitalism, and undermined the prospects for community control (DeFilippis, 2004). Other avenues of collective ownership were emerging around this time, but these were small scale and localized alternative institutions (ibid). 
During the same period in a different geography and for a different populace, "new wave" food cooperatives were formed during as part of a growing environmentalism and emerging critique of conventional food industry practices and false marketing claims (Knupfer, 2013). Most co-ops formed during this era were in middleclass communities, although the Economic Opportunity Act of 1966 prompted many community action agencies to start producer and consumer coops, and some were started in housing projects and on Indian reservations (ibid). People's Food Co-op in Portland, OR was formed as a food buying club by some Reed College students in the late 1960s and became an incorporated nonprofit in 1970 (People's Coop, 2016). Food Front Cooperative Grocery was also formed in this era, formed by some NW Portland neighbors in 1972 to provide access to good quality foods not available in supermarkets (Food Front, 2016). While the formation of cooperatives demonstrates a movement away from capitalist approaches to enterprise, during this era they were largely a white, middle class phenomenon, relatively self-contained, and thus somewhat removed from the race and class struggles that low-income communities were contending with at the time (DeFilippis, 2004).

In low-income urban communities, CDCs became the venue of choice for economic change. As was the case with black power, momentum that first generation CDCs had around enhancing community control was channeled toward nonconfrontational activities through funding (DeFilippis, 2004). The OEO's decline and demise under President Nixon left them without one of their significant sources of funds, and they became increasingly focused on entrepreneurship and individualistic objectives. A second generation of CDCs formed in the 1970s grew out of protest 
movements but became more cooperative and professionalized as they began to work more proactively with the local institutions around neighborhood concerns (ibid). They typically focused on grassroots economic development (Peirce \& Steinbach, 1987). A third generation of CDCs took up housing provision when state and federal governments withdrew from that role (DeFilippis, 2004). In a climate of scarce federal funding, they patched together monies from a variety of sources, which necessitated even further professionalization (Peirce \& Steinbach, 1987). They became more project-oriented. A small number of CDCs took on the task of bringing supermarkets back to their neighborhoods in the $1980 \mathrm{~s}$ and 1990s. Case studies of 16 projects from $10,000 \mathrm{ft}^{2}$ to $100,000 \mathrm{ft}^{2}$ around the U.S. required from $\$ 2-\$ 29$ million in financing, some of these for larger shopping centers that included a grocery store, but all involved recruiting grocery chains with the exception of one endeavor that involved enlisting an independent wholesaler to open a retail establishment (Abell, 1998). The metrics of success were jobs provided, the benefits these supermarkets give in terms of reduced "leakage" from the local economy and a source of revenue to the CDC (that typically retains an ownership stake in the project). These benefits are accompanied by the risk of taking on a complex and demanding task. That study profiled 20 CDCs nationwide that successfully navigated the challenge, from the first success by the Bedford Stuyvesant Restoration Corporation in 1979 through the late 1990s.

CDCs today operate in much the same way as their forebears. DeFilippis characterizes the current practice of community development, embodied by marketorientation, non-confrontational approaches, and a belief in shared interests among community members, as "neoliberal communitarianism" (2004). He finds this orientation 
inadequate to helping low-income people improve control over their economic circumstances or otherwise improve the lives of people in their communities, the two objectives he is concerned with. He finds both the neoliberal dimension and the communitarian dimension of these approaches as theoretically misaligned to the pursuit of local autonomy. On the one hand, the interests of capital cannot be assured to be in step with the interests of community, competition is a necessary part of playing the economic game, and a history of disinvestment means that the prospects for endogenous economic growth to occur in low-income communities are slim. On the other, gains to individuals do not equate to community gains, co-location does not necessarily mean shared interests, and communities are shaped by forces that extend beyond their borders. Community development, then, operates under a fundamentally flawed framework.

This brief history of community development organizations is included to provide context for the actions of Home Forward in recruiting Village Gardens to take on this project and as a means for considering the implications for the organization. CDCs have long served as economic development agents, a tactic initially employed to direct organizing efforts toward non-confrontational approaches through professionalization and neoliberalization. Although Village Gardens is a community-based organization (CBO) and not a $\mathrm{CDC}$, it is involved in community development and shares the communitarian underpinnings that DeFilippis describes. They refer to themselves as a community building organization. Prior to the formation of the Village Market, they had primarily engaged in gardening and food production activities that made a difference in the resources their participants had, but didn't necessarily provide income, although the FoodWorks program has an income generation dimension. Past efforts by CDCs to bring 
grocery stores to underserved communities indicated that these project were significant undertakings that often involved millions of dollars and many years to complete, but the case studies of each project were short, just a few pages each. This research contributes a much more in-depth case study of a grocery development, albeit for a small store rather than a larger one.

\section{Implications of the Social Economy}

This segment considers the implications of participation in the social economy for the Village Market as an enterprise as well as for the community it aims to serve. This project could be seen as an extraordinary measure to shore up a single market failure within a flawed economic system by those who would dismiss it as reformist or accommodative rather than transformative (Hadjimichalis \& Hudson, 2007). Others might see value in using the social economy as an economic development strategy, especially for disadvantaged populations, because it both provides jobs and strengthens civil society (Lukkarinen, 2005). The use of small markets has similarly been identified as an important "third wave" economic development strategy, particularly for neighborhoods of color where these markets often proliferate (Raja, Ma et al. 2008) and groceries in general are argued to be important economic development endeavors (Treuhaft \& Karpyn, 2009).

The Village Market expected to produce 15 paid positions, some part-time, some full-time, most of them intended to be filled by community members. For the first few years it had an advisory committee of community members providing oversight. It provides some traditional economic development and also some community “chaperoning" (DeFilippis, 2004) and fits neatly within Shaffer et al's definition of 
community economic development (CED). They define CED as a comprehensive concept for changing the economic situation within the community in an interdisciplinary, democratic fashion by improving the capacity to act and innovate (Shaffer, Deller, \& Marcouiller, 2006). While they seem to have had profit-making ventures in mind, the social economy/social enterprise approach arguably shares the qualities they describe.

But this market may also be considered economic development in other ways. To the extent that it improves community health, it improves economic development capacity (Subramanian et al., 2002). One could also look at this project for its effect on the diverse economy (Gibson-Graham, 2006) that includes alternative paid and unpaid, alternative market and non-market, alternative capitalist and non-capitalist as well as traditional paid labor within a market setting. This view portrays the formal market economy as just the tip of an iceberg of economic activity. Seen through this lens, the Village Market may have a much greater economic importance to a community of people who are on the margins of the mainstream economy. For example, there was a great deal of knowledge and skill building as part of the launch process. New relationships formed. Favors were exchanged. The checkout counter was the result of a barter arrangement. As a social economy venture enmeshed in a larger social context of vast and growing inequalities, the capacity of this endeavor to promote wider change is worth exploring. The food justice typology in Appendix D characterizes social economy efforts as progressive. But Hadjmichalis and Hudson consider whether local development approaches that may otherwise be dismissed as reformist or accomodative may in fact be transformative if viewed as means rather than ends and if they provide spaces of co- 
production (Hadjimichalis \& Hudson, 2007). They argue that neoliberalism is not uniform, but shaped by place. Social economy activities often focus on symptoms, underplay the significance of class, constrain social exclusion to specific places, and aid and abet abandonment of a universal welfare state (ibid). However, they find this connection with neoliberalism unnecessary, and discuss the case of a social economy project in Umbria, Italy where radical initiatives were preserved. They argue that by creating spaces of humane, cooperative, and alternative forms of social and economic organizing and forging links with other organizations seeking to support alternative routes, the social economy can be used to signify other possible ways of living and being that challenge the mainstream rather than seeking to fit into it. While the situation of the Village Market in a publicly created housing community in the United States may constrain the prospects for transformative change to come out of the project, it is nonetheless worth observing for that possibility. The question then becomes one of what to look for.

Because social economy organizations have more concerns than the narrow efficiency objectives of market actors, their evaluation becomes more challenging, and different evaluation criteria for alternative organizations are needed. These could include learning, involvement, development of critical consciousness, flexibility, creativity, and security (this last one aimed at capital mobility) (Tomas Carpi, 1997). Another criterion that addresses concerns about the dominance of the economy by large corporations is local autonomy. James DeFilippis defines the phrase through its component terms, local as a set of relatively shared experiences and perspectives (both relationally and in an operational sense), and autonomy as power in the form of relationships that one is able to 
control (2004). DeFilippis focuses on binding capital to place, and is particularly interested in collective ownership models. Still, this is a useful criterion for thinking about the impact of this project in the community and its ability to enhance food justice. On the other hand, practices that impede local autonomy must also be watched for as well. The community board that was formed was given limited access to the financials of the store, and was largely under the direction of Village Gardens staff and employees of the store until its demise. More recent discussions around re-launching the body from current management indicate that the store may be at a point where it could more productively engage with a group of community stakeholders.

This case study offers perspective on the meaning of this store as an economic endeavor. It is not only the first Healthy Corner Store in the country to be done as a nonprofit with community involvement, it is also going into a space formerly occupied by a small full service grocery that was receiving subsidies from HAP to be there. As such, this case provides a unique opportunity to glean perspectives from the people most affected regarding the relative merits of a subsidized private business versus a nonprofit endeavor, and place these findings within the broader discussion of food regimes and our food system.

\section{Summary}

This case study draws on a wide range of literatures to consider the neighborhood context of the Village Market, the complexities of food and health, and the nonprofit dimension of the store. Literature on mixed-income communities indicates that although they do seem to enhance social control, they have less success in fostering social contact among different groups as patterns of micro-segregation tend to emerge. This case uses 
the lens of a small grocery store to consider the degree of shared interests among the different social and economic groups in a mixed-income neighborhood.

Food equity scholarship draws attention to the connections among race, class, and food that inspired the Village Market's formation, but research on "food deserts" shows that access is more complicated than geographic proximity. My exploration of the food procurement practices of New Columbia residents elaborates on the complexity of these practices that calls into question the validity of the Healthy Corner Store model that seeks to address the "food desert" problem by fortifying convenience stores. Food insecurity offers some explanation why, as residents' shopping habits reflected their tight food budgets. Food justice scholarship has highlighted the diversity of activities that fall under the rubric of "food justice," but critics note the incompleteness of the movement's engagement with race, class, and gender differences. This study represents a significant qualitative research project that explores food in these arenas of oppression, and uses a typology of food justice/food regimes to consider the situation of the Village Market relative to other Healthy Corner Stores, but also critiques the larger nutritional project of the movement. Research in critical dietetics and critical nutrition underscores the value of this case in demonstrating the need for a different approach to nutrition. Scholarship on the relationship between food and class documents significant differences in taste as well as a history of the use of food and nutrition as a means of imposing class labels on individuals. This study contributes to what is at this stage a scant body of knowledge on food with respect to class, and also explores race and national origin.

Research on health conditions and health disparities helps illustrate the politics of food and nutrition. While obesity is commonly understood as a result of an energy 
imbalance, too many calories and too little exercise, obesity research demonstrates that it is a much more complicated phenomenon, the health risks of which are poorly understood. Diabetes is similarly more complex than popular understanding allows. Research on the social determinants of health $(\mathrm{SDOH})$ implicates the very existence of social distance in these as well as other conditions that negatively impact health, yet the $\mathrm{SDOH}$ perspective is often reduced to differences in lifestyle that are the result of social inequities. This research seeks to interpret the Village Market project through a SDOH perspective to highlight the shortcomings of a food and nutrition-based approach to health. Community health workers offer a potential venue for valuing and even producing alternative knowledges that relate to health. In the context of the store, Village Gardens community health workers played a significant role in its formation and a mildly supportive role to its operations once it opened, but did not question or explore the nature of its project around food and nutrition. This research shows that if they had engaged the community more fully around this topic, they might have created a very different Village Market.

Scholarship on the nonprofit sector places Village Gardens' community-based activities in a broader context. While research often critiques this sector for its use in supporting the rollback of the state from social safety net functions, it also demonstrates its potential for use as a means of cultivating agency. Research on social enterprise shows that mixing business and nonprofit logics is a difficult business. This case documents the development of community leaders in the context of a nonprofit venture and the way that the transition of that project to a social enterprise undermined that leadership. It illustrates both technical difficulties and challenging power dynamics that unfolded in the 
recruitment of a community based organization by a quasi-government agency to launch a business in a challenging sector. 


\section{Chapter 4: Research Design and Methods}

\section{Research Questions and Expectations}

While the Village Market's model departs from typical Healthy Corner Stores, as an alternate solution to the problem facing residents of "food deserts" it has potential to influence the movement's path. Although many compelling facets shaped this project, the case focuses on four aspects in particular. First, it reviews the Village Market as a food justice project. Second, it critically examines how the store attempts to improve health equity. Third, it considers the project for its contributions to the local economy through its impact on local autonomy. Finally, it explores how the neighborhood context comes to bear on the store implementation. Specific research questions are:

1. How do the perspectives on food justice and health equity differ among the Healthy Corner Store movement, the people planning and implementing the Village Market, and the residents of the New Columbia neighborhood? How does this situate the Village Market within the food regimes/food movements typology in Appendix D relative to other Healthy Corner Stores?

2. How does a nonprofit approach to a Healthy Corner Store impact local autonomy, food justice, and health equity as well as its outcomes?

3. How does a small grocery support and challenge the assumptions behind the advocacy for mixed-income communities?

This chapter details how these three questions will be explored. It begins with a general overview of my research methodology and a discussion of how each question seeks to address theory. Next, I review each method employed. I then go through the data and methods used to explore each question. I end with a discussion of the analytical process I employed to make sense of the data I collected.

Inquiry into these questions was approached through a multi-method critical case study employing participant observation, secondary data analysis, interviews, and focus 
groups. As is the case with grounded theory, these research questions arose from the data I collected through participant observation (Charmaz, 2006). They reflect certain expectations that I had of the project based on this participation, and were influenced by two sensitizing concepts in particular. Sensitizing concepts are assumptions and perspectives that shape the way questions develop from research topics (ibid). One key sensitizing concept was co-production. Co-production is defined by four core values: people as assets, reproductive labor as work, reciprocity, and social capital - all working together to address social justice issues (Cahn, 2004). It was a quality that I looked for in the Village Market project as well as a standard for my own actions. A second sensitizing concept was paternalism. My study of poverty-related programs and policies made me keenly aware of the degree to which paternalism is often present in many programs targeting poor and minority populations (Zelizer, 1994; O'Connor, 2002). The Village Market held my interest as a research topic because its departure from typical approaches within the Healthy Corner Store movement represented a potential turn away from the paternalism that was so prevalent in attempts to address symptoms of social inequality. All three questions are infused with my interest in seeking greater co-production and less paternalism.

Question \#1 explores one of the key distinctions between the Village Market and the Healthy Corner Store movement: the involvement of community-members in the process. It explores how meaningful this participation was with respect to what the store became, and how the store fits into larger discussions of food regimes and food movements. It grew out of my observation that there seemed to be a great deal of difference among community members as far as interest in the store itself as well as in its 
goal of contributing to the health of the community. Even among those participating in the project, interest in healthy eating per se and ideas about what that looks like varied quite a bit.

The perception of need for a grocery among community members was a more fundamental question. For a community of three thousand, there were perhaps 15-20 people from the community involved in the store effort to varying degrees, and many of the participants were involved with Village Gardens in other ways. This limited participation was in part due to attrition as the project took much longer than anticipated, but it also reflected what appeared to be low interest in project goals. Much of the energy for the project came from just three people, apart from the Village Gardens or HAP staff. For a surprising number of people, paper-covered windows and notices posted on the doors of the vacant store space right on the main thoroughfare escaped notice. Several folks came inside during planning meetings, surprised to learn that the previous store was no longer there, and others were clearly unaware that a new store was in the works. It didn't seem to be something that the entire community was awaiting with bated breath. Still, many people were very interested in seeing a store there. Based on the level of awareness and interest in the store that I observed, however, I expected that concerted outreach efforts might be necessary to make people aware of the store and get them to shop there. I also expected difficulties concerning people's acceptance of the store itself, particularly over some of the things that either weren't in the store at all or had a very small presence: soda, chips, candy, cigarettes, and alcohol. How residents' perspectives of food justice and their degree of concern about health and health equity matched with the store's offerings seemed critical to its viability. Posed in this way, this question gets 
at what I felt would be a critical factor in the success of the store - whether it felt to residents as if it was "their" store or whether it reflected the influence of paternalistic others seeking to do good for the residents rather than working with the community to improve health. An assumption that I made was that people prefer the products of coproduction over those of paternalism, whether or not they want to make the effort to actually become co-producers. Characterizing the Village Market with respect to the food regimes/food movements typology allows me to explore how community involvement shaped the vision and outcomes of the store and what the implications of this are for New Columbia residents.

Question \#2 explores another marked difference between the Village Market and other Healthy Corner Stores: its nonprofit status. The social economy is argued to be valuable for economic development in disenfranchised communities, and from a food regimes perspective this choice of model for the store represents a political shift in the approach to a Healthy Corner Store. So, this approach has potential to have a different impact on local autonomy, food justice, and health equity than the typical model. One noticeable impact it had early on was the timeline of the project. The private enterprise that had first occupied the space was comparably quick to implement, but it took the Village Market a lot longer than anticipated to secure grants to finish the store interior and stock the shelves. On the other hand, a Seattle neighborhood identified as a "food desert" that began organizing a coop around the time the Village Market started exploring their project has yet to open its doors. The Village Market faced a number of challenges once it opened. It offered the possibility of giving the community some control over what the store became and expanding economic opportunity for people without substantial 
resources, what James DeFilippis calls "local autonomy.” This question explores how well the nonprofit approach to the store has navigated these challenges so far. A community advisory board was formed to help with such matters. Its role and longevity offer one telling barometer of the store's capacity to meet its aspirations.

The prospects for food justice and health equity impacts are similarly of interest. The Healthy Corner Store movement articulates some simple food justice goals: make more fresh, healthy food physically available and perhaps distribute some nutritional information with a goal of improving health equity. The Village Market initially sought to address additional, broader goals: reducing unhealthy food availability, offering the types of ingredients residents need to cook cuisines appropriate to their cultural heritage, making fresh food extremely affordable, and engaging more deeply with the lifestyle issues that contribute to poor health. However, while these goals reflect aspirations to create greater opportunities for healthier diets and lifestyles, the processes observed by the organization and the qualities of the market itself are important to community health as well. The ability of Village Gardens to maintain the character of their program in the context of a significantly larger project than they had previously taken on figured prominently in the shape of their social enterprise and how it has changed over time.

Question \#3 delves into the relevance of the community context to the store. Advocates for mixed-income communities make a number of assumptions in their claims that such developments will benefit poor people. Such assumptions include: that they will create different social dynamics than those that exist in neighborhoods of concentrated poverty; that different income/racial/ethnic groups will mix socially; and that mixedincome neighborhoods will be hospitable to those with higher and lower incomes (Tach, 
2010). The operation of the Village Market offers insight into the latter two, and this question is directed at examining whether the social aspects of life at New Columbia impact patronage of the store as well as whether some aspects of the store influence its appeal to the different groups they hope to serve. The market was touted as a valuable community space, a place where people will meet neighbors. They expected to draw customers from the surrounding neighborhoods that are within walking distance of New Columbia. But questions arose over whose store it would become and whether microsegregation patterns meant that only certain populations would shop there. A marketing survey I participated in indicated to me that people from the surrounding areas had limited awareness of the store and had established food-buying practices that they were unlikely to alter. Further, physical cues that might encourage segregation were present in the previous store. It had problems with kids leaving their bikes piled by the front door. Loitering was also considered to be a problem by some. How the Village Market handled these and other issues influence how the store is perceived and received by the different people in the community.

The selection of products the store offers impacts who shops there. Residents of the surrounding neighborhood that I surveyed mentioned interest in specialty items that seem impractical for such a small store to carry. These folks offered organics, gluten-free items, and non-dairy milks as priority items, and while the store has some items that fall into these categories, their ability to stock a critical mass of such items in the space they have remains in question. Another potential difficulty was dissatisfaction with the brands the store carried. Some people involved in the store advocated stocking "Western Family" products because such generic brands don't have the overhead costs of 
marketing campaigns, others liked their trusted brands and products. It seemed likely that community members would have similarly varied positions. In addition, New Columbia residents may have a wide variety of culturally-driven tastes and preferences that influence their shopping habits. For example, there was a fairly small selection of Mexican foods when the store opened compared to the list of items identified as desirable through discussions with some local women who were Mexican immigrants. This question guided exploration of how the store navigated the economic and social diversity of the community and how well it succeeded among the various populations encompassed in the study. This exploration provides a basis for considering what the difficulties the store experienced mean in terms of the debates over planned mixedincome communities.

\section{Research Strategy and Design}

My approach to this inquiry is a single critical case study. Single because approximating my depth of involvement in this project elsewhere would be difficult. Critical both because the launch of this store represents a potential watershed event in the Healthy Corner Store movement and the research was done in the critical paradigm. My choice of strategy was motivated by two considerations. First, as the first nonprofit, builtfrom-scratch Healthy Corner Store, it was a unique endeavor (Yin, 2003). Participants and supporters saw the store as a potential model for future Healthy Corner Stores elsewhere, and as such particularly merited the depth of consideration and concrete knowledge that a case study approach can offer (Flyvbjerg, 2001). I was a participant observer for over five years. This depth of involvement helped me understand the people involved in the project and the trials the store experienced along the way, which allows 
me to tell a more nuanced story of the store and how community members received it. Second, the context of a mixed-income community was a compelling dimension to this study, and a case study allowed for inclusion of the context to a greater extent than many other strategies do. This context was necessary for interpreting residents' perspectives on this project and how privilege shaped it. Consistent with the extended case method (Burawoy, 1991), my aim was to consider how the macro environment of the Healthy Corner Store movement and the nonprofit approach shaped outcomes on the micro level of the store, and how that macro environment was contested through the participation of community members.

Modes of inquiry into this case included participant observation, study of available materials (store business plan, marketing survey data, and other documents from the project), interviews with project stakeholders and others from the community, and interviews and focus groups with community members not involved in the store. Together, these methods constitute a solid ethnographic framework for studying this endeavor. Document analysis was used to get a sense of the history of both the neighborhood and the Healthy Corner Store movement. Participant observation provided first hand knowledge of the project that was valuable for interpreting the other data collected, as well as a source of data. Focus groups and interviews were the primary venue for investigating the perspectives of residents. I expected the sharing and comparing that focus groups inspire to yield richer data than I could elicit any other way. Interviews with key participants offered an opportunity to go into greater depth than focus groups do, so they were used to gather information from individuals with particular insights but also in cases where I had difficulty recruiting sufficient quantities of certain 
demographic groups at a time. Interviews also provided important preparation for the development of focus group and interview protocols. A table depicting how each question was approached appears below (Table 2).

The store opened in Spring 2011. I began interviews in the early part of 2012 and continued to do them through the Fall of 2015. Focus groups were conducted between the Summer of 2012 and the Fall of 2015. My participation continued through the Winter of 2013, and observation has been an ongoing activity, though less frequent since 2014 than it was for the first few years.

\section{Methodological Notes}

\section{Participant Observation}

Participant observation was extremely valuable in the exploratory phase of this project. I could engage with the participants and observe meetings without IRB approval, and it was a way for me to gain contacts and learn more about the different cultures in the community that were important later on. My approach to participant observation was guided by the belief that in order for the store to be successful both financially and otherwise, it needed to address community members' needs and wants. As such, I began by strictly observing, not wanting to influence the project's direction at all until I had some understanding of what was going on. The nature of my participant observation changed as my involvement deepened. I found that by merely observing public meetings, I wasn't able to get enough of a sense of what was going on, so I began participating in ways that I felt I could contribute without materially shaping the direction of the project. Much of this participation involved doing administrative type tasks like data entry or 


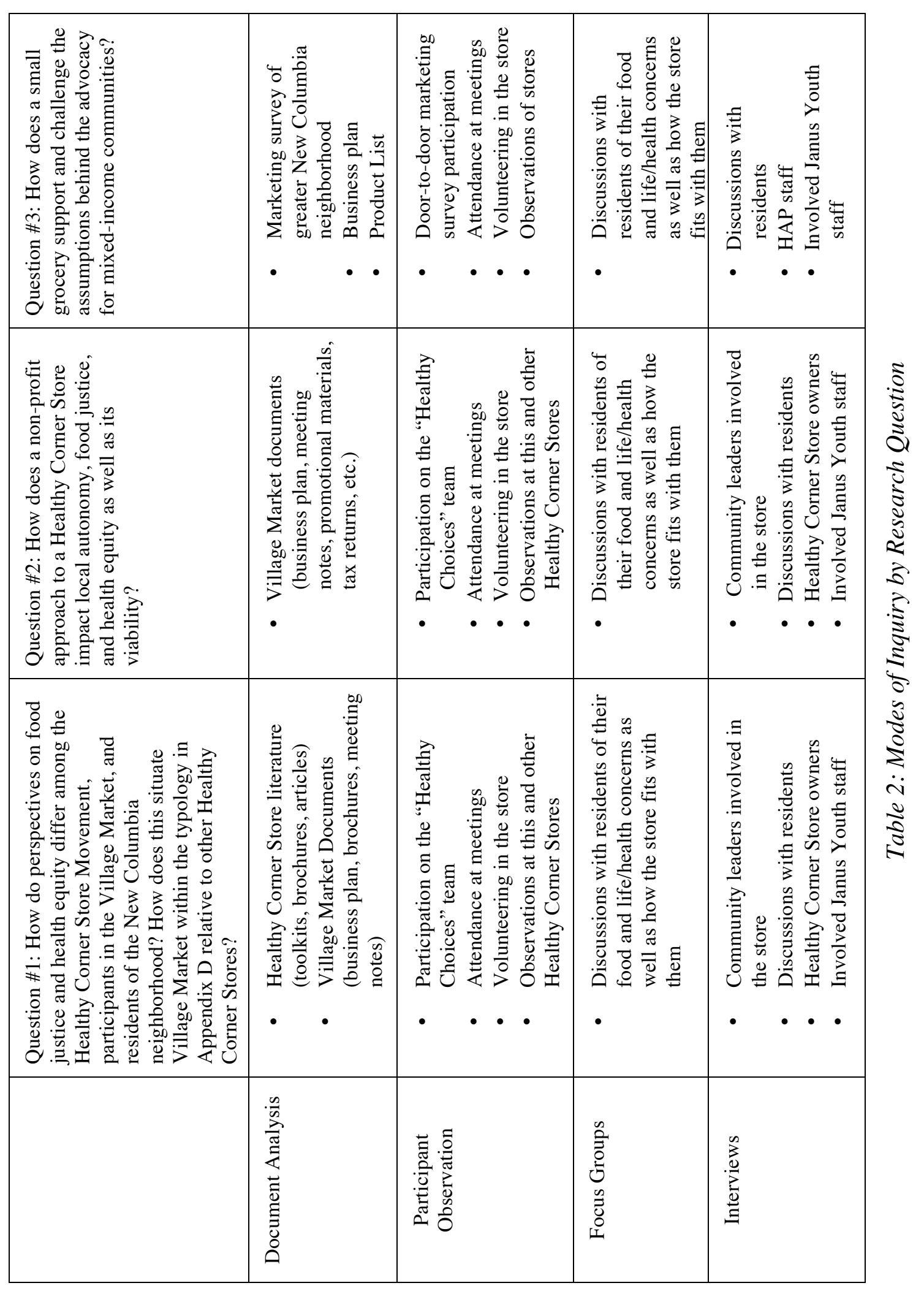


gathering price information. I provided transportation on occasions when it was helpful for me to do so. Such participations gave me access to more information about how the store was developing, but limited my influence. However, the simple fact of my participation certainly had an impact on others involved and the project as a whole. My contributions to discussions about how to go about certain tasks, for example, had an impact on data entry processes that were adopted. Where I was most reluctant to offer comment was in the arena of diet and health. This was at times problematic for my participation in the Healthy Food Choices team, but I for the most part was able to abstain from expressing opinions about what the store should be encouraging people to eat and what products the store shouldn't carry for health reasons. Nonetheless, my dietary practices were observed and noted and my opinions around health sometimes came out in informal chit-chat of a more personal nature. In some cases I did intentionally provide some limited food guidance. As an avid cook, I was able to provide information on the uses of certain foodstuffs (particularly from different ethnic cuisines) to aid consideration of whether such products might be desirable for the store.

\section{Focus Groups}

Focus group preparations began with individual interviews with three to four community members to refine my approach to the focus group topics. The protocols I used are attached in Appendices B and C. A few key community stakeholders were used to help recruit participants for each of the groups. Group participants were drawn from different populations at New Columbia but did not include those who participated in the formation of the store. I hoped to do separate focus groups for seniors, low-income renters, low-income and market-rate homeowners at New Columbia, residents of the 
surrounding neighborhood, and African and Latino immigrants. I had difficulty recruiting some of these populations as groups, particularly those categories that didn't match up with an established social identity. So I was able to recruit seniors, Congolese refugees, Somali refugees, and Latin American immigrants and refugees in groups, but I was not able to recruit people in quantity according to residence type or location. With the help of some friends, I was able to recruit people individually and did interviews instead. I had poor response from some populations, and had only a few interviews each with homeowners of both types and just a handful of people from the surrounding neighborhood. I did interview a few renters who paid market-rate rent, so they provided some additional representation of more affluent residents. Judging from the number of for sale signs that were posted around the owned homes within New Columbia, I attributed their low response in part to lower occupancy rates.

For each community segment for which I was able to recruit sufficient numbers, I conducted two focus groups of individuals who were regularly involved in obtaining and preparing food for their household. Groups varied in size from three to nine participants. Some larger groups were less successful in that they tended to produce side conversations that were distracting and made transcription difficult. Because groups were drawn from stressed populations, some consideration was taken to make participation feasible and comfortable. Each group was held at a neighborhood location, and began with informal discussion over a meal or snack (depending on time of day) that I provided. This was to provide food for thought, as well as to reduce discomfort among those who were experiencing hunger or food insecurity. I used rooms that were suitable to accommodate parents who wanted to bring their children. 
Group discussions were moderately structured around the topics of food justice, health equity, and the Village Market. Groups that required interpretation needed more time to address each question, so those groups were restricted to questions about food justice and the Village Market, although health topics did emerge in some instances. All groups began with a structured question to get conversation flowing. After that, discussion was directed to food and health topics, concluding with a discussion of the Village Market. Recordings from these groups were transcribed and coded. Coding of the data was an emergent process, and because saturation was indicated after two groups in each category, no others were added.

\section{Moderating Strategy}

I had initially intended to make focus groups loosely structured and be minimally involved. What I found was that this was unsatisfying to participants because they wanted to understand something about me. This was especially true for residents in the senior housing across the street from the store, who had seen me around a lot due to my friendship with someone in the building. I expected there to be differences among groups as to what their concerns were in each topic area, so although I did have some probes that I occasionally used to get discussion flowing, I allowed participants to take discussion around the general topics where they wanted them to go.

The attached outlines in Appendices B and C provide broad overviews of the focus group discussions. They began with a factual ice-breaker question and then a question about food that was intended to be easy to discuss among strangers. Because the focus groups were conducted with food present, my hope was that this would stimulate discussion over what good food was to them. After these lighter-weight questions, we 
delved into the main topics of food justice, the Village Market, and health equity. These topics had some potential to be upsetting, which I managed by making sure people understood that they didn't need to talk about anything they don't want to and allowing supportive conversations among the group to play out as seemed appropriate. A wrap-up question offered participants an opportunity to turn the tables and ask me any questions they liked.

\section{Interviews}

As is consistent with a grounded-theoretic approach, interviews were open-ended, attempting to draw out people's meanings, assumptions, and perspectives on the topics at hand, which generally included food, health, and the Village Market. They were used both where particular individual's insights were sought and to generally inform focus group protocols. In cases where I wasn't able to recruit residents in numbers according to the demographic categories I intended, I did interviews instead. They were especially valuable in providing historical context to the project and gathering a range of perspectives on the store. Sample topics and interview questions are attached as Appendix A. Interview questions were asked according to the interviewee's role and longevity with the project.

All told I spoke with 98 people over the course of the study. Of those, 16 people were involved in the store in some capacity and two others had grocery expertise that drove my interest in talking with them. A total of 83 people were residents of New Columbia or the surrounding neighborhood. Of these, 17 were residents of the senior housing facility, 15 were African refugees (mostly from Congo or Somalia), nine were Latin American immigrants or refugees, 50 were living in subsidized or disability 
housing either through their own circumstances or as part of a caregiving relationship they were involved in, four were homeowners in New Columbia, 2 paid market-rate rent and seven lived in the surrounding neighborhood. I did not ask people how they identified racially or ethnically, but 28 of my participants from the neighborhood appeared to have some African American heritage, one voluntarily identified as being of mixed racial heritage, and 24 appeared to be Caucasian.

\section{Research Strategy by Question}

\section{Question \#1:}

How do the perspectives on food justice and health equity differ among the Healthy Corner Store movement, the people planning and implementing the Village Market, and the residents of the New Columbia neighborhood? How does this situate the Village Market within the food regimes/food movements typology in Appendix D relative to other Healthy Corner Stores?

This question was explored via all four inquiry methods. Materials created for the Village Market provided an initial basis for gleaning participants' perspectives on the concepts of food justice and health equity. Notes from early meetings, the business plan, and the marketing survey helped elucidate which aspects of people's lives they were most concerned with improving and how they chose to do that. Documentation from existing Healthy Corner Store Programs (toolkits, pamphlets, web sites, etc.) and articles (academic, policy, and popular) discussing such stores was used to identify the concepts of food justice and health equity in the movement, a necessary precursor to comparison with the other perspectives. Differences between how documents characterized its objectives and approach relative to those of the Healthy Corner Store movement helped clarify where both approaches fits in the food justice typology. 
Participant observation offered insights into perspectives of participants as well as other residents. Attendance at community meetings discussing the store assured me that price, acceptance of SNAP and availability of culturally appropriate foods were concerns among New Columbia neighbors, as was having a store that provided healthier options. Participation in the marketing survey made it clear to me that nearby residents were very interested in organics, non-dairy milks, and gluten-free items. Further participation yielded insights into more general circumstances like management and staff dynamics. The issues raised at meetings and the way the store aimed to address them indicated that Village Market initially fit in the progressive category, but its position shifted over time. Interviews provided in-depth perspectives from people in the community as well as those involved in the store. I also spoke with a few people in the grocery business to get a better sense of the industry. A variety of New Columbia residents and some nearby neighbors were interviewed both to give me a sense of their perspectives on food justice and health equity, and to inform the focus groups discussed below. People involved in the project had a wide range of longevity, depth of involvement, and role. Village Gardens staff and community leaders working on the project shed light on how the Village Market came to be conceived as a Healthy Corner Store and what they had in mind when they were thinking of the market in terms of its impact on the health of the community. Other participants shared how their different activities added to the health dimension of the store. These included GO FOOD team members, who worked with a group at Rosa Parks Elementary School to find ways that the store could encourage healthy snacking among kids. Residents not involved in the project had perspectives and experiences that were valuable for considering how well this store matched with their needs and concerns 
around food and health. The way they spoke about these issues helped me understand how to best approach the topics of interest for the focus groups and later interviews.

Focus groups were a valuable tool for gleaning insights on food justice and health equity from several populations living in and around New Columbia. They were particularly useful for gathering many ideas and perspectives as participants shared and compared their experiences and thoughts. Several focus group participants expressed gratitude for the opportunity to discuss these topics and particularly to share their thoughts about the store. A few groups felt like they could be community organizing endeavors, and one in particular led to some valuable exchanges of information about ways to get some of the costs of medical necessities deducted from rents. There is an opportunity with focus groups to have reduced moderator presence and control relative to interviews (ibid), which I thought would be particularly helpful for the grounded theory approach to this project because it allows more natural discussion to emerge. I took this approach in the groups I moderated myself, but a group of Congolese immigrants that was facilitated in Swahili was done in a much more structured fashion. This worked better for translation purposes. Focus groups can be useful for subjects that participants haven't thought extensively about (ibid). I suspected this would be the case for health equity, if not for food justice. I addressed this concern by first asking more concrete questions about participants' food or health concerns in general before having the group discuss the more abstract concepts. As it turned out, lack of engagement around health meant that discussions of that topic did not often get beyond the concrete. Residents were more interested in food topics, and I was able to gather much richer data on food justice.

\section{Question \#2:}


How does a nonprofit approach to a Healthy Corner Store impact local autonomy, food justice, and health equity as well as its outcomes?

For this question, materials produced for the store (business plan, promotional materials, meeting notes, marketing survey results, product list, etc.) shed light on the nonprofit approach to the store and how it was expected to address those issues. A marketing survey conducted in the neighborhood and its environs, for example, gave some insights into what community members asked for. Comparison of the survey results with the product list for the store indicated product selection or omission based on criteria other than profitability, inviting consideration of how the nonprofit approach played a role in this decision. This was the case when the store decided not to offer Frito-Lay chips, for example.

Participant observation was particularly illuminating with respect to the pace and processes of the project. The first community meeting I attended was in May of 2010, at which point the team had been working on the project for 7 months. It took another 7 month for the first grant to come in, and I watched and waited with store volunteers and Village Gardens staff as they tried to stay motivated through the funding limbo. I observed firsthand the decision-making processes used and the degree of co-production in the launch of the store, and once the store opened, I was able to discern some organizational shifts. After my interviews were completed, store staff gained the capacity to explore some new ways to use Village Market's nonprofit status to serve the community, and participant observation alerted me to these developments.

Interviews were particularly valuable for gaining perspective on how the nonprofit approach shaped the store. Those who worked on the concept for the store from 
the beginning provided their insights into how it developed over time. Grocery experts and consultants offered perspective on how this endeavor was similar and different from others they had been involved in. Community members who were not involved in the store gave their views of how it changed over time, the degree to which it impacted their lives, and its similarities and differences from Big City Produce, all of which allowed me to consider the role of the nonprofit model in effecting these differences.

Focus groups explored this question most directly through the topic of the Village Market. Community members discussed their experiences with the store and thoughts on how it has impacted their lives. Through these experiences, I got a sense of how the nonprofit model has tended to community needs differently than did Big City Produce, although in some cases, this was contrary to their wishes. These conversations were quite a telling evaluation of the processes that were employed throughout the development of the store.

\section{Question \#3:}

How does a small grocery support and challenge the assumptions behind the advocacy for mixed-income communities?

Available materials particularly useful for examining this question included the business plan, a marketing survey conducted in New Columbia and the surrounding neighborhood, and the product list. The business plan gave me some indication of the assumptions made by those planning the store, which reflected some of the same assumptions underlying the advocacy for mixed-income communities. The marketing survey revealed a variety of tastes and preferences, indicating potential challenges to the store's ability to serve such a diverse community. The initial product list and how 
offerings changed over time offered further basis for assessing assumptions regarding who would shop there.

Participation provided some insights into the difficulty of creating a business to serve a socially and economically diverse population. The Village Market has a small footprint - about the size of a convenience store. Door-to-door marketing surveys I conducted indicated to me that there was likely to be a great deal of difference between items that low-income residents were interested in having and those desired by middle class community members. Middle class neighbors I surveyed wanted organic produce, gluten-free items, and non-dairy milks, whereas the concerns voiced over price by people at store meetings indicated that many residents may not have interest in or capacity to purchase such items. These differences in tastes and preferences invited questions over whether race, class, and ethnic differences in terms of food were substantial enough to counter arguments for mixed-income communities. Participation following the opening yielded some insight into who did and didn't shop there.

Interviews with Village Market participants were less critical to the exploration of this question, although I did glean some useful data from them. In particular, I heard about tensions among different groups in the community and some frustration over cultural differences in the context of the store. Those who helped write the business plan shared their beliefs about who would come to the store, but those were based largely on proximity and car ownership rather than social and economic characteristics. The consultant who advised store planners on the demographics of the neighborhood and how the store would fit into the community offered some insight into the importance of price for neighborhood residents with respect to their shopping behaviors. 
Interview and focus group questions with residents not involved in the store did not directly target this research question. However, comparison of the discussions about food justice, health equity, and the store itself amongst different groups provided some basis for considering how economic and social differences influenced people's needs and wants with respect to the store. These comparisons yielded insights as to who shops there, who doesn't and some of the factors that influence these decisions. Further, because they were experiencing life in a planned mixed-income community, I expected that residents' conversations would indirectly provide insight into the benefits and costs of such a community and how those matched with the expectations that planners designing such communities have made.

Analysis

The data from all of these inquiries was substantially qualitative in nature. Available materials, field notes and interview/focus group transcripts were coded and memoed according to a grounded theory approach using TAMS Analyzer software. I attempted to be consistent with that approach by making coding an ongoing process, but I had many periods when I got a lot of interviews and I could not keep up with the transcription. I proceeded by interrogating data for important initial codes and generally coded line by line for available materials, interviews and focus group transcripts, and incident by incident for field notes from participant observations. These codes were a product of both the content of the data and my interpretation of what was significant in them as I tried to understand the perspectives of those I studied (Charmaz, 2006). Initial codes stayed close to the data, and revealed a few gaps that I filled through further inquiry (ibid). A second round of coding was more focused, using analytic directions that 
emerged from initial coding as a guide as data are compared against each other as Charmaz suggests. Memo-writing was incorporated throughout the coding process as thoughts occurred to me about what the data might mean, how they compared to other data, or how they might be analyzed, but was also helpful as data were compared for the focused coding. I did not do a theoretical coding, but instead constructed a narrative to get theoretical insights. Use of storytelling as an analytical tool is recommended for drawing out the conceptual and theoretical significance of data, as well as a means of conveying it (Bailey, 2007), and fit well with how I often find myself developing my understanding of my everyday experiences.

One further analytical step that I conclude this research with is a materialist feminist discourse analysis. This involves using the transcripts and documents as texts to explore the dynamic between social movements and institutional power and involves analysis of movement frames and "relations of ruling" (Rosenberg, 2008). It builds on Foucauldian conceptualizations of discourse that include both language and practice (ibid). Foucault's analytic conceives of the social as a "network of alliances" rather than a "totality governed by a fixed unifying principle," which means that it is descriptive in nature (Hennessey, 1993, p. 18). Consequently,

Foucault's social logic cannot explain the relationship between the social construction of difference and power in any systemic way, nor can it allow for any necessary relation between the multiple registers in which the modalities of difference circulate (ibid, p. 21).

Feminist materialist discourse analysis admits hierarchical concepts of power, thus allowing the incorporation of gender, race, and class dynamics into the analytical frame 
to a greater degree (Naples, 2003). It enabled me to consider more deeply what the differences in perspectives explored in my first and third research questions signified. My foray into this analytical technique is limited, intended to bring a wider frame into view and motivate further analysis of the discourses at work in the food movement.

In order to allow participants in my study an opportunity to critique my work, I did a member-check presentation in May 2016 at which I offered my interpretations of the perspectives they shared. Approximately 25 people attended some portion of the presentation, some arriving late and others leaving early. The feedback I received was generally positive, so I did not need to alter my interpretations. The Latin American immigrants and refugees who came to the presentation did offer some additional criticisms of the store that they charged me with passing along.

The next three chapters address the research questions in the order discussed. 


\section{Chapter 5: Varied Perspectives on Food and Health}

This chapter explores the question of how perspectives on food justice and health equity compared among the Healthy Corner Store movement, those involved in the Village Market project, and the residents of the New Columbia neighborhood. It begins with an examination of perspectives from the Healthy Corner Store movement, then discusses those among the different participants and influences on the Village Market as well as how they materialized in the store itself. The perspectives embodied in the Village Market are compared with those of the Healthy Corner Store movement to establish their respective orientations relative to the food regimes/food movements typology in Appendix D. Then, I compare the perspectives of New Columbia residents who were not involved in the store with those who did. Significant differences emerged in the foods that many residents desired in the store relative to what was anticipated by those who planned it, and this chapter considers the nature and meaning of those differences as well as the forces that shaped those expectations.

\section{The Healthy Corner Store Movement}

The Healthy Corner Store movement began in 2005 as a collaboration between The Food Trust, a Philadelphia- based nonprofit working to increase the healthiness of food environments, and the Healthy Stores Project at Johns Hopkins Bloomberg School

of Public Health. While that initial national network grew to 40 members, their activities subsided after funding ran out that same year. In 2007, the network was relaunched as a partnership among The Food Trust, the Community Food Security Coalition (a Portland, OR based nonprofit group that was actively engaged in promoting food system change through 2012) and ChangeLab Solutions (formerly Public Health Law and Policy) an 
Oakland, CA-based nonprofit that drafts model laws and policies around health and environmental goals. Urbane Development, a New York, NY-based community development organization that uses a venture model to seed and support community institutions, particularly around food entrepreneurship, joined the group later. Together they formed the Healthy Corner Store Network (HCSN). The network is a venue for sharing best practices around and building momentum for the effort to recruit corner store owners in "underserved" areas to add healthy foods to their stores.

Documents posted to the HCSN website were the primary basis for assessing the food justice orientation of the movement, although some documents were retrieved from the Food Trust's and ChangeLab Solutions' sites as well. The web sites of all affiliate institutions were examined for their perspective, too, although the Community Food Security Coalition appears to have become dormant since 2012.

The Healthy Corner Store (HCS) movement is a pragmatic approach to a very narrowly defined problem: improving the supply of healthy foods in "food deserts" as a means of addressing chronic diseases like overweight/obesity and diabetes. Members of their movement may be community activists, nonprofits or city agencies, and their content is fairly agnostic on the matter of who instigates the projects, although they do argue that community involvement in a project is important to a store's "transition" being successful. They see that supermarket chains are difficult to bring to certain areas and that developing full-size stores takes significant time and resources, whereas small stores tend to be owned by individuals and require only a modest investment to change. They recognize the limited nature of their approach and see it as a piece of a broader strategy for altering the food environment - two of the "parent" organizations are deeply involved 
in policy work from the local to the national level. They understand corner stores to primarily sell packaged, energy-dense, nutrient-poor foods, and their work is focused on recruiting corner store owners to provide a wider array of "healthy" foods like low and no-fat dairy, fresh produce, and whole grain products. The predominance of "junk" food in corner stores is attributed to changes in the grocery industry. The advent of larger stores and the lower prices they offered enticed shoppers away from smaller neighborhood stores (Healthy Corner Store Network [HCSN], 2010). As big grocery grew and gained more control over supply chains, many distributors to smaller stores got squeezed out, and smaller stores turned to less perishable inventory and high margin items like alcohol and cigarettes. Overview documents and articles posted on their news feed discuss factors involved in accessing healthy food that include proximity, quality, and price.

The movement also feels compelled to work on the demand side of healthy food provision. Signage and social marketing to educate and encourage consumers to choose healthier foods are often part of HCS interventions. The Food Trust tries to connect store owners with community partners involved in promoting healthy changes such as school nutrition programs through its Healthy Corner Store Initiative (Food Trust, 2012b). The eating habits of urban children who have easy access to corner stores are a particular concern to that organization, and they suggest trying to involve local youth in the changes to neighborhood stores in order to create effective marketing strategies and promote behavior change among peers (Food Trust, 2011b). Other partners emphasize the disproportionate burden of poor access to fresh foods on people of color, and cite the 
health disparities among African Americans and Latinos as evidence of that injustice. Expanding participation in their movement from such populations is cited as a goal.

Of course, store owners are a key component of the whole strategy. The HCSN offers advice on selecting owners, stores to recruit and the logistics of stocking and selling produce in such stores. Challenges like teaching store owners how to handle fresh food and finding affordable sources for it make a big difference in the success of the intervention. The HCSN makes a business case for why store owners would benefit from a conversion. They position their work as economic development for the food dollars it keeps in the local community, potentially creating jobs for residents, and expanding possibilities for store owners to create value-added items (Food Trust, 2011a). They argue that profit margins are higher on fresh products than snacks and canned goods, so potential exists for increased profits, although they acknowledge that additional risks and demands accompany that potential (ibid).

In making their argument for their solution, some self-contradiction emerges. A general Q\&A document that gives an overview of the HCS movement describes produce as difficult to handle and expensive for small stores to purchase because they have to buy in small quantities (HCSN, 2010), while an issue brief arguing that HCS modifications constitute economic development argues that store owners can make more profit from fresh products because profit margins are often higher than on packaged snacks and canned goods. The brief mentions the skill and equipment needed to manage produce, but not the difficulties small stores have finding distributors or getting prices that allow them to sell produce at affordable prices that are mentioned elsewhere (Food Trust, 2011a). This makes their project seem disingenuous, an attempt to promote a strategy that is 
financially precarious and dupe owners into making changes rather than being forthright about the challenges involved.

My visit to a HCS in the Delridge neighborhood of Seattle underscored the difficulties of trying to implement this strategy. Mr. Bihm Singh bought the Super24 store in 2006, and added a basket of fresh fruit by the register when he did. In 2009, he was recruited to participate in the King County Food and Fitness Initiative funded by the Kellogg Foundation and implemented through the Delridge Neighborhoods Development Association to increase access to healthy foods in the neighborhood (Ramirez, 2009). The store got a facelift as volunteers removed old cigarette and alcohol advertisements and painted a mural on the wall outside, and he brought in more produce. Apparently the first few months were hard and he brought a lot of wilting produce home for his wife to use, but then things picked up. He even tried hosting a farmers' market in his parking lot in 2010. By the time I visited his store in June of 2015, the mural was still there, but the fresh produce was for the most part gone. The basket of fresh fruit remained by the counter and he had potatoes, onions, and garlic in a bin. He does bring in some seasonal fruit sometimes, but he mostly sticks with the basics that sell well (June 11, 2015, interview). He said that the changes didn't really fit the neighborhood, people didn't buy the produce and it rotted. He felt it was an especially difficult time for people because of the slow economy, and his inability to accept food stamps didn't help. The store had been eligible to accept food stamps when he bought it, but an employee of his committed fraud and he as the owner was sanctioned. Although he fired the employee, he lost his status with the USDA. He felt that there should be some way to get re-instated, but the research I did on his behalf indicated a zero-tolerance policy for such violations. He wasn't aware 
of that. Demand for (which encompasses an ability to afford) fresh foods did appear to be a question, however. Despite working on the project since 2009 , as of this writing, a community group has not yet accumulated enough members to form a cooperative grocery that they've been trying to launch in a space across the street from Singh's store. Access to capital, of course, may be a factor as well.

The difficulty the Delridge Grocery coop has faced in its attempt to get off the ground also offers some support for the way the HCS movement skirts a full-size solution to the problems they identify. An effort in Greensboro, NC appears to be having greater fundraising success than the Delridge project, although it, too, has experienced difficulties and delays. The Renaissance Community Cooperative raised and borrowed over \$2 million for their store, but initial expectations of opening in 2015 were revised to May of 2016, and then delayed even further. As of July 2016, construction was still underway. People's Grocery in Oakland, CA has also struggled to find the funds to open a brick and mortar location in spite of success with more transient healthy food provision strategies. Still, the HCS model may not be able to adequately meet the needs of populations with limited financial resources. The chairman of the board of the Renaissance Community Cooperative cited the high prices of the nearby corner stores as part of the motivation for their store (Pleasant, 2015). And, after 14 years of failing to draw a corporate grocery chain to the location that had previously been a profitable Winn-Dixie, the opportunity to have an ownership in the store resonated strongly with residents. Their plan is for it to be different from a typical coop in a high-income neighborhood, focusing on bringing in the foods that the mostly low-income black community members said they wanted. 
Food Justice for Healthy Corner Stores

In terms of food regimes, the HCS movement is a reformist attempt to address some failings of a market-based food economy that occasionally presents their work as food justice to suit their own needs (Ortega et al., 2015). Their primary concern is improving access to healthy foods like the fresh produce, whole grain foods, and low or no-fat dairy that are in line with recommendations by the USDA (United States Department of Agriculture, 2015) and motivating people to choose those healthier foods over the deep fried or processed options that they see as ubiquitous in low-income urban areas. They recognize that price is an important factor in people being able to purchase such foods and that the cost to store owners for these items is problematic due to the small quantities they can use, but their primary aim is to make it physically available. Some HCS projects have been creative in finding ways to procure fresh produce affordably, but there is no simple, universal solution, so it is left to the implementers to figure out. Their discourse is one of mainstream healthy eating, backed by nutrition science and the institutional power of the USDA (Beagan et al., 2015). This discourse revolves around the four food groups, the nutrients in food, and the "badness" of foods high in fat, sugar, and salt (ibid). While the Healthy Corner Store Network does suggest local food producers as a way to overcome distribution difficulties (Food Trust, 2012b) and youth gardeners are offered as a potential source of produce for corner stores (HCSN 2010), engagement around local and organic is missing from the larger narrative of the movement.

The movement characterizes children and residents of the neighborhoods needing such intervention as vulnerable, being disproportionately exposed to toxic food and 
denied a right to healthy food. Although community involvement and input are discussed as desirable for their value in helping a store modification to succeed, community leadership is not essential. While community organizations are viewed as potential partners with skills and resources to bring to the table, they do not need to determine the nature or existence of an intervention. Youth are suggested as valuable participants for their passion and ability to help shape marketing messages and to influence their peers and families. However, the overarching message is that residents need to be educated about healthy food and encouraged to make the "right" choices. Engaging in social marketing efforts like use of shelf talkers and other nutritional signage and convincing store owners to reduce advertisements for unhealthy products are important strategic pieces of the intervention. They've already defined the problem and designed the solution. Residents are objects, not subjects.

The movement concerns itself with economic justice to the extent that it offers some arguments about interventions providing an additional revenue stream for owners that can increase their profits, keep local food dollars in the neighborhood, and potentially create more jobs (Food Trust, 2011a). But as with the residents of the neighborhoods they want to serve, their documents depict store owners more as objects to manipulate rather than subjects to engage. Mention of them as small business owners and minority business owners meriting support and encouragement is secondary to their role in making changes in their stores to suit the movement's goals. Advocating tactics of using kids to "tug at the heart strings of the owners" to get them to participate in the desired program (Food Trust, 2011b) and positioning fresh foods as valuable revenue streams for owners when organizers recognize the difficulties around affordable sourcing 
suggests that their interest in owners extends only as far as gaining their compliance with the desired store modifications. Nonetheless, each project must certainly reflect the people and the circumstances surrounding that particular project.

\section{Health Equity for the Healthy Corner Store Movement}

Health equity for the Healthy Corner Store movement comprises three elements: improving access to healthy, affordable food for vulnerable populations; improved knowledge about the value of and skills involved in healthy food preparation; and reduced exposure to "bad" foods. Changes in the larger food economy drive the health disparities that certain populations experience. Living near an abundance of convenience stores is cited as problematic for mortality, obesity and diabetes and living near a supermarket improves odds of meeting the USDA's dietary guidelines (National Policy and Legal Analysis Network to Prevent Childhood Obesity [NPLAN], 2013). So in the problem as defined lies the solution. Improving access to healthy, affordable foods in low-income and/or "underserved" neighborhoods is a way to improve the health of the communities targeted for intervention. Food insecurity is lower on the radar of the HCSN, although not entirely absent. The physical presence of healthy food, however, is the main objective, with affordability trailing behind as a desirable but often difficult objective.

Although the health of neighborhood residents is understood to be suffering as a result of living in a "food desert," their interest in or knowledge of healthy foods is not taken as given. Marketing efforts to raise awareness of the healthy additions often incorporate nutrition education. "Shelf talkers" that identify healthy foods or proclaim their nutritional benefit in greater detail are one approach. One intervention employed 
green, yellow, and red indicators to highlight the recommended frequency with which foods should be consumed (Food Trust, 2014). Product placement is another tactic used to encourage the selection of healthy foods. Making sure customers know how to use healthy foods and understand the nutritional benefits is also part of the work involved. Owners are advised to carefully consider which healthy foods will most appeal to their customers. Suggestions include taste tests, cooking demos, and providing nutrition information in multiple languages (HCSN, 2010).

Some interventions go a step further and aim to restrict or discourage unhealthy products. Removal of tobacco and alcohol advertising is a suggested intervention, and was part of the makeover of the Seattle Super24 I visited. Signage that discourages "bad" foods like soda is sometimes incorporated into interventions. The Hartford, CT intervention involves having store owners convert a percentage of their shelf space to healthy foods and commit to increasing that percentage every year for three years (Ferris and Martin 2010). An intervention at a Baltimore store that involved placing signs with calorie information by the sugar-sweetened beverages was offered as a success because sales fell by $50 \%$ (NPLAN, 2013). The excess of calories in these foods is frequently cited as a cause of obesity, and the risk childhood obesity poses to later health is of great concern.

The health equity aspirations of the Healthy Corner Store movement are to improve the health of vulnerable populations through access to healthier foods. Concerns over obesity and Type 2 diabetes are sometimes mentioned as the impetus for the movement, although they are implied more than directly stated. Childhood obesity is an explicit motivator for some programs. Obesity is understood to be a result of excess 
calories relative to expenditure, so the energy balance model is assumed. The importance of having access to healthy food to allow people to make healthier choices is the universal mantra of the movement. Residents of the communities where interventions are planned are seen as victims of market failures both in terms of the food they have access to and exposure to the proper food knowledge to make use of healthy foods. The mainstream healthy eating discourse of the Healthy Corner Store movement is infused with moral overtones. Over its long history, nutrition reform has been a moral project as much as a health project. Eating habits have been used to differentiate people by class from the beginning of nutrition science, and Progressive Era reformers sought to make good citizens of the poor by reforming their diets (Biltekoff, 2013; Turner, 2014).

\section{The Village Market}

\section{Resident-Participants}

As with the HCSN, improving neighborhood access to healthy foods was an early goal for the Village Market. Many of the resident-participants involved in the store (and all of the core group of three that stuck with it through the opening) were trained as community health workers (CHWs) through the Village Gardens' CHW program. The founder of Village Gardens submitted grant proposals for the program not very long before she left, and funding came through for the program in 2009, around the same time as the invitation to open a store in the vacated space. People involved in the gardens had been asking for skill development and income generation opportunities, and they wanted to build more relationships in the community. The $\mathrm{CHW}$ program met some of those goals and provided stipends. CHWs received 40 hours of training through Multnomah County's Capacitation Center in early 2010. The prospect of a store, however, seemed to 
have potential and captured participants' imaginations (Village Gardens staff member, January 14, 2014, interview), so in spite of initial misgivings, the project moved forward (Village Gardens staff member, October 19, 2015). While their shared roles as CHWs meant that most of the residents planning the store were engaged around improving health in the community, there was also a diversity of opinion on what that encompassed and how it should be approached. Participants expressed a variety of motivations for involvement in the store and varied intentions for its implementation. When it came to health in the context of the store, however, food was at the center of the discussion.

While everyone wanted the store to have healthy food at reasonable prices, other factors also motivated residents to participate. The initial exploration of the store happened internal to Village Gardens, so many of the people involved from the very beginning were active in the gardens already. Village Gardens had been organizing around healthy food access for years, so there was already a certain level of consensus among program participants around good food being healthy food. Fresh fruits and vegetables were important to them. But residents also wanted jobs. Community health workers and other Village Gardens participants wanted a venue for having a constant presence in the community. And some resident-participants were particularly motivated by the labels that outsiders put on their neighborhood. The media attention on chronic diseases and "unhealthy" neighborhoods and the designation imposed on this neighborhood as a "food desert" inspired them to get involved in this project, as much as to escape the disparagement as to improve access to healthy food.

"Well, specially this area, it has a bad rap. You know, this is No. Poor, No Po, North Portland, gangs, whatever, this, that, low-income, poor people 
... I live in this community now, so, yeah, I want a store. Don't we deserve a store? There's lots of kids. I'm tired of the "We don't eat healthy" ... there's no store around here. I mean, there's lots of reasons. There's the desert, there's poor health, poor health for a lot of ... elderly people and children. You know, open the store, get a store open to ... to serve the community that deserves it as much as any other community, whether you're rich or poor ... it doesn't always have to be grease and jojos, now they're all hooked to the nice sandwiches. Hello. If we had jojos and chicken, they'll be hooked to that, but that's, let's go a different avenue. Now we got soups, salads, and that's where our attention is, you know (Village Market participant and New Columbia resident, August 13, 2012, interview).

While there was a great deal of interest in the Village Market project for the healthy options it could bring to the community, it also spoke to a deeper sense of disenfranchisement participants sought to heal through their engagement around food and community.

A number of resident-participants had critiques of the processed food industry that came out of their own experiences, whether that was as chefs and workers in the food sector, as patients with chronic disease, or as citizens of countries where different food practices were the norm. One opined that the processes of growing and making food were essential to food justice: "Say I'm food, right? I want you to treat me right. I want you to grow me right ... You know, I don't wanna be a pesticides. I'm a cow. Don't give me anything that's gonna make me sick and make me Ahahahaha. I'm water, what are you 
gonna do, put some more chlorine in me? You know, food justice is about ... treating food right. You know what I mean, because if you treat food right, then people are going to be right" (Village Market participant and New Columbia resident, May 7, 2012, interview). This person felt that the planet was sick and we needed to connect with it by growing food - it should be done naturally, not be pumped full of chemicals. People had a right to healthy food, whether that was from a church, food bank, or a garden. It should be affordable. One resident-participant noted that people in the community were being denied a right to grow food because renters weren’t allowed to garden in their yards. Another had developed diabetes that he attributed to excesses of his younger days and was very wary of processed foods. The store articulated an intention around building some control over the food environment that appealed to him. A refugee from a country less under the throes of advanced capitalism carefully distinguished between deliciousness and healthiness. Good food for him included a notion of being beneficial, not just tasting good. He articulated skepticism of modern food practices, essentially arguing that capitalism has undermined both our understanding of how good food is prepared and the agricultural practices that create the raw materials for preparation. Good food should make you feel good. He also felt that food that is locally grown food contains substances that are protective against illness in that locality. Other residents involved in the store development process expressed additional, specific anti-corporate sentiments. So critiques of modern foodways were an important impetus for people to get involved in the store.

Many of the resident-participants were also motivated by dissatisfaction with the previous store. Although some felt that it had started off okay, all agreed that after the 
original owner handed operations over to his son, things were not good. Critiques offered were that it had too much candy, sparse shelves, outdated merchandise, and second-class produce. They wanted to create something different. One participant who moved in during the latter era had this to say about it:

... it was dirty, it was disheveled, the produce I wouldn't feed to my dog, let alone buy, it was at an extreme price and a poor quality, combination ... it was a hangout, you know, the people that worked there were not committed to excellence, they were committed to hanging out and bullshitting with their friends, and that's what they did. There were drug transactions, probably in the store, definitely in front of the store, on a regular basis, it was ... a really sad example of a neighborhood store. (Village Market participant, New Columbia resident, August 23, 2012, interview)

This desire to create something better wasn't only about healthiness. People were excited to bring more first class food to the community, while also fully aware that they needed to make it really affordable. In the context of the store, quality meant having some brand names in addition to generics and bargain brands, top-notch produce and using Grand Central bread and good quality ingredients in their sandwiches. They were thrilled when Grand Central offered to deliver free bread for their deli operations.

Aspirations to create something that was more than just a corner store, but a piece of a larger wellness program formed. A central tension emerged between the project lead and a particularly outspoken resident-participant over whether to create a defined 
program structure or to have community members drive its implementation. The project lead felt that it should involve people learning from each other and exploring health together, doing with rather than doing for, whereas his antagonist wanted the program to take a more prescriptive stance to promote behavior change around healthy eating and active living with measurable outcomes. This aspect of the project was put on the shelf as managing daily store operations alone stretched the capacity of the organization.

A larger interest in wellness didn't mean that resident participants were particularly observant about the healthiness of their food. The offerings at community meetings were pretty standard fare, though sometimes done with a little flair from the cooks in the community. One meeting there were tacos, another there were bánh mì sandwiches, and a potluck included hummus, veggies with ranch dressing, pickles wrapped with ham, packaged chips and cookies. At different times I was around participants and food, there were homemade chicken strips, pasta dishes, and cookies, but also Cup 'O Noodles, Egg McMuffins, and Cheetos. Some people liked to cook and lots of things were homemade. But the group also went out for Mexican food, and on other occasions I was asked to stop at McDonalds, a hot dog joint, and Baskin Robbins. Volunteers planning the store readily consumed sample bags of potato chips and baked goods from potential vendors. There were occasional comments from a few individuals that seemed to be critical of the healthiness of the food, but they were from people on the periphery. When it came time to select products for the store, however, a different level of concern arose over the products they would carry.

\section{External Influences}


As the store developed, ideas were forming around what their store could and should be. Although Village Gardens programs had up to that point been run by and for people in the communities in which they operated (with the exception of a few staff members from outside the community), the Village Market project drew in a number of folks from outside the neighborhood, including me. The founder and former director of Village Gardens had at this point become a member of the Portland/Multnomah Food Policy Council (PMFPC), and was involved in a workgroup around healthy retail. The workgroup met with the leadership team from the Village Market at the store site in March 2010, just a few months after the planning process began, and a partnership had ensued. As one store resident-participant described, they more or less took it over. The store participants shared the barriers they were confronting and the group was used to explore ways that policy might be used to address them. In June of that year, there was a policy brainstorming session around ideas for healthy retail. The Multnomah County Health Department's Community Wellness and Prevention Program sought input into the policies for their Healthy Corner Store project that was formed in accordance with President Obama's Healthy Food Financing Initiative. In July, the leadership team hosted the Healthy Retail Workgroup. One individual led a discussion around food deserts and why they were getting so much attention, and they heard from another person working for an organization that did statewide policy advocacy around health. She had a grant from Robert Wood Johnson that potentially had stipends around healthy food retail, and pointed them to a webinar from the Healthy Food Financing Initiative. The leadership team was asked to consider further involvement with the Food Policy Council and was pointed to a Google Doc with the policy brainstorm list to review and comment on. In 
August, two of the resident-participants and two of the staff members attended a meeting where those brainstorm ideas were collated and prioritized. There were suggestions on that list around providing economic incentives to stores that don't sell alcohol or tobacco or that do sell fresh food and staples in underserved areas, increasing prices on unhealthy food options in order to subsidize healthier options, and creating "healthy school zones." Later revisions included creating a county-level tax on sugar-sweetened beverages and tobacco to fund healthy retail in underserved areas, creating a standard around what constituted a healthy store, and incentivizing purchase of local foods. At least one resident-participant was aware that the Portland Plan had published draft language around both short-term and long-term goals for healthy food access: living within $1 / 2$ mile walking distance of a full-service market; limiting "bad" foods sold in public venues; providing resources for nutrition/healthy food education in target communities; expanding alternative retail settings; incentivizing retailers to sell healthy food; using zoning to limit certain types of food outlets; and working with transit agencies to help improve access by neighborhoods with poor access (Portland, 2012).

Another venue for external influence emerged more closely tied to the store. In the fall of 2010, a team of people, the Healthy Choices Team, was charged with formulating ideas for a grant from the Multnomah County Health Department around improving access to healthy foods. The group was advised to think about ideas that would inform policy and given examples to think about, such as what would help vendors sell fruits, vegetables and whole grains, how they could incentivize "good" foods and discourage "bad" foods, and how the store could help set standards for what a Healthy Corner Store is. The store was struggling to find funding at this point. A first round of 
grant applications had come up empty, and a second round was in progress. The Healthy Choices team was led by the team member who continued to participate in the Healthy Retail Workgroup (his CHW stipend was related to this work) and included a woman with a background in public health who met the group through the Food Policy Council, a nutritionist the group leader had become friends with, and a long-time friend who used to live in the neighborhood. I first met the group at a community-wide meeting where I joined them to prepare a skit to present the ideas they had talked about at their last meeting - it was around the recommendations they had come up with for the grant. Once the grant proposal was submitted, some team members started working on nutrition information for foods that would be in the store. As a vegetarian and someone more health-inclined than the average person, I was very conscious of the ways my dietary beliefs and practices might not be a good fit for the community and tried to avoid involvement in the food debates, although I was not always successful. While several community members were involved in this group at different stages, by the time we settled into the nitty-gritty of product selection, the group had whittled down to me, the nutritionist, the longtime friend, and the resident leader of the group.

\section{The Store}

It was during the product selection that the store's identity as a Healthy Corner Store took more tangible form. The shared understanding of what it meant to be a new model of a Healthy Corner Store was forged through the months of debates over what to put in the store, what to promote, what to omit, and what to discourage. In order to come up with a master list of products for the store, we began with one compiled from a community survey done the previous March. 
In terms of what to put in the store, some of the offerings were easy to identify. Fresh fruits and vegetables and a wide variety of them were pretty easily agreed upon. Differences of opinion were over their seasonality, their local-ness, and the vendors to use. Although several resident-participants were advocates of locally grown food for its benefits to both the local economy and the eater's health, they weren't particularly religious about it. Cost was a more important factor. One of the more active residentparticipants had a strategy in mind to use many vendors in order to get the lowest prices and was also a strong proponent of using smaller vendors under the belief that they would have better quality offerings. Intentions around the use of many and smaller vendors and the interest in stocking locally grown foods gave way as the logistics of managing the ordering process and the realities of vendor fees became a concern, although there was some movement back and forth in all of these arenas over time as staff came and went and relationships waxed and waned. The store's location in a mixed-income, multi-ethnic neighborhood and the involvement of many Latin American and African refugees in the garden programs meant that there was an interest in stocking the foods these communities wanted. There may not have been sufficient awareness of some of those cultures to understand that they have different staple foods, however. One of the chefs in the group knew the importance of having certain specialty meats to please African Americans and Muslims in the area and lobbied successfully to get those included. A few folks in the group had food intolerances, so there was also interest in stocking things for gluten and lactose-intolerant folks. Having a "healthy" store meant stocking a wide variety of raw materials so that people from all of the cultures in the area could cook their traditional foods. 
Fresh fruits and vegetables were the principle items the store wanted to promote, but the store also had general intentions around encouraging people to choose "healthier" foods. The nutritionist in our group was charged with making signs for fruits and vegetables to indicate what particular health benefits they had. We spent a bit of time discussing ways to incentivize "healthy choices" through coupons, passports, or "Healthy Choice Bucks.” A team of volunteers who were fellows with the Ladders to Leadership Program with Robert Wood Johnson worked with a class at Rosa Parks Elementary to develop a healthy kids snack corner. They did a lot of education around foods and had kids taste them and pick out a selection of healthy snacks that they liked. Initially, a big display of fruit was placed in front by the cash registers to encourage fruit as snacks. The sandwiches from the deli were supposedly going to be approved by the American Heart Association. At different times there have been volunteers or nursing students who took on a one-off project like healthy labeling or recipes, or other ways to encourage use of fresh foods. None of these ideas has become fully rooted in the store.

In addition to promoting "healthy" choices, the store was seen as a venue to protect people from themselves. For some items, this was to be accomplished by omitting them from the store entirely. In the very first meetings, community members said that they didn't want there to be cigarettes, alcohol, or lottery tickets in the store. This had been a stipulation by Home Forward for the first store, a deal that was made in exchange for free rent. But very early on in the process, community participants identified these items as in conflict with the store's identity as a community-led institution. A desire emerged to protect people from unhealthy food as well. During our product selection meetings, the nutritionist produced a list of ingredients that was to be used to exclude 
items from the product list. He and the team leader had been discussing this between themselves. I was present for a lively debate over frozen prepared potato products where one resident-participant was adamantly opposed to stocking anything frozen that could be provided in fresh form - particularly potato products. In the transition from a nonprofit community project to a social enterprise run by staff, many of whom had been involved in the store all along, some of these nutritional goals were set aside. The list that the Healthy Choices Team produced was married with the list of top 100 sellers of similarsized stores from the distributor they planned to use and a compromise product list was born. By the time of the opening, specialty potato chips by a local brand (Kettle) were in the store along with Pringles and Nabisco products like Triscuits and Oreos and a number of other snack foods, but not Frito-Lay chips. Part of the reason for this may have been that stocking Frito-Lay products requires having a separate relationship with that company, but the idea of not having "bad" chips in the store was definitely on the minds of several people. Omitting things seen as unhealthy from the product mix was intended to shape people's behavior, but the process was partial, as debates over certain categories of foods occurred, rather than systematic.

Some items caused a great deal of controversy and instead of choosing to omit them, the decision made was to discourage their consumption. In one early product meeting, I was given the list from the candy vendor that had been highlighted, and was to write down the items and their prices on a separate piece of paper. Apparently there had been a huge debate that dragged on over days around whether the store would have candy, and they finally opted to have a small selection. The means of controlling behavior around candy came in the form of punitive pricing. The nutritionist among us 
had pointed out a potential healthy snack option for the store, and after looking at its wholesale cost, one of the main resident-participants suggested pricing candy higher in order to subsidize the healthier snack foods like this bar. This was put into practice, but didn't last long:

We like super-inflated the price of candy at the very beginning. And people were pissed! PISSED about it. And one of our assistant managers just went in and, like, boop, boop, boop, boop, boop, changed it without talking to anyone because she didn't want people to be mad at her. (Village Gardens staff member, November 20, 2014, interview).

Another key resident-participant planned to have a merchandizer friend who worked at Safeway come in and arrange the store to disincentivize impulse buying of bad foods. But apparently product placement didn't happen in a way that pleased everyone:

You know, I remember the day before we opened, we had a few partners come in who were ... public health partners to ... walk around. They're like ... 'there are cookies on the shelf at eye level. For kids.' And I was, like, 'I'm sorry, but I don't have time for this ... I don't know if you've noticed, but we don't have shopping bags.' ... I was, like, that's great, you know, let's have that conversation tomorrow (Village Gardens staff member, November 20, 2014, interview).

While the punitive pricing of candy went away quickly, also did the display move behind the counter where only staff could reach it. This was motivated by the amount of theft that was happening, but also felt like an unwelcome barrier to its purchase by customers. 
The project of the Village Market to re-invent the Healthy Corner Store with a team of people without a lot of grocery experience meant that the product mix was a reflection of personal tastes and preferences as well as guidelines around the healthfulness of the foods and ideas from external partners. On opening day, there was a very limited selection of regular sodas, a wider range of budget sodas, natural sodas, and juices in a cooler inside the door and lots of juice and Gatorade on the shelves. Cereals and grocery staples lined the interior shelves. There were Kettle chips and other snack foods that might be described as healthy like Sun Chips and Pop Chips, lots of Nutella, and Nabisco products as well as a bountiful 30' cooler of fresh-looking produce and a modest bulk section along the front wall. There were a number of organic offerings, with bunches of organic kale selling for $\$ 3.25$ each. The market did not have a very big selection of ethnic foods, and none of the Mexican cheeses that had been talked about. The big freezer housed potato products, burritos and Hungry Man Dinners along with other convenience foods, vegetables and ice cream. A smaller meat freezer contained chitlins, smoked turkey legs and wings, and goat meat as well as more ordinary frozen chicken parts and ground beef, some of which was Halal.

The Village Market's first few years were largely spent trying to learn the nuts and bolts of the grocery business. Staff transitions and difficulty finding the right expertise made meeting their grand aspirations difficult. For some time after the store opened, a great deal of the produce was relegated to the compost pile as it didn't move quickly and the store policy was to not reduce prices. The deli made sandwiches to order, which made some people very happy, but left others frustrated by the length of time they might spend in line as a result. Deli operations expanded to include fresh smoothies, and different 
volunteer efforts used the kitchen to produce hot foods for sale in the store. These volunteer efforts came and went, and eventually a prepared foods manager was hired to provide some ready-to-eat items consistently. The store has improved its offerings aimed to please Latin American immigrants, but they have struggled with foods for African refugees, although they did have an Ethiopian community member making fresh injera to sell in the store for a while.

Over time, management has relaxed on the healthiness of the store. This change happened slowly at first. A larger selection of candy was brought in. More sodas. Fruit drinks in Day-Glo colors. In the store's third year, a management transition led to a reset of the store both in physical shelf layout and in terms of the thinking around what the store did and did not carry. An ice cream freezer was brought in to carry popsicles and frozen novelties that summer, and the Kids' Snack Corner gave way to end caps with Hostess products and other popular snacks. The feedback the program manager got was mixed. Some people were upset about the inclusion of more junk food, while others said, "FINALLY, I can buy something that I want here" (Village Gardens staff member, November 20, 2014, interview). While the initial intent of the store had been to create some community control over their food environment, that intent failed to resonate more broadly. The new manager decided to listen to customers and trust that they could make up their own minds about what they wanted in the store. Perhaps the relationship could lead somewhere later. One reflection of the disparity between the aspirations residentparticipants held for the community's diet and the reality of what they want from the store has been the percentage of the cooler space devoted to produce. It has shrunk considerably, as it has been adjusted to fit what people purchase. 
Food Justice for The Village Market

Relative to the Healthy Corner Store movement as a whole, the Village Market took a much stronger position on the healthiness of its food selections. This was in part a result of the fact that they created the store from the ground up. As resident-participants debated the merits of candy, frozen potato products and potato chips among what proved to be an engaged but not very representative sampling of the population, the store that emerged looked like the offspring of a natural foods coop and a 7-11 with a little bit of ethnic grocery somewhere back in the family tree. There was organic produce and a bulk section with quinoa and gluten-free pasta, Pringles and Chips Ahoy, and fresh injera and goat meat. Local, seasonal, organic, and cultural appropriateness were desirable qualities in food, so the USDA's guidelines weren't sufficient. But it was in the items not available where the distance between the Village Market and other Healthy Corner Stores was most apparent. While that has changed to some degree, the deli offers readymade sandwiches, salads and hot soups rather than fried chicken and jojos, so some distinction lingers.

The language Village Market participants used reflected the sort of alternative healthy food discourse that infuses both the alternative food movement and the food justice movement. The alternative healthy food discourse encompasses local and organic, eschews processed foods for the additives in them and the industry that produces them, and questions dominant nutrition messages (Beagan et al., 2015). Village Gardens does not commonly refer to their work as food justice, however, in the context of difficulty trying to communicate their project to others, one staff member referred to "the food justice-y thing we were trying to do" (November 20, 2014, interview) and others 
certainly interpret their work as food justice. Village Market participants spoke about the same issues of affordable and equitable access that are part of the food justice discourse. Staff and volunteers alike underscored the project's mission to bring healthy food to the community in a way that suggested they also wanted to assert the goodness of the people living there. The market had to succeed because it just couldn't contribute to that stigma. This attachment to demonstrating the value of the people in the community was one key distinguishing aspect of the Village Market relative to other Healthy Corner Store implementations I observed and read about. However, both the mainstream healthy eating discourses invoked by the Healthy Corner Store movement and alternative healthy eating discourse used by Village Market participants obscure class, race, and gender by ignoring cost, taste, and who generally prepares the "healthy" food that tends to be more laborintensive.

Both the Healthy Corner Store movement and the Village Market purport economic justice goals around keeping food dollars in the community and providing jobs for neighborhood residents. The Village Market has had some limited success in these areas, although they have also experienced difficulty in finding applicants with particular skills within the community and have had to do some hiring from the broader area. They have also had difficulty finding resident employees who are as excited about the larger intent of the store as the organization. To most staff, it hasn't seemed to be anything more than a job, and at times a very stressful one. A plan to use the store's commercial kitchen as an incubator for entrepreneurs is in the works and may yet add to the economic justice impact of the store. Also akin to other Healthy Corner Stores, the Village Market faces inventory costs much higher than those paid by larger stores, and they are simply not 
price-competitive with large grocers on many items even though they have set a very low target margin. This is in part due to the nature of the grocery industry where a number of products are typically sold at a loss. The Village Market started out trying to sell such items at cost, but because many of them are staples and a significant percentage of what they sell, they found that strategy untenable. But their inability to compete on price is also reflective of their inability to set their own prices for most things. Their distributor does that for the packaged grocery items in the store - all they get to choose is the target profit margin. That was in the process of changing in the fall of 2015, but was going to require a great deal of administrative effort. Theft was also a problem for their bottom line, and thus their prices, although they have not been able to quantify the scale of that problem. The difficulty of acquiring inventory at low prices coupled with their inability to set prices themselves means that the Village Market's affordability goals haven't been achievable to the degree that they had hoped.

As a food justice project the Village Market was striving for food sovereignty, and thus aimed for a deeper transformation than the Healthy Corner Store movement as a whole. And some aspects of the project reflect that intent. Resident-participants were recognized as full subjects. Village Gardens had been working on food justice in the neighborhood for years through their other programs, so they had fostered a critical consciousness around healthy food in a number of community members. Much excitement over the project from the outset was around creating some community control over their food environment that had been lacking when the previous grocer occupied the space. They used a consensus approach to decision-making in the formation process and created an advisory board to keep the store connected to the community once it had 
transitioned to a staff-led enterprise. But on some counts this reach for food sovereignty falls short. The community board had an advisory role rather than a governance role. The food sovereignty claimed by participants through the limited junk food offered by the store initially felt like food oppression to those who had different desires. The transition from a community-led nonprofit project to a manager-led social enterprise also failed to preserve the consensus processes that had been employed up to that point. This constituted a shift in the status of community participants who became staff, effectively reducing their subjectivity.

\section{Health Equity for the Village Market}

For all the effort Village Gardens put into organizing around food justice, the concept of health equity guiding the store implementation reflected the conventional wisdom embodied in the "food desert" literature. People were being denied a right to consume healthy foods by their lack of proximity to a grocery store. Thus, its manifestation in the store resembled interventions of the Healthy Corner Store movement in many ways. Healthy eating and active living were the avenues for addressing chronic diseases like obesity and diabetes, and improving access to healthy foods was paramount. While participants were treated as fully human subjects, residents at large were more or less seen as objects to be manipulated toward greater healthy ends. Nutritional signage was planned to educate people so they would make better choices, and "unhealthy" products were omitted in order to reduce exposure. While the Village Market invoked the alternative food discourse rather than the mainstream healthy food discourse of the Healthy Corner Store movement, both these discourses promote natural, unprocessed foods and draw on the moral responsibility of people to govern their own dietary health 
(Beagan et al., 2015). The health equity project of the Village Market, as it is with other Healthy Corner Stores, was to create a more hospitable environment for them to do so. Involvement with the Healthy Retail group of the Portland/Multnomah Food Policy Council and by extension the Multnomah County Health Department "nudged" resident-participants to emphasize health in the context in the store (Shannon, 2014) just as the trials and tribulations of the adventure informed the council as to barriers the current food regime presents to addressing food access through market mechanisms at the community level. The availability of stipends and grant funds for healthy retail through community partners directed thinking and activity in the direction of health. This was evident in the way one resident-participant advocated for a set wellness program with measurable outcomes that could be shown to grant funders instead of the communitydriven approach that the person running the program preferred.

The Village Market's departure from the Healthy Corner Store movement's concept of health equity came through their greater ability to control the contents of the store, the discussions around what healthy food encompassed, and the intention to engage the community more deeply around health. The decision to not sell cigarettes, alcohol, and lottery tickets came from early meetings of community members engaged in the store visioning. While several of the resident-participants smoked themselves, they felt that the store should promote healthy ideals. This seemed to be the driver behind the limited offerings of chips and soda as well. Although resident-participants did consume these things, when it came to the store they stocked it according to how they aspired to eat. So when the store opened it had a 30' produce cooler stocked with all manner of fresh fruits and vegetables and a limited selection of "junk" food. While fresh fruits and vegetables 
and whole grains are part and parcel of the Healthy Corner Store movement, the origins and production practices of that produce are not a significant focus. The engagement of Village Gardens around food production through Food Works and the gardens meant that the store was more engaged around the benefits of local and organic food. The store has offered Food Works produce in the store at times, although this has not been a constant, sustained partnership. The Food Works youth leadership team that makes those decisions changes from year to year. The intention of the Village Market to create a wellness program also departs from the limited nutritional education that accompanies some Healthy Corner Store interventions. Unfortunately, the discussion around the program faded as the day-to-day challenges of operating the store dwarfed all other concerns. Community health workers have continued to be involved in the store in various ways, so this idea may resurface. The tensions around its design and implementation indicate that a community-driven engagement around health may yet emerge.

\section{Resident Non-Participants}

County Commissioner Jeff Cogin's speech at the opening day ceremony of the Village Market referenced the status of New Columbia as a "food desert," the low vehicle ownership in the neighborhood and how it had the worst access to supermarkets in the state. He cited residents' request for a supermarket as motivation for Home Forward to make space in the redevelopment to make that happen. He said that the store could show people how to eat and be a model of healthy retail. My interest lay in finding out what people in the neighborhood thought of that model. As a way to get at their perspectives on food justice, I asked residents to share their thoughts about what good food was to them and about any difficulties they had accessing such food. I was similarly oblique 
about inquiries with respect to health equity. I asked people about their daily lives, the challenges they contended with, and any health concerns they had or health conditions they were managing and what that involved. Most people were engaged around the food questions, but although almost half of the people I spoke with had a health condition they were managing, my questions around health didn't prove to be as compelling a topic as food was. Health frequently came up in the context of food, however.

\section{Factors Involved in What People Eat}

When it came to the food questions, people's responses spanned of a spectrum of needs and wants that influenced their decisions around food. Almost all of them fell into one of five dimensions: health, taste, fellowship/identity, accessibility, and cost that reflected their daily lives and the roles and responsibilities that were a part of them. For desires expressed at the individual level, this meant navigating the tension among these five dimensions according to their own circumstances. For desires expressed at a larger level of aggregation, whether family or community, this meant negotiating among the differing tastes and perspectives of others.

\section{Health}

For more than half of the residents I spoke with, the healthiness of food was an important part of its goodness. For many of these folks, health issues that they or other family members were managing provided motivation to eat healthier and were an ongoing learning process as they figured out their body's particular needs. This process generally meant finding a balance between eating solely for health and enjoying some of the pleasures that less "healthy" foods can bring. Overweight/obesity and diabetes were two health concerns that came up regularly, but other issues mentioned were 
fibromyalgia, high blood pressure, cancer and ADHD. Practices of a "healthy" diet ranged from eating regularly and watching sugar intake to minimizing use of processed foods to portion control to cutting out certain foods or types of food entirely. For some individuals, experiences with illness changed their ideas about what good food was. One parent coping with health concerns took the opportunity to change her children's habits at the same time that she changed her own in order to be proactive about their health. A handful of people expressed ideals around vegetarianism/veganism and other ethical beliefs around consumption as important, whether or not they faithfully observed those eating patterns themselves. Muslim and 7th Day Adventist traditions have moral guidelines around dietary practices that were represented in the perspectives I heard from African American residents, and several residents expressed a sense of guilt for not eating as healthily as they felt they should. Part of the healthiness of food was the cleanliness and the sanitary practices observed in environments where food was produced and sold. Specific critiques of additives to foods via processing and the use of chemicals in food production were prevalent among immigrant groups quite explicitly, but also more obliquely present among others in an expressed preference for cooking from scratch and some interest in organics. Many people with inclinations toward eating healthily expressed concern over the children in the community and the negative impacts of sugar and other junk food on them. Not surprisingly, fresh fruits and vegetables were very desirable foods for people concerned about the healthiness of their food.

Taste

Fresh fruits and vegetables were valued for their deliciousness as well as their healthfulness, and good food in this sense was food that brought pleasure to the eater. 
Residents I would characterize as more oriented toward good home cooking than eating for health, also sought good quality fresh vegetables to make the most of their cooking efforts: "Ooh, fruits and veggies. I'm not a health food freak at all ... I love fried chicken, that's my favorite food ... but ... we eat veggies ... raw, cooked, it doesn't matter, we're veggie and fruit eaters" (New Columbia resident, November 20, 2013, interview). Sensory factors were important for the goodness of food in this sense, so the flavor and crunch of the chip was as valuable as the sweet juiciness of the ripe nectarine. Valuing food for pleasure was not without a health dimension, as some foods were enjoyed for how they made people feel afterward. So choosing foods for healthiness and for the pleasures they bring were not mutually exclusive. Nearly everyone expressed appreciation for at least one "unhealthy" food or another that was a favorite, whether or not they were particularly health oriented. For the folks who were less health conscious, however, this dimension of food figured more prominently in their daily choices of what to eat. For a significant number of New Columbia residents, good food meant good home cooking.

\section{Fellowship/Identity}

The role of food in connecting people with others or with a cultural heritage was another aspect that emerged from the data. This was reflected simply, as in the necessity of having food at social gatherings to make them more festive or in the sharing practices that emerged as people expressed caring and affection for one another. It was also reflected in the way meals were conducted, such as the long, slow meals out described by Latin American immigrants/refugees that they contrasted with the move 'em in, move 'em out mentality of restaurants in the U.S. But food is also intimately tied with identity. 
Identity may be reflected in a treasured family recipe or a more general affinity for foods people associate with a group to which they belong. In this sense, good food is best understood as "my food." Tastes and preferences for many foods reflect race, class, and other group affiliations or aversions, and in the context of grocery shopping, the absence or presence of certain foods can be strong signals as to whether the store is and isn't for them (Nichols, co-owner Cherry Sprout, June 19, 2014, interview). In this way, food becomes a means of inclusion and exclusion. Mustard, turnip, beet, and collard greens were cited by many African American residents as culturally important foods for them that were sometimes hard to find. Congolese refugees related the difficulties they experienced trying to find foods from their country and the profound disappointment they felt when the place that they were told had this food did not in fact have it. Having the right chips in the neighborhood store was important to both kids and seniors, as was stocking Halal meats to the Muslim community. Dietary restrictions that come with food sensitivities or illness may also become part of one's identity, as may dietary choices like vegetarianism or veganism that may reflect an ethics or a politics beyond a health interest. While the identity dimension of food may also be intimately related to its economic aspect, many people I spoke with articulated brand loyalty that transcended cost. While the prevalence of generics or "off brand" items on the shelves signaled a desirable affordability to some people, to those who had specific brand preferences it represented an off-putting cheapness.

Access

Ability to get food figures prominently in the decision to consume it. The food desert literature has paid a great deal of attention to physical proximity as an important 
part of food access, but other factors influence access as well. Because the neighborhood around New Columbia had been portrayed as a "food desert," I made a point to ask residents about where they shopped and what factors involved their decisions about where to shop. Their responses revealed a sophisticated combination of temporal, price and configuration factors that shaped their shopping habits, but also some emotional and psychological ones as well.

No one I interviewed admitted to not getting enough food. With nine food banks in the area, the impression I was given was that there were enough resources that people weren't hungry. That does not mean that they were food secure. Many people mentioned general financial difficulty or shortages of desired items at the end of the month. More creativity or a trip to the food bank was needed to put together meals at those times. Getting food involved more than a simple distance computation to the nearest source for desired items, but a more complex calculus of figuring out where to shop to best afford the full array of the foods they sought and how and when to get to those shopping destinations. The cost aspects of this challenge are discussed in the following section. About a third of the people I spoke with had a car or ready access to a car for grocery shopping. For many others, traveling the distance to the two nearest regular groceries or the bargain outlet store by bus wasn't depicted as a great difficulty. It was a fact of life. In addition, a Wal-Mart store that opened three miles away during the time of this study provides a shuttle service from the neighborhood. The distance to one of the favorite discount shopping destinations (WinCo), however, involved an hour-plus bus ride with a transfer on the bus line, and many residents without cars, especially those with children, perceived shopping there as a hardship. WinCo's price and variety were an important part 
of many residents' shopping strategies, and it was the favored store of Congolese women, who generally expressed more frustration with physical proximity to their foods. Many of their staples were not readily available at regular grocery stores. There were also several people whose health and energy issues made going to the store a hardship whether they had a car or not. For them, the convenience of the Village Market often made it feel like their only option. Physical access also involved navigability for people with wheelchairs or scooters, and elderly residents were very conscious of slip and trip hazards like the bicycles that kids at one point would leave in a pile in front of the door. The selection of items was another important dimension of access. Quite a few people valued having a variety of items to choose from and appreciated the range of services offered at the fullsize grocery stores where they did the bulk of their shopping in contrast to the range of goods a small store can offer.

While few residents depicted physical access to food sources as a pressing problem, the ready availability of some food items was contentious. More healthconscious residents praised the limited selection of junk food that the Village Market started out with, and quite a few mothers and grandmothers expressed frustration when that changed and a full line of Frito-Lay chips and soft drinks was added. Some mothers felt they couldn't send their children to the store to get something for them because they would spend some of their carefully budgeted food stamps on things that weren't on their shopping list. For others, however, the limited selection that the store started out with and the placement of the candy behind the registers where only staff could get it felt oppressive and paternal and they were relieved when the store finally got some things they wanted. 
Other barriers to food access that were more emotional or psychological in nature emerged as well. The inclusion or exclusion of desired foods seemed to play a role in which stores were on people's maps, as did service quality. Several residents commented to me that the store was "too white" when it opened, and part of that was due to the prominence of organics and "healthy" food. One nearby neighbor described how cashiering mistakes result in almost $\$ 14$ in overcharges on an $\$ 89$ bill that impacted when she would shop at the Village Market so she could avoid a certain cashier. It isn't difficult to imagine how that might influence some people to avoid the store altogether. Difficulties getting refunds on purchases that turned out to be spoiled or rotten when they got home left some residents wary of shopping at the store. People who felt that they were treated differently because of their race or otherwise disrespected at different food access points were inclined to go elsewhere. Safety has an emotional/psychological component beyond the physical. Some people discussed how they didn't feel comfortable going to the previous store because of the number of people hanging out in front. Cost

Considering food as an economic entity recognizes that food is both an expense and a source of work. As an expense, food was a carefully budgeted item for most households. A number of people rattled off the costs of specific items at the different stores they visited or could name the specific items on which the Village Market was price competitive with other shopping destinations. Many had careful food preparation or shopping strategies to make their dollars stretch, such as buying in large quantities for items they regularly consumed, cutting more expensive ingredients with cheaper ones, or taking advantage of coupons, specials, and discounts as much as they could. For some 
shoppers, the size of the package made a difference in whether they perceived the store as having the desired food item. Sources of free food, like the nearby food banks, the community center nearby where a selection of free breads seemed to be always on display and Loaves and Fishes offers free hot lunches to seniors, or the lunches in the parks during the summer for kids were utilized in some capacity by most of the people I interviewed. Federal programs like Women, Infants and Children (WIC) were valuable tools in helping many families meet their food needs, as was the Supplemental Nutrition Assistance Program, SNAP, formerly known as food stamps. A group of Congolese women, however, noted the discrepancy between the amount of money they got in food stamps relative to the expense of the native foods that they were told to consume for the bulk of their diet for health reasons. Other immigrant and refugee groups seemed to have less difficulty with their staple foods being competitively priced, and expressed a hardship of a similar order to what other residents felt. Affording fresh produce was a particular problem for some of the seniors I talked to and involved careful shopping from many others. The monthly produce food bank hosted by a neighborhood church was much appreciated by many neighborhood folks. Nonetheless, not everyone in the neighborhood struggled with the cost of food to the same degree. Some families had generous allotments of food stamps relative to their families' appetites, some had assistance from family members, and because it is a mixed-income neighborhood, others simply had more money available to spend. Still, the picture that came out of my discussions was that food was a carefully considered expenditure for nearly everyone.

The challenge of procuring food as well as the time and energy involved in its preparation means that food can also be a lot of work. The home-cooked meals that most 
people described as their ideal "good food" must be prepared by someone, or foregone in favor of easier options. Residents from different backgrounds perceived this work differently. Latin American immigrants and refugees offered that they didn't have refrigerators in their homelands, so nearly every meal involved some combination of going to the store, foraging in the garden, and cooking fresh food. Eating out was not an affordable option in their country, so it was a rarity. Cooking at home was the norm. This didn't mean that it wasn't a burden, however. Mothers and grandmothers from all populations I spoke with expressed some degree of frustration with fussy kids and the additional work that attempting to placate them involved. Somali residents offered that if you were tired or didn't feel like cooking, then you did something quick, like noodles. Packaged convenience foods were not something immigrants and refugees were used to. But many residents, some busy parents, others workers with erratic schedules, seniors living by themselves, or still others struggling with illnesses that sapped their energy embraced frozen convenience foods, ready-to-eat options, and getting food made for them for the burden it lifted from their lives. Other options widely practiced were to cook in big batches and freeze for later use or to prepare simpler meals that didn't involve much effort like a bowl of cereal or a peanut butter sandwich. For most of the residents I spoke with, getting food made for you meant grabbing a deli sandwich or choosing an affordable restaurant option like fast food, pizza, or Chinese food. Although a few individuals mentioned being able to do this regularly, the impression I got was that most residents ate the vast majority of their meals at home. Cost trumped convenience. Deciding What to Eat 
The health, taste, fellowship/identity, access and economic dimensions of food consumption are, of course, just one organizing scheme for the perspectives that people shared with me. Residents grapple with tensions among the different factors all the time, and each of them differently so that between any two individuals there might be disagreement about how a particular food is good or whether it is good at all. A few examples from the data help elucidate the multitude of perspectives that must be considered in an attempt to characterize food justice on the community level.

Greens were one food where all five dimensions of food choice were represented among the residents I interviewed. Together, these perspectives illuminate the challenge involved in trying to address varying needs at an aggregate level. Many African American residents, whether they were interested in the healthiness of their food or not, valued greens. For many of them, the social and cultural significance of this food was paramount. But not everyone was able to afford greens to the level they desired or could take the time and energy to prepare them, highlighting the dominance of the economic dimension for them. Some residents would stretch out the more expensive greens with cheaper cabbage in order to be able to satisfy their taste for greens. One resident I interviewed in the fall of 2013 had health concerns that sapped her energy and left her in chronic pain. She had only been able to cook greens once that year, and she was very frustrated by her experience getting them at the Village Market. The collards she got were expensive and in poor condition: "all hung over like this, and I went ahead and bought some, I had to cook those things, I had to turn them off, and put 'em back on the stove, let 'em cool, put 'em in the fridge and put them back on the stove the next day. They were tough as leather." On top of that, the manager she spoke with was rude to her 
when she asked about dropping the price because of their condition. So for her, the decision to buy greens involved weighing her desire to eat this food that had health, culinary, and fellowship/identity significance for her with the financial expense and the labor involved in getting and preparing it. The poor shopping experience she had accessing that food probably affected her future decisions around getting food. She said that she didn't shop at the Village Market much, but attributed it to the prices. A healthoriented white resident was very happy to have discovered kale at the Village Market, and was really enjoying the kale salads that they had in the deli section. For her the health and sensory dimensions were priorities, and she was thrilled to have been introduced to a new food that fit with her needs and wants. But that same kale represented gentrification by an African American resident, for whom greens were also cited as important food. Those greens were not her greens, and made the social and cultural nature of the fellowship/identity dimension particularly salient for her:

respondant: I notice sometimes that there are certain areas that I go to in certain ... grocery stores, and for instance, black people like to eat greens ... Mustard, collard greens, things like that. Some stores you can go to neighborhoods, they won't have it. They'll have, um, kale. Is that what you call it? Kale? interviewer: Right. There is kale, yeah. respondant: And, we're not familiar with that, we're not familiar with how to cook that, or what it is ... But then again, it could be something that's even better than our greens, and, and you know, whatever ... 
interviewer: But you want your turnip greens, your beet greens, and your mustard greens ... respondant: But we do want that, still. Yes. interviewer: Yeah, and not all the stores have that. respondant: There's just certain items and different things you won't find in certain areas (New Columbia resident, November 20, 2013, interview) Although this same person was also interested in eating food for its health dimension, getting this "good food" had social justice elements that resonated even more deeply and connected to the perceived whiteness of the store and the changes in the neighborhood that came along with the redevelopment.

Similar differences in opinion were expressed around organics. Many people I spoke with believed that organic meant that the food was healthier, and some even expressed an interest in having a greater selection of organics and a willingness to pay a little more for them. For most, however, organics were out of their price range. Quite a few health-oriented residents expressed either confusion about what organic really meant in terms of actual farming practice or significant skepticism about the legitimacy of claims that something was organic. A couple of interviewees shared some very strong negative thoughts about it, one calling it a scam used to charge higher prices and the other arguing that their presence at the store demonstrated how out of touch it was with the community's needs. The specter of exploitation was raised by their concerns. The immigrant and refugee communities I talked to, however, all had very positive associations with organics because they saw it as closer to how food was grown in their home countries. They desired them for the health and flavor benefits, but affordability 
was the overriding factor in the consumption of organic foods: "you see I buy one week of organic food, I'm not going to eat three weeks in my house. So I have to stretch my food stamps for a month, and um, it is hard, especially when you're not working and, I mean, you do want it, but it's hard to do it." (New Columbia resident and Latin American refugee 2015, focus group). While organics were desirable for some, they were offputting to others, and few were willing or able to pay the higher prices that often accompany them.

A significant tension in residents' food decisions also existed within the economic dimension, as the labor-saving convenience of the Village Market contended with its perceived higher prices. For some, the convenience of the store overrode other issues they had. One woman whose split shift schedule at work didn't allow her to make regular shopping trips really valued the way she could pick things up as needed at the store. A senior living across the street had enough resources that she could do a lot of her shopping there and appreciated not having to make the trip to the big store. Moms with WIC vouchers are able to take advantage of the convenience for those items without worrying about the price. For many residents, however, the Village Market's prices don't fit with their budget for most of the items they want, and the store is used as a convenience store. Some residents found the prices especially troubling because the folks planning the store "swore up and down they was gonna keep the prices down. And no sooner did they get in there and their prices are way up." (New Columbia resident and senior citizen 2012, focus group). One resident said that she used to use the little store all the time (back when it was Big City Produce), but with the transition to the Village Market, prices got too high, so she has to go to Safeway or Fred Meyer in between trips 
to WinCo. For her, the cost of convenience was just too high. As they have learned the grocery business, the management at Village Market has been able to drop the prices some. They are more competitive on some specific things, especially produce, chips and drinks, but staples like cornmeal, flour, sugar, and oil are still considered too high. Expectation and perception figure into how prices are received. Residents who had experience shopping at small stores had different expectations of the prices they could offer and saw the market's prices as pretty good. Others without that perspective shop there occasionally but really resent the prices and feel exploited themselves or on behalf of others. Still others avoid the store nearly completely or will only go for an emergency item. One interviewee who felt that the store was not doing a good job with the quality of their produce and had observed what he felt was opportunistic price increases reported that his mother resents the store so much that "Even my mother has said, "Where you going? You going to the store? Are you going to THAT store?' I say 'No, Mom.' She says 'OK'." (New Columbia resident, November 18, 2013, interview). He felt that the store needed to reach out to the community more and be more transparent about their workings, and without that he didn't trust them:

It seems like they forgot where they are, you know? And they're here to help us. Um, well, you're going to make your money, too, of course, but I thought the whole ideal of the Village Market was to help, you know, those who don't have a lot. That was my thought, anyway.

In a community that is extremely price sensitive, the Village Market's prices are an imposition on many and feel oppressive to some. 
The tension between the dominant decision-making factors of different residents became apparent in the controversy over the selection of chips, soda, and other "junk" food in the store and how accessible it was. Some residents wanted regular chips and were happy when the store finally got them. For others this change brought significant challenges with the healthiness of the food they wanted for others. In some cases this interest was directed at populations that were seen as vulnerable and worthy of protection, in others it was more general and suggested paternalism. Two of the more affluent residents of the neighborhood represented this distinction beautifully. Both expressed dissatisfaction with the amount of "junk" food in the store. One objected to the sugary items in the store and didn't like to see kids buying them, but appreciated that the store also placed healthier snack items like fruit and packages of trail mix near them. When asked about the chips, she stated very plainly that she liked chips. The other lamented the presence of "convenience store kinds of foods" and thought the store should discourage people from buying them, but had earlier stated, "I do have my addiction to chips, you know" (nearby homeowner, July 14, 2014, interview). She saw herself as capable of regulating her own food choices, but seemed to worry that others in the community might not be similarly endowed. As was the case with the resident mentioned above, a number of people were concerned about the welfare of the children in the neighborhood and the healthfulness of the foods that they consumed. For some residents this was a difficulty that resulted from a caregiving role for children. One grandmother hated having her grandchild ask her for ice cream every time they went to the store. Latin American mothers were particularly troubled about the easy access their kids had to junk food in this country because they were used to a food environment where those things 
weren't available. For others, concern was directed at other people's children. Worrying about other people's children can be read as paternalism or as taking your place in the village that is raising the child ${ }^{1}$.

\section{Food Justice for Resident Non-Participants}

With respect to food justice, New Columbia residents and nearby neighbors that did not participate in the store articulated desires that mapped onto the accessibility of good food, the right to the pleasures that food can bring, and a need for economic justice as it relates to their acquisition and preparation of food. These interests matched up well with another study done in a "food desert" in Boston (Walker et al., 2012). While many residents view the Village Market's success according to these measures as uneven, the biggest rifts between the store and the larger community have been over price and the presence of snack foods. Residents not involved in the store were not as engaged around health as store participants were, and for those who were, they invoked a traditional healthy eating discourse more frequently than either the mainstream or the alternative healthy eating discourses of the Healthy Corner Store movement or the Village Market. The traditional healthy eating discourse eschews processed food in favor of home cooking, but is relatively indifferent to nutritional components (Beagan et al., 2015). Having meat and vegetables is a common expression of this discourse (ibid).

Accessing good food meant being able to find a wide selection of good quality, desirable foods at an affordable price. It meant being fully included in the shopping experience, so having your culture's foods or your favorite brands was part of that, but it

\footnotetext{
${ }^{1}$ With the limited data I have on the topic, I don't feel able to comment any further.
} 
also involved being treated with respect and courtesy and feeling safe in and around shopping venues. This was certainly in line with the Village Market's aspirations, but their collective inexperience in the grocery industry hindered their ability to achieve these objectives from the outset. For example, because of the way that WIC and SNAP/EBT is administered, the store wasn't allowed to apply to accept them until it had been open for a period of time. They were able to expedite this, but for the first month they weren't able to accept either WIC or SNAP/EBT, which may have had some impact on residents' first impressions of the store as an access point for food. No one raised that as a concern, however, and sales dramatically increased once their eligibility came through. Discrepancy over what constituted good quality food was also problematic. The store exhibited a belief in the value of organics that wasn't shared by a lot of residents. For those who did value them, they were outside their budgets. The presence of organics and other "health food" coupled with a comparative lack of culturally significant foods for African Americans, Muslims, African immigrants and, even to some degree, Latin Americans turned a number of residents off. The store had hoped to offer a wider range of ethnic foods, but finding the right distribution channels proved to be challenging as has cost. Still, many people appreciated having a source for healthy foods in the community. The size of the store, however, constrains their ability to stock all of the desired items, especially for perishables like produce and dairy. The feasibility of creating a store that has the right food for everyone in a socially and economically diverse community seems like a tall order, and with some undercurrents of tension around race and class already present, people read deeper significance into every detail. Residents who were alienated by the selection of products in the store, by perceived variations in how staff treated 
customers and some safety concerns that were ultimately resolved questioned the inclusiveness of the store space.

Residents also expressed food justice requirements around choosing foods for pleasure, whether that was around the deliciousness of food or for connection to and celebration with others. That meant having fresh, ripe produce as well as a selection of treats available. Again, this was an area where the Village Market struggled for a while as distribution channels, community tastes and staff transitions were figured out. Produce was not always ripe or in good condition for the first several years. The program director said that they did not have any programmatic intention to use the store to dictate how people ate, but individuals both internal to the project and in positions of influence from the outside did express inclinations along those lines (November 20, 2014, interview). These influences were reflected in the initial product mix. To many residents the first mix in the store felt like a condemnation of their food choices, and for people who said they purchased snack foods to get them through a long and tedious shift at work this was unwelcome. Perceptions of excessively high prices on foods like cooking oil, sugar, and SPAM reinforced this feeling of judgment and exploitation. In their eagerness to provide "healthy choices," those planning the store failed to anticipate the demand for snacks and treats. The store did provide some traditional home-cooking style foods, however. The kitchen staff was cooking up biscuits and gravy for a while, then breakfast burritos and French toast. Many residents told me of the delight they took in getting sandwiches made to order and how much they missed that luxury after it went away. Some were exposed to new foods that they found great satisfaction in. But the store took a few years to get to a mix of foods that suited many community members. The addition of the ice cream freezer 
and the improved selection of chips and sodas relieved this tension tremendously for a number of people, although as mentioned previously, it frustrated others.

The economic justice aspect of food justice came through in residents' concerns over exploitation by the store. Organic foods were seen by some as a scam used to charge higher prices. The store's policy of not reducing prices for produce past its prime was similarly perceived as unfair. In some ways, however, the Village Market is a victim of the power of the big grocery because it is not able to acquire inventory at the same prices of the big stores, yet many people regard the prices at such stores as "the price" an item should cost. Prices much above those were often seen as the result of either poor management of store resources or price gouging of the neighborhood. Several residents felt that the store was doing harm to people through their high prices because so many families in the community were on food stamps. This was further exacerbated when staff failed to consistently offer good service when customers found that a purchase was spoiled after they got it home. Residents also expressed economic justice aims around the labor aspect of shopping and preparing meals, particularly moms, seniors, and those managing illnesses. The convenience foods that the market offers, whether it was the frozen potpies or the sandwiches and salads in the deli case, were very much appreciated, as was the location of the store.

The differing opinions on the snack foods in the store raise an important food justice question. When some members of a community view the exclusion of certain foods they understand to be harmful as increasing their food sovereignty, while others view that exclusion as an infringement on their rights, whose perspective should be sovereign? The limited options for chips and sodas contributed to the whiteness of the 
store in many people's eyes and aggravated feelings of exclusion in their neighborhood. Residents who were low income and people of color but also came from other countries where junk food was not as available to them either physically or economically did not share in this desire. They were more inclined to control their food environment, especially for their kids' sake. Village Gardens has a history of engaging people in the community around food justice subjects, but in the context of the store, they were overwhelmed with learning the grocery business for several years and didn't have the capacity to do a broader community engagement around these foods. The path the market took to add the junk food seems the path of least resistance in a neoliberal context where constraining freedom of choice goes against the conventional wisdom, but their inability to start a dialogue on the subject is a significant missed opportunity. But nor has that discussion been approached constructively by many in the larger food movement.

\section{Health Equity for Resident Non-participants}

New Columbia residents not involved in the opening of the Village Market expressed varying levels of engagement around health with little departure from the HEAL approach to health management. Several of the specific health difficulties they mentioned, however, could be attributable to systemic causes. A fair number of residents, approximately a third of the people I spoke with, were not very engaged around health at all. For some, this was because they didn't have any particular health concerns themselves and therefore didn't give it much thought. Others had health conditions but expressed a fatalistic attitude about their management. Younger residents I spoke with tended to be less concerned about their health. 
About a third of the resident non-participants I spoke with were very actively managing health through their daily activities. It was this group that most invoked the mainstream and alternative healthy eating discourses. For many of them, their interest was driven by a malady either they or someone they cared for was experiencing. A smaller number were simply being proactive. Another third of the resident nonparticipants were more moderately engaged, and indicated some measures they took in pursuit of better health. These folks were more likely to echo traditional healthy eating discourses. For all residents who were engaged around health, medication, diet and exercise were commonly cited avenues of pursuit. Several people mentioned spiritual practices that were part of their self-care and some tied those in with health. Several people mentioned managing weight concerns. Food quality and quantity were understood to be the drivers of weight, although several people mentioned stress eating as a problem for them. Some African American residents offered their cultural food traditions as a significant factor in the illness they experienced. Diet was understood to be a critical component of managing diabetes. A few people recognized that the neighborhood probably had a number of people with that disease, but it was not thought of as a social justice issue. No one articulated any thoughts about either of these two conditions originating from external factors. Family history was understood to be a risk factor for diabetes. Perceptions were similar around heart disease and high blood pressure, although there was some awareness of the role of stress in high blood pressure. Some more systemic inequalities were observed. One resident offered the inadequacy of the health care system as a significant motivation for being proactive about health. Others criticized the pharmaceutical industry, the food industry, and its extensive marketing tentacles in 
the U.S., but no one attributed illness to systemic forces beyond how they influenced behavior. New Columbia residents, whether they participated in the store or not, appear to have accepted the argument that health is largely a product of genetics and individual behavior. Because my questions focused on people's lives, experiences and situations, they may have discouraged systemic thinking along these lines.

Among those experiences, however, were a number of circumstances that potentially impacted health. Nearly everyone I talked with was managing tight budgets as part of their daily lives, particularly the residents of Trenton Terrace, the senior housing unit across the street from the Village Market, and their fixed incomes. Many residents reported difficulty sleeping because of early morning delivery trucks on one end of the day and neighbors making noise outside at the other end. Resident non-participants experienced stress from a number of sources, especially from challenging employment situations and the limited financial resources that resulted. Many people were trying to find work or dealing with irregular work situations that made their financial situations especially precarious. Concern over friends and family members going through hard times also created anxiety for many study participants. Refugees were recovering from trauma they experienced in their home countries and the refugee camps they had resided in for many years. Congolese refugees cited difficulty finding steady work in environments they felt were discriminatory and were struggling to afford the traditional foods they believed were important for their health ${ }^{2}$. Immigrants and refugees alike were coping with separation from friends and family in their home countries; those from Latin

\footnotetext{
${ }^{2}$ A Congolese colleague told me that, in Portland, many positions for which African refugees are sought specifically indicate that they are for Somali refugees.
} 
America particularly mentioned feeling the loss of their traditional modes of meal preparation and eating. These groups noted problems with diseases that they didn't have back home, and some criticality around the U.S. food system came out of that. Disease was attributed to the limitations they faced with respect to eating healthy food, however, and not beyond. So, the perspectives of resident non-participants on the avenues to health were in agreement with those who helped open the store. Discord was substantially over differing degrees of interest in health. Health equity was for the most part expressed in the desire to have more resources with which to tend to their health needs, and in this sense the store presented some conflicts as its patronage involved a price penalty. Some engagement around addressing health equity through improved access to the health care system was expressed, but for many residents health equity was present in the desire to not be denied the snack foods they enjoyed because they were considered unhealthy.

\section{Discussion}

Having a constructive dialogue about food means engaging with its significance on many levels from the material to the symbolic. Materially, it is the substance that sustains us, and for many people of limited income, acquiring enough food is already a problem. Many people I spoke with utilized free food sources to help them make their food budgets work. As with other urban dwellers in the U.S. (Alkon et al., 2013), lowincome Canadians (Beagan et al., 2015) and others more generally (Koch, 2012), many New Columbia residents established complex shopping regimens to acquire the foods they wanted for the best prices they could find. Many residents were not particularly engaged around health, indicative of the classed (Wills et al., 2011; Koch, 2012; Beagan 
et al., 2015) and gendered (Beagan et al., 2015) nature of that interest that others have noted.

Many residents who were engaged around health struggled to eat in the ways that they associated with better health, and a closer look at our food assistance programs elucidates why. Food stamp allotments are not calculated on the basis of a nutritionally sound diet, they are based on the USDA's Thrifty Food Plan that requires the use of cheap food (Gottlieb \& Joshi, 2010). Implementation of the Thrifty Food Plan assumes the labor of someone to prepare it, and its labor-intensity is seen as a barrier to its adoption (Davis \& You, 2010). What this means is that if people are relying on SNAP for their food budgets, unless they are spending a considerable amount of time cooking, they're probably not eating a healthy diet by USDA's standards. The way that costs have been figured for the Thrifty Food Plan has also been called into question (Wilde \& Llobrera, 2009). Most of the people I interviewed received SNAP, and demonstrated their lived understanding of this circumstance through their sophisticated shopping strategies. The food desert literature, due to its origins in a perspective of class privilege and fueled by "foodie logics" (Bradley \& Galt, 2014) and largely positivist research paradigms, fails to grasp this. But food tastes and practices are deeply classed (Bourdieu, 1984; Wills et al., 2011; Johnston et al., 2012; Koch, 2012; Beagan et al., 2015), in spite of what mainstream and alternative healthy eating discourses would lead us to believe. Indeed, food and nutrition both have histories of use as tools of race, class, and gender oppression (Bourdieu, 1984; DeVault, 1991; Alkon \& Agyeman, 2011; Biltekoff, 2013). The reason why in-depth, critical, qualitative research is needed on "food deserts" and other manifestations of food inequality is not to further the understanding of these phenomena, 
it is to offer fully dimensional characterizations of disenfranchised populations rather than reducing them to statistics and behaviors. Only once that has occurred can discussion about the ways our economic system fails to meet our most basic needs truly begin. But we can't get to that discussion unless we first get past the classist, racist, and paternalist assumptions underlying our discourses around food. It is because food is so powerful, however, that it affords us the opportunity to engage around these subjects, and a good place to begin is with a democratization of taste (Hayes-Conroy \& Hayes-Conroy, 2008).

The Hayes-Conroys used an observation of a Slow Food jam tasting with elementary school children to reflect on the way we often dichotomize tastes into "right" and "wrong" and suggest instead understanding taste as a rhizome-like outcropping of experiences and beliefs/ideologies about food that reflect a personal context of memory, perception, thought, historical experience, and other factors (ibid). So the supermarket brand of grape jelly that your mom put on your peanut butter sandwiches is allowed to be just as delicious as the artisan pinot noir grape jam from the farmers market. If we do this, then we can move past the epistemological violence of labeling neighborhoods and scholarship that 'others' poor people and people of color while framing it as food justice. This approach leads to interventions that don't meaningfully address people's needs, as the Village Market case illustrates. We need to build a body of nutrition knowledge that acknowledges food's many roles and has cultural relevance for a diversity of peoples instead of the "healthism" (Guthman, 2011) or "nutritionism" (Coveney, 2011) that currently dominate our perspectives on diet. Done differently, a taste testing could be a way to explore social differences and politically engage around food inequities (Hayes- 
Conroy \& Hayes-Conroy, 2008) in ways that simply adding certain items to or omitting certain items from a store's offerings does not.

Understanding the true origins of chronic health conditions like obesity and diabetes are critical to unfixing our beliefs around nutrition. Because these conditions are so widely believed to be a product of diet, incidence and irresponsibility become conflated. But as the research demonstrates, both are far more complex than popular understanding allows. The role of non-dietary factors from stress to environmental toxin exposure to sleep quality in the emergence of a population-wide, world-wide increase in the incidence of both obesity and diabetes indicates that we need to recognize the "neoliberal paternalism" inherent in our attempts to address a systemic health problem (Shannon, 2014). A social determinants of health (SDOH) perspective could motivate action around addressing the fundamental causes of these conditions rather than just applying knowledge of epigenetic mechanisms to develop interventions to treat the problem at the individual level (Link \& Phelan, 1995; Marmot \& Wilkinson, 1999). If the current political economy of health equity research is any indication (Krieger, 2013), the prospect for such action in that arena seems slim. Funding remains directed toward genetic explanations of biology, even in the realm of health disparities.

The question then arises of how a SDOH perspective might inform interventions at the community level. Building a deeper understanding of the causes of obesity and diabetes could support interventions that are focused on the whole human: mind, body, and spirit. The mutual support that has been shown to help forestall the onset of diabetes in Latin Americans could prove more widely beneficial. Embracing the Health at Every Size paradigm could redirect the conflation of obesity with pathology and teach us to be 
more agnostic about food. Use of processes that are based on respect could help mitigate the stress of being treated as an object in other contexts and help produce better health outcomes in its own right. Epigenetics tells us that brains and therefore bodies are plastic and adaptable, and may even be restorable. A wellness program that started with SDOH as a framework might actually be able to address some health disparities in ways that creating a grocery store can only begin to.

The Village Market's experience illustrates perfectly how precarious that solution can be. The store provides a convenience that makes people's lives a little easier and adds some life to the neighborhood, but is not as yet a "vital place" (Walton, 2014). Part of its difficulty in this regard is the perceived "whiteness" of the space. Its environment (Slocum, 2007) and selection of products (Kwate, 2015) are part of what made it "white" but the situation of that particular store probably created even greater dis-ease than is already present for people of color trying to procure their shopping needs (Bay \& Fabian, 2015). The store that had occupied the space previously was owned by a man with a long history of providing culturally relevant foods through his grocery in a historically African American neighborhood nearby. Simply by association, the store he opened in New Columbia was a "black" space. Older African Americans I spoke with much preferred the Big City store to the Village Market. It had their foods, the owner marked down older produce, and some people reported getting discounts. The decline of Big City Produce when the owner's son took over the operation was noted, but the space remained black, and this was significant (Anguelovski, 2016). In the context of a city with a troubled racial history that is experiencing gentrification in many of its historically black neighborhoods, the replacement of a black space with a white one surely contributed to 
people's negative impressions, especially when coupled with the early management struggles and the perceived high prices. In spite of their previous work in the community around food and their intentions around cultural sensitivity, in a retail setting Village Gardens' inexperience in the grocery arena and the influences of a white alternative food movement meant that for some residents, the store became a space of exclusion rather than the food justice hub that had been envisioned.

Food is incredibly personal, and while snack food manufacturers have perfected ways to titillate our taste buds and insert themselves into our lives, the segment of the food movement that organizes around a different, albeit healthier, aesthetic seeks to do the same. The difference, of course, is the profit motive on the part of the snack food manufacturers, but the "neoliberal paternalism" (Shannon, 2014) of the latter discourse is problematic as well. We have come to depend on cheap food, but we have forgotten how we got here. The reasons behind and even the existence of the Robinson-Patman act of 1936 that tried to limit the power of grocery store chains have long been forgotten. As we engage in this discussion about what we want our food system to look like and we consider how we might respect a variety of tastes rather than condemn some of them as wrong, we need to consider that supermarkets may in fact be a much greater part of the problem with our food system than we have acknowledged (Russell \& Heidkamp, 2011). The advent of cheap food enabled the wage stagnation across all other sectors of the economy because people could subsist on smaller incomes (Wrigley, 1999). Reducing our dependence on cheap food, then, requires significant fundamental economic intervention. 


\section{Chapter 6: The Nonprofit Dimension}

In December of 2009, a half-page inset on the inside front page of The New Columbia Neighbor, the monthly newsletter delivered to every household in New Columbia, described the preliminary efforts of Village Gardens' exploration of the formation of a community corner store. The article cited the consensus that had already been formed around offering healthy and affordable food to the community, and invited anyone who had "an interest in bringing a healthy and positive store to New Columbia" to join in. The group forming the store was characterized as consisting of primarily Village Gardens participants, and although the time and location of the next meeting date was mentioned, interested residents were asked to contact Molly, a Community Builder, if they wanted to attend. Community Builders are residents of New Columbia who are given a discount in rent (up to \$200) in exchange for efforts they undertake to foster community in the neighborhood (Home Forward, 2015). They form social and support groups, host events, and otherwise take an active role in empowering residents. As an organization, Village Gardens takes a community building approach to its work of "uniting people through dirt" as one of their t-shirts proclaims. Their programs at that point were generally run by and for the participants in them with staff playing a supportive role, although community members at large also benefitted from their programs through the free produce they often shared. As a nonprofit, they generally relied on grant funding to cover their program costs, and some staffing needs were filled through AmeriCorps positions.

The organization in many ways embodied some progressive ideals as they pursued their mission of bringing hope to people through growing and sharing healthy 
food, teaching skills, and empowering community leaders. The power-sharing intent in their hiring practices described earlier was further embodied in their consensus model of decision-making as well as other practices that embraced co-production. When I inquired about researching the market for my dissertation, for example, I needed to get the approval of the group of community members planning the store in order to proceed. Staff and volunteers with the organization were generally required to go through an orientation that emphasized race privilege as a means of sensitizing people to ways in which their actions might reproduce inequalities.

Although some of Village Gardens' other programs offered income generation opportunities for their participants, the Village Market sought to become a full-fledged social enterprise, sustaining itself through its operations as well as pursuing its social goals. Some Village Gardens staff hoped that it might provide a source of income that could support their other programs as well. The primary objective of the store and the essence of its social mission, however, was to provide healthy food at an affordable price to the community and to create some job opportunities for residents in the process. The "enterprise" was to provide this food in a way that would win customers through knowledgeable, friendly service, quality products, and a safe, clean and welcoming environment. An early brochure drafted by the program manager additionally proclaimed: "The grocery store will be designed, run, governed, and supported by the residents of New Columbia and the Greater Portsmouth neighborhood." The initial plan was for the store to continue the power-equalizing practices that their other programs observed, although this time there were some fiscal elements they intended to manage as well. 
This chapter explores the meaning of the nonprofit and social enterprise dimensions of the Village Market as it moved from aspiration to implementation. Although specific influences of the project on local autonomy, food justice, and health equity are of particular interest, a more general consideration of the store's fiscal and organizational situation provides a useful backdrop to the case.

\section{Village Market Outcomes}

The Village Market's incorporation had financial, social, and emotional impacts on participants, staff, and residents alike. While its nonprofit status conferred some advantages, it also carried with it some disadvantages and entailed a shift in orientation from what had existed within Village Gardens up to that point. The business of social enterprise further impacted the way the market operated relative to a privately held store, and the transition of the Village Market from a community-led project to a manager-run social enterprise brought its own set of challenges that influenced the way the organization related to its participants. Confusion over the store's ownership within the community resulted from the store's hybrid nature, and overall the project came to dominate Village Gardens as an organization.

While the Village Market reaped some financial benefits from its nonprofit status, it also bore greater responsibilities and experienced some incongruities because of it. The store was able to finance its opening without incurring any debt. The trade-off for that was the length of time it took to secure the grants that funded it (over a year), but it meant that the store had a cushion to help it get on its feet operationally. They had no tax liability because the landlord (Home Forward) did not need to pay property taxes on the space they occupied due to their status. Operationally, Village Market was able to utilize 
the administrative infrastructure of their parent organization, so they didn't have to take care of legal work, bill payment and a lot of the other details themselves as a small business would (Village Gardens staff, November 20, 2014, interview). On the other hand, most stores of this size are mom and pop operations that use family members to provide labor, which means that labor laws don't apply to them, whereas the Village Market has HR policies inherited from their parent organization that they need to follow that translate into relatively higher labor costs (ibid).

The Market also created an efficacy challenge for an organization that up to this point had been fairly insular in its operations. Village Gardens programs worked to build leadership amongst their participants through cultivation and sharing of food. When it came to the Village Market, the project was significantly larger than anything they had taken on up to that point and people from outside the community began to participate. While this sort of presence had previously involved an orientation, the strain the organization was under meant that these orientations didn't happen. So there was a mix of participants from within the community as well as outside, and there were people participating out of a desire to help "bring good food to others" (Guthman, 2008) instead of the mutual self-interest that was historically the nature of Village Gardens projects. The intent of the Village Market to serve the larger community meant that it was externally oriented, and this difference didn't seem to be well understood in terms of its implications for voluntarism. A presumption that people would continue to give their time left some participants feeling under-appreciated and wondering why there hadn't been some sort of incentive program created because the work involved had been considerable and participation had dwindled (Village Market participant, September 25, 
2014, interview). One disillusioned participant had done some Internet research to try and understand what it meant to be nonprofit because what she saw happening confused her. So, while doing the store as a nonprofit conferred some advantages it also brought some confusion and unexpected financial burdens.

The Village Market was treading new ground and struggled to figure out what it meant to be a nonprofit grocery store that wasn't a cooperative. Although they had planned to become a self-sustaining social enterprise and perhaps even generate some surplus, the realities of the grocery industry cast doubt on the feasibility of these aspirations. Staff learned that "the grocery industry is a game of pennies" (Village Gardens staff, January 14, 2014, interview) and that social enterprise is "a hard wire to go" (Village Gardens staff, November 20, 2014, interview) in an industry where margins are really small and volume is the key to success. Their financial challenges intensified due to their social mission to not sell cigarettes, alcohol, and lottery tickets and to limit their selection of snack foods. What this meant in terms of daily operations was that while they initially approached the store with a perspective of abundance, they very quickly adopted one of scarcity. Difficulty reaching consensus on the assistant manager candidates led to the creation of four assistant manager positions instead of the planned three (Village Gardens staff, February 12, 2013, interview). The result of this and other staffing choices was that relative to other stores of its size, the Village Market had triple the staff and the management structure was top-heavy (Grocery expert, June 20, 2014, interview). Because one of their social goals was to provide jobs for community members, this was not necessarily seen as a problem, but it added to their financial overhead. The nonprofit roots of the store also presented some difficulties in terms of 
adopting business-like practices. There was resistance to doing training in various routine skills and tasks, written policies were emphasized instead of the hands-on practice typically involved in training employees, and staff was not working very effectively (ibid). Systems that could have helped create uniformity of product and manage workflows were not fully implemented (Village Market staff, February 7, 2013, interview). Another staff member observed that management practices adopted conformed to top-down, fear-based management styles, whereas other approaches could have been used (July 13, 2015, interview). The Village Market did a lot of stumbling those first few years.

As the store transitioned from community-led project to manager-run social enterprise, it went through many changes that came along with being more business-like in two important ways. First, the governance structure changed. Any illusions project staff had around who they were accountable to and how far community leadership could get them broke open (Village Gardens staff, November 20, 2014, interview). For example, during their planning phase they had a group of people with very limited grocery knowledge debating things they had no basis for deciding, like which days of the year they would be open or the layout of the shelves (Village Gardens staff, January 14, 2014, interview). A management collective where staff had the appropriate knowledge might have been able to successfully apply a consensus model to the store once it opened, but without that experience it wouldn't likely have worked. Regardless, a hierarchical management structure was adopted as planned, and decision-making practices reflected it. Management at all levels of the organization were learning the grocery business, too, so while the decision-making process may have become more expedient, it didn't 
necessarily produce better outcomes. Second, their relationships with stakeholders became more market-oriented. The change in governance meant a reduced subjectivity/agency of staff who had been participants in the store during its formation. The consensus decision-making process where everyone was valued and respected gave way to the discipline of a hierarchical work environment where time cards were punched, rules needed to be followed, and mistakes could mean dismissal. As one staff member observed, "Relationships were hurt through the process" (Village Gardens staff, November 20, 2014, interview). Then, as funds got tight, sources of subsidized labor were prioritized over staff from the community (Resident, October 14, 2012, interview). Staff was not happy.

Overall, the Village Market was professionalized by the transition. Management rather than committees of community stakeholders made hiring decisions. Staff positions were re-worked to be more in line with recommendations of their consultants. In all, the changes the Village Market went through in its transition to a social enterprise made it much more business-like. One staff member observed that these changes reinforced the white supremacy culture reflected in the dominant American business model (July 13, 2015, interview). Employee regulations homogenized staff appearance and constrained behaviors, and enforcement was based on fear rather than trust. Yet, at the same time that these concessions to the dominant business model were made, certain aspects of entrepreneurship were omitted from the picture. One staff member opined that the store decision-makers had yet to take seriously what it means to be a business (October 19, 2015, interview). While more than $50 \%$ of small businesses fail in the first 5 years (Small Business Administration, 2012), the risk that is an acknowledged part of any business 
venture was not part of the organizational culture. Nor were funds allocated to things like marketing that are common expenses for new enterprises (Village Gardens staff, October 19, 2015, interview). As one nonprofit executive director with business experience who was interviewed in the course of a study of the funding implications of social enterprise said, "In the nonprofit sector, there's a real naïveté about what's involved in starting a business, never mind a social enterprise, which is fraught with a whole level of other challenges conventional businesses don't even see" (Smith et al., 2012, p. 145). Business is hard, and social enterprise is harder because of the need to both pursue social objectives and turn a profit.

The Village Market's hybrid nature wasn't distinguishable to many residents who simply used it as a corner store. Many people thought the manager was the owner and some felt that the store was exploiting the community for profit. One person observed that they had too many people working there and felt that was why the prices were so high. But for a number of others who had a little more knowledge of the store's status, the social enterprise model created more confusion than anything else. Some people thought that because the store was a nonprofit, everyone working there was a volunteer, but others found expectations around volunteerism strange in the context of a store. Several residents with food skills mentioned a desire to use the store to sell things they made to earn a little extra money. The store's policy that only those who volunteered in the store could do so was really puzzling to a single mom with very little time on her hands, especially in light of her perception that their prices were higher than they should be (December 4, 2013, interview). Lack of understanding of the hybrid nature of the store also created mistrust: 
[Sigh.] Well that's what they said, you know, but you know, I'm thinking that maybe it's not, you know, on the up and up. Not calling them crooks or anything like that, but it seems that if it is a nonprofit, now I know they have to pay their bills, too, and things like that, but um, from my point of view, I really have a problem, really trusting in that $100 \%$...They need more transparency. That's what I think. And I think they should, you know, like they did in the beginning, try to, you know, ... get people involved and ask them, too. You know, hey, how can we, what do you guys like about the store ... Reaching out to their community. And this is, you know, I don't want them to think this is theirs. This is not just yours (Resident, November 18, 2013, interview).

Part of the confusion was due to the perception of high prices. People didn't understand why their prices were so high if they were a nonprofit, or why anyone was giving them grants to charge the prices they did. One participant felt that "it just seemed that for something that's nonprofit, it seems too money-oriented. You know?" (September 25, 2014, interview). In this very price-sensitive community, even the things that their consultants felt were right were negatively perceived: "Because, uh, it seemed like even when you did some things right, they still weren't right ... ok, you're selling milk below cost, competitively, you're matching Fred Meyer, you know, which you should be doing. We're still complaining about the price of milk" (June 20, 2014, interview). So while some saw potential for the nonprofit/social enterprise dimension of the store to feel less exploitive, they rightly acknowledged that this wasn't the prevailing perception (Village Gardens staff, November 20,2014, interview). The store didn't do much during its first 
four years to raise awareness of its unusual approach, but in late 2015 they began working on changing that: "we're starting to think about ... doing more branding and brand identity in the store around who we are as a nonprofit, what our goals are, what our mission is, what our core values are ... things [that] should have been on the wall, like, the first week that we opened" (Village Market staff, October 19, 2015, interview). So, they are at last taking up the identity marketing recognized to be an important part of social enterprise (Smith et al., 2010).

The launch of the Village Market required a great deal of attention from the larger Village Gardens organization and took them well outside their comfort zone. The size and scope of the project dwarfed the rest of the programs, and although they were solid enough to withstand the loss of the Director's attention when it came to daily operations, it compromised her ability to pay the necessary attention to future plans and the bigger picture. When asked about what the project was like for them as an organization, she said “it's been really painful. (laughing). It's been really challenging. I think it almost broke us ... we weren't able to do everything we wanted to do, it didn't all happen the way we thought it was gonna happen" (November 20, 2014, interview). Not knowing much about grocery and lacking business experience, they didn't know what they needed, and "hired the wrong person a number of times ... It was a total, epic flop" (ibid). It was a rough start all the way around. Referencing the group development phases of forming, storming, norming, performing (Tuckman, 1965), she commented:

from, like, a few months before opening on, it was like, storming, and it's been storming for about $31 / 2$ years. And I feel like the last year we're like "Whew" it's not exactly what we thought it was gonna be, but ... I even 
had this conversation with a board member .... you know, someone was saying, "Oh, I don't know, is it gonna work?" He's like, "You guys just got to the beginning. You've just got to the beginning." We're like, "yeah, we just finally got to the place where we can say like, ok, this is where we're at." (laughing) We didn't even know where we were for 3 years (Village Gardens staff 2014, interview).

As of fall 2015, the store is on more solid ground and has had the same manager for a few years. The current manager had some prior grocery experience, has sought out training and seems to have made strides toward helping the store fit community needs and wants. People like it better and its bottom line is approaching the break-even point. In terms of economic development, however, staff members commented that the nonprofit realm was not a very impactful model. They felt that community ownership was desirable toward that end, but that it would require a substantial training program. One staff member expressed a hope that it would happen in the future. Potential remains for residents to become: “different type[s] of stakeholder[s]" (Village Gardens staff, October 19, 2015, interview) in the enterprise, whether through cooperative ownership or through a renewed community board.

\section{Local Autonomy}

The concept of local autonomy is invoked by James DeFilippis to characterize the ability that people have to mitigate the influence that capital flight in the context of a global economy can have on their lives. While he is interested in ownership structures that are capable of creating community owned and controlled institutions of capital accumulation (DeFilippis, 2008), a broader understanding of autonomy as power in the 
form of relationships that one is able to control is more appropriate to this project. Any discussion of local autonomy in the context of New Columbia must begin by acknowledging that as the product of a housing authority channeling federal funds, the neighborhood itself is a socially engineered place. In this case, space for a grocery was planned in the development by a well-regarded housing authority that sought to provide some amenities for the new community. The neighborhood represents some state redistribution of resources, but also an effort to channel behaviors in socially desirable ways. The grocery store space was intended as a venue for healthy foods (Portland, 2002). So the possibilities for local autonomy in this neighborhood may differ from even those of most low-income communities, particularly in terms of what forms the binding of capital to place and local ownership take. While as a nonprofit social enterprise the Village Market is not locally owned in the same way that a worker-owned or memberowned cooperative is, it does afford the possibility of creating local stakeholders, whether it has realized this potential or not. A number of barriers stand in the way of such a transformation.

As a nonprofit social enterprise, the Village Market has constrained potential for capital accumulation in the community. By definition it can distribute no assets beyond wages to individuals. Upon dissolution, assets need to be transferred to another nonprofit, which need not be connected to the same community. However, it does provide a venue through which funds have been invested from outside the community, and has brought almost \$1 million in resources to a neighborhood that has little economic infrastructure. Nonprofit social enterprise constitutes a limited form of collective ownership, although its governance and the nature of the opportunities it provides figure prominently in the 
impact it has on community control. In the case of the Village Market, participants in Village Gardens programs had been asking for ways to make and save money, and the idea of launching a store came "right as the economy was collapsing, and obviously this neighborhood, maybe not obviously to everyone, obviously to us and to a lot of people, this kind of neighborhood was getting just slammed. Like way worse than everyone else" (Village Gardens staff, November 20, 2014, interview). The jobs the store planned to provide were a strong motivator to get involved in the project, as was the base the store could provide for the food work they were already engaged in. One participant imagined having a crew catering through the commercial kitchen, and another saw its potential use as an incubator for food entrepreneurs. In a community where many people were underemployed relative to their wishes, the store seemed to have some potential. What they learned through the process, however, is that there are a lot of systemic constraints on grocery that they have no control over (Village Gardens staff, November 20, 2014, interview), so their ability to acquire the right inventory at an affordable price is limited, as was their ability to set their own prices up until the fall of 2015. They became embroiled in the paradox of seeking to increase community control through a small store in a grocery business dominated by powerful corporations with global supply chains without the requisite knowledge and management expertise to piece together a workable strategy of meeting their price goals as Cherry Sprout has managed to do.

What the Village Market was able to do was build some local creative ownership of the project among its participants. The leadership development in which Village Gardens invested time and energy paid off in terms of creating a group of residents ready and willing to take on the challenge of opening a store: 
... when we met with both [the city commissioner], and ... we met with ... several of the board members ... they played predominant roles, even when [the grocery consultant] was there ... It was so clear to that board that they not only cared deeply about this, but that they were working their tails off to do it. ... But that's when I began to see that [the] whole concept of building leadership was starting to happen (Village Gardens staff, February 12, 2013, interview).

Unfortunately, the thin profit margins of the grocery industry meant that there was little room for error, and they made some mistakes. Because the store represented a significant financial risk to the parent organization, decisions were not always under the program's control. But there is also a difference in creating a sense of ownership over a project and developing the capacity to execute it successfully. Village Gardens managed the former in the context of the Village Market through its formation processes, but struggled with the latter. They didn't fully appreciate the nuances of people's food choices or the intricacies of inventory management. A staff member suggested that for a project like this to be successful, it needs to:

really work on getting actual stakeholders in their community, but also stakeholders outside of the community who are committed long-term to the success of the market ... who have the expertise and skills to really think through ... what are the specific offerings you're gonna [have], what are the profit margins gonna be per department, and how does that all line up against what the projected expenses are, and if there are ... programmatic types of mission goals in the community ... that those things 
are substantial parts of the budget, or are part of already well-established partnerships (October 19, 2015, interview).

Without both pieces, the store wasn't able to accomplish its goal of creating a community-run enterprise, although now that it has a much better grasp of what is required to make the store successful, the possibility remains for that transition to occur.

While the potential for the store to re-engage community members and revisit the question of what sort of stakeholders they could be, some barriers remain for a transformation of this endeavor into something that adds further to local autonomy. In its shift from community-led project to manager-run social enterprise, the Village Market first dealt with the conflicting logics of its social mission to provide jobs for community members and its requirements to be self-sustaining by subordinating its social goals. Funds got tight and employees had trouble getting hours as subsidized workers were given them instead (Resident, October 14, 2012, interview). Earned paid time off was denied (ibid). When staff come from the community that you're trying to draw in as customers, the same community that you're trying to engage and build relationships with, their treatment is all that much more important. As one staff member claimed, "I've said all along that once Village Market opened, that became our PR. That became our public relations every single day ... Every single interaction, that's who we are" (January 14, 2014, interview). Another difficulty that presents itself as far as re-invigorating community participation is the failure of their food mission to resonate with the larger community. Their programs have drawn in like-minded individuals, but the store needs to have wider appeal and utility to survive financially. Their identity marketing plans, then, are faced with the challenge of how to present a store with an interest in health promotion 
in a way that doesn't alienate residents who are not as health-inclined. This is both an internal and an external challenge. To most of the staff, working at the Village Market is just a job (Village Gardens staff, September 21, 2015, interview). Village Gardens originated as an organization that used food as an organizing tool to bring people together and create positive change in their community. As they became more established and staff transitioned, their organizational focus on food justice grew but in the context of the store, their roots in power equalization withered. In order for the store to become a community-run endeavor, those priorities need to be revisited.

\section{Food Justice}

As a nonprofit engaged in food justice work, the notion of good food embodied by the Village Market at inception reflected the prevailing sensibilities of the alternative food movement: fresh, local, organic, albeit with some concessions to the store's neighborhood context. It was presumably Village Gardens' orientation around healthy food beyond their history in the community that led Steve Rudman, then executive director of Home Forward, to ask them to start a store in the space after Big City Produce closed. The Portsmouth neighborhood plan called for a store in the neighborhood to further their objective of encouraging businesses that offer healthy and affordable food. It was Village Gardens' nonprofit status that made giving their brand of food justice form possible and their characteristics as an internally-focused community building organization that directed their food justice orientation toward residents rather than the larger systemic inequalities in the food system. As the store transitioned from community-led project to management-run social enterprise, participants' hopes of controlling the food environment in the neighborhood as a food justice intervention 
morphed into goals of influencing individuals' food choices. It was not simply market forces directing the store that engendered this shift but also a greater awareness of and response to the stated desires of their neighborhood customers, coupled with a reluctance to entirely abandon objectives to address concerns over diet and health.

The food justice that the Village Market set out to provide was convenient and affordable access to fresh, healthy food, preferably local and organic. In many ways, it was their status as a nonprofit that shaped this vision and made its realization possible, but as the previous chapter details, healthy eating discourses played a role as well. Village Gardens staff engaged their participants along with a few other interested parties in a discussion of what the store should be and proceeded along those lines in the belief that community members would support it. Although funders did not embrace the concept initially and were concerned with whether Village Gardens knew how to run a business, intervention on their behalf helped them raise the initial funds to start the store: and I think honestly, the only reason why it happened was because we had Steve Rudman from Home Forward who, like, called people up at the foundations and said, I know you looked at their proposal, you need to talk to them again. Um, if we didn't have that, I don't know if we would have gotten them to come back. They needed to understand how a grocery store was going to build community the way they understood the garden built community (Village Gardens staff member, November 20, 2014, interview).

The passion and knowledge that community participants articulated regarding the project helped sway other funders, and without needing to deeply engage a more diverse 
assembly of community stakeholders around food and their desires for a store, they were able to launch the Village Market. A survey of the neighborhood wasn't enough to reveal the complexities of people's foodways or cause Village Market participants to question their food vision in part because healthy eating discourses were invoked in its presentation and shaped how results were translated into store offerings. For example, snacks and candy were among the most requested items for the store, yet those things were either minimally present initially or offered in a healthy form. So although it was by no means easy to obtain the needed start-up capital, store participants were in a relatively privileged position in terms of being able to open the store without any grocery experience and with no personal financial risk if it failed.

Participants' enthusiastic pursuit of their mission coupled with their lack of grocery experience sometimes resulted in a curious bravado regarding the store that came through in daily activities. The consultant's observation was that participants "felt that the populace was going to support them no matter what. Because the community wanted the store, so the community was going to support the store" (June 20, 2014, interview). Village Gardens' insular nature as a community building nonprofit also resulted in the store exhibiting a fair amount of paternalism with respect to the needs and wants of the residents at large, and assumptions that their mission of bringing healthy food to the neighborhood and encouraging healthier eating habits would resonate. Several participants had a belief that they knew what the community wanted and needed, and the advice of the grocery consultant they hired was therefore taken very lightly when it came to the selection of products in the store. He had "never been told [he] was wrong ... so many times," and felt that cutting out foods and food categories in pursuit of social aims 
compromised their ability to win customers away from other stores, a necessary goal for any new store (June 20, 2014, interview).

The focus of the store's food justice intentions on residents meant that at times other food system actors were treated poorly. Store staff members were not always respectful in their relationships with vendors. Unreasonable price breaks were demanded, orders were submitted late, deliveries were not always met and invoices were not always paid in a timely fashion. Bills would be left unpaid, then declared too old to pay by bookkeepers at the parent organization. Word got out amongst the vendor community and some refused to deliver to the store. Their grocery consultant had to use his personal relationships to get some essential vendors to hang in there. As a business, the Village Market had difficulty establishing the necessary practices and systems to run smoothly and also exhibited some contradictory logics. Residents were asked to volunteer their time in the kitchen, either in exchange for eventually being able to make things to sell in the store or simply out of their own beneficence. Low-income volunteers that prepared a catered lunch didn't even get the tip the customer left. In the context of the store's daily struggles to break even, the emphasis turned toward supporting the store rather than empowering staff or serving the needs of residents. Nonetheless, in the midst of these difficulties some attempts to further the store's social objectives emerged. For a few months the store sold hot oatmeal for a really cheap price so neighborhood kids could have breakfast before school.

The transition of the Village Market from community-led project to manager-run social enterprise coincided with a neoliberalization of the organization as a whole. This was reflected not only in its work supplying residents the opportunity to purchase the 
right foods, but also in the nature of the opportunities that Village Gardens sought to create. Whereas Food Works, the community gardens, and the Community Health Worker programs all established collectivist governance practices, newer programs are more individual-based and market-oriented. In 2013, Village Gardens started a weekly summertime farmers' market at New Columbia and allowed residents to set up booths. A market gardener program started that same year gave five immigrant families access to $2000 \mathrm{ft}^{2}$ plots of land for growing produce they could then sell at the farmers' market. The store is also creating a microenterprise program to help food entrepreneurs use the certified commercial kitchen in the store to start up businesses. Even the intent of the store to enhance food sovereignty by limiting exposure of residents to "bad" foods by constraining the supply yielded to market forces in the form of community demand as more chips, soda and other snack foods were brought in. By early 2014 they were the topselling store in North Portland for Frito-Lay chips (Village Gardens staff 2014, interview), indicating strong interest among community members in having those foods. However, several staff expressed interest in addressing that demand through education and organizing, an expression of neoliberal governmentality, the notion that we have both the right as consumers to make our own choices and the moral responsibility as citizens to exercise good judgment in those choices (Guthman \& DuPuis, 2006). Further, by recruiting Village Gardens to launch a social enterprise, a quasi-government entity initiated a transformation of an organization with a history of activating leaders into a tool of the state that suppressed agency and directed behavior.

This is a "strong theory" interpretation of the changes in Village Gardens after the launch of the store. Strong theorizing is a way of framing things such that they relate to a 
core thesis so that they are recognizable, but this type of theorizing is "paranoid" and constrains thinking about what could be by focusing on what is (Gibson-Graham, 2006). A "weak theory" reading of these same phenomena adopts a "beginner's mind" that can explore power with fresh energy to work toward new possibilities (ibid). A weak theory interpretation of the changes at Village Gardens engendered by the implementation of the store allows focus on the successes and potential within the structure. In this light, one might see a housing authority with a distinguished history garnering resources within the community to try to bring an amenity that would make residents' lives a little easier and make the neighborhood a little more convivial. Although they weren't able to sustain this energy, Village Gardens put a lot of effort into building residents' skills and followed decision-making processes that fostered respect for others. They listened when community members said that they wanted "regular" chips and sodas, setting aside their health concerns about such things and trusting that community members could decide for themselves. Participants expressed desires for income generation opportunities and Village Gardens helped provide some alternative market means for people to both earn some money and provide some hard-to-find foods for a diverse community that isn't well-served by North Portland's chain grocery stores. The organization weathered a painful process learning the intricacies of a challenging business, and may yet find ways to create new avenues for community members to become stakeholders in the store, promote further skill development and foster a culture of inclusivity that has been elusive in mixed-income communities. The future is uncertain.

As indicated in the previous chapter, the Village Market initially took a food justice stance that reflected concerns of a larger food movement that was very active in 
Portland at the time. A debate over the definition of food justice by the Portland/Multnomah Food Policy Council (PMFPC) illustrates how healthy eating discourses constrain what can be said and what can be heard. Food Justice Committee members conducted four listening sessions that drew over 100 total participants and presented a draft definition to a broad spectrum of community members to get their responses. The inclusion of the right of individuals to make their own food choices was deemed necessary by those stakeholders, but was met with objections by some PMFPC members and the final food justice definition they adopted for their use in June 2012 omitted that element. The Village Market exhibited similar disinclination to hear dissenting opinions in their weak invitation to community members to participate in the store formation as well as in their interpretation of survey results. As a result, the store that opened in 2011 had the look and feel of a natural foods cooperative, albeit with some more conventional foods in the product mix. While they eventually followed the community's lead with respect to the "junk" food, staff members expressed an intention to do some organizing to develop a more critical stance toward such foods among New Columbia residents. They have an opportunity, however, to create a more agnostic food justice that is capable of engaging a more diverse group of eaters than the food justice movement does through its embrace of the same tastes as the alternative food movement.

\section{Health Equity}

As a nonprofit and a social enterprise the Village Market has had uneven impacts in terms of health equity. Staff and volunteers of Village Gardens proper did not really distinguish health equity from food justice in the context of the store. Its health impact was to be through the healthiness of the food they offered, with some support/education 
around making healthy choices, although there was also an expectation that the store would build community in the neighborhood. While some of the store's actual impacts on health equity can be attributed to its nonprofit status, it is the transition to social enterprise that may have had the most unintended potential health impacts as the shift in governance practices and financial woes created an unhealthy work environment for a time. A community health worker $(\mathrm{CHW})$ program that might have inspired greater criticality around health developed along fairly conventional lines and became almost entirely voluntary as the funding landscape for the sorts of activities they engaged in dropped away in response to reforms accompanying the implementation of Affordable Care Act provisions around coordinated care.

As a nonprofit, the Village Market has garnered support from various external parties to help it pursue health. Nursing students from the University of Portland have volunteered with the prepared-foods manager every semester, and while they have done projects like nutritional signage and recipes, there was also a project in the works in the fall of 2015 to do a canvas of the neighborhood to explore residents' food needs and develop some ways the store could address them. The prepared-foods manager, also a trained dietician, was planning to involve Community Builders in the neighborhood to implement her survey rather than the community health workers that had trained through Village Gardens. That fall the store was also able to secure a grant to subsidize fresh and frozen produce for customers eligible for SNAP. Through its nonprofit status, the store attracted volunteers and funds to promote health in New Columbia and maintained its different orientation relative to its other programs. 
As a store/social enterprise, the Village Market has made many people's lives easier and improved their access to healthy foods, succeeding in this part of its mission to the degree that its wares have been financially accessible to residents. Many people noted that the quality and prices of the produce had improved since the inconsistency of its first years to the extent that they were able to purchase fruits and vegetables there with some regularity. But I would argue that their transition to a social enterprise meant a change in governance that reduced the subjectivity/agency of staff who had been participants in the store during its formation and potentially had negative health consequences as a result. A consensus decision-making process where everyone was valued and respected gave way to the discipline of a hierarchical work environment with inadequate staff support. Some employees were given significant latitude while others were not. One staff person suggested that the whiteness of the command and control approach to work at the Village Market was out of step with the cultures of many community members (July 13, 2015, interview). Management felt that many individuals might have been more successful under different direct supervision (November 20, 2014, interview). As funding got tight in the fall of 2012, the store manager at the time was given:

these horrible constraints, like, you only have $\$ 9000 /$ month to use on staffing. I mean, our staffing budget is twice that this year because we've been able to get some additional subsidy. So now the store can actually operate the way it needs to. I mean ... that was all coming from a perspective ... that ... we will not lose a penny, you either have to shut it down or make it break even ... So the whole mentality and messaging was 
... cut back, cut back, cut back, cut back, cut back (Village Gardens staff, November 20, 2014, interview).

It created a really unhealthy work environment that one staff member referred to as "toxic." It was a wake-up call to the organization and they made some changes to improve the situation that seem to have helped. The program manager decided to find the money elsewhere to maintain the right staffing to foster a healthy work environment. It has meant that the store is not yet in the black, but one participant interviewee thought the era of disgruntled staff was over (August 20, 2015 interview).

In the planning stages of the store, some energy was focused on finding a role that Village Gardens' Community Health Workers could play in facilitating health in connection with the store. A total of 52 CHWs were trained overall, 17 in 2009, and another 15 in 2010 as the store was being planned. The objectives for the 2010 to 2012 period included encouraging CHWs to pursue self-care towards their own health, improving access of residents in their target communities to health and social services, and taking steps to reduce chronic disease in those communities. Although the training they received included popular education and emphasized organizing as a means of enabling communities to address their own problems, the work plan was largely focused on behaviors of CHWs and residents and practical steps like connecting residents to information and resources rather than the organizing dimension. Although these are worthwhile objectives, they are not particularly critical or transformational. CHWs offered a number of workshops on a variety of topics in 2010. They led some cooking events, placed a rack of announcements and fact sheets on various health conditions in 
the store, and some helped out in the Village Market kitchen, but overall CHW involvement in the store was fairly piecemeal.

Although ideas had been discussed around using the store as a hub for wellness activities, this didn't really materialize. This was in part a reflection of a disagreement between the chief advocate of the wellness program and the person in charge of the CHWs over the programmatic approach the CHWs should take, but also perhaps a reflection of the degree to which simply running the market overwhelmed the organization:

it really impacted the rest of our programs and our capacity. It took up almost all of my time for 2-3 years and I think the rest of our programs ... again, they're solid programs, so they kept going. They didn't need me like on a daily basis, but they ... the whole organization needed me to be putting my energy toward the future instead of like, counting money in the mornings at the store (Village Gardens management, November 20, 2014, interview).

Instead of being a hub for wellness and community building, the store negatively impacted other Village Gardens programs and at least initially alienated a number of customers through its high prices, uneven service and product quality. It speaks volumes that a CHW and long-time garden participant discussing a new gazebo being built at the Seeds of Harmony garden and the cooking programs that it would enable offered Cherry Sprout Produce as a place to buy affordable collard greens (Parks, 2014).

Discussion 
The creation of a grocery store by an organization focused on community building revealed some limitations of that approach in terms of how difference was elided and commonalities assumed. As DeFilippis et al describe of non-confrontational communitybased efforts "their emphases ... tend to promote a form of community that is essentially de-politicized and inward-looking, essentially absent of tensions, let alone deep differences" (DeFilippis, Fisher, \& Shragge, 2010, p. 99). The newsletter description of the project and weak invitation to participate reveal constraints on the Village Market that shaped what it could and would become. In this respect the store seemed destined to become a way to reform and regulate the poor (Piven \& Cloward, 1993; Zelizer, 1994) as much as it was to give health-minded residents control over their food environment. Foundation funding enabled the launch of the Village Market without requiring substantive engagement with the class privilege embodied in the food sensibilities they promoted. DeFilippis et al argue that such naïvely communitarian approaches buttress neoliberalism because they identify lack of community as the source of the existing political economic system's failure to adequately address people's needs (ibid). In the context of the Village Market, it meant that the initial product offerings didn't suit the tastes of many community members. Although Village Gardens programs to this point had been quite progressive in their outlook and use of participatory governance practices, the Village Market exhausted their organizational capacity and overwhelmed them with the day-to-day essentials of running a social enterprise. The project also broke open illusions staff had about the organization's ability to equalize power relations on a larger scale. In the context of the store, Village Gardens became more business-like and subsequently created other new programs like the market-gardening program, the 
farmers' market, and the microenterprise program that appeared to reinforce neoliberal subjectivities (Guthman, 2008), revealing some limits to their ability or intent to intervene in the existing political economy.

Reducing the Village Market to such an interpretation, however, obscures the ways that it has enriched the community. The participatory processes that Village Gardens facilitated helped develop leadership that was able to advocate for and garner substantial resources for the community. The project gave residents an opportunity to intervene in the inequities of the capitalist economy to provide an amenity for the neighborhood that makes residents' daily lives a little easier as the nonprofit sector can help localities do (Gunn, 2004). While some might discount and dismiss the provision of a grocery store as part of a reformist food regime that flanks neoliberalism, such essentialist positions belie the value of being included in market-based activities to populations that are frequently marginalized in such contexts (Bay \& Fabian, 2015) or easing the care work, unpaid or underpaid, that is disproportionately a burden for women (Waring, 1988; Folbre, 2001; Bowen et al., 2014), especially low-income women and women of color (Glenn, 1992; Duffy, 2007). Now that they have a better understanding of the grocery business, the Village Market has greater capacity to consider what it means to be a nonprofit grocery store. While social enterprise is a particularly challenging form of business (Smith et al., 2012) and successful income generation opportunities are rare for community development organizations (Stiefvater, 2001) re-engaging community members in the Village Market in some participatory, democratic fashion could re-align them with the progressive identity they exhibited when they used food as an organizing tool rather than an end goal. 
The Village Market's status as a nonprofit enabled them to launch the store without delving into a deep discussion of food with a broad cross-section of community members. However, unless they are able to continue to find subsidies, they may need to engage around food differences in a way that they have not yet done, moreover in a way that the food justice movement has not yet done (Guthman, 2015). One approach that might be helpful is de-centering food in their pursuit of food justice. Meleiza Figueroa argues for a need to focus food sovereignty theorizations on everyday life rather than on food in order to highlight the relationships that construct our food system and liberate thinking and action both from the prevailing neoliberal frames and the white middle-class sensibilities that infuse food justice work (2015). This might make it possible for food justice to encompass people's rights to self-determination with respect to food, even if what they want for lunch is Flamin' Hot Cheetos and a Coke. The healthy eating discourses that infuse Village Gardens' work as well as that of the larger food justice movement don't allow such perspectives to be voiced or heard. Foodways are complex, and our notions of food justice need to acknowledge that people can have a taste for and a desire to eat both home-cooked foods and industrial foods at the same time (Bradley \& Galt, 2014). The Village Market has given Village Gardens a way to interact with a much greater diversity of residents and thus creates an opportunity for them to rethink the food and nutrition work they do (Hayes-Conroy \& Hayes-Conroy, 2008). While they had developed some organizational sensitivity around race privilege and expressed an interest in providing culturally appropriate foods, they didn't exhibit particularly deep thinking around how other factors shape food tastes beyond ability to afford the fresh, local, and organic foods that they sought to promote. Those tastes haven't been shared by all 
community members. As with youth crew members of Dig Deep Farms, a discrepancy existed between the value that Village Market staff placed on the jobs that the organization provided and the "foodie logics" it embraced (Bradley \& Galt, 2014). My hope is that Village Gardens will use the opportunity to revisit their progressive origins and find space to consider more broadly the neoliberal logics they are immersed in, particularly around food and nutrition, as they bridge food gaps in their communities (Sbicca, 2014).

As the product of an organization deeply engaged in food justice, the Village Market took a substantially instrumental approach to improving health equity through food. In doing so, they failed to appreciate how they may have been influencing health beyond their cultivation and selling of fresh, healthy food. After a rough start, the store has been able to accomplish its health goals of providing healthy food at a reasonable cost to a significant degree. Residents like the store much better now that it has become less paternalistic with respect to the foods it offers, and find their prices on fruits and vegetables to be reasonably competitive with larger stores. In its role as a social enterprise, then, the Village Market has achieved its health goals. But it may also have positively impacted health to the extent that it helped to reduce the stigma of the neighborhood (Keene \& Padilla, 2014), and the participatory processes the store used during its formation probably contributed to the well-being of participants (Link \& Phelan, 1995; Marmot \& Wilkinson, 1999). Hopes of putting together a larger wellness program involving the store as part of a larger partnership, however, failed to materialize. The CHW program run through Village Gardens operated largely independently of the Village Market. They were oriented more toward a Healthy Eating Active Living 
approach to health and an awareness of the social determinants of health did not appear to be incorporated into their conceptions, although the leader of that program did support the community-driven approach that would reflect a SDOH perspective. Health promotion done in the context of the store was instead largely taken up by non-resident participants drawn in by the health mission of the store, encouraged by its nonprofit status to help. A study of the Poder es Salud/Power for Health (PES/PFH) project in Portland offers some insights into what the wellness program might have become. CHWs were organizers more than providers of health education, direct service, or outreach (Farquhar et al., 2009). The Village Gardens program occupied a middle ground between the social action model of PES/PFH and more procedural/top-down CHW programs, taking some community direction on what kinds of workshops to do and trying to engage community members around health, but embodied a fairly traditional conception of what that entailed.

Overall, the saga of the Village Market is a cautionary tale to those who think that success in community building nonprofit work translates easily into the realm of social enterprise, particularly in the grocery sector. Indeed, a guide to "entrepreneurial community development" is pessimistic about community development nonprofits developing grocery stores because the low profit margins put significant constraints on rents stores can pay (Stiefvater, 2001). While a case study of 16 successful projects implemented by CDCs nationwide (Abell, 1998) shows that it is possible, all of those projects recruited experienced food vendors to operate their stores. The Village Market took an especially difficult tack, and although the organization overseeing the whole operation, Village Gardens, was fairly adept at facilitating community dialogues and 
processes, their inexperience in the grocery industry figured prominently in the outcomes the store engendered. But as they have developed that expertise in-house, they have the opportunity to return to the anti-oppression, leadership development practices that they began with. The question is whether they will. 


\section{Chapter 7: Mixing Incomes, Ethnicities, and Ages}

This chapter discusses how a small grocery supports and challenges assumptions behind the advocacy for mixed income communities. In order to explore these issues, I begin with a comparison of the dispositions of the social and economic groups in the community with respect to the Village Market. Their thoughts on food, health, and the store as well as their usage of it have much to say about the way that gender, race, class, and national origin shape our identities and our most basic activities. They provide a basis for considering what needs and interests are shared among the different populations living at New Columbia, and whether and where they conflict.

\section{Subsidized Senior Renters}

The seniors I spoke with lived alone in single bedroom Section 8-based apartments at Trenton Terrace, a senior housing facility across the street from the Village Market. My focus groups with them were conducted in the late summer and early fall of 2012, after the store had been open for more than a year, but a few interviews were done earlier in 2012 and a few later ones were done in 2013. The store instituted a senior discount day in the fall of 2013, after the focus groups took place. Overall, I spoke with three African American men, one white man, three African American women, and 11 white women that lived in Trenton Terrace.

Fresh vegetables and meats were valued foods, but many seniors struggled to afford fresh vegetables. Frozen and canned vegetables were more typical. Some prioritized fresh, however, and a few felt strongly about the value of organics. This was a point of controversy. One African American senior remarked, "These people, they just believe in one thing, and that's organic. Everybody's not into organic" (October 16, 2012, 
focus group). Other seniors embraced organic, with one woman saying that it reminded her of the food they got from the garden when she was growing up. Because meat was an important and expensive food, many seniors had very strong preferences about where they bought it. Most of them shopped very carefully because of limited budgets, and money was a significant barrier to them being able to eat the foods they desired. They cited the inflation in food prices as a source of strain, and most of them utilized one or more of the food banks in the area. They also had cooking strategies to support both eating affordably and minimizing work. Many didn't want to spend a lot of time cooking. One person, however, had a collection of cookbooks and loved to try different international recipes. Several people regularly cooked up large batches of food to freeze portions of it for later consumption. A number of people also had to balance health concerns and energy levels, so toward that end, meals were made of simple-to-prepare things that fit their budgets.

Seniors expressed a range of opinions on food with respect to the importance of its healthiness. For the most part, they voiced these opinions in relation to the store, and quite a few seniors felt that the store was too healthy. This was in the early period, before they had added Frito-Lay chips or had much soda. About Big City Produce, one African American male resident commented "Yeah. I liked the other [store] better, because the guy who had it, he worked for Fred Meyers, and he knew what to put in there for the people" (October 16, 2012, focus group). However, a number of seniors tried to eat more vegetables and eat more naturally. Several women in the building mentioned an aversion to processed foods, while others embraced them. A debate emerged over Hamburger Helper: 
Senior 1:You know that, like, Hamburger Helper, that's the worst thing I've ever tasted. (laughing) I brought about 5 or 6 boxes down here just to give away, but ...

Senior 2: I've used it for 100 years. I think it's excellent.

Senior 1: Well, then, you've gotten used to it. Your body has accepted it. When you get away from things like that, your body tells you you don't like it.

Senior 2: Oh.

Senior 1: It doesn't taste right.

Senior 2: And I ain't gonna stop eating it. You can't scare me. (October 16, 2012 , focus group)

A similar exchange happened around soda when someone brought up the high prices of 2-liter bottles at the store. By the time complaints about the price of SPAM were raised, however, the debate over processed foods had been exhausted. The healthiness of the products at the Village Market didn't match the desires of some residents: “And you go there and buy bread, they don't have the bread that I like. It might not be healthy, but I like the Franz bread. They have Franz over there, but it's not the Franz I want" (August 14,2012 , focus group). One woman wanted regular chips, not "them hard chips" that they stocked. Another resident remarked on the absence of cream style corn while still others commented on lack of cigarettes and the uneven availability of cornmeal, bread, milk, and cheese. Still, the store did stock some particular items that people appreciated, and several people felt that this store was better stocked than the previous one. The Village Market accommodated some tastes better than others. 
Many people wished that the store was bigger, ideally a full-size store, in part because of the selection and availability concerns mentioned above, but mostly because of price. The produce prices at the Village Market were seen to be reasonable by many seniors, although some were less satisfied: "So they don't have really nothing good in there, and they vegetables is $45 \%$ more than anybody else's. They killing us, because most of us is on food stamps" (August 14, 2012, focus group). The Village Market's prices on staples like cornmeal, sugar, oil, and dairy products were generally too high, as they were for most other things. The prices and quality of the meats at the Village Market were another source of dissatisfaction. However, one person mentioned liking their hot links, and another commented on the cuts and varieties of meats they stocked for the different populations in the community. Many people felt they were taking advantage of the community through their prices. One man was upset over the price of milk: "With the amount of kids you have in this community, you shouldn't have to pay that price for milk. You just shouldn't. Got too many kids around here" (October 16, 2012, focus group). People noted the number of staff working there, and while some assumed they were volunteers, others attributed their high prices to the overhead of keeping such a large staff. Because of price concerns, many seniors used discount stores or warehouse stores to do a bit of their shopping, although many of them also shopped at the Safeway or Fred Meyer stores within a few miles of their homes. A few people were able to use the Village Market as a secondary store, but for many, it was used only for emergencies. Still, most people appreciated having it there and felt that it added to the community. One area of particular concern for the seniors I spoke with was their ability to safely enter and navigate the store. For the first few years, neighborhood kids would 
leave their bicycles laying on the sidewalk in front of the store, creating a barrier for those using wheelchairs and scooters. It was one of the residents of Trenton Terrace who resolved the situation:

So I had a little conversation with our local Portland Police and they started on their rounds to roust the kids with bikes in the middle of the sidewalk. And, uh, the first technique I thought was cuter than heck. They'd go take the bike and take it around the corner and let the kid come look for it, and then explain to him why it wasn't where it was. I got a kick out of that one. And, um, but just generally, the kids are doing better (December 2, 2013, interview).

Some seniors expressed other, ongoing concerns about trip and slip hazards in the store, particularly power cords taped down on the floor and the way the floors would get mopped in the evening before the store closed. Their fragility made them particularly aware of these problems.

\section{Subsidized Renters}

Subsidized housing represents the largest portion of the units at New Columbia (370 of 854). Occupants of these units were well-represented in my sample population. I spoke with a total of 30 subsidized renters. Among those 30, six were white women, seven were African American men, 12 were African American women, and two were white men. This group included people on disability and in Section 8-based housing as well as public housing. My interviews with subsidized renters were among the earliest interviews I did in 2012 and the last interviews of 2015, so they spanned different eras of the Village Market's existence, most notably before and after the selection of snack foods 
including Coke and Frito-Lay products was added to the store. Most participants in this group relied on SNAP for their food budgets, and a few had children young enough to receive WIC, as well. Nearly everyone budgeted their food shopping very carefully, although food stamp allocations stretched further in some families than others as appetites varied. Approximately one-fourth of the subsidized renters reported using the food banks in the area to some degree when things got tight. Several coped with shortages at the end of the month with creative cooking, making meals from what they had on hand.

The subsidized renters I spoke with expressed a variety of tastes and eating habits. Some, particularly the men in the group, emphasized the meat in their diets, while some, including one grandfather, had vegetarian leanings. Quite a few people mentioned having a taste for seafood, at least as many as emphasized meat. Most renters cited fruits and vegetables as important foods, although some were more inclined toward fruit and others more inclined toward vegetables. Generally, they preferred fresh vegetables, but used canned and frozen as well. They held very mixed opinions on organics, ranging from opposition to skepticism to support of their value, with a fairly even distribution across that spectrum. Even skeptics purchased organics to some degree, but price presented a barrier to many subsidized renters getting as much organic food as they would have liked. There were a number of avid cooks and even some professionals among this population, and home-cooked meals from scratch were typical. This is not to say that convenience foods weren't utilized. Mothers with young kids particularly mentioned using canned, frozen and ready-to-eat foods to satisfy their kids, but they also made simple meals for those less inclined or able to cook. Baked goods, snack foods, soda, and candy were 
appreciated by most residents in this group, although for some people they were occasional indulgences while for others they were more regularly consumed pleasures. Salads and sandwiches were quick and easy meal options. Beans, rice, grains and pastas were important staple foods, and although many people expressed a preference for simpler preparations, there were a few creative souls who liked to explore more exotic tastes as well.

In terms of health, about a third of the subsidized renters I spoke with were inclined to eat with health in mind to some degree. Some were motivated by issues their children had, while others chose it for themselves. A handful of people paid very close attention to what their bodies seemed to want, and ate according to how it made them feel. Another third of this group was more guided by taste and pleasure than by health in their food choices. They much appreciated the addition of a better selection of ice cream, chips, and sodas to the store, as did some of the more health-inclined individuals. One mom commented: "And all this extra organic stuff, and you're trying to divert kids from eating candy? It's not gonna happen. Society is not like that. You need to provide what the community desires, and it's not always wholesome, organic, all-natural foods. You need junk food" (July 25, 2012, interview). Only a few people among this group expressed any reservations about the added snack foods, and one of them was of mixed mind. Several people in this category smoked, and some of them lamented that the store didn't carry alcohol and cigarettes. Overall, although many subsidized renters were inclined toward healthy eating themselves, they weren't sanctimonious about it and didn't express any need to direct the behaviors of others. Indeed, several of them were frustrated by what they felt was excessive healthiness on the part of the Village Market, particularly 
during its early phase. One African American resident who was working hard to find ways to manage her ailments through food expressed the difficulty with the healthiness of the store beautifully: "I do appreciate that they do have healthy food there, ok, but, what I really do truly believe is that a lot of food there, you know, is really meant for people who have the money for it. If you don't have enough money, yes, you do feel like you're condemned to buy cheaper food and cheap food is not healthy food a lot of times" (November 7, 2013, interview). Having physical proximity to healthy food without economic access to it can be a source of frustration and stress whether you have interest in consuming it or not, as it is either a source of judgment or a source of exclusion.

Although there were a handful of subsidized renters who shopped at the store quite a bit, at least half of those I spoke with felt the prices at the store were too high, at least for some things that they would like to use it for. A few people who used the store more frequently also needed to use the food pantries nearby at times. The prices at the store left some people frustrated: "It's their store, exactly. And I don't ... that's not comfortable with me. Why would I want to go all the way somewhere else, when I should be able to come here" (November 18, 2013, interview). But because households had varying degrees of room in their food budgets, a few individuals felt it was more reasonable, and a good handful thought their produce prices were pretty good. Most subsidized renters did the bulk of their shopping at large stores around town, using a mix of stores to get the best combination of price and quality for the things they needed. The Village Market was used for snacks and to pick up last minute needs. However, the overall impression I was left with was that the store was improving in their eyes, as one African American mother and grandmother said: 
You know, I like the store now. I mean as far as the items in there ... I know when they first opened there, some of the products that wasn't in there, like the Coca Cola pops and stuff that they knew that the community was looking for. Why they don't have this, why they don't have that? ... But, like I said, the prices, they could just adjust the prices a little bit (November 25, 2013, interview).

A lot of people in this group did miss the made-to-order sandwiches that they did for a little while, but still really appreciated the deli. While they indicated room for further improvement, subsidized renters felt less alienated by the store than they did initially.

In my conversations with this group about the Village Market, some comparisons arose with the previous inhabitant of the space that speak to the shifting identity from public housing project to mixed-income neighborhood. Many people expressed an affinity for the price, quality, and selection of items that Big City Produce had. As one African American mother said, "It fit out here. The only thing bad about that is just too many people started hanging out ... you know, and it gave it a bad look. It made it almost an eyesore, but everyone was nice" (November 20, 2013, interview). Big City was noted to be dirtier, less bright and inviting a space by other subsidized renters who otherwise liked the store. The ambiance the store created didn't quite fit the aspirations planners had for the neighborhood, as one white subsidized renter noted, "it was like a kick-it spot ... you know, it was like a hood store" (July 25, 2012, interview). Subsidized renters generally viewed the Village Market as an improvement in this regard, although a realtor resident critiqued their practice of leaving their garbage and recycling piled by the door. She felt like this habit detracted from the aesthetic of the neighborhood. It has been a 
challenge for the Village Market to figure out a product mix that suits the social and economic diversity of the community. Big City Produce's owner understood the food needs of the African American community quite well, whereas the Village Market has particularly struggled with the prices of some important ingredients for that population: "I hear ... people of color [saying] that the grease is too high to cook the chicken in. I hear them say about the cornmeal ... about the seasoning. So there's 3 or 4 little things I hear that's a little unreasonable" (African American mother 2013, interview) but also with selection and quality. Multiple critiques were leveled about the condition of their greens and the freshness of their milk, particularly in the first few years of their existence. Struggles with these items may have contributed to the perceptions people shared that the store was too healthy and "too white."

The subsidized renters I spoke with also had a bit to say about theft in the store. One African American mother figure was concerned about how to teach children not to steal because it ingrained habits that could get them into trouble later on. She mentioned that a whole group of young boys were told that they couldn't come in the store for 30 days because one of them had stolen. She thought that was a good start, but felt there ought to be a class or something to further deter them from getting in the habit of stealing. It's a problem the store has struggled with, particularly because many staff members are from the community and it puts them in a potentially difficult situation. One attempt by a new assistant manager also new to the community produced some turmoil. She had tried following kids they knew had been stealing around the store, only to have them come back with one of their mothers to chew her out. After she was threatened by some kids as a result, "She quit and they talked her back in. But, you can't talk to these 
little street kids around here. They'll tear you up ... You in the Ville. You gotta know where you at! They got street manners, so, you've got to talk to them like you've got some sense. Even their mamas got some street manners" (African American mother 2012, interview). Trying to find solutions that support staff and don't vilify those doing the stealing has been an ongoing challenge, especially to the extent that it is motivated by need. They've taken some steps that people I spoke with thought were positive, including moving candy and medicines behind the counter, lowering some tall shelves that obstructed visibility, limiting the number of kids allowed in the store without supervision, and adding bins for people to put bags when they're in the store, but it remains a difficulty. Other subsidized renters shared that it was older kids and adults who were stealing as well. One young African American man expressed concern for how it reflected on the neighborhood: "that's not a good look on the community" (October 29, 2013 , interview) and wanted them to find a way to deal with it.

\section{Market-Rate Residents and Neighbors}

I spoke with a number of people over the five years of my fieldwork who paid market rates for their housing. These included both homeowners and renters in and around New Columbia. This was a harder demographic to identify and recruit as a group, so I did 13 individual interviews rather than focus groups. Three interviewees were men, one white, one African, and one of mixed racial heritage. The remaining 10 participants were five white women and five African American women. The market-rate neighbors ranged in age from 24 to 70, and some received SNAP or WIC benefits while others did not, so the spectrum of financial wherewithal within this group was wider than might be expected. Some were retired and living on fixed incomes while others were recuperating 
from the Great Recession and living paycheck to paycheck. A few occasionally accessed the food banks in the area.

Nearly everyone in this category placed fresh fruits and vegetables high on their list of desired foods, and the impression I got was that everyone was able to afford them, although they budgeted their food purchases very carefully to be able to do so. A few people used cooking as a creative venue, indicating they took pleasure in food preparation, although others reported difficulty finding the energy to cook wholesome meals. There was more interest in the bulk bins in the store among this group than others I spoke with, and some people expressed a desire to have a greater selection of dry beans, rice, and pastas, especially some whole grain options. One of the renters was newly vegan, one homeowner from the neighborhood around New Columbia expressed a particular affinity for seafood and several people had very specific procurement practices around meat. For two people, it was something they budgeted for very carefully, buying in quantity when prices were good and using their freezers to store it in between purchases, and for another, quality was a particular concern that motivated her to buy it at Green Zebra, where it was "pure and local.” Another resident from the surrounding neighborhood was beginning to cut certain meats out of her diet because her body was no longer tolerating beef and pork. For market-rate residents and neighbors as a group, there was significant interest in "ethical eating" of some nature. Almost half of them expressed an affinity for local foods, and there was similar degree of interest in organics by an overlapping, but not entirely synonymous subset of people. Affording organics was cited as a difficulty for some who also expressed a lukewarm conviction in its value. 
Health was an important factor in their food choices for nearly all of the marketrate renters and neighbors. Homemade meals with fresh ingredients were the typical fare for most of them. A few had experienced some health issues that motivated them to make some dietary changes in pursuit of better health, but most were taking proactive measures to maintain wellness. Several people mentioned avoiding processed foods in general, and junk food in particular. One particularly health-inclined renter commented, "Chips and soda'll do us in ... it's almost as bad as the beer and wine" (August 13, 2014, interview). This interest in health extended to others, and members of this group expressed a much greater degree of interest in encouraging healthy food behaviors, with different people expressing concerns around chips, soda, candy, and ice cream in the store. A few people would have preferred less prominent placement of junk food and even less junk food overall. Several newer residents were very excited by the presence of the Village Market in the neighborhood, and it was cited as one positive factor in their choice to move to the neighborhood. They were intrigued by my descriptions of the store in its initial form, and indicated that the greater emphasis on healthy, organic foods and the Healthy Kids Snack Corner would have pleased them even more. This is not to say that market-rate neighbors didn't indulge themselves in some ways that might be considered unhealthy. A few people mentioned chips as favorite treats and a couple of people smoked.

Food shopping for this group was just as complex as it was for other people I spoke with. The difference between this group and the others I spoke with was that some employed careful budgeting in order to do some of their shopping at the higher end grocery stores in the area: New Seasons and Green Zebra. They still made the bulk of their purchases at regular grocery stores or discount/warehouse stores. A young mother 
renting nearby had found a discount warehouse that had very affordable organics that helped her provide the fresh homemade meals she valued for herself and her son.

Although the Village Market's prices for produce were seen as competitive by most of the people in this group, one senior homeowner rattled off Village Market's produce prices in comparison to the discount worker-owned grocery store she favored. She felt like their prices just kept getting higher, and she hadn't been there for 6 months or so. For another senior living nearby, however, the prices at the market were a concession she made because she could get there reasonably easily on her scooter, whereas a trip to a larger store was harder for her to manage. She loved being able to get fresh vegetables nearby, and others also agreed that the convenience of the store made it worth paying a little more. A few more price-conscious market-rate renters and neighbors used the Village Market occasionally, when they ran out of things while cooking or needed to get something for lunch. The more affluent among this group appreciated the deli cooler stocked with sandwiches and salads, and for those receiving food stamps, their ability to purchase them with SNAP was important. The selection of things available in the market left gaps, however. One African American mother wished they had her greens, another renter expressed a desire for fresh meats, and a couple of people lamented the fact that a popular local bread hadn't garnered enough sales for them to keep stocking it.

Some discussion that came up with market-rate neighbors that wasn't mentioned by other groups was around shopping as part of their neighboring practices. Among this group were a few people who intentionally shopped at the Village Market in order to support it, even though its offerings didn't entirely fit with their larger shopping practices. For one person who was very committed to organics, this meant buying 
conventional produce at the market from time to time: "I would love to totally support this store and buy everything here, because I really believe in it. So I buy as much as I can here" (August 13, 2014, interview). For some people it meant spending a little more for some things than they otherwise would. Two recent arrivals to the neighborhood had intentionally sought to live in a diverse community, influenced in part by their faiths, and the store project really spoke to them. Some neighbors that were interested in the store's success, however, were less inspired to change their shopping habits. One longtime homeowner from the nearby neighborhood had only been to the store once, hoping to find the African woman who for a time had been making fresh injera to sell in the store. This woman had been expecting to find more unusual foods and was surprised to see that it was more or less a regular store. Due to a combination of uneasiness because of some shootings in the neighborhood and the prices being higher than she thought they should be, she hadn't modified her shopping habits to include the store. A homeowner who had been on the community board mentioned that drawing in customers from the surrounding neighborhoods had been a challenge for the store. Another homeowner and board participant was disillusioned with the larger neighborhood income-mixing project and no longer shopped in the store. He felt that the homeowners really tried to get involved in the neighborhood for the first several years, but noticed that very few renters attended the HOA meetings and meetings about the grounds, even though they also paid HOA fees. He concluded that people of lower socioeconomic status were not as inclined to be civically involved in the community for a variety of reasons including time constraints and a lack of civic engagement in their culture that he attributed to learned helplessness. He would occasionally drive the 3 blocks to the store for milk in a pinch, but otherwise 
did his shopping elsewhere. Still, the market's presence was seen as a sign of faith in the community that was appreciated by several market-rate neighbors.

\section{African Refugees}

I conducted two focus groups with African refugees, one with Congolese women in the fall of 2014, and another with Somali women in the summer of 2015. A total of 14 African women participated in these groups, 9 from Congo and 5 from Somalia. I also interviewed one Congolese man. These women shared a number of characteristics that impacted their shopping practices. They typically had large families, so they preferred to shop at larger discount stores for staple foods where they could get the best deals. For many of them, this meant bus trips with multiple transfers, a particular hardship during the seven to eight months of the year when it is typically rainy in Portland. But they also shopped at specialty stores to get specific foods that weren't more generally available. This meant smaller stores and higher prices.

Congolese refugees utilized more staple foods that weren't available at American stores: smoked meats and fish; dried and salted fish; cassava leaves and flour; and many varieties of vegetables. They cooked nearly all of their meals because they believed that eating American foods, especially fast food, would be damaging to their health. This was a struggle with their children who often requested American foods like noodles and hamburgers. Congolese women reported discrimination at work in terms of difficulty getting hours at the low-wage jobs that were available to them given their limited English proficiency. This made the challenge of trying to stretch food stamps for expensive, imported African foods even harder. The Village Market didn't have many of the foods 
that they typically ate, and the sizes and prices of the things they did have didn't fit with their budgets or lifestyles.

Somali refugees could find most of their staple foods in American stores. Somalia was an Italian colony, so they had pasta and breads in their diets as a result of that history. They required Halal foods, however, which meant going to specialty stores for their meats. Asian stores had some of the other important foods not readily available at American markets. Although the Village Market doesn't have suitable sizes of their staple foods that fit with their regular budgets, they were better able to use it to fill in gaps between trips to the other stores they frequented. However, the store didn't stock the right cuts of beef for their needs. As for the Congolese women, food stamp allocations were generally not enough to cover their food expenses, but they did help. Somali women did not express the same degree of concern over food budgets that the Congolese women did, although this may be attributable to factors other than hardship. The Congolese women met regularly in a group with an organizer from Africa House, a local nonprofit that helps African refugees adjust to life in the U.S., so they may have cultivated a deeper sense of solidarity and engagement as a result.

\section{Latin American Immigrants \& Refugees}

Focus groups with Latin Americans were done in the summer of 2015. Overall, nine immigrants and refugees from Cuba, Honduras, Mexico, and Guatemala participated in these groups, seven women and two men. The women were all mothers who had children at home they were caring for. One of the men was in his late 50s and the other was much younger but was only recently cleared of leukemia after a three-year battle with the disease. 
As a group, the Latin Americans I spoke with were very expressive about the quality of the food in their countries, and missed the freshness and the flavors of foods from home. Many varieties of fruits are not available in the U.S., and the foods that are available here don't taste the same, which they attributed both to the chemicals used in its production and to the flavor that comes from the place where it is grown. American foods like pizza and hamburgers would be too expensive for them to afford back home, but are ubiquitous and cheap in the U.S., which makes getting their kids to eat homemade food harder. They confront an element of peer pressure as their kids bring home friends that want convenience foods for snacks rather than their good, homemade food. Eating back home was very different: "I mean, another thing over there than over here is, everybody has ... their refrigerator full of food. Nasty food. In our country, we eat 3 meals, every time we eat a meal, we go to the store ... we don't even have refrigerators over there, so we know what we're eating" (August 18, 2015, focus group). They still cooked the vast majority of their meals at home, but did eat out occasionally. Back home, meat was a luxury food for most of them, only consumed on weekends or special occasions. One participant particularly mentioned eating too much meat here, and it not being of very good quality relative to what they had back home where it might be wild or at least freshly butchered.

Food back home was valued for its healthiness as much as its flavor, and trying to feed their families healthy food was the dominant concern of the mothers in the groups. Organics was part of that:

Wish we can eat organic food every day. That would be ... I mean, for a cheaper price, that would be great. That would be more than perfect 
because sometimes we really want to give our kids or our family the healthy food flavor ... And it's not only the taste, but is um, the healthy ... if you go to our country, we don't [have]... I mean, overweight kids, old people over there because ... we eat organic food every day, healthy food every day, veggies, fruits ... (August 18, 2015, focus group).

Although organics were very desirable and more typical of how they would eat back home, they were out of reach financially for this group here. Whereas at home organic was the status quo, here processed foods were the norm. They struggled with their kids wanting more junk food than just the treats that they tried to allow. Limits on the sugar and juice their kids consumed were an important part of managing their health.

While Latin American immigrants and refugees were used to daily shopping in local venues, here they need to use bigger stores to make their food dollars stretch. They used the Village Market for small purchases, but several people commented that they didn't like the amount of junk food that the store carried because it was hard to prevent their kids from eating it. Some of the Latin Americans I spoke with really valued the selection and quality of the fruits and vegetables, and the prices were seen as reasonable, even cheap for some things. They also appreciated the convenience of the location and the selection of Hispanic foods. The leukemia patient particularly loved the fresh juices for their restorative powers, although their price was a hardship. Different individuals offered other specific foods that they found to be too expensive, and several of the women felt that the lack of fresh meat in the store was a problem. One individual was particularly unhappy about the long lines that often formed in the store while one till sat empty. While food stamps helped them a lot, as did trips to the food bank down the street 
for fresh produce, extensive shopping at the Village Market was not within reach for many of the Latin Americans I spoke with, although some felt it was more affordable than others.

\section{Cross-Group Comparisons}

Differing tastes and budget capacities across the various social groups illustrate the challenge of serving such a socially and economically diverse community with a small store. Class shapes tastes and income impacts residents' purchasing power. Most people across all income and social groups desired fresh fruits and vegetables, but they were largely out of reach for seniors. Congolese women had a number of uncommon vegetables that were staples in their diets. Higher-income groups had more developed ethical eating dictates, perhaps due to their increased ability to participate in alternative food networks. While immigrant and refugee populations, almost half of the market-rate residents and neighbors, a fair number of subsidized renters, and a few seniors valued organic produce, only some of the market-rate residents and neighbors could financially afford to fully realize those desires through their shopping activities. Only market-rate residents and neighbors expressed a value for local foods. Meat was a food that excited strong preferences across the board, with little discernible patterns emerging from my admittedly small sample. People had well-formed opinions on which meats they wanted, where they shopped for them and the degree to which they consumed them at all. Somali women needed Halal meats, Latin American immigrants and refugees as well as some market-rate neighbors wanted fresh rather than frozen meats, and a few seniors and market-rate residents and neighbors were cutting back on or removing meat from their 
diet entirely. Seafood was a food valued by seniors, subsidized renters, and market-rate residents and neighbors alike, but seniors had difficulty affording much of it.

Attitudes around health, processed foods, and snack foods all followed a similar pattern shaped by class and national origin. Although processed foods were embraced by some seniors and used by many but not all of the subsidized renters, they were generally eschewed by the immigrant and refugee populations as well as most of the market-rate renters and neighbors and a small contingent of seniors. People generally seemed to have similar attitudes towards sodas and snack foods as they did for processed foods, although a few of the homeowners had a taste for chips. Both immigrants and refugees and marketrate renters and neighbors expressed critiques of the way capitalism has shaped the food system in this country. The immigrants and refugees I spoke with came from countries where capitalism is less advanced, and seemed to be rejecting "neoliberal subjectivities" (Guthman, 2008), at least in the realm of food. They resented the plethora of cheap, processed food that was available in this country, particularly on behalf of their kids. Higher income groups rejected those foods through a neoliberal subjectivity. They wanted different choices to be available and could afford to pay for them. Active interest in health also followed class and national origin contours. While some seniors and subsidized renters expressly pursued health, it was the dominant orientation among market-rate residents and neighbors as well as immigrant and refugee populations. The groups most engaged around health were also most likely to invoke the alternative healthy eating discourses espousing the value of local and organic that the Village Gardens projects shared, although some echoed mainstream health eating discourses as 
well. It was predominantly among the market-rate residents and neighbors, however, that a desire to influence the health of others was expressed.

In the context of the Village Market, the way that class and national origin shaped taste meant that the store's selection suited some populations better than others. For Congolese women, the store had very few of the foods they regularly ate. The selection was better for Somali refugees, and Latin Americans were generally fairly pleased with the availability of their foods there. Once the store added a greater variety of snack foods, ice cream, and sodas, the seniors and subsidized renters were happier with the selection of items in the store, although they still found a few desired items missing. Market-rate residents and neighbors cited the lack of organics in the store as problematic, as was the limited variety of bulk foods, particularly rice, beans, and pasta. Price also presented difficulties for different groups of residents. Most residents found it too expensive for more than occasional shopping, with increasing access that followed an upward trend in food budgets from seniors to subsidized renters to market-rate residents and neighbors. Both Somalis and Latin Americans could afford to use it some, particularly for the fruits and vegetables that they were primarily interested in. Meeting both price and selection requirements for shoppers in such a diverse community is a feat the Village Market has not yet managed to accomplish. It is a most revealing general comment on the store's ability to meet residents' needs that at my member check presentation, where I had a selection of gift cards from a variety of grocery stores to raffle off to attendees, the cards for the Village Market were the last ones taken.

Discussion 
The four propositions underlying advocacy for mixed-income communities argue that (1) social interaction among different income levels will create opportunity for poor people; (2) social control over delinquent behaviors will increase as a result of new relationships; (3) poor people will learn the desired middle class culture from models within their communities; and (4) mixed-income developments will garner better infrastructure. The case of the Village Market provided food for thought with respect to all four propositions, but provided more support for the argument regarding social control than the others. However, it also gives some support for more homogeneous neighborhoods.

With respect to the proposition arguing the value of cross-class social interaction, I found little evidence that the store has been able to attract the full spectrum of community residents to its doors. My most effective means of recruiting participants was by approaching those who shopped in the store. These efforts yielded no homeowners or market-rate residents from New Columbia and only one person from the surrounding neighborhood. I had friends helping me with this recruitment, however, so it is possible that there was some selection bias in terms of who was approached for an interview. The market-rate residents and neighbors I was able to recruit came through personal contacts and a postcard campaign to both homeowners in New Columbia and residents of the surrounding neighborhood. The number of "For Sale" signs in these areas as I walked through them indicated that many of them may have been vacant, perhaps due to foreclosures following the Great Recession. If the board member who had been active in the homeowners association early on was any indication, a combination of disillusionment with the intent of the neighborhood and easy access to other stores by car 
may mean that most homeowners don't include the Village Market in their shopping habits. In any case, the few renters and homeowners from the surrounding community that contacted me had particular motivations that drew them to the neighborhood. For one it was employment, for two others it was personal ties, and for another it was mobility issues that prevented her from getting to a regular store. Two market-rate residents of New Columbia and one home-owning neighbor from the surrounding neighborhood, however, were actively shopping in the market as a way to support both it and the larger goals of the neighborhood.

Resurrection of the community board may be a way for the store to cultivate cross-class relationships in the future, but for now it appears that the store attracts more subsidized renters, seniors, and immigrant and refugee populations than the more affluent residents that proponents of mixed-income communities see as instrumental to the betterment of low-income populations. This is consistent with other research that shows little evidence of social interaction among different income levels (Tach, 2010; Kleit \& Carnegie, 2011; Owens, 2012; Burns, 2013) and the development of micro-segregation patterns (Tach, 2010). It also provides some evidence that creating more low-risk shared places that provide opportunities for finding some commonality, like retail and recreation (Chaskin \& Joseph, 2013) may not help with mixing. This case demonstrates that such spaces can be a means of exclusion, because tastes differ by class and other social factors, judgment accompanies those differing tastes, and price, at least in a small grocery, is a barrier for the low-income to such an extent that it makes the store's viability questionable. A documentary film of this neighborhood also indicated that some 
micro-segregation did develop with respect to the use of parks (Arbuthnot \& Wilhelm, 2009).

The Village Market did provide a focal point for implementing some social control measures. From the outset, the store left certain "sin tax" generating elements out of its product mix: cigarettes, alcohol, and lottery tickets. While this restriction had been a stipulation by the Housing Authority for the first store, participants wanted it to continue in their store. While this doesn't necessarily prevent people from smoking, drinking, and gambling, it creates a means of disparaging and discouraging those behaviors. These social control efforts didn't emerge from higher income echelons, but rather from community members, and not just from "outsider" participants in the store. A concerned senior citizen from Trenton Terrace approached the neighborhood police officers about finding a solution to the piles of bicycles that neighborhood children were leaving in front of the store. These examples raise questions over whether it is income that drives one's investment in community, or some other factor. The policing and surveillance that addressed the kids and their bicycles seems like a fine example of community policing rather than the sort that would make people uncomfortable as was observed at other HOPE VI developments (Fraser et al., 2012; Burns, 2013; August, 2014; Khare et al., 2015). Other surveillance efforts in the area may not have been so innocuous (Arbuthnot \& Wilhelm, 2009), but my observations and discussions didn’t yield any data on those.

Social control remains a developing project within the Village Market in a few other areas. One problematic behavior the store has struggled with is the theft that has been an issue from the beginning. The grocery expert who consulted on the project said, 
“Theft was phenomenal. I've never seen anything like it ... It was just incredible" (June 20, 2013, interview). The store has taken measures to address theft that fit with its identity as a community store, but it remains an ongoing challenge to find ways to do that effectively. With the store's financial viability already so tenuous, it does add to its difficulties. An area where social control efforts have shifted is in health promotion. The addition of more snack foods and drinks didn't mean that the store gave up on its healthy intent, it meant that health promotion efforts became more discursive in nature. The prepared foods manager that was hired in late 2013 seeks to engage with people around nutrition in addition to her kitchen responsibilities. Her conversations with community members and the nutritional signage and recipes created by the nursing students that she works with each semester all constitute nutrition discourses. The historical use of food and nutrition as a paternalistic tool to create "good" citizens out of poor and working class people whose ways were viewed as deficient (Biltekoff, 2013; Turner, 2014) suggests that such work should be approached very cautiously, especially given that the prepared foods manager is white, there is a need for an African American-defined notion of healthy eating (Kumanyika, 2002), and institutional racism is a problem in the field of dietetics (White, 2012). As Charlotte Biltekoff argues, we need to understand "that talking about dietary health is inevitably talking about social values, morality, ideals of good citizenship, and class" (2013, p. 154) in order to "motivate us to pay more attention to all our entanglements with ideas about eating right” (2013, p. 154-55). Invoking healthy eating discourses through recipes, nutritional signage, or face-to-face interactions are intended to influence behavior and exert social control, but also have potential to make people feel excluded by the store (Paddock, 2014). 
In addition to its application to behaviors, social control can also emerge from contested ideas about the use of space. In the context of the Village Market, this contestation was over shelf space. While the current manager honored the wishes of community members for "regular" chips and sodas, a market-rate neighbor lamented that "it seems as though the more convenience store kinds of foods have been taking up more shelf space" (July 14, 2014, interview). This seems to be one case where the purchasing power of lower-income groups made their voices heard, but it is perhaps a small victory in a larger battle. Politicians across the U.S. are debating further restricting food stamp purchases to healthier items (Eng, 2012; Burkhalter, 2013). This research indicates that this would be an unwelcome intrusion into people's lives and complicate access to some of the small and inexpensive ways they can treat themselves and others (Chen, 2016).

As far as the social modeling proposition goes, in the context of the Village Market it was largely focused on demonstrating desirable eating habits to New Columbia residents. By initially providing more of the "right" foods and fewer of the "wrong" ones, the store embodied the tastes of white middle class eaters more than the low-income residents of the community. While it was not the conscious intention of the organization or the institution to tell people what to eat, the store effectively modeled the "right" way to eat. While product selection has shifted to include "junk" food, the modeling continues. The prepared foods manager stocks the grab and go cooler in a way that showcases quick and healthy options. Another part of her job is to engage community members around health and nutrition in a positive way. She spoke about her role in the store as supporting residents as a friend in order to 
encourage them that maybe their kids will like what they're about to eat, or what they're about to take home that they've never made before, and then injecting in our conversation a sense of hope that, like, this might seem like the worst idea to you to go home and to make your own spaghetti sauce, but I know that you can do it, and I know that this is probably not what you're looking forward to doing today after a long day of work, but you are adding so much value to your family and to your own sense of self by trying something you've never done before (September 21, 2015, interview).

In essence, she acts as a nutrition mentor to help people adopt the behaviors the store models. While this may be a service that community members value, it risks privileging middle class tastes in a way that ignores the significance of potential negative consequences for people who may be struggling to feed their families.

However, those tastes happened to coincide with those of the immigrant and refugee communities who also preferred the fresh, local, and organic foods favored by the market-rate residents and neighbors. These foreign-born populations couldn't afford those foods to the same extent. This raises the question of what purpose it serves to model behaviors that are not attainable by those who are supposed to adopt them. Trying to provide nutrition advice to a population whose foodways are poorly understood seems potentially problematic (Delormier et al., 2009). The depths and nuances of class-based differences in taste are still not well understood, either within economic groups where some 'othered' their peers over their tastes for soda and Hamburger Helper in order to raise their own status (Beagan et al., 2015; Chen, 2016), or across class boundaries, and 
class is merely one social factor that impacts taste. Although the Latin American mothers in this study seemed to accept comiendo bien (eating well) as part of their cultural heritage just as another group of mothers in San Francisco did (Martinez, 2016), they may need material support more than encouragement or education to fulfill those roles. Thanks to grant funds that became available in early 2016, the Village Market has been able to provide discounts on produce and other "healthy" foods for SNAP-eligible customers. Whether they recognize the extent of the constraints many New Columbia residents face with respect to their food budgets or whether they are simply trying to incentivize the "right" behaviors I cannot say, but in any case, it offers an option to assist the seniors, subsidized renters, and immigrants and refugees who indicated that affording fresh produce was difficult for them. They just need to be willing to fill out the required survey and use the discount card that accompanies the program.

With regard to the final proposition, the status of New Columbia as a mixedincome community did presumably make it easier for the Village Market to assemble the requisite funds to open, so in that sense it has provided an amenity to the entire community that all residents benefit from to some degree. The difficulty for the most economically marginalized members of the community is that the store's convenience comes at a cost. The economics of the grocery business mean that the Village Market can't compete on price with the large supermarket chains and discount stores that most New Columbia residents rely on to meet their food needs. This raises the question of who such infrastructure is able to serve (Joseph et al., 2007). The store needs to make more money in order to survive - it is not yet financially self-sufficient. This means that either people who have more money need to be drawn to the store or the purchasing power of 
those who already shop there needs to be increased. As we are expecting further cuts to SNAP (Bolen, Rosenbaum, Dean, \& Keith-Jennings, 2016) and food prices over the last several years seem to be experiencing periods of rapid inflation compared to the $1990 \mathrm{~s}$ and early 2000s (Fedec, 2016), it is reasonable to conclude that the market will need to draw in higher-income patrons. The decorative display of high-end chocolate bars for Valentine's Day and the one of artisan pasta that followed it indicate that the management is under that impression. The Village Market may prove to be an example of supermarket "greenlining" and contribute to the gentrification of the surrounding neighborhood as other community development projects have done (Brown, 2011; Anguelovski, 2016), although the two high-end markets that have opened within a few miles of New Columbia are likely to do so to a greater extent. The fact that two newcomers were drawn to the neighborhood in part by the Village Market, however, provides some support for the claim that mixed-income developments are an example of state-sanctioned gentrification (Fraser et al., 2012). It is unlikely that such a store would have found the necessary funding in a traditional housing project.

If we use the diversity of perspectives of New Columbia residents and those of its surrounding neighborhood around food as an indication of the range of perspectives present in other arenas, living in mixed-income communities requires a great deal more "tolerance" - and I would argue appreciation for - difference than currently exists in most cities (Bannister \& Kearns, 2013). What I observed in the course of this research was a fair bit of paternalism and 'othering' around food, even within social groups, that is reflective of a very narrow understanding of health and nutrition. That understanding is premised on Western scientific beliefs that deny the significance of food beyond its 
nutrients and instead use it as a means of 'distinction' and expression of moral superiority. If we truly want to create and foster diverse communities, we need to cultivate ways to become a lot less judgmental of each other, especially across difference. As one New Columbia resident observed with respect to the re-population of the neighborhood after the redevelopment, "I know they had the orientation for housecleaning, you know, how to keep your stove and refrigerator, but I think they should have had an orientation on culture" (Arbuthnot \& Wilhelm, 2009). While such an orientation seems like something that would be beneficial for the larger populace, the case of the Village Market also makes some argument for greater homogeneity of neighborhoods, provided sufficient funding is allocated for the maintenance of infrastructure and the services necessary to support the needs of the population. The diversity of the New Columbia neighborhood makes the population much harder to accommodate with such a small market. However, they would likely contend with the same challenges with price/affordability, perhaps to an even greater extent, if all of the residents were low-income. 


\section{Chapter 8: Findings, Conclusions and Limitations}

\section{Findings}

Launching the Village Market was an ambitious project for a community-building nonprofit with no significant experience in the business arena. Its only commercial endeavor prior to the store involved cultivation of donated land and operated differently than a real farm business would. That project's objectives were empowerment and leadership development, not self-sufficiency. There were different expectations of the Village Market. Before a very rude awakening with respect to the harsh realities of the grocery business, Village Gardens staff had hopes that it might subsidize some of their other programs and provide jobs as well as opportunities for community members to run the business. Instead, the organization was overwhelmed with learning the ins and outs of managing a small store and was unable to tend to its larger goals for the store. In retrospect, the program manager reflected:

But the store ... we tried to do everything at once ... and if I could do it over again, I would just open a store ... I wouldn't try to have it also do a lot of health promotion really actively. Or, you know, I wouldn't necessarily try to make it, like, a job training program at the same time as trying to ... get a business off the ground (November 20, 2014, interview). While the store has made great strides, it remains in the red financially. Residents, however, are much happier with the store than they were for the first few years. The prices fit their budgets better, the quality of the produce has improved, and the selection of products is more in line with what many (though not all) community members want from a corner store. Staff suggested that anyone attempting to take on a similar project 
would do well to assemble a committed group of stakeholders who have the expertise to really figure out both the financial and mission pieces of the endeavor to a much greater degree than the hand-waving that they, in their naïveté, engaged in. This case documents some of the difficulties the Village Market encountered along the way, and generated two key findings around the foodways of low-income populations and the grocery sector.

Finding 1 - The food procurement practices of low-income individuals are complex and shaped not just by class, but also by race, gender, household size and composition, religious affiliation, and national origin as well as the many roles that food plays in people's lives.

As I talked with New Columbia residents about food and grocery shopping and their thoughts about the Village Market, one thing became extremely clear: this was a neighborhood full of savvy shoppers who knew down to the penny the prices of the things they frequently bought at a variety of stores. People's identities shaped their shopping patterns, and in addition to the trips to regular grocery stores and discount chains to meet their basic needs, shoppers included specific destinations according to their particular needs. African Americans visited Cherry Sprout to obtain the greens and yams that were necessary for their holiday tables or at other times, as necessary, to get good quality greens if the ones at the Village Market weren't up to snuff. Halal stores were a regular stop for Muslims, as were ethnic groceries for those whose families moved to the U.S. from elsewhere. Meat was an important food, particularly for many men, and their choice of stores was heavily influenced by which store's selection, price, and quality best suited them. Women as a group seemed to be more engaged around the healthiness of their food, although the lower participation of men in the study means that this 
generalization should be interpreted cautiously, particular because several of the men I spoke with were still fairly young and unencumbered by health problems.

Food is one of the most tangible ways that that we demonstrate affection for our friends and family members, and those connections often drive our food choices. One young African American man who rarely cooked otherwise would do so when his friends were coming over. Latin American mothers tried to welcome their children's friends into their families by "making them our good food" (August 18, 2015, focus group) only to be turned down because it wasn't the frozen convenience foods they favored. One young mother scrimped and saved to be able to afford the birthday cake her son wanted:

This month was really hard, because my son's birthday was on the 22nd, and so I had to save enough food stamps to pay for his birthday cake. And $1 / 4$ sheet birthday cake no matter where you go is $\$ 23.99$. 1/4 sheet! That's as big as this piece of paper. \$24! Albertson's, Fred Meyer's, \$23.99. Safeway is $\$ 22.99$. And Safeway didn't even have a baker in and all they could do for me is they told me I could get a cake off the shelf, and then they would stick the toys on it. I said "Click." I don't want your cake. My son wanted a chocolate cake with strawberry filling with buttercream frosting and he want it to be like [some decorative theme that I didn't recognize] and that's exactly what he got. So, yeah, I really have to budget what I spend and how I shop (July 25, 2012, interview).

Finding him the right cake and taking the necessary steps to be able to afford it was her way of being a good mom (Chen, 2016). She had even made the journey out to a remote store on the bus because that store made the best cakes. 
The chips, sodas, and candy that many food justice advocates refer to as "junk" food have an important place in the lives of many people, not just the low-income. But for the low-income, they are small tastes of luxury that are within their reach and desirable in this regard, even for those who otherwise observed healthy eating patterns. Convenience foods can be considered in a similar light. They offer an affordable option to mothers and others who have few other alternatives to cooking. Incorporating the recognition of meal preparation as labor into the food justice discussion is an important element that has been largely neglected (Sachs \& Patel-Campillo, 2014). This study documents the labor intensity of the provisioning practices that low-income populations adopt.

Finding 2 - Having a mix of incomes and social demographics complicates the already challenging task of operating a small grocery because food tastes are significantly influenced by a variety of social and economic factors.

The grocery industry is a game of pennies that relies on volume to yield profit. Large corporations dominate supply chains, leaving smaller retailers at a disadvantage in terms of food distribution. While stores in more affluent Portland neighborhoods price goods to attain a 40-50\% margin storewide, the Village Market attempts to get by with prices only $25-30 \%$ above cost (Village Gardens staff 2014, interview). Still, according to residents, their prices are well above what the larger stores charge for many grocery items. Large stores sell a number of goods below cost but make that loss up through profits gained on other items. In a small store, however, such practices don't pencil out. With such a thin "profit" margin, there is little room for error in terms of ordering the perishable products that form the healthy food options the store sought to provide to the 
neighborhood. This is the daily challenge the Village Market contends with from a business standpoint.

To this challenge is added the social and economic diversity of a community that translates into a greater range of tastes and preferences than more demographically uniform neighborhoods. Significant percentages of African Americans, Latin Americans, senior citizens, and families with young children constitute greater social diversity than most neighborhoods have. While the widespread adoption of Mexican foods in American culture means that some Latin American foods and many staples are more generally of interest, quite a few staples remain more the domain of peoples from south of the border, like corn masa, nopales, and most varieties of dried chiles. African Americans have "their" foods, too. Curly mustards, turnip, and beet greens are culturally important foods, along with ham hocks, smoked turkey parts, and fish fry. These foods may be less familiar to the other populations in the neighborhood. Seniors were more price-sensitive than anyone else. Many of them had prescription medications that their fixed incomes needed to supply, and the fact that their food stamps can be used like cash (no purchase restrictions) meant that at least some of them met many of their food needs through the food banks and other free food sources and saved their food stamps for other expenses. Families with young children valued kid-friendly foods like chicken nuggets, hot dogs, and spicy chips, but children in at least one family expressed clear preferences on hot dog varieties that meant the selection at the Village Market didn't work for them. More affluent residents wanted organic and local foods, while for others they were too expensive even if they were desirable. This is already a tremendous range of needs to be addressed with 1700 square feet of shelving. 
Then, in addition to the more commonly represented racial and ethnic groups in the U.S., New Columbia is home to refugees from multiple African nations. Congolese refugees struggle to afford the African staples they are told are critical to maintaining their health, and desire a cheaper, more convenient alternative than the bus ride that requires two transfers. One store they frequent, however, also appears to be the distributor for these foods, so any of these desired foods would come with a price at least as high as they were already paying. The SNAP funds that are calculated based on the consumption of an American diet don't go very far in their households. Somali refugees have religious beliefs that dictate which meats may be consumed and how they must be processed. They also have big families and in order to make their budgets work, they need to buy their staple foods in volume to get the best possible price.

The Village Market has very little freezer space or storage space, so it is limited in the variety, size and quantity of items it can order. It simply can't stock the range of products and sizes that would ideally fit the many populations of New Columbia. Low demand for produce meant great difficulty keeping the vegetable cooler that runs one length of the store stocked and fresh-looking. A lot of produce went in the compost bin before some of that cooler space got reallocated to more accurately reflect the quantity that went through the front door. Some of these difficulties would be aided by better sales volume and hence greater flow of inventory through the store, but a number of items linger on the shelves in ways that consume precious stock space as the minimum quantities that must be ordered relegate what doesn't fit on the shelves to storage elsewhere. Prices certainly impact what people are willing and able to buy, but the Village Market hasn't had much control over most of its prices for the first five years of 
its life. It gives the distributor of its grocery items a target margin, and they get back a set of prices based on consumption models that are supposed to help them meet that target margin. Based on the complaints I heard about the prices of SPAM, corn meal, cooking oil, flour, and sugar, it might be interesting to explore the possibility of price discrimination, but within the context of this study, the purchasing power of the New Columbia residents is the more immediate concern. This Healthy Corner Store isn't within the budgets of most residents for more than emergency or occasional use, and in order for it to survive, the Village Market needs to become a regular, secondary market for more people.

Because SNAP is such an important part of residents' purchasing power, a SNAP State of the Union is warranted. An argument that SNAP spent on junk food amounts to corporate welfare sparked recent debate over placing restrictions on their use (Eng, 2012). Attempts to remove soda from SNAP-eligible purchases in New York in 2011 led to further debate about whether poor people should be allowed to make their own decisions about how they spend their food resources (Burkhalter, 2013). The USDA is currently proposing to require any retailer accepting SNAP to stock at least 168 healthy items (Jalonick, 2016). Apparently, increases in SNAP usage that resulted from the Great Recession gave conservatives a target that they have managed to hit (Krugman, 2013). We have a long history of paternalism when it comes to poor people (Piven \& Cloward, 1993; O'Connor, 2002), and their food practices are no exception (Zelizer, 1994;

Biltekoff, 2013; Goldberg, 2013; Turner, 2014). This most recent excitement is driven at least in part by concern over obesity, but represents an old argument that people are poor because of something that is wrong with them. My case study of the Village Market 
revealed what a challenge it is to address the food needs of low-income families and seniors, not because of their deficiencies, but because of the extent of the financial constraints they operate under. If we really want to address the health of the food that poor people consume, a good start would be to allocate sufficient food stamps that people could maintain a healthy diet without the extreme householding necessary at current levels (Davis \& You, 2010; Gottlieb \& Joshi, 2010). Agricultural subsidies could also be used to alter which foods are affordable. The most recent farm bill failed on both of these counts (Nixon, 2014).

Oregon recently imposed time limits on SNAP benefits on adults age 18-49 without minor children or a disability, as are 21 other states (Bolen et al., 2016). This is a move in the wrong direction given the recent inflation in food prices (Fedec, 2016) and the explosion in rents in the City of Portland (King, 2015), especially with Oregon's troubled history with hunger. It certainly will pose further challenges for many New Columbia residents as well as the Village Market.

\section{Conclusions}

A brief feminist materialist discourse analysis provides a broader perspective on the forces at work in the Village Market project through the larger food justice movement and motivates some final thoughts. The food justice movement seeks to alter the food system to address many disparities the current system creates and perpetuates, and it is premised on expanding production of and access to healthy food in ways that are socially and ecologically responsible (Gottlieb \& Joshi, 2010). Attempts to bring systemic inequities by race and class into the food justice dialogue uphold this interest in healthy food (Alkon \& Agyeman, 2011), reinforcing the dominance of alternative healthy eating 
discourses that privilege fresh, local, and organic food. While Healthy Corner Store advocates invoke mainstream rather than alternative healthy eating discourses, discussions of "food deserts" still construct representations of people living in them as being denied a right to healthy food. Village Market participants shared concern over this injustice, although their ideas of good food were more aligned with those espoused by the food justice movement.

Dominant discourses shape what can and cannot be said. By inviting only those with "interest in bringing a healthy and positive store to New Columbia" to participate in the project, Village Gardens was effectively limiting what could be said about the food in the store, what could be heard and who would be allowed to speak. The debate over the working definition of food justice by the Portland/Multnomah Food Policy Council similarly restricted what could be spoken of as food justice. The problem that this creates is that it these healthy eating discourses are infused with moral imperatives about "eating right" that obscure the barriers beyond acquisition that make such food less "good" from alternate perspectives than conceived. Beliefs that poor eating undermines morality and citizenship have a long history (Coveney, 2011; Biltekoff, 2013; Turner, 2014) and were incorporated into the way the early American welfare state placed the responsibility of raising good citizens on mothers (Mink, 1990) and the way reformers sought to assimilate immigrants (Mink, 1990; Zelizer, 1994). Gender and class are particularly subordinated by this notion of what constitutes good food. The constructed subject of the food justice movement is presumably a female, with the time, energy, skills and tools needed to make scratch meals from said healthy food who will bear no negative consequences from doing so. However, the packaged convenience foods that these discourses disparage are simply 
the modern equivalent of the cheap, ready edibles that urban workers purchased from pushcarts just as fast food outlets parallel the free lunches that were available at saloons for the price of a beer (for men, anyway) at the turn of the 20th century (Turner, 2014). Use of those options was denigrated by food reformers of that era as well, but constituted an important part of people managing to both eat and work. New Columbia residents illustrated how problematic such a constrained vision of "good food" was through their variegated tastes and foodways, even though many of them did value healthy food and home-cooked meals were an important part of strategic resource management for most of them.

The Village Market project unwittingly participated in "relations of ruling" (Smith, 1999) by discouraging participation by those that didn't share its definition of good food, as does the larger food justice movement. There are risks of having such a narrow definition. It makes coercion around making "healthy choices" legitimate as a policy intervention. While paternalism around food is not new, the rise of alternative food movements, concern over chronic diseases, and tension over what remains of the welfare state have meant that activists, health advocates, and policymakers alike have exerted themselves scrutinizing food-related policy. Food policy councils have sprung up in cities around the country, and the most recent "Farm Bill" excited a great deal of debate over subsidies and SNAP/food stamps (Nixon, 2014). Restrictions on SNAP benefits that are being considered reflect a potential point of agreement by leftist critics who see them as corporate welfare and those on the right who are inclined to undermine the program. Our experience with welfare reform should make us wary of such alignment (Naples, 2003). The welfare reform instituted by the Personal Responsibility and Work Opportunity 
Reconciliation Act (PRWORA) has been disastrous for poor single mothers (Burnham, 2001; Mink, 2001). As a means of avoiding PRWORA-like policy reform in the realm of SNAP, this case study argues for a more reflexive food justice that allows for multiple perspectives on what constitutes "good” food (Dupuis, Harrison, \& Goodman, 2011).

Getting to a more balanced position on the healthiness of food, however, may require acknowledging some inherent mental models that shape how we as humans interpret the world. Social psychologist Jonathan Haidt argues that the human brain has six cognitive modules that have helped our species withstand threats (Haidt, 2012). Activation of one of these modules triggers intuitive reactions. The six foundational modules are Care/Harm, Fairness/Cheating, Loyalty/Betrayal, Authority/Subversion, Sanctity/Degradation, and Liberty/Oppression. Each has cultural variations and within a culture a given behavior can be connected to different moral modules to construct it as acceptable. For example, the practice of spanking triggers judgments of harm and oppression for more politically liberal individuals, whereas for those on the political right it may be linked to authority. This means that the moral matrices of any two individuals may differ in spite of being premised on the same six foundations. Haidt argues that those on the political left are generally less activated when it comes to the Sanctity/Degradation foundation of morality than those on the political right. This foundation is triggered by disgust over something "untouchable" as well as a desire to protect things that are revered. Where it is frequently activated for those on the political left, however, is in the realm of food (Haidt, 2008). This presents a challenge for the food justice movement to navigate because this Sanctity/Degradation foundation is likely to be triggered by "bad" food for its advocates. The key to moving food justice forward may be activating other 
modules in its place, so that the Liberty/Oppression, for example, becomes more important in the realm of food than Sanctity/Degradation.

\section{Limitations}

There are a number of limitations to this research approach that must be acknowledged. As a white woman from a middle class background, I became aware of a few blind spots on my part that come from things I take for granted, much as Mitchell Duneier did in his research on street vendors (Duneier, 2000). I have easy access to a car, so transporting large quantities of groceries isn't a problem for me. I have enough disposable income to go out to eat if I don't have the energy or inclination to cook. I understand little to nothing of the territorialities of urban youth. The friends I made while spending time on this project took time and energy to help me understand some of these things as I gradually noticed them and sought to learn more. I expect there were many others to which I remained oblivious. I studied the things that I was allowed to see, and as such did not have the full experience of the process of creating the store or living in the neighborhood. The rapport I established may not have been genuine trust, and certainly whatever trust I established differed according to participant. However, because social processes often have a structure to them that yields transparencies (Duneier, 2000), I feel that the process was illuminating in spite of any rapport quality issues I encountered. I did not need to revise my approach to the research process.

I had many interpretation challenges that I took great pains to address. As a person of several privileges, my ability to faithfully represent residents' perspectives is certainly a concern that I did my best to mitigate. I worked to discover my biases through dialogue with my fellow participants and followed reflective practices, striving to be 
sensitive to the power differentials between us (Burawoy, 1991). In all honesty, it often felt like those power differentials ran in the opposite direction than expected. I had difficulty declining "opportunities" to help and accommodating the expectations of availability that many of my new friends had of me. Language barriers were also present, and created further interpretive difficulties, particularly where interviews and focus groups involved non-native English speakers but also with the Southern accents that several participants had. I transcribed those recordings as best I could, but there remained numerous words and phrases that I could not decipher. I don't feel that they compromised my overall ability to understand their larger message, but small details that might have been interesting were obscured. One topic that presented a particular challenge in conversation was the non-profit dimension of the store. It wasn't until late in my interviews that I figured out how to phrase the question about the store's ownership in a way that people understood what I was asking. This was partially due to the fact that very few people knew the store was a non-profit and didn't have a great deal of understanding of what that meant. I ultimately asked people "What do you know about the owner of the store?" as a way to explore this area, and that seemed to make more sense. Unfortunately, I had done most of the interviews before I figured that out. The program manager acknowledged to me that a lot of people in the neighborhood thought that the manager was the owner. One indication that my interpretation efforts were reasonably successful is the positive feedback participants gave me at the member check presentation.

The research process itself involved a learning curve. As a participant observer, I was very mindful of the need to go about this research in ways that were sensitive to those involved in the process. My venture into the use of focus groups for social science 
research put me on relatively unfamiliar ground. I had limited experience with them, and while my plan included preparatory interviews to aid in formulating my questions, my skills as a moderator are still developing. While I had been trained to keep distance from group participants to let them "own" the discussion, I found that for those who had seen me around and noticed me talking with others, I had a social obligation to acknowledge their contributions and establish rapport in the focus groups just as I did in interviews. I had difficulty recruiting certain populations, particularly homeowners, those from the surrounding community, and people who don't use the store for one reason or another. I attempted to reach those people through postcard campaigns and walks through the neighborhood, but it remained a problem and a limitation of the study. I resorted to the fallback plan, which was to solely do interviews for the groups that couldn't be recruited en masse. While I was able to recruit large numbers of subsidized renters, they trickled in over time, so I only did interviews with them as well.

\section{Contributions to Scholarship, Policy, and Practice}

This research contributes to scholarship, policy, and practice. Scholarship contributions come from at least two areas. Investigation of my third question adds to the debate on mixed-income communities by taking a critical look at some of the assumptions advocates make through a unique lens - that of a community institution. This study revealed that social control is not only a result of relationships among income groups, but also emerges as residents claim responsibility for their communities. I did not observe any signs of increased cross-class interaction. Little academic work has placed the voices of those targeted by Healthy Corner Store interventions front and center. This case showed great complexity and discernment in the foodways of low-income shoppers 
that defies their characterization as static and passive. This work is relevant to policy debates on food deserts, Healthy Corner Stores as a remedy for them, and SNAP funding and restrictions. Findings from my exploration of my first question allowed me to draw connections between work in this movement and the broader health equity debates, as part of my larger interest in directing focus away from behaviors and toward an appreciation of the fundamental causes of the diseases those in the movement are so concerned with. This research makes the cultural limitations of the dominant paradigm for nutrition and dietetics work in the U.S. more apparent, and provides some motivation for pursuing alternatives. Finally, this study shows how communitarian frameworks break down in the context of enterprises that require recognition of difference as part of their success. As the trials and tribulations of the Village Market indicate, running a grocery store requires sophisticated knowledge of people's varying tastes and preferences as well as skill in the grocery business.

\section{Future Work}

My research on the Village Market cultivated interest in several potential future research avenues, but two stand apart from the rest. The project sensitized me to the judgment that is wrapped up in how we think and talk about food. My foray into feminist materialist discourse analysis was motivated by similar efforts around welfare reform (Naples, 2003) that I felt contributed valuable insights into the politics of governance. I believe that a more substantive analysis of past and present policy debates around food and nutrition, and how the accompanying discourses have changed over time would be similarly enlightening. To my knowledge such an analysis has not yet been undertaken in this arena. 
Also compelling to me is how we might approach nutrition in a way that dispels the judgment and 'othering' that our current science and practice often do. As a Family Food Educator with Clackamas County (OR) Extension, I'm part of a group that delivers nutrition programs to marginalized populations. One of the realities of our current food system is that many people don't know how to cook. Home economics is no longer taught in schools, and many people rely on convenience foods and restaurants to subsist. While I object to the USDA framework of healthy eating that Extension programs endorse, what I have found is that in the hands of skilled and sensitive leadership, such programs can be co-productive and build community in addition to skills. They can resist views of marginalized populations as deficient and requiring remediation. But the question of what sort of approach to nutrition might be capable of transforming our food system remains. My study of the Village Market has convinced me that programs with transformation as an objective would do well to incorporate a planetary decolonial feminist praxis (Maese-Cohen, 2010), aimed at fostering new subjectivities for both dominant and subordinated groups. Such an approach would mean that volunteers and participants both become aware of how the current food system is entwined with the history of colonialism, science-based nutrition knowledge is put in its proper historical and political context, and traditional knowledges might be recovered. Popular education is often touted as a way to de-center "expert" knowledge (Freire, 2007). My participation in a popular education-style food justice workshop, however, left me keenly aware that our discourses around food, health, and nutrition are infused with distinction, so that even an educational approach intended to address power differences can reinforce judgment. A transformational approach to nutrition means developing methods that spark recognition 
that we moralize about food and reflection on why we do. Such an approach seems critical to the pursuit of a food justice that engenders real solidarity and community. 


\section{References}

Abdulrahim, S., James, S. A., Rouham, Y., \& Baker, W. (2012). "Discrimination and Psychological Distress: Does Whiteness Matter for Arab Americans?" Social Science \& Medicine 75: 2116-2123.

Abell, B. (1998). Supermarket Development: CDCs and Inner City Economic Development. Washington, DC, National Congress for Community Economic Development.

Abraham, T. M., K. Pencina, K. M., Pencino, M. J., \& Fox, C. S. (2015). "Trends in Diabetes Incidence: The Framingham Heart Study." Diabetes Care 38: 482-487.

Agyeman, J. \& J. McEntee, J. (2014). "Moving the Field of Food Justice Forward through the Lens of Urban Political Ecology." Geography Compass 8(3): 211-220.

Ahn, C. E. (2007). Democratizing American Philanthropy. The Revolution Will Not Be Funded: Beyond the Non-Profit Industrial Complex. I. W. o. C. A. Violence. Cambridge, MA, South End Press.

Akram-Lodhi, A. H. (2013). Hungry for Change: Farmers, Food, Justice, and the Agrarian Question. Sterling, VA, Kumarian Press.

AlHasan, D. M. \& Eberth, J. M. (2016). "An Ecological Analysis of Food Outlet Density and Prevalence of Type II Diabetes in South Carolina Counties." BMC Public Health 16(10).

Alkon, A. H. \& Agyeman, J. Eds. (2011). Cultivating Food Justice. Cambridge, MA, MIT Press.

Alkon, A. H. \& Agyeman, J. (2011). Introduction. Cultivating Food Justice. A. H. Alkon and J. Agyeman. Cambridge, MA, MIT Press: 1-20.

Alkon, A. H., Block, D., Moore, K. Gillis, C., DiNuccio, N., \& Chavez, N. (2013). "Foodways of the Urban Poor." Geoforum 48: 126-135.

Alkon, A. H. \& Norgaard, K. M. (2009). "Breaking the Food Chains: An Investigation of Food Justice Activism." Sociological Inquiry 79(3): 289-305.

Allen, R. L. (2007). from "Black Awakening in Capitalist America". The Revolution Will Not Be Funded: Beyond the Non-Profit Industrial Complex. I. W. o. C. A. Violence. Cambridge, MA, South End Press.

Alter, K. (2007). Social Enterprise Typology, Virtue Ventures, LLC. 
An, R. (2015). "Educational Disparity in Obesity among U.S. Adults, 1984-2013." Annals of Epidemiology 25: 637-642.

An, R. \& Sturm, R. (2012). "School and Residential Neighborhood Food Environment and Diet among California Youth." American Journal of Preventive Medicine 42(2): 129-135.

Anderson, J. (2012). New Columbia Takes Small Steps Toward New Life. Portland Tribune. Portland, OR.

Anguelovski, I. (2016). "Healthy Food Stores, Greenlining, and Food Gentrification: Contesting New Forms of Privilege, Displacement and Locally Unwanted Land Uses in Racially Mixed Neighborhoods." International Journal of Urban and Regional Research forthcoming.

Anzaldua, G. (1999). Borderlands: The New Mestiza = La Frontera, Second Edition. San Francisco, Aunt Lute Books.

Apovian, C. M. (2016). "The Obesity Epidemic - Understanding the Disease and the Treatment." The New England Journal of Medicine 374(2): 177-179.

Arbuthnot, S. \& Wilhelm, R. (2009). Imagining Home. U.S., Hare in the Gate Productions, LLC: 79 minutes.

August, M. (2014). "Negotiating Social Mix in Toronto's First Public Housing Redevelopment: Power, Space and Social Control in Don Mount Court"." International Journal of Urban and Regional Research 38(4): 1160-1180.

Baer, T. E., Scherer, E. A., Fleeger, E. W., \& Hassan, A. (2015). "Food Insecurity and the Burden of Health-Related Social Problems in an Urban Youth Population." Journal of Adolescent Health 57: 601-607.

Bannister, J. \& Kearns, A. (2013). "The Function and Foundation of Urban Tolerance: Encountering and Engaging with Difference in the City." Urban Studies 50(13): 2700-2717.

Barcega, N. (2013). GPP105: Cultural Sensitivity Check: Food Deserts. GPP105. 2015.

Bay, M. \& Fabian, A. Eds. (2015). Race and Retail. New Brunswick, New Jersey, Rutgers University Press.

Beagan, B. L., Chapman, G. E., Johnston, J., McPhail, D., Power, E., \& Vallianatos, H. (2015). Acquired Tastes: Why Families Eat the Way They Do. Vancouver, UBC Press. 
Beagan, B. L., Chapman, G. E., \& Power, E. M. (2016). "Cultural and Symbolic Capital With and Without Economic Constraint." Food, Culture \& Society 19(1): 45-70.

Beagan, B. L., Power, E. M., \& Chapman, G. E. (2015). " Eating isn't just swallowing food": Food Practices in the Context of Social Class Trajectory." Canadian Food Studies 2(1): 75-98.

Bean, M. K., Stewart, K., \& Olbrisch, M. E. (2008). "Obesity in America: Implications for Clinical and Health Psychologists." Journal of Clinical Psychology in Medical Settings 15: 214-224.

Beauboeuf-Lafontant, T. (2013). Our Plates are Full: Black Women and the Weight of Being Strong. Critical Food Studies: Doing Nutrition Differently: Critical Approaches to Diet and Dietary Intervention. A. Hayes-Conroy and J. Hayes-Conroy. Farnham, Surrey, GBR, Ashgate Publishing.

Beaudry, J. L. \& Riddell, M. C. (2012). "Effects of Glucocorticoids and Exercise on Pancreatic B-Cell Function and Diabetes Development." Diabetes/Metabolism Research and Reviews 28: 560-573.

Becker, E. J. (2015). Beyond Fruit: Examining Community in a Community Orchard. Urban Studies and Planning. Portland, OR, Portland State University. M.S.

Bell, J., Rogers, V. W., Dietz, W. H., Ogden, C. L., Schuler, C., \& Popovic, T. (2011). "CDC Grand Rounds: Childhood Obesity in the United States." JAMA: The Journal of the American Medical Association 305(10): 988-991.

Bellisari, A. (2008). "Evolutionary Origins of Obesity." Obesity Reviews 9: 165-180.

Ben-Ner, A. \& T. Ren, T. (2015). "Comparing Workplace Organization Design Based on Form of Ownership: Nonprofit, For-Profit, and Local Government." Nonprofit and Voluntary Sector Quarterly 44(2): 340-359.

Berkowitz, S. A., Baggett, T. P., Wexler, D. J., Khuskey, K. W., \& Wee, C. C. (2013). "Food Insecurity and Metabolic Control among U.S. Adults with Diabetes." Diabetes Care 36: 3093-3099.

Berkowitz, S. A., Gao, X., \& Tucker, K. L. (2014). "Food-Insecure Dietary Patterns are Associated with Poor Longitudinal Glycemic Control in Diabetes: Results from the Boston Puerto Rican Health Study." Diabetes Care 37: 2587-2592.

Biltekoff, C. (2013). Eating Right in America: The Cultural Politics of Food \& Health. Durham, NC, Duke University Press. 
Blair, S. \& La Monte, M. (2006). "Commentary: Current Perspectives on Obesity and Health: Black and White or Shades of Grey." International Journal of Epidemiology 35(1): 69-72.

Blake, G. F., Abbott, M. L., \& Lindberg, D. (1990). An Evaluation of Columbia Villa/Tamaracks Community Service Intervention Project. Portland, OR, Center for Urban Studies, School of Urban and Public Affairs.

Blaustein, A. \& G. Faux, G. (1972). Star-Spangled Hustle. New York, NY, Doubleday.

Bodor, J. N., Rice, J. C., Farley, T. A., Swalm, C. M., \& Rose, D. (2010). "The Association between Obesity and Urban Food Environments." Journal of Urban Health 87(5): 771-781.

Bolen, E. \& Hecht, K. (2003). Neighborhood Groceries: New Access to Healthy Food in Low-Income Communities, California Food Policy Advocates.

Bolen, E., Rosenbaum, D., Dean, S., \& Keith-Jennings, B. (2016). More Than 500,000 Adults Will Lose SNAP Benefits in 2016 as Waivers Expire. Washington, D.C., Center on Budget and Policy Priorities.

Boukouvalas, G., Shankar, B., \& Traill, W. B.(2009). "Determinants of Fruit and Vegetable Intake in England: A Re-examination Based on Quantile Regression." Public Health Nutrition 12(11): 2183-2191.

Bourdieu, P. (1984). Distinction: A Social Critique of the Judgement of Taste. Cambridge, MA, Harvard University Press.

Bowen, S., Elliott, S., \& Brenton, J. (2014). "The Joy of Cooking?" Contexts 13(3): 2025.

Bradley, K. \& Galt, R. E. (2014). "Practicing Food Justice at Dig Deep Farms \& Produce, East Bay Area, California: Self-Determination as a Guiding Value and Intersections with Foodie Logics." Local Environment 19(2): 172-186.

Bratt, R. G. (1986). Public Housing: The Controversy and Contribution. Critical Perspectives on Housing. R. G. Bratt, C. Hartman and A. Meyerson. Philadelphia, Temple University Press: 335-361.

Breeze Harper, A., Ed. (2010). Sistah Vegan: Black Female Vegans Speak on Food, Identity, Health, and Society. New York, Lantern Books.

Brent, Z. W., Schiavoni, C. M., \& Alonso-Fradejas, A. (2015). "Contextualising Food Sovereignty: the Politics of Convergence among Movements in the USA." Third World Quarterly 36(3): 618-635. 
Breyer, B. \& Voss-Andreae, A. (2013). "Food Mirages: Geographic and Economic Barriers to Healthful Food Access in Portland, Oregon." Health and Place 24: 131139.

Bridge, G., Butler, T., \& Lees, L. (2011). Mixed Communities: Gentrification by Stealth? Bristol, Policy Press.

Brown, L. J. (2011). The Dynamics of Change among Community Development Corporations in Inner North/Northeast Portland, 1987-2006. Urban Studies and Planning. Portland, OR, Portland State University. PhD.

Brown, W. (1992). ""Finding the Man in the State"." Feminist Studies 18(1): 7-34.

Budnick, N. (2007). Fruits of Their Labor. Portland Tribune. Portland, OR.

Budnick, N. (2012). Access to Food Improves in Oregon. The Oregonian. Portland, OR.

Budzynska, K., West, P., Savoy-Moore, R. T., Lindsey, D., Winter, M. \& Newby, P. K. (2013). "A Food Desert in Detroit: Associations with Food Shopping and Eating Behaviors, Dietary Intakes, and Obesity." Public Health Nutrition 16(12): 2114-2123.

Burawoy, M., Ed. (1991). Ethnography Unbound. Berkeley, University of California Press.

Burkhalter, A. (2013). Soft Drinks, Hard-liners. Street Roots. Portland, OR.

Burnham, L. (2001). "Welfare Reform, Family Hardship, and Women of Color." ANnals of the Academy of Political and Social Science 577(1): 38-48.

Burns, A. B. (2013). New Communities in Old Spaces: Evidence from HOPE VI. Public Policy Studies. Durham, NC, Duke. PhD.

Cahn, E. (2004). No More Throwaway People: The Co-Production Imperative. Washington, D.C., Essential Books.

Campbell, H. \& Dixon, J. (2009). "Introduction to the Special Symposium: Reflecting on Twenty Years of the Food Regimes Approach in Agri-Food Studies." Agriculture and Human Values 26: 261-265.

Campos, P., Saguy, A., Ernsberger, P., Oliver, E., \& Gaesser, G. (2006). "The Epidemiology of Overweight and Obesity: Public Health Crisis or Moral Panic." The International Journal of Epidemiology 35(1): 55-60. 
Canale, M. P., Manca di Villahermosa, S., Martino, G., Rovella, V., Noce, A., De Lorenzo, A., \& Di Daniele, N. (2013). "Obesity-Related Metabolic Syndrome: Mechanisms of Sympathetic Overactivity." International Journal of Endocrinology 2013.

Cannuscio, C. C., Hillier, A., \& Karpyn, A. (2014). "The Social Dynamics of Healthy Food Shopping and Store Choice in an Urban Environment." Social Science \& Medicine 122: 13-20.

Caraher, M., Dixon, P., Lang, T., \& Carr-Hill, R. (1998). "Access to Healthy Foods: Part I. Barriers to Accessing Healthy Foods: Differentials by Gender, Social Class, Income, and Mode of Transport." Health Education Journal 57(3): 191-201.

Carey, G., Braunack-Mayer, A., \& Barraket, J. (2009). "Spaces of Care in the Third Sector: Understanding the Effects of Professionalization." Health 13(6): 629-646.

Carlson, A. \& Frazao, E. (2014). "Food Costs, Diet Quality, and Energy Balance in the United States." Physiology \& Behavior 134: 20-31.

Carnethon, M. R., Kinder, L. S., Fair, J. M., Stafford, R. S., \& Fortmann, S. P. (2003). "Symptoms of Depression as a Risk Factor for Incident Diabetes: Findings from the National Health and Nutrition Examination Epidemiologic Follow-up Study 19711992." American Journal of Epidemiology 158(5): 416-423.

Caspi, C. E., Kawachi, I., Subramanian, S. V., Adamiewicz, G., \& Sorenson, G. (2012). "The Relationship Between Diet and Perceived and Objective Access to Supermarkets among Low-Income Housing Residents." Social Science \& Medicine 75: $1254-1262$.

Cavanaugh, E., Green, S., Mallya, G., Tierney, A., Brensinger, C., \& Glanz, K. (2014). "Changes in Food and Beverage Environments after an Urban Corner Store Intervention." Preventive Medicine 65: 7-12.

Cavanaugh, E., Mallya, G., Brensinger, C., Tierney, A., \& Glanz, K. (2013). "Nutrition Environments in Corner Stores in Philadelphia." Preventive Medicine 56: 149-151.

Cawley, J. (2015). "An Economy of Scales: A Selective Review of Obesity's Economic Causes, Consequences, and Solutions." Journal of Health Economics 43: 244-268.

Center for Disease Control (2016). "Frequently Asked Questions I Social Determinants of Health I NCHHSTP I CDC." Retrieved January 9, 2016, 2016, from http://www.cdc.gov/nchhstp/socialdeterminants/faq.html. 
Chan, J. C. N., Malik, V., Jia, W., Kadowaki, T., Yajnik, C. S., Yoon, K., \& Hu, F. (2009). "Diabetes in Asia: Epidemiology, RIsk Factors, and Pathophysiology." JAMA: The Journal of the American Medical Association 301(20): 2129-2140.

Charmaz, K. (2006). Constructing Grounded Theory: A Practical Guide through Qualitative Analysis. Thousand Oaks, Sage Publications.

Charmaz, K. (2009). Shifting the Grounds: Constructivist Grounded Theory Methods. Developing Grounded Theory: The Second Generation. J. M. Morse, P. N. Stern, J. M. Corbin, B. Bowers and A. E. Clarke. Walnut Creek, Left Coast Press.

Chaskin, R. \& Joseph, M. (2010). "Building "Community" in Mixed-Income Developments: Assumptions, Approaches, and Early Experiences." Urban Affairs Review 45(3): 299-335.

Chaskin, R. \& Joseph, M. L. (2013). "'Positive' Gentrification, Social Control and the 'Right to the City' in Mixed-Income Communities: Uses and Expectations of Space and Place." International Journal of Urban and Regional Research 37(2): 480-502.

Chaskin, R. J. \& Greenberg, D. M. (2015). "Between Public and Private Action: Neighborhood Organizations and Local Governance." Nonprofit and Voluntary Sector Quarterly 44(2): 248-267.

Chaskin, R. J., Sichling, F., \& Joseph, M. L. (2013). "Youth in Mixed-Income Communities Replacing Public Housing Complexes: Context, Dynamics and Response." Cities: 423-431.

Chaufan, C., Constantino, S., \& Davis, M. (2012). "'It's a full time job being poor': Understanding Barriers to Diabetes Prevention in Immigrant Communities in the USA." Critical Public Health 22(2): 147-158.

Chen, W. (2016). "From "Junk Food" to "Treats"." Food, Culture, \& Society 19(1): 151170 .

Chen, Y. \& Qian, L. (2012). "Association between Lifetime Stress and Obesity in Canadians." Preventive Medicine 55: 464-467.

Chilton, M. \& Rose, D. (2009). "A Rights-Based Approach to Food Insecurity in the United States." American Journal of Public Health 99(7): 1203-1211.

Chiolero, A. \& Paccaud, F. (2009). "An Obesity Epidemic Booga Booga?" European Journal of Public Health 19(6): 568-569.

Clampet-Lundquist, S. (2010). ""Everyone Had Your Back": Social Ties, Perceived Safety, and Public Housing Relocation." City \& Community 9(1): 87-108. 
Clarke, S. (2011). "A Politics of Knowledge: Reviewing the Dietetics Curriculum." Journal of Critical Dietetics 1(1): 4-9.

Colasanti, K. J. A., Hamm, M. W., \& Litjens, C. M. (2012). "The City as an "Agricultural Powerhouse"? Perspectives on Expanding Urban Agriculture from Detroit, Michigan." Urban Geography 33(3): 348-369.

Coleman-Jensen, A., Rabbitt, M. P., Gregory, C., \& Singh, A. (2015). Household Food Security in the United States in 2014, United States Department of Agriculture.

Collier, T. (2016). New Columbia Demographics - Initial. H. Forward. Portland, OR.

Collins, P. H. (1986). "Learning from the Outsider Within: The Sociological Significance of Black Feminist Thought." Social Problems 33(6): S14-S32.

Cook, J. T. (2002). "Clinical Implications of Household Food Security: Definitions, Monitoring, and Policy." Nutrition in Clinical Care 5(4): 152-167.

Cook, J. T. \& Frank, D. A. (2008). "Food Security, Poverty, and Human Development in the United States." Annals of the New York Academy of Sciences 1135: 193-209.

Cook, J. T., Frank, D. A., Berkowitz, C., Black, M. M., Casey, P. H., Cutts, D. B., ... Nord, M. (2004). "Food Insecurity is Associated with Adverse Health Outcomes among Human Infants and Toddlers." The Journal of Nutrition 134: 1432-1438.

Cooney, K. \& Willams Shanks, T. R. (2010). "New Approaches to Old Problems: Market-Based Strategies for Poverty Alleviation." The Social Service Review 84(1): 29-55.

Cortes, D. E., Millan-Ferro, A., Schneider, K., Vega, R. R., \& Caballero, A. E. (2013). "Food Purchasing Selection Among Low-Income, Spanish-Speaking Latinos." American Journal of Preventive Medicine 44(3S3): S267-S273.

Coveney, J. (2011). "Social and Cultural Theories of Nutrition and Dietetics." Journal of Critical Dietetics 1(1): 14-19.

Crump, J. (2002). "Deconcentration by Demolition: Public Housing, Poverty, and Urban Policy." Environment and Planning D: Society and Space 20(5): 581-596.

Cummins, S., Flint, E., \& Matthews, S. A. (2014). "New Neighborhood Grocery Store Increased Awareness of Food Access But Did Not Alter Dietary Habits or Obesity." Health Affairs 33(2): 283-291. 
Cummins, S., Pettigrew, M., Higgins, C., Findlay, A., \& Sparks, L. (2005). "Large Scale Food Retailing as an Intervention for Diet and Health: Quasi-experimental Evaluation of a Natural Experiment." Journal of Epidemiology and Community Health 59: 10351040.

Curl, A. (2003). Blasting the Ghetto. Willamette Week. Portland, OR.

Curley, A. M. (2010). "Relocating the Poor: Social Capital and Neighborhood Resources." Journal of Urban Affairs 32(1): 79-103.

Curtis, K. (2011). The Multnomah County Healthy Retail Initiative and the Village Market: A Closer Look. BlueOregon. Portland, OR. 2014.

Dalgaard, K., Landgraf, K., Heyne, S., Lempradl, Al, Longinotto, J., Gossens, K., ... Pospisilik, J. A. (2016). "Trim28 Haploinsufficiency Triggers Bi-stable Epigenetic Obesity." Cell 164: 353-364.

Dannefer, R., Williams, D. A., Baronberg, S., \& Silver, L. (2012). "Healthy Bodegas: Increasing and Promoting Healthy Foods at Corner Stores in New York City." American Journal of Public Health 102(10): e27-e31.

Davis, G. C. \& You, W. (2010). "The Thrifty Food Plan is Not Thrifty When Labor Cost is Considered." Journal of Nutrition 140(4): 854-857.

DeFilippis, J. (2004). Unmaking Goliath. New York, Routledge.

DeFilippis, J. (2008). "Paradoxes of Community-building: Community Control in the Global Economy." International Social Science Journal 59(192): 223-234.

DeFilippis, J., Fisher, R., \& Shragge, E. (2010). Contesting Community: The Limits and Potential of Local Organizing. New Brunswick, New Jersey, Rutgers University Press.

Delahanty, L. M., Pan, Q., Jablonski, K. A., Aroda, V. R., Watson, K. E., Bray, G. A., ... Franks, P. W. (2014). "Effects of Weight Loss, Weight Cycling, and Weight Loss Maintenance on Diabetes Incidence and Change in Cardiometabolic Traits in the Diabetes Prevention Program." Diabetes Care 37: 2738-2745.

Delormier, T., Frohlich, K. L., \& Potvin, L. (2009). "Food and Eating as Social Practice Understanding Eating Patterns as Social Phenomena and Implications for Public Health." Sociology of Health \& Illness 31(2): 215-228.

DeMarco, M., Thorburn, S., \& Kue, J. (2009). "'In a Country as Affluent as America, People Should Be Eating': Experiences With and Perceptions of Food Insecurity Among Rural and Urban Oregonians." Qualitative Health Research 19: 1010-1024. 
DeVault, M. L. (1991). Feeding the Family: The Social Organization of Caring as Gendered Work. Chicago, University of Chicago Press.

Dharod, J. M., Croom, J. E., \& Sady, C. G. (2013). "Food Insecurity: Its Relationship to Dietary Intake and Body Weight among Somali Refugee Women in the Unted States." Journal of Nutrition Education and Behavior 45(1): 47-53.

Oregon Department of Human Services. (2015). High Poverty Hotspots - North and Inner-Northeast Portland, Multnomah County. Salem, OR, Oregon DHS Office of Forecasting, Research, \& Analysis.

Ding, M., Bhupathiraju, S. N., Chen, M., van Dam, R. M., \& Hu, F. B. (2014). "Caffeinated and Decaffeinated Coffee Consumption and Risk of Type 2 Diabetes: A Systematic Review and a Dose-Response Meta-analysis." Diabetes Care 37: 569-586.

Ding, M., Keiley, M. K., Garza, K. B., Duffy, P. A., \& Zizza, C. A. (2015). "Food Insecurity is Associated with Poor Sleep Outcomes among U.S. Adults." The Journal of Nutrition 145: 615-621.

Dinour, L. M., Bergen, D., \& Yeh, M. (2007). "The Food Insecurity-Obesity Paradox: A Review of the Literature and the Role Food Stamps May Play." Journal of the American Dietetic Association 107(11): 1952-1961.

Donald, B. (2013). "Food Retail and Access after The Crash: Rethinking the Food Desert Problem." Journal of Economic Geography 13: 231-237.

Drewnowski, A., Aggarwal, A., Hurvitz, P. M., Monsivais, P., \& Moudon, A. V. (2012). "Obesity and Supermarket Access: Proximity or Price?" American Journal of Public Health 102(8): e74-380.

Duffy, M. (2007). "Doing the Dirty Work: Gender, Race, and Reproductive Labor in Historical Perspective." Gender \& Society 21(3): 313-336.

Duneier, M. (2000). Race and Peeing on Sixth Avenue. Racing Research, Researching Race: Methodological Dilemmas in Critical Race Studies. F. W. Twine and J. W. Warren. New York, New York University Press.

Dupuis, E. M., Harrison, J. L., \& Goodman, D. (2011). Just Food? Cultivating Food Justice: Race, Class, and Sustainability. A. H. Alkon and J. Agyeman. Cambridge, MA, MIT Press.

Edgington, N. (2012). Solving Urban Food Deserts: An Interview with Dennis Morrow. Social Velocity. 2014. 
Ellickson, P. B. (2011). The Evolution of the Supermarket Industry: From A\&P to Walmart". Rochester, NY, University of Rochester.

Eng, M. (2012). 'Healthy' Stamp or Heavy Hand? The Oregonian. Portland, OR.

Espey, D. K., Jim, M. A., Cobb, N., Bartholomew, M., Becker, T., Haverkamp, D., \& Plescia, M. (2014). "Leading Causes of Death and All-Cause Mortality in American Indians and Alaska Natives." American Journal of Public Health 104: S303-S311.

Everson-Rose, S. A. \& Lewis, T. T. (2005). "Psychosocial Factors and Cardiovascular Diseases." Annual Review of Public Health 26: 469-500.

Fairbairn, B . (2004). The History of Cooperatives. Cooperatives and Local Development: Theory and Applications for the 21st Century. C. D. Merrett and N. Walzer. New York, NY, ME Sharpe.

Farquhar, S., Wiggins, N., Michael, Y. L., Luhr, G., \& Jordan, J. (2009). "'Sitting in Different Chairs:" Roles of the Community Health Workers in Poder es Salud/Power for Health Project." Education for Health: Change In Learning \& Practice (Network: Towards Unity for Health) 21(2).

Fedec, A. (2016). "United States Food Inflation 1914-2016." Trading Economics. Retrieved March 25, 2016, 2016, from http://www.tradingeconomics.com/unitedstates/food-inflation.

Ferris, A. M. \& Martin, K. (2010). Healthy Food in Hartford: Evaluating Changes to the Local Food Environment. Hartford, CT, University of Connecticut Center for Public Health and Health Policy.

Figueroa, M. (2015). "Food Sovereignty in Everyday Life: Toward a People-centered Approach to Food Systems." Globalizations 12(4): 498-512.

Flegal, K. M. (2006). "Commentary: The Epidemic of Obesity - What's in a Name?" International Journal of Epidemiology 35(1): 72-74.

Flegal, K. M., Carroll, M. D., Ogden, C. L., \& Curtin, L. R. (2010). "Prevalence and Trends in Obesity among U.S. Adults, 1999-2008." JAMA: The Journal of the American Medical Association 303(3): 235-241.

Flegal, K. M., Kit, B. K., Orpana, H., \& Graubard, B. I. (2013). "Association of AllCause Mortality with Overweight and Obesity using Standard Body Mass Index Categories: A Systematic Review and Meta-analysis." JAMA: The Journal of the American Medical Association 309(1): 71-82. 
Florez, K. R., Dubowitz, T., Saito, N., Borges, G., \& Breslau, J. (2012). "Mexico-United States Migration and the Prevalence of Obesity: A Transnational Perspective." Archives of Internal Medicine 172(22): 1760-1762.

Flournoy, R. \& Treuhaft, S. (2005). Healthy Food, Healthy Communities: Improving Access and Opportunities Through Food Retailing, Policy Link.

Folbre, N. (2001). The Invisible Heart: Economics and Family Values. New York, New Press.

Foley, D. \& Valenzuela, A. (2008). Critical Ethnography: The Politics of Collaboration. The Landscape of Qualitative Research. N. Denzin and Y. Lincoln. Los Angeles, Sage Publications.

Food Front. (2016). "Mission, Ends \& History." Retrieved February 18, 2016, from http://foodfront.coop/about/mission-history/.

Food Trust. (2011a) Healthy Corner Stores as an Economic Development Strategy. Healthy Corner Stores Issue Brief

Food Trust. (2011b) Youth as Change Agents. Healthy Corner Stores Issue Brief

Food Trust. (2012a). Philadelphia's Healthy Corner Store Initiative: 2010-2012. Philadelphia, The Food Trust.

Food Trust. (2012b) The Supplier-Retailer Gap: Connecting Corner Stores with Local Foods. Healthy Corner Stores Issue Brief Winter 2012,

Food Trust. (2014). Healthy Corner Store Initiative - Overview. Philadelphia, The Food Trust.

Frankel, C. \& Bromberger, A. (2013). The Art of Social Enterprise. Gabriola Island, BC, New Society Publishers.

Fraser, J. C., Burns, A. B., Bazuin, J. T., \& Oakley, D. A. (2012). "HOPE VI, Colonization, and the Production of Difference." Urban Affairs Review 49(4): 525556.

Freire, P. (2007). Pedagogy of the Oppressed, $30^{\text {th }}$ Anniversary edition. New York: Bloomsbury.

Fretts, A. M., Howard, B. V., McKnight, B., Duncan, G. E., Beresford, S. A. A., Mete, M., ... Siscovick, D. S. (2014). "Life's Simple 7 and Incidence of Diabetes Among American Indians: The Strong Heart Family Study." Diabetes Care 37: 2240-2245. 
Galaskiewicz, J. \& Barringer, S. N. (2012). Social Enterprises and Social Categories. Social Enterprise: An Organizational Perspective. B. Gidron and Y. Hasenfeld. New York, NY, Palgrave MacMillan.

Gallagher, D., Heshka, S., Kelley, D. E., Baxt, L., Pi-Sunyer, F. X., Patricio, J., ... Zhang, P. (2014). "Changes in Adipose Tissue Depots and Metabolic Markers Following a 1-Year Diet and Exercise Intervention in Overweight and Obese Patients with Type 2 Diabetes." Diabetes Care 37: 3325-3332.

Gallo, L. C., Fortmann, A. L., McCurley, J. L., Isasi, C. R., Penedo, F. J., Daviglus, M. L., ... Carnethon, M. R. (2015). "Associations of Structural and Functional Social Support with Diabetes Prevalence in U.S. Hispanics/Latinos: Results from the HCHS/SOL Sociocultural Ancillary Study." Journal of Behavioral Medicine 38: 160170.

Gardner, K. R., Sapienza, C., \& Fisher, J. O. (2015). "Genetic and Epigenetic Associations to Obesity-Related Appetite Phenotypes among African-American Children." Pediatric Obesity 10: 476-482.

Garrow, E. \& Hasenfeld, Y. (2012). Managing Conflicting Institutional Logics: Social Service Versus Market. Social Enterprises: An Organizational Perspective. B. Gidron and Y. Hasenfeld. New York, NY, Palgrave MacMillan.

Garrow, E. E. \& Hasenfeld, Y. (2014). "Social Enterprises as an Embodiment of a Neoliberal Welfare Logic." American Behavioral Scientist 58(11): 1475-1493.

Gauthier, J. G. (2002). Measuring America: The Decennial Censuses from 1970 to 2000. Washington, D.C., U.S. Department of Commerce.

Ghose, R. \& Pettygrove, M. (2014). "Urban Community Gardens as Spaces of Citizenship." Antipode 46(4): 1092-1112.

Ghosh-Dastidar, B., Cohen, D., Hunter, G., Zenk, S., Huang, C., Beckman, R., \& Dubowitz, T. (2014). "Distance to Store, Food Prices, and Obesity in Urban Food Deserts." American Journal of Preventive Medicine 47(5): 587-595.

Gibson, K. J. (2007a). "Bleeding Albina: A History of Community Disinvestment, 19402000." Transforming Anthropology 15(1): 3-25.

Gibson, K. J. (2007b). "The Relocation of Columbia Villa Community: Views from the Residents." Journal of Planning Education and Research 27(1): 5-19.

Gibson-Graham, J. K. (2006). A Postcapitalist Politics. Minneapolis, University of Minnesota Press. 
Gidron, B. \& Hasenfeld, Y. (2012). Social Enterprises: An Organizational Perspective. New York, NY, Palgrave MacMillan.

Gidron, B. \& Hasenfeld, Y. Eds. (2012). Social Enterprises: An Organizational Perspective. New York, NY, Palgrave MacMillan.

Gill, L. (2014). "Deconstructing Supermarket Intervention Effects on Fruit and Vegetable Consumption in Areas of Limited Retail Access: Evidence from the Seacroft Study." Environment and Planning A 46: 649-665.

Gilles, N. (2014). Cornering the Market. Edible Portland. Portland, OR. Winter 2014.

Gilmore, R. W. (2002). Race and Globalization. Geographies of Global Change: Remapping the World. R. J. Johnston, P. J. Taylor and M. Watts. Malden, Blackwell Publishing.

Gilmore, R. W. (2007). In the Shadow of the Shadow State. The Revolution Will Not Be Funded: Beyond the Non-Profit Industrial Complex. I. W. o. C. A. Violence. Cambridge, MA, South End Press.

Gingras, J. (2008). "Sacra Conversazione - A Tender Dialectic Invoking an Arts PracticeBased Authoethnography to Bridge Language and Silence in Dietetics." Educational Insights 12(2).

Gittelsohn, J., Franceschini, M. C., Rasooly, I., Ries, A. V., Ho, L. S., Pavlovich, W., ... Frick, K. D. (2007). " Understanding the Food Environment in a Low Income Urban Setting: Implications for Food Store Interventions." Journal of Hunger and Environmental Nutrition 2(2/3): 33-50.

Gittelsohn, J., Song, H.-J., Suratkar, S., Kumar, M. Henry, E. G., Sharma, S., .. Anliker, J. (2010). "An Urban Food Store Intervention Positively Impacts on Food-Related Psychosocial Variables and Food Behaviors." Health Education and Behavior 37(3): 390-402.

Gittelsohn, J., Suratkar, S., Song, J-J., Sacher, S. Rajan, R., Rasooly, I., ... Anliker, J. (2010). "Process evaluation of Baltimore Healthy Stores: A Pilot Health Intervention Program with Supermarkets and Corner Stores in Baltimore City." Health Promotion Practice 11(5): 723-732.

Glenn, E. N. (1992). "From Servitude to Service Work: Historical Continuities in the Racial Division of Paid Reproductive Labor." Signs 18(1): 1-43.

Glenn, E. N. (1999). The Social Construction of Race and Gender. Revisioning Gender. M. F. e. al. Thousand Oaks, Sage Publications. 
Goetz, E. (2003). "Housing Dispersal Programs." Journal of Planning Literature 18(1): 316.

Goetz, E. (2015). "From Breaking Down Barriers to Breaking Up Communities: The Expanding Spatial Strategies of Fair Housing Advocacy." Urban Affairs Review 51(6): 820-842.

Goldberg, R. L. (2013). "No Such Thing as a Free Lunch: Paternalism, Poverty, and Food Justice." Stanford Law \& Policy Review 24(1): 35-98.

Gollust, S. E. \& Lantz, P. M. (2009). "Communicating Population Health: Print News Media Coverage of Type 2 Diabetes." Social Science \& Medicine 69: 1091-1098.

Gollust, S. E. \& Lantz, P. M. (2009). "Communicating Population Health: Print News Media Coverage of Type 2 Diabetes." Social Science \& Medicine 69: 1090-1098.

Golob, U., Podnar, K., \& Lah, M. (2009). "Social Economy and Social Responsibility: Alternatives to Global Anarchy of Neoliberalism?" International Journal of Social Economics 36(5): 626-640.

Goni, L., Milagro, F. I., Cuervo, M., \& Martinez, J. A. (2014). "Single-Nucleotide Polymorphisms and DNA Methylation Markers Associated with Central Obesity and Regulation of Body Weight." Nutrition Reviews 72(11): 673-690.

Goodkind, J. R., Hess, J. M., Gorman, B., \& Parker, D. P. (2012). ""We're Still in a Struggle": Dine Resilience, Survival, Historical Trauma, and Healing." Qualitative Health Research 22(8): 1019-1036.

Gord, C. (2011). "A Dietetics Imaginary." Journal of Critical Dietetics 1(1): 20-29.

Gordon, A. (1997). Ghostly Matters: Haunting and the Sociological Imagination. Minneapolis, University of Minnesota Press.

Gordon, K. (2012). Diary of a Diabetic Chef. Oregonian. Portland, OR.

Gorton, D., Bullen, C. R., \& Mhurchu, C. N. (2009). "Environmental Influences on Food Security in High-Income Countries." Nutrition Reviews 68(1): 1-29.

Gottlieb, R. \&. Joshi, A. (2010). Food Justice. Cambridge, MA, MIT Press.

Graefe, P. (2006). "The Social Economy and the American Model." Global Social Policy 6(2): 197-219.

Graves, E. (2010). "The Structuring of Urban Life in a Mixed-Income Housing "Community"." City \& Community 9(1): 109-131. 
Gravlee, C. C. (2009). "How Race Becomes Biology: Embodiment of Social Inequality." American Journal of Physical Anthropology 139: 47-57.

Green, J. J., Green, E. M., \& Kleiner, A. M. (2011). From the Past to the Present: Agricultural Development and Black Farmers in the American South. Cultivating Food Justice. A. H. Alkon and J. Agyeman. Cambridge, MA, MIT Press: 47-64.

Greenbaum, S. (2008). "Poverty and the Willful Destruction of Social Capital: Displacement and Dispossession in African American Communities." Rethinking Marxism 20(1): 42-54.

Griffin, A. (2013). East Portland Food Effort Withers. The Oregonian. Portland, OR.

Gross, J. \& Rosenberger, N. (2010). "The Double Binds of Getting Food among the Poor in Rural Oregon." Food, Culture, \& Society 13(1): 47-70.

Gunn, C. (2004). Making Up for the Market. Ithaca, NY, Cornell University Press.

Guthman, J. (2008). "Bringing Good Food to Others: Investigating the Subjects of Alternative Food Practice." Cultural Geographies 15: 431-447.

Guthman, J. (2008). "Neoliberalism and the Making of Food Politics in California." Geoforum 39(3): 1171-1183.

Guthman, J. (2011). "If They Only Knew". Cultivating Food Justice. A. H. Alkon and J. Agyeman. Cambridge, MA, MIT Press: 263-281.

Guthman, J. (2011). Weighing In. Berkeley, CA, University of California Press.

Guthman, J. (2015, June 1, 2015). "Food Justice." Critical Sustainabilities. Retrieved April 14, 2016, 2016, from https://critical-sustainabilities.ucsc.edu/food-justice/.

Guthman, J. \& DuPuis, M. (2006). "Embodying Neoliberalism: Economy, Culture, and the Politics of Fat." Environment and Planning D: Society and Space 24(3): 427-448.

Hadjimichalis, C. \& Hudson, R. (2007). "Rethinking Local and Regional Development: Implications for Radical Political Practice in Europe." European Urban and Regional Studies 14(2): 99-113.

Haidt, J. (2008). The Moral Roots of Liberals and Conservatives, TED.

Haidt, J. (2012). The Righteous Mind: Why Good People are Divided by Politics and Religion. New York, Vintage Books. 
Halpern, R. (1995). Rebuilding the Inner City: A History of Neighborhood initiatives to Address Poverty in the United States. New York, NY, Columbia University Press.

Haman, F., Fontaine-Bisson, B., Batal, M., Imbeault, P., Blais, J. M., \& Robidoux, M. A. (2010). "Obesity and Type 2 Diabetes in Northern Canada's Remote First Nations Communities: The Dietary Dilemma." International Journal of Obesity 34: S24-S31.

Hannah-Jones, N. (2011). In Portland's Heart, Diversity Dwindles. The Oregonian. Portland, OR.

Haraway, D. (1988). "Situated Knowledges: The Science Question in Feminism and the Privilege of Partial Perspective." Feminist Studies 14(3): 575-599.

Harding, S. (1993). Rethinking Standpoint Epistemology: What is "Strong Objectivity"? Feminist Epistemologies. L. Alcoff and E. Potter. New York, Routledge.

Harris, C. (1993). "Whiteness as Property." Harvard Law Review 106(8): 1724-1737.

Hartford Food System (2008). Strategies that Work: Real Solutions to Community Food Problems. Hartford, Hartford Food System.

Harvey, D. (2005). A Brief History of Neoliberalism. New York, Oxford University Press.

Hayes-Conroy, A. \& Hayes-Conroy, J. (2008). "Taking Back Taste: Feminism, Food and Visceral Politics." Gender, Place and Culture 15(5): 461-473.

Hayes-Conroy, A. \& Hayes-Conroy, J. (2013). Feminist Nutrition: Difference, Decolonization, and Dietary Change. Critical Food Studies: Doing Nutrition Differently: Critical Approaches to Diet and Dietary Interventions. A. Hayes-Conroy and J. Hayes-Conroy. Fernham, Surrey, GBR, Ashgate Publishing.

Hays, S. (1996). The Cultural Contradictions of Motherhood. New Haven, CT, Yale University Press.

Healthy Corner Store Network (2010). Healthy Corner Stores Q \& A, Healthy Corner Store Network.

Healthy Corner Store Network. (2015). "About Us I Healthy Corner Store Network." from http://www.healthycornerstores.org/about-us.

Henneberg, M. \& Grantham, J. (2014). "Obesity - A Natural Consequence of Human Evolution." Anthropological Review 77(1): 1-10. 
Hennessey, R. (1993). Materialist Feminism and the Politics of Discourse. New York, Routledge.

Herman, W. H. \& Rothberg, A. E. (2015). "Prevalence of Diabetes in the United States: A Glimmer of Hope?" JAMA: The Journal of the American Medical Association 314(10): 1005-1007.

Herman, W. H. \& Zimmet, P. (2012). "Type 2 Diabetes: An Epidemic Requiring Global Attention and Urgent Action." Diabetes Care 35: 943-944.

Heynen, N., Kurtz, H. E., \& Trauger, A. (2012). "Food Justice, Hunger, and the City." Geography Compass 6(5): 304-311.

Hill, J. O., Galloway, J. M., Goley, A., Marrero, D. G., Minners, R., Montgomery, B., ... Aroda, V. (2013). "Scientific Statement: Socioecological Determinants of Prediabetes and Type 2 Diabetes." Diabetes Care 36: 2430-2439.

Hillier, A., Cannuscio, C. C., Karpyn, A., McLaughlin, J., Chilton, M., \& Glanz, K. (2011). "How Far Do Low-Income Parents Travel to Shop for Food? Empirical Evidence from Two Urban Neighborhoods." Urban Geography 32(5): 712-729.

Holsten, J. E. (2009). "Obesity and the Community Food Environment: A Systematic Review." Public Health Nutrition 12(3): 397-405.

Holt-Gimenez, E. \& Shattuck, A. (2011). "Food Crises, Food Regimes, and Food Movements: Rumblings of Reform or Tides of Transformation?" Journal of Peasant Studies 38(1): 109-144.

Home Forward. (2015). The New Columbia Neighbor. Portland, OR, Home Forward.

Hosford, A. (2009). "The Impacts of Gentrification on the African American Business Community of Portland, Oregon." Anthos 1(1).

Houde, A.-A., Legare, C., Biron, S., Lescelleur, O., Biertho, L., Marceau, S., ... Bouchard, L. (2015). "Leptin and Adiponectin DNA Methylation Levels in Adipose Tissues and Blood Cells are Associated with BMI, Waist Girth, and LDL-Cholesterol Levels in Severely Obese Men and Women." BMC Medical Genetics 16(29).

Housing Authority of Portland (2007). New Columbia: Report on Development Goals. Portland, Housing Authority of Portland.

Huddleston-Casas, C., Charnigo, R., \& Simmons, L. A. (2008). "Food Insecurity and Maternal Depression in Rural, Low-Income Families: A Longitudinal Investigation." Public Health Nutrition 12(8): 1133-1140. 
Hussain, A., Claussen, B., Ramachandran, A., \& Williams, R. (2007). "Prevention of Type 2 Diabetes: A Review." Diabetes Research and Clinical Practice 76(3): 317326.

Imbroscio, D. (2008). "'[U]nited and Actuated by Some Common Impulse of Passion': Challenging the Dispersal Consensus in American Housing Policy Research." Journal of Urban Affairs 30(2): 111-130.

Isaacs, S. L. \& Schroeder, S. A. (2004). "Class - The Ignored Determinant of the Nation's Health." New England Journal of Medicine 351(11): 1137-1142.

Jalonick, M. C. (2016). USDA Rules Would Increase Food Stamp Access to Healthy Foods. Seattle PI. Seattle, WA.

James, S. A., Strogatz, D. S., Wing, S. B., \& Ramsey, D. L. (1987). "Socioeconomic Status, John Henryism, and Hypertension in Blacks and Whites." American Journal of Epidemiology 126(4): 664-673.

Jargowsky, P. (1997). Poverty and Place: Ghettos, Barrios, and the American City. New York, Russell Sage Foundation.

Jauch-Chara, K. \& Oltmanns, K. M. (2014). "Obesity - A Neuropsychological Disease? Systematic Review and Neuropsychological Model." Progress in Neurobiology 114: 84-101.

Johns, A. (2007). New Columbia Gets to Work. Portland Tribune. Portland, OR.

Johnston, J., Rodney, A., \& Szabo, M. (2012). "Place, Ethics, and Everyday Eating: A Tale of Two Neighborhoods." Sociology 46(6): 1091-1108.

Johnston, J., Szabo, M., \& Rodney, A. (2011). "Good Food, Good People: Understanding the Cultural Repertoire of Ethical Eating." Journal of Consumer Culture 11(3): 293318.

Jolliffe, D. (2011). "Overweight and Poor? On the Relationship between Income and the Body Mass Index." Economics and Human Biology 9: 342-355.

Joseph, M. (2008). "Early Resident Experiences at a New Mixed-Income Development in Chicago." Journal of Urban Affairs 30(3): 229-257.

Joseph, M. \& Chaskin, R. (2010). "Living in a Mixed-Income Development: Resident Perceptions of the Benefits and Disadvantages of Two Developments in Chicago." Urban Studies 47(11): 2347-2366. 
Joseph, M., Chaskin, R., \& Webber, H. (2007). "The Theoretical Basis for Addressing Poverty Through Mixed-Income Development." Urban Affairs Review 42(3): 369409.

Jourdan, D., Van Zandt, S., \& Tarlton, E. (2013). "Coming Home: Resident Satisfaction Regarding Return to a Revitalized HOPE VI Community." Cities 35: 439-444.

Juster, R. P., McEwen, B. S., \& Lupien, S. J. (2009). "Allostatic Load Biomarkers of Chronic Stress and Impact on Health and Cognition." Neuroscience \& Biobehavioral Reviews 35(1): 2-16.

Kahn, R. \& Davidson, M. B. (2014). "The Reality of Type 2 Diabetes Prevention." Diabetes Care 37: 943-949.

Kanaya, A. M., Herrington, D., Vittinghoff, E., Ewing, S. K., Liu, K., Blaha, M. J., ... Kandula, N. R. (2014). "Understanding the High Prevalence of Diabetes in U.S. South Asians Compared with Four Racial/Ethnic Groups: The MASALA and MESA Studies." Diabetes Care 37: 1621-1628.

Keating, L. (2000). "Redeveloping Public Housing: Relearning Urban Renewal's Immutable Lesson." APA Journal 66(4): 384-397.

Keene, D. E. \& Padilla, M. B. (2014). "Spatial Stigma and Health Inequality." Critical Public Health 24(4): 392-404.

Khare, A. T., Joseph, M. L., \& Chaskin, R. J. (2015). "The Enduring Significance of Race in Mixed-Income Developments." Urban Affairs Review 51(4): 474-503.

Kim, A. E., Kumanyika, S., Shive, D., Igweatu, Uzy, \& Kim, S. (2010). "Coverage and Framing of Racial and Ethnic Health Disparities in US Newspapers, 1996-2005." American Journal of Public Health 100: S224-S231.

Kim, S., \& Popkin, B. (2006). "Commentary: Understanding the Epidemiology of Overweight and Obesity - a Real Global Public Health Concern." International Journal of Epidemiology 35(1): 60-67.

Kimbro, R. T. \& Denney, J. T. (2015). "Transitions into Food Insecurity Associated with Behavioral Problems and Worse Overall Health Among Children." Health Affairs 34(11): 1949-1955.

King, S. R. (2015). A Summer of Evictions: Portland Renters Are in a State of Emergency. Portland Mercury. Portland, OR. 16.

Kleit, R. G. (2005). "HOPE VI New Communities: Neighborhood Relationships in Mixed-Income Housing." Environment and Planning A 37: 1413-1441. 
Kleit, R. G. \&. Carnegie, N. B. (2011). "Integrated or Isolate? The Impact of Public Housing Redevelopment on Social Network Homophily." Social Networks 33: 152 165.

Knupfer, A. M. (2013). Food Co-Ops in America: Communities, Consumption, and Economic Democracy. Ithaca, NY, Cornell University Press.

Koch, E. (1998). A Summary of the National Community Health Advisor Study: Weaving the Future. Washington, DC, Georgetown University Law Center.

Koch, S. L. (2012). A Theory of Grocery Shopping: Food, Choice, and Conflict. London, Berg.

Koffman, R. (2011). Grocery Store Coming to New Columbia Development. The Oregonian. Portland, OR.

Koffman, R. (2011). Village Market, a Healthy Corner Store, Opens in North Portland's New Columbia. The Oregonian. Portland, OR.

Krieger, N. (2013). "History, Biology, and Health Inequities: Emergent Embodied Phenotypes and the Illustrative Case of the Breast Cancer Estrogen Receptor." American Journal of Public Health 103(1): 22-27.

Krieger, N., Kosheleva, A., Waterman, P. D., Chen, J. T., \& Koenen, K. (2011). "Racial Discrimination, Psychological Distress, and Self-Rated Health among U.S.-Born and Foreign-Born Black Americans." American Journal of Public Health 101: 1704-1713.

Krugman, P. (2013). In America, It Seems, We're Free to Be Hungry. The Oregonian. Portland, OR.

Kumanyika, S. (2002). "The Minority Factor in the Obesity Epidemic." Ethnicity Disease 12(Summer 2002).

Kwate, N. O. A. (2015). Retail Messages in the Ghetto Belt. Race and Retail: Consumption across the Color Line. M. Bay and A. Fabian. New Brunswick, New Jersey, Rutgers University Press.

Law, S. (2011). The Corner Store Gets a New Mission. Portland Tribune. Portland, OR.

LeDoux, T. F. \& Vojnovic, I. (2013). "Going Outside the Neighborhood: The Shopping Patterns and Adaptations of Disadvantaged Consumers Living in the Lower Eastside Neighborhoods of Detroit, Michigan." Health \& Place 19: 1-14. 
Lee, H. (2012). "The Role of Local Food Availability in Explaining Obesity Risk Among Young School-Aged Children." Social Science \& Medicine 74: 1193-1206.

Lethabo King, T. \& Osayande, E. (2007). The Filth on Philanthropy: Progressive Philanthropy's Agenda to Misdirect Social Justice Movements. The Revolution Will Not Be Funded: Beyond the Non-Profit Industrial Complex. I. W. o. C. A. Violence. Cambridge, MA, South End Press.

Levi, Y. \& Davis, P. (2008). "Cooperatives as the "Enfants Terribles" of Economics: Some Implications for the Social Economy." The Journal of Socio-Economics 37: 2178-2188.

Levy, D. \& Woolley, M. (2007). Relocation is Not Enough: Employment Barriers among HOPE VI Families. M. H. a. C. Center. Washington, DC, Urban Institute.

Liburd, L. C. \& Vinicor, F. (2003). "Commentary: Rethinking Diabetes Prevention and Control in Racial and Ethnic Communities." Journal of Public Health Management Practice 9: S74-S79.

Link, B. G. \& Phelan, J. (1995). "Social Conditions as Fundamental Causes of Disease." Journal of Health and Social Behavior 35(extra issue): 80-94.

Literacy for Justice (2011). "Literacy for Justice: Food Justice." Retrieved March 28, 2011, 2011, from http://www.lejyouth.org/programs/food.html.

Liu, G., Takeda, S., \& Ko, W. (2012). "Strategic Orientation and Social Enterprise Performance." Nonprofit and Voluntary Sector Quarterly 43(3): 480-501.

Liu, J., Park, Y. M., Berkowitz, S. A., Hu, Q., Han, K. Ortaglia, A., ... Liese, A. D. (2015). "Gender Differences in the Association between Food Insecurity and Insulin Resistance among U.S. Adults: National Health and Nutrition Examination Survey, 2005-2010." Annals of Epidemiology 25: 643-648.

Liu, Y. Y. \& Apollon, D. (2011). The Color of Food, Applied Research Center.

Ljungvall, A. \& Zimmerman, F. J. (2012). "Bigger Bodies: Long-term Trends and Disparities in Obesity and Body-Mass Index among U.S. Adults, 1960-2008." Social Science \& Medicine 75(109-119).

Lucan, S. C., Barg, F. K., Karasz, A., Palmer, C. S., \& Long, J. A. (2012). "Concepts of Healthy Diet Among Urban, Low-Income African Americans." Journal of Community Health 37: 754-762. 
Lugones, M. C. \& Spelman, E. V. (1983). "Have We Got a Theory for You! Feminist Theory, Cultural Imperialism and the Demand for 'The Woman's Voice'." Women's Studies International Forum 6(6): ${ }^{573-581}$.

Lukkarinen, M. (2005). "Community Development, Local Economic Development, and the Social Economy." Community Development Journal 40(4): 419-424.

Ma, R. C. W., Tutino, G. E., Lillycrop, K. A., Hanson, M. A., \& Tam, W. H. (2015). "Maternal Diabetes, Gestational Diabetes, and the Role of Epigenetics in Their Long Term Effects on Offspring." Progress in Biophysics and Molecular Biology 118: 5568.

Maese-Cohen, M. (2010). "Introduction: Toward Planetary Decolonial Feminisms." Qui Parle: Critical Humanities and Social Sciences 18(2): 3-27.

Mahmood, W. A. W., Yusoff, M. S. D., Behan, L. A., Di Perna, Al, Tun, T. K., McDermott, J., \& Sreenan, S. (2013). "Associations between Sleep Disruption and Levels of Lipids in Caucasians with Type 2 Diabetes." International Journal of Endocrinology 2013.

Maier, F., Meyer, \& M., Steinbereithner, M. (2016). "Nonprofit Organizations: Becoming Business-Like: A Systematic Review." Nonprofit and Voluntary Sector Quarterly 45(1): 64-86.

Majic, S. (2011). "Serving Sex Workers and Promoting Democratic Engagement: Rethinking Nonprofits' Role in American Civic and Political Life." Perspectives on Politics 9(4): 821-839.

Manikkam, M., Tracey, R., Guerrero-Bosagna, C., \& Skinner, M. K. (2013). "Plastics Derived Endocrine Disruptors (BPA, DEHP and DBP) Induce Epigenetic Transgenerational Inheritance of Obesity, Reproductive Disease, Sperm Epimutations." PLoS One 8(1): 1-18.

Manjarrez, C., Popkin, S., \& Guernsey, E. (2007). Poor Health: Adding Insult to Injury for HOPE VI Families. M. H. a. C. Center. Washington, DC, Urban Institute.

Manning, J. (2010). Portland Area among the Cities Hardest Hit by Recession. The Oregonian. Portland, OR.

Mares, T. M. \& Pena, D. G. Eds. (2011). Environmental and Food Justice: Toward Local, Slow, and Deep Food Systems. Cambridge, MA, The MIT Press.

Marler, J. B. \& Wallin, J. R. (2006). Human Health, the Nutritional Quality of Harvested Food and Sustainable Farming Systems. Bellevue, WA, Nutrition Security Institute. 
Marmot, M. \& Wilkinson, R. Eds. (1999). Social Determinants of Health. Oxford, Oxford University Press.

Martin, K. S., Ghosh, D., Page, M., Wolf, M., McMinimee, K., \& Zhang, M. (2014). "What Role do Local Grocery Stores Play in Urban Food Environments? A Case Study of Hartford-Connecticut." PLOS One 9(4).

Martin, K. S., Havens, E., Boyle, K. E., \& Schilling, E. A. (2012). "If You Stock It, Will They Buy It? Healthy Food Availability and Customer Purchasing Behavior within Corner Stores in Hartford, Ct, USA." Public Health Nutrition 15(10): 1973-1978.

Martinez, A. D. (2016). "Comiendo Bien: The Production of Latinidad through the Perfomance of Healthy Eating among Latino Immigrant Families in San Francisco." Symbolic Interaction 39(1): 66-85.

Marum, A. (2014). Green Zebra Grocery Finds Footing, Plans to Expand. The Oregonian. Portland, OR.

Marx, J. (2016). What Can Communities Do Now for Health Equity. Culture of Health, Robert Wood Johnson Foundation. 2016.

Massetti, B. (2012). "The Duality of Social Enterprise: A Framework for Social Action." Review Of Business: St. John's University 33(1).

Massey, D. (2006). Race, Class and Markets: Social Policy in the 21st Century. Poverty and Inequality. D. B. Grusky and S. M. Ravi Kanbur. Stanford, Stanford University Press.

Massey, D. S. \& Denton, N. (1993). American Apartheid: Segregation and the Making of an Underclass. Cambridge, MA, Harvard University Press.

Maty, S. C., James, S. A., \& Kaplan, G. A. (2010). "Life-Course Socioeconomic Position and Incidence of Diabetes Mellitus Among Blacks and Whites: The Alameda County Study, 1965-1999." American Journal of Public Health 100(1): 137-145.

May, A. L., Freedman, D., Sherry, B., \& Blanck, H. M. (2013). "Obesity - United States, 1999-2010." MMWR 62(3): 120-128.

McClintock, N. (2014). "Radical, Reformist, and Garden-Variety Neoliberal: Coming to Terms with Urban Agriculture's Contradictions." Local Environment 19(2): 147-171.

McCutcheon, P. (2011). Community Food Security "For Us, By Us". Cultivating Food Justice. A. H. Alkon and J. Agyeman. Cambridge, MA, MIT Press: 177-196. 
McEwen, B. S. (2012). "Brain on Stress: How the Social Environment Gets under the Skin." Proceedings of the National Academy of Science 109: 17180-17185.

McEwen, B. S., Gray, J. D., \& Nasca, C. (2015). "Recognizing Resilience: Learning from the Effects of Stress on the Brain " Neurobiology of Stress 1: 1-11.

McEwen, B. S. \& Seeman, T. (1999). "Protective and Damaging Effects of Mediators of Stress: Elaborating and Testing the Concepts of Allostasis and Allostatic Load." Annals of the New York Academy of Science 896: 30-47.

McKenna, M. (2012). Diabetes Mystery: Why are Type 1 Cases Surging? Scientific American.

Menke, A., Casagrande, S., Geiss, L., \& Cowie, C. (2015). "Prevalence of and Trends in Diabetes among Adults in the Unted States, 1988-2012." JAMA: The Journal of the American Medical Association 314(10): 1021-1029.

Mertens, S. (1999). "Nonprofit Organizations and Social Economy: Two Ways of Understanding the Third Sector." Annals of Public and Cooperative Economic 70(3): 501-520.

Miewald, C. \& McCann, E. (2014). "Foodscapes and the Geographies of Poverty: Sustenance, Strategy, and Politics in an Urban Neighborhood." Antipode 46(2): 537556.

Mink, G. (1990). The Lady and the Tramp: Gender, Race, and the Origins of the American Welfare State. Women, the State, and Welfare. L. Gordon. Madison, University of Wisconsin Press.

Mink, G. (2001). "Violating Women: Rights Abuses in the Welfare Police State." Annals of the Academy of Political and Social Science 577(1): 79-93.

Mitchell, F. M. (2012). "Reframing Diabetes in American Indian Communities: A Social Determinants of Health Perspective." Health \& Social Work 37(2): 71-79.

Moffat, T. (2010). "The "Childhood Obesity Epidemic": Health Crisis or Social Construction?" Medical Anthropology Quarterly 24(1): 1-21.

Morales, A. (2011). Growing Food and Justice: Dismantling Racism through Sustainable Food Systems. A. H. Alkon and J. Agyeman. Cambridge, MA, The MIT Press.

Morgan, K. \& Campbell, A. (2010). The Delegated Welfare State: Marketizing American Social Provision in Comparative and Historical Perspective. Midwest Political Science Association 67th Annual National Conference, The Palmer House Hilgon, Chicago, IL. 
Moulaert, F. \& Ailenei, A. (2005). "Social Economy, Third Sector, and Solidarity Relations: A Conceptual Synthesis from History to Present." Urban Studies 42(11): 2037-2053.

Mozaffarian, D., Kamineni, A., Carnethon, M., Djousse, L., Mukamal, K. J., \& Siscovick, D. (2009). "Lifestyle Risk Factors and New-Onset Diabetes Mellitus in Older Adults." Archives of Internal Medicine 169(8): 798-807.

Muennig, P., Jia, H., Lee, R., \& Lubetkin. E. (2008). "I Think Therefore I Am: Perceived Ideal Weight as a Determinant of Health." American Journal of Public Health 98(3): 501-506.

Muukkonen, M. (2009). "Framing the Field: Civil Society and Related Concepts." Nonprofit and Voluntary Sector Quarterly 38(4): 684-700.

Myers, J. (2013). Food-stamp Pie Sliced. The Oregonian. Portland, OR.

Naples, N. (2003). Feminism and Method: Ethnography, Discourse Analysis, and Activist Research. New York, Routledge.

National Policy and Legal Analysis Network to Prevent Childhood Obesity (2013). Toward a Sustainable Model for Small-Scale Healthy Food Retail, National Policy and Legal Analysis Network to Prevent Childhood Obesity.

Nayga, J., R. M. \& Weinberg, Z. (1999). "Supermarket Access in the Inner Cities." Journal of Retailing and Consumer Services 6(3): 141-145.

Nevarez, L., Tobin, K., \& Walternaurer, E. (2016). "Food Acquisition in Poughkeepsie, NY." Food, Culture \& Society 19(1): 19-44.

Ng, M., Fleming, T., Robinson, M., Thomson, B., Graetz, N., Margono, C., ... Ammar, W. (2014). "Global, Regional, and National Prevalence of Overweight and Obesity in Children and Adults during 1980-2013: A Systematic Analysis for the Global Burden of Disease Study 2013." Lancet 384(9945): 766-781.

Nicolopoulou, K., Lucas, I., Tatli, A., Karatas-Ozkan, K., Costanzo, L. A., Ozbilgin, M., \& Manville, G. (2015). "Questioning the Legitimacy of Social Enterprises through Gramscian and Bourdieusian Perspectives: The Case of British Social Enterprises." Journal of Social Entrepreneurship 6(2): 161-185.

Nie, C. \& Zepeda, L. (2011). "Lifestyle Segmentation of US Food Shoppers to Examine Organic and Local Food Consumption." Appetite 57: 28-37. 
Nilsson, E., Jansson, P. A., Perfilyev, A., Volkov, P. Pedersen, M., Svensson, M., ... Ling, C. (2014). "Altered DNA Methylation and Differential Expression of Genes Influencing Metabolism and Inflammation in Adipose Tissue from Subjects with Type 2 Diabetes." Diabetes 63: 2962-2976.

Nixon, R. (2014). Senate Passes Long-Stalled Farm Bill, With Clear Winners and Losers. New York Times. New York, New York.

Nobrega, S., Champagne, N., Abreu, M., Goldstein-Gelb, M., Montano, M., Lopez, I., ... Punnett, L. (2016). "Obesity/Overweight and the Role of Working Conditions: A Qualitative, Participatory Investigation." Health Promotion Practice 17(1): 127-136.

Nord, M., Coleman-Jensen, A. C., Andrews, M., \& Carlson, S. (2010). Household Food Security in the United States, 2009, United States Department of Agriculture.

Norgaard, K. M., Reed, R., \& Van Horn, C. (2011). A Continuing Legacy: Institutional Racism, Hunger, and Nutritional Justice on the Klamath. Cultivating Food Justice. A. H. Alkon and J. Agyeman. Cambridge, MA, MIT Press.

Nyberg, S. T., Fransson, E. I., Heikkila, K., Ahola, K., Alfredsson, L., Bjorner, J. B., ... Kivimaki, M. (2014). "Job Strain as a Risk Factor for Type 2 Diabetes: A Pooled Analysis of 124,808 Men and Women." Diabetes Care 37(2268-2275).

O'Connor, A. (2002). Poverty Knowledge. Princeton, Princeton University Press.

O'Malley, K., Gustat, J., Rice, J., \& Johnson, C. C. (2013). "Feasibility of Increasing Access to Healthy Foods in Neighborhood Corner Stores." Journal of Community Health 38: 741-749.

Odegaard, A. O., Jacobs Jr., D. R., Steffen, L. M., Van Horn, L., Ludwig, D. S., \& Pereira, M. A. (2013). "Breakfast Frequency and Development of Metabolic Risk." Diabetes Care 36: 3100-3106.

Ogden, C. L., Carroll, M., Kit, B. K., \& Flegal, K. M. (2014). "Prevalence of Childhood and Adult Obesity in the United States, 2011-2012." Journal of the American Medical Association 311(8): 806-814.

Ogden, C. L. \& Carroll, M. D. (2010). Prevalence of Overweight, Obesity, and Extremem Obesity Among Adults: United States, Trends 1976-1980 Through 2007-2008, National Center for Health Statistics.

Ogden, C. L., Carroll, M. D., Curtin, L. R., Lamb, M. M., \& Flegal, K. M. (2006). "Prevalence of Overweight and Obesity in the United States, 1999-2004." JAMA: The Journal of the American Medical Association 295(13): 1549-1555. 
Ohana, M., Meyer, M., \& Swaton, S. (2012). "Decision-Making in Social Enterprises: Exploring the Link between Employee Participation and Organizational Commitment." Nonprofit and Voluntary Sector Quarterly 42(6): 1092-1110.

Olsson, A. H., Volkov, P., Bacos, K., Bacos, K., Dayeh, T., Hall, E., ... Ling, C. (2014). "Genome-Wide Associations between Genetic and Epigenetic Variation Influence mRNA Expression and Insulin Secretion in Human Pancreatic Islets." PLoS Genetics 10(11).

Omi, M. \& Winant, H. (1986). Racial Formation in the United States: From the 1960s to teh 1980s. New York, Routledge.

Orbach, S. (2006). "Commentary: There is a Public Health Crisis - It's Not Fat on the Body but Fat in the Mind and the Fat of Profit." International Journal of Epidemiology 35(1): 67-69.

Oregon Center for Public Policy (2015). Hunger and Food Insecurity Rise in Oregon, Despite Economic Recovery. Silverton, OR, Oregon Center for Public Policy.

Oregon Center for Public Policy (2015). Poverty in Oregon in Six Charts. Silverton, OR, Oregon Center for Public Policy.

Oregon Food Bank (2008). Profiles of Hunger and Poverty in Oregon: 2008 Oregon Hunger Factors Assessment, Oregon Food Bank.

Ortega, A. N., Albert, S. L., Sharif, M. Z., Langellier, B. A., Garcia, R. E., Glik, D. C., ... Prelip, M. L. (2015). "Proyecto MercadoFRESCO: A Multi-level, CommunityEngaged Corner Store Intervention in East Los Angeles and Boyle Heights." Journal of Community Health 40: 347-356.

Ortega, F. B., Lee, D., Katzmarzyk, P. T., Ruiz, J. R., Sui, X., Church, T. S., \& Blair, S. N. (2013). " The Intriguing Metabolically Helathy But Obese Phenotype: Cardiovascular Prognosis and Role of Fitness." European Heart Journal 34(5): 389397.

Ortega-Montiel, J., Posadas-Romero, C., Ocampo-Arcos, W., Medina-Urrutia, A., Cardoso-Saldana, G., Jorge-Galarza, E., \& Posadas-Sanchez, R. (2015). "SelfPerceived Stress is Associated with Adiposity and Atherosclerosis. The GEA Study." BMC Public Health 15(780).

Owens, K. D. (2012). The Social Construction of a Public/Private Neighborhood: Examining Neighbor Interaction and Neighborhood Meaning in a New Orleans Mixed-Income Development. Urban Studies. New Orleans, LA, University of New Orleans. PhD. 
Paddock, J. (2014). "Invoking Simplicity: 'Alternative' Food and the Reinvention of Distinction." Sociologia Ruralis 55(1).

Palmas, W., Teresi, J. A., Findley, S., Mejia, M., Batista, M., Kong, J., ... Carrasquillo, O. (2012). "Protocol for the Northern Manhattan Diabetes Commnity Outreach Project. A Randomized Trial of a Community Health Worker Intervention to Improve Diabetes Care in Hispanic Adults." BMJ Open 2(2).

Papan, A. S. \& Clow, B. (2015). "The Food Insecurity-Obesity Paradox as a Vicious Cycle for Women: Inequalities and Health." Gender and Development 23(2): 299317.

Parker, K. F. \& Pruitt, M. V. (2000). "Poverty, Poverty Concentration, and Homicide." Social Science Quarterly 81(2): 555-570.

Parks, C. (2014). Good Health Grows Here. The Oregonian. Portland, OR.

Patel, R. (2009). "What Does Food Sovereignty Look Like." The Journal of Peasant Studies 36(3): 663-706.

Pearson, T., Russell, J., Campbell, M. J., \& Barker, M. E. (2005). "Do 'Food Deserts' Influence Fruit and Vegetable Consumption? - A Cross-Sectional Study." Appetite 45: 195-197.

Peck, J. \& Tickell, A. (2002). "Neoliberalizing Space." Antipode 34(3): 380-404.

Peckett, A. J., Wright, D. C., \& Riddell, M. C. (2011). "The Effects of Glucocorticoids on Adipose Tissue Lipid Metabolism." Metabolism 60: 1500-1510.

Peirce, N. \& Steinbach, C. (1987). Corrective Capitalism: The Rise of America's Community Development Corporations. New York, The Ford Foundation.

Penney, T. L. \& Kirk, S. F. L. (2015). "The Health at Every Size Paradigm and Obesity: Missing Empirical Evidence May Help Push the Reframing Obesity Debate Forward." American Journal of Public Health 105(5): e38-e42.

People's Coop. (2016). "People's History." Retrieved February 18, 2016, 2016, from http://www.peoples.coop/peoples-history/.

Perez, A. H. (2007). Between Radical Theory and Community Praxis: Reflections on Organizing and the Non-Profit Industrial Complex. The Revolution Will Not Be Funded: Beyond the Non-Profit Industrial Complex. I. W. o. C. A. Violence. Cambridge, MA, South End Press. 
Perez-Escamilla, R., Damio, G., Chhabra, J., Fernandez, M. L., Segura-Perez, S., VegaLopez, S., ... D'Agostino, D. (2015). "Impact of a Community Health Workers-Led Structured Program on Blood Glucose Control Among Latinos with Type 2 Diabetes: The DIALBEST Trial." Diabetes Care 38: 107-205.

Pitt, C. E. (2016). "Cutting through the Paleo Hype: The Evidence for the Paleolithic Diet." Australian Family Physician 45(1-2): 35-38.

Piven, F. F. \& Cloward, R. (1993). Regulating the Poor: The Functions of Public Welfare, 2nd edition. New York, Vintage Books.

Pleasant, L. (2015). After Decades in a Food Desert, These Neighbors Are Building a \$2 Million Co-op - And They Own It. Yes Magazine.

Pollan, M. (2006). The Omnivore's Dilemma. London, Bloomsbury Publishing.

Pollan, M. (2009). Food Rules. New York, NY, Penguin Books.

Popkin, S. J., Katz, B., Cunningham, M. K., Brown, K. D., Gustafson, J., \& Turner, M. A. (2004). A Decade of HOPE VI: Research Findings and Policy Changes. Washington, D.C., The Urban Institute.

Portland, City of. (2002). Adopted Portsmouth Neighborhood Plan: Walking Together. Bureau of Planning. Portland, OR.

Portland, City of (2012). Prosperous. Educated. Healthy. Equitable. The Portland Plan. Portland, OR.

Pothukuchi, K. (2004). "Community Food Assessment: A First Step in Planning for Community Food Security." Journal of Planning Education and Research 23: 356377.

Public Health Law and Policy (2009). Healthy Corner Stores: The State of the Movement, Public Health Law and Policy.

Pudup, M. B. (2008). "It Takes a Garden: Cultivating Citizen-Subjects in Organized Garden Projects." Geoforum 39(3): 1228-1240.

Puhl, R., Peterson, J. L., \& Luedicke, J. (2013). "Motivating or Stigmatizing? Public Perceptions of Weight-Related Language Used by Health Providers." International Journal of Obesity 37: 612-619.

Raciti, G. A., Longo, M., Parrillo, L., Ciccarelli, M., Mirra, P., Ungaro, P., ... Beguinot, F. (2015). "Understanding Type 2 Diabetes: From Genetics to Epigenetics." Acta Diabetologica 52: 821-827. 
Raja, S., Ma, C., \& Yadav, P. (2008). "Beyond Food Deserts: Measuring and Mapping Racial Disparities in Neighborhood Food Environments." Journal of Planning Education and Research 27: 469-482.

Ramirez, M. (2009). Delridge Area's 'Food Desert' Gets Fruit, Veggie Oasis. Seattle Times. Seattle, WA.

Ramirez, M. M. (2015). "The Elusive Inclusive: Black Food Geographies and Racialized Food Spaces." Antipode 47(3): 748-769.

Ravussin, E., Valencia, M. E., Esparza, J., Bennett, P. H., \& Schulz, L. O. (1994). "Effects of a Traditional Lifestyle on Obesity in Pima Indians." Diabetes Care 17(9): 1067-1074.

Rayner, C. K., Talley, N. J., \& Horowitz, M. (2012). "Stomach Bugs and Diabetes: An Astounding Observation or Just Confounding?" Diabetes Care 35: 463-646.

Read, R. (2011). The State of Oregon: Hungry. The Oregonian. Portland, OR.

Robbins, J., Vaccarino, V., Zhang, H., \& Kasl, S. (2001). "Socioeconomic Status and Type 2 Diabetes in African American and Non-Hispanic White Women and Men: Evidence from the Third National Health and Nutrition Examination Survey." American Journal of Public Health 91(1): 76-83.

Roccisano, D. \& Henneberg, M. (2012). "Soy Consumption and Obesity." Food and Nutrition Sciences 3(2): 260-266.

Rock, M. (2005). "Diabetes Portrayals in North America Print Media: A Qualitative and Quantitative Analysis." American Journal of Public Health 95(10): 1832-1838.

Rodriguez, A. C. I., Epel, E. S., White, M. L., Standen, E. C., Seckl, J. R., \& Tomiyama, A. J. (2015). "Hypothalamic-Pituitary-Adrenal Axis Dysregulation and Cortisol Activity in Obesity: A Systemic Review." Psychoneuroendocrinology 62: 301-318.

Rodriguez, D. (2007). The Political Logic of the Non-Profit Industrial Complex. The Revolution Will Not Be Funded: Beyond the Non-Profit Industrial Complex. I. W. o. C. A. Violence. Cambridge, MA, South End Press.

Rosenberg, K. (2008). From Moderate Chastisement to Mandatory Arrest: Responses to Violence against Women in Canada and the United States. Women's Studies. Seattle, University of Washington. PhD.

Rosset, P. (2008). "Food Sovereignty and the Contemporary Food Crisis." Development 51(4): 460-463. 
Roy, P. (2011). "Non-profit and Community-based Green Space Production in Milwaukee: Maintaining a Counter-weight within Neo-liberal Urban Environmental Governance." Space and Polity 15(2): 87-105.

Roy, T. \& Lloyd, C. E. (2012). "Epidemiology of Depression and Diabetes: A systematic Review." Journal of Affective Disorders 142(S1): S8-S21.

Ruiz-Varvaez, E. A., Palmer, J. R., Gerlovin, H., Wise, L., Vimalananda, V. G., Rosenzweig, J. L., \& Rosenberg, L. (2014). "Birth Weight and Risk of Type 2 Diabetes in the Black Women's Health Study: Does Adult BMI Play a Mediating Role." Diabetes Care 37: 2572-2578.

Rummo, P. E., Meyer, K. A., Boone-Heinonen, J., Jacobs, D. R., Kiefe, C., Lewis, C. E., ... Gordon-Larsen, P. (2015). "Neighborhood Availability of Convenience Stores and Diet Quality: Findings from 20 Years of Follow-Up in the Coronary Artery Risk Development in Young Adults Study." American Journal of Public Health 105(5): e65-e73.

Russell, S. E. \& Heidkamp, C. P. (2011). "'Food Desertification': The Loss of a Major Supermarket in New Haven, Connecticut." Applied Geography 31: 1197-1209.

Sachs, C. \& Patel-Campillo, A. (2014). "Feminist Food Justice: Crafting a New Vision." Feminist Studies 40(2): 396-410.

Sampson, R. J. (2003). "The Neighborhood Context of Well-Being." Perspectives in Biology and Medicine 46(3): S53-S64.

Sanderson, P. R., Little, M., Vasquez, M. M., Lomadafkie, B., Brings Him Back, J. M., Trujillo, O. V., ... Bounds, R. (2012). "A Perspective on Diabetes from Indigenous Views." Fourth World Journal 11(2): 57-78.

Sandoval, C. (2000). Methodology of the Oppressed. Minneapolis, University of Minnesota Press.

Sarasohn, D. (2011). Shadow of Empty Plates. The Oregonian. Portland, OR.

Sarasohn, D. (2012). A Hunger for Facing Oregon's Most Basic Issue. The Oregonian. Portland, OR.

Sato, P., Gittelsohn, J., Unsain, R. F., Roble, O. J., \& Scagliusi, F. B. (2016). "The use of Pierre Bourdieu's Distinction Concepts in Scientific Articles Studying Food and Eating: A Narrative Review." Appetite 96: 174-186. 
Saul, N. \& Curtis, A. (2013). The Stop: How the Fight for Good Food Transformed a Community and Inspired a Movement. Brooklyn, NY, Melville House Publishing.

Savoye, M., Caprio, S., Dziura, J., Camp, A., Germain, G., Summers, C., ... Tamborlane, W. V. (2014). "Reversal of Early Abnormalities in Glucose Metabolism in Obese Youth: Results of an Intensive Lifestyle Randomized Controlled Trial." Diabetes Care 37: 317-324.

Small Business Administration (2012). Small Business Facts. Small Business Administration. Washington, DC.

Sbicca, J. (2012). "Growing Food Justice by Planting and Anti-Oppression Foundation: Opportunities and Obstacles for a Budding Movement." Agriculture and Human Values 29(4): 455-466.

Sbicca, J. (2014). "The Need to Feed: Urban Metabolic Struggles of Actually Existing Radical Projects." Critical Sociology 40(6): 817-834.

Schafer, M. H. \& Ferraro, K. F. (2011). "The Stigma of Obesity: Does Perceived Weight Discrimination Affect Identity and Physical Health?" Social Psychology Quarterly 74(1): 76-97.

Schlosser, E. (2001). Fast Food Nation: The Dark Side of the American Meal. Boston, MA, Houghton-Mifflin.

Schneiderman, N., Llabre, M., Cowie, C. C., Barnhart, J., Carnethon, M., Gallo, L. C., ... Aviles-Santa, M. L. (2014). "Prevalence of Diabetes Among Hispanics/Latinos From Diverse Backgrounds: The Hispanic Community Health Study/Study of Latinos (HCHS/SOL)." Diabetes Care 37: 2233-2239.

Schulz, L. O., Bennett, P. H., Ravussin, E., Kidd, J. R., Kidd, K. K., Esparza, J., \& Valencia, M. E. (2006). "Effects of Traditional and Western Environments on Prevalence of Type 2 Diabetes in Pima Indians in Mexico and the U. S." Diabetes Care 29(8): 1866-1871.

Scott, J. W. (1986). "Gender: A Useful Category of Historical Analysis." The American Historical Review 91(5): 1053-1075.

Seaberry, E. (2014). USDA Report: 15\% of Oregon Families Food Insecure. Partners for a Hunger-Free Oregon. 2016.

Sepulveda, L. (2015). "Social Enterprise - A New Phenomenon in the Field of Economic and Social Welfare?" Social Policy and Administration 49(7): 842-861. 
Shaffer, A. (2002). The Persistence of L.A.'s Grocery Gap: The Need for a New Food Policy and Approach to Market Development. Los Angeles, Center for Food and Justice, Occidental College.

Shaffer, R., Deller, S., \& Marcouiller, D. (2006). "Rethinking Community Economic Development." Economic Development Quarterly 10(1): 59-74.

Shannon, J. (2014). "Food Deserts: Governing Obesity in the Neoliberal City." Progress in Human Geography 38(2): 248-266.

Shannon, J. (2014). "What Does SNAP Benefit Usage Tell Us about Food Access in Low-Income Neighborhoods." Social Science \& Medicine 107: 89-99.

Shaw, H. (2006). "Food Deserts: Towards the Development of a Classification." Geografiska Annaler: Series B, Human Geography 88: 231-247.

Shiva, V. (2011). Food \& Seed Sovereignty: Creating a People's Food System. Food Justice, Eugene, OR.

Short, A., Guthman, J., \& Raskin, S. (2007). "Food Deserts, Oases or Mirages?: Small Markets and Community Food Security in the San Francisco Bay Area." Journal of Planning Education and Research 26: 352-364.

Shum, H. (2008). The New Corner Grocers. The Oregonian. Portland, OR.

Slocum, R. (2007). "Whiteness, Space and Alternative Food Practice." Geoforum 38(3): 520-533.

Smith, B. R., Cronley, M. L., \& Barr, T. F. (2012). "Funding Implications of Social Enterprise: The Role of Mission Consistency, Entrepreneurial Competence, and Attitude toward Social Enterprise on Donor Behavior." Journal of Public Policy \& Marketing 31(1): 142-157.

Smith, B. R., Knapp, J., Barr, T. F., Stevens, C. E., \& Cannatelli, B. L. (2010). "Social Enterprises and the Timing of Conception: Organizational Identity, Tension, Management, and Marketing." Journal of Nonprofit and Public Sector Marketing 22: 108-134.

Smith, B. T., Lynch, J. W., Fox, C. S., Harper, S., Abrahamowicz, M., Almeida, N. D., \& Loucks, E. B. (2011). "Life-Course Socioeconomic Position and Type 2 Diabetes Mellitus: The Framingham Offspring Study." American Journal of Epidemiology 173(4): 438-447.

Smith, D. (1987). The Everyday World as Problematic: A Feminist Sociology. Boston, Northeastern University Press. 
Smith, D. (1999). Writing the Social. Toronto, University of Toronto Press.

Smith, T. M., Colon-Ramos, U., Pinard, C. A., \& Yaroch, A. L. (2015). "Household Food Insecurity as a Determinant of Overweight and Obesity among Low-Income Hispanic Subgroups: Data from the 2011-2012 California Health Interview Survey." Appetite 97: $37-42$.

Smith, W. K., Besharov, M., Wessels, A. K., \& Chertok, M. (2012). "A Paradoxical Leadership Model for Social Entrepreneurs: Challenges, Leadership Skills, and Pedagogical Tools for Managing Social and Commercial Demands." Academy of Management Learning and Education 11(3): 463-478.

Smith, W. K., Gonin, M., \& Besharov, M. L. (2013). "Managing Social-Business Tensions: A Review and Research Agenda for Social Enterprise." Business Ethics Quarterly 23(3): 407-422.

Sobngwi, E., Mauvais-Jarvis, F., Vexiau, P., Mbanya, J., \& Gautier, J. F. (2002). "Diabetes in Africans." Diabetes Metabolism 28: 5-12.

Social Enterprise Alliance. (2010). Succeeding at Social Enterprise: Hard-won Lessons for Non-profits and Social Entrepreneurs. San Francisco, CA, Jossey-Bass.

Social Enterprise Knowledge Network. (2006). Effective Management of Social Enterprise. Cambridge, MA, Harvard University Press.

Song, H., Gittelsohn, J., Kim, M. Suratkar, S., Sharma, S., \& Anliker, J. (2009). "A Corner Store Intervention in a Low-income Urban Community is Associated with Increased Availability and Sales of Some Healthy Foods." Public Health Nutrition 12(11): 2060-2067.

Song, H., Gittelsohn, J., Kim, M., Suratkar, S., Sharma, S., \& Anliker, J. (2010). "Korean-American Storeowners' Perceived Barriers and Motivators for Implementing a Corner Store-Based Program." Health Promotion Practice.

Sparks, A., Bania, N., \& Leete, L. (2009). Finding Food Deserts: Methodology and Measurement of Food Access in Portland, Oregon. National Poverty Center/USDA Economic Research Service Research Conference. Washington, D. C.

Stein, C. J. \& Colditz, G. A. (2004). "The Epidemic of Obesity." Journal of Clinical Endocrinology and Metabolism 89(6): 2522-2525.

Stenvinkel, P. (2015). "Obesity - a Disease with Many Aetiologies Disguised in the Same Oversized Phenotype: Has the Overeating Theory Failed?" Nephrology Dialysis Transplant 30: 1656-1664. 
Stevens, G. A., Singh, G. M., Lu, Y., Danaei, G., Lin, J. K., Finucane, M. M., ... Ezzati, M. (2012). "National, Regional, and Global Trends in Adult Overweight and Obesity Prevalence." Population Health Metrics 10: 22-37.

Stiefvater, E. (2001). Entrepreneurial Community Development: Exploring EarnedIncome Activities and Strategic Alliances for Community-Development Nonprofits. Cambridge, MA, Joint Center for Housing Studies of Harvard University/Neighborhood Reinvestment Corporation.

Street Roots (2013). Oregon's Deep Poverty at Great Recession Levels. Street Roots. Portland, OR.

Stuff, J. E., Casey, P. H., Szeto, K. L., Gossett, J. M., Robbins, J. M., Simpson, P. M., ... Bogle, M. L. (2004). "Household Food Insecurity Is Associated with Adult Health Status." The Journal of Nutrition 134: 2330-2335.

Subramanian, S. V., Belli, P., \& Kawachi, I. (2002). "The Macroeconomic Determinants of Health." 23 (287-302).

Sum, A. \& Khatiwada, I. (2009). The Great Recession of 2007-2009: Its Post-World War II Record Impacts on Rising Unemployment and Underutilization Problems among U.S. Workers. Boston, MA, Center for Labor Market Studies, Northeastern University.

Sun, Q., Wedick, N. M., Pan, A., Townsend, M. K., Cassidy, A., Franke, A. A., ... van Dam, R. M. (2014). "Gut Microbia Metabolites of Dietary Lignans and Risk of Type 2 Diabetes: A Prospective Investigation in Two Cohorts of U.S. Women." Diabetes Care 37: 1287-1295.

Swart, C. (2012). Nonprofit Grocery Store in North Portland's New Columbia Turns 1, Learns To Adjust. The Oregonian. Portland, OR.

Tach, L. M. (2010). Beyond Concentrated Poverty: The Social and Temporal Dynamics of Mixed-Income Neighborhoods. Sociology and Social Policy. Cambridge, MA, Harvard. Ph.D.: 302.

Tarasuk, V., Mitchell, A., McLaren, L., \& McIntyre, L. (2013). "Chronic Physical and Mental Health Conditions among Adults May Increase Vulnerability to Household Food Insecurity." The Journal of Nutrition 143: 1785-1793.

Teasdale, S. (2010). "How Can Social Enterprise Address Disadvantage? Evidence from an Inner City Community." Journal of Nonprofit \& Public Sector Marketing 22(2): 89-107. 
The White House Office of Communications. (2010) Obama Administration Details Healthy Food Financing Initiative.

Thomas, D. (2003). "A Study on the Mineral Depletion of the Foods Available to Us as a Nation over the Period 1940 to 1991." Nutrition and Health 17: 85-115.

Tivadar, B. \& Luthar, B. (2005). "Food, Ethics, and Aesthetics." Appetite 44: 215-233.

Tomas Carpi, J. A. (1997). "The Prospects for the Social Economy in a Changing World." Annals of Public and Cooperative Economics 68(2): 247-279.

Tomlinson, M. (2003). "Lifestyle and Social Class." European Sociological Review 19(1): 97-111.

Tremblay, A. \& Chaput, J. (2012). "Obesity: The Allostatic Load of Weight Loss Dieting." Physiology \& Behavior 106: 16-21.

Treuhaft, S. \& Karpyn, A. (2009). The Grocery Gap: Who Has Access to Healthy Food and Why It Matters, Policy Link and The Food Trust.

Trudeau, D. (2008). "Junior Partner or Empowered Community? The Role of Non-profit Social Service Providers amidst State Restructuring in the US." Urban Studies 45(13): 2805-2827.

Tuckman, B. (1965). "Development Sequence in Small Groups." Psychological Bulletin 63(6): 384-399.

Turner, K. L. (2014). How The Other Half Ate: A History of Working-Class Meals at the Turn of the Century. Berkeley, CA, University of California Press.

United States Department of Agriculture (2015). 2015-2020 Dietary Guidelines for Americans. 8th Edition. U. S. D. o. Agriculture. Washington, D.C.

Urban League of Portland (2015). State of Black Oregon 2015. Portland, OR, Urban League of Portland.

Vafaelmanesh, J., Parham, M., \& Bagherzadeh, M. (2015). "Helicobacter Pylori Infection Prevalence: Is It Different in Diabetics and Non-Diabetics?" Indian Journal of Endocrinology Metabolism 19(3): 364-368.

Vale, L. J. (1999). "The Future of Planned Poverty: Redeveloping America's Most Distressed Public Housing Projects." Netherlands Journal of Housing and the Built Environment 14(1): 13-31. 
Vasquez, V. B., Lanza, D., Hennessey-Lavery, S., Halpin, S., \& Minkler, M. (2007). "Addressing Food Security through Public Policy Action in a Community-Based Participatory Research Partnership." Health Promotion Practice 8(4): 342-349.

Vehik, K. \& Dabelea, D. (2011). "The Changing Epidemiology of Type 1 Diabetes: Why Is It Going through the Roof?" Diabetes Metabolism Research and Reviews 27(3): 313.

Village Gardens. (2016). "About Us I Village Gardens." Retrieved February 8, 2016, from http://villagegardens.org/about/.

Virtanen, M., Ferrie, J. E., Tabak, A. G., Akbaraly, Tasnime, Vahtera, J., Singh-Manoux, A., \& Kvimaki, M. (2014). "Psychological Distress and Incidence of Type 2 Diabetes in High-Risk and Low-Risk Populations: The Whitehall II Cohort Study." Diabetes Care 37: 2091-2097.

von Hippel, P. \& Benson, R. (2014). "Obesity and the Natural Environment across U.S. Counties." American Journal of Public Health 104(7): 1287-1293.

Voss, J. D., Masuoka, P., Webber, B. J., Scher, A., \& Atkins, R. L. (2013). "Association of Elevation, Urbanization and Ambient Temperature with Obesity Prevalence in the United States." International Journal of Obesity 2013(37).

Waldroupe, A. (2011). Making Portland's Complex Food Deserts Grow Green. Street Roots. Portland, OR.

Walker, R., Block, J., \& Kawachi, I. (2012). "Do Residents of Food Deserts Express Different Food Buying Preferences Compared to Residents of Food Oases? A Mixedmethods Analysis." International Journal of Behavioral Nutrition and Physical Activity 9(41).

Walker, R. E., Keane, C. R., \& Burke, J. G. (2010). "Disparities and Access to Healthy Food in the United States: A Review of Food Deserts Literature." Health and Place 16: $876-884$.

Walton, E. (2014). "Vital Places: Facilitators of Behavioral and Social Health Mechanisms in Low-income Neighborhoods." Social Science \& Medicine 122: 1-12.

Wang, Y. \& Beydoun, M. A. (2007). "The Obesity Epidemic in the United States Gender, Age, Socioeconomic, Racial/Ethnic, and Geographic Characteristics: A Systematic Review and Meta-Regression Analysis." Epidemiologic Reviews 29: 628. 
Wang, Y., Beydoun, M. A., Liang, L, Caballero, B., Kumanyika, \& S. K. (2008). "Will All Americans Become Overweight or Obese? Estimating the Progression and Cost of the US Obesity Epidemic." Obesity 16: 2323-2330.

Wang, Y.\& Lobstein, T. (2006). "Worldwide Trends in Childhood Overweight and Obesity." International Journal of Pediatric Obesity 1(1): 11-25.

Waring, M. (1988). If Women Counted: A New Feminist Economics. London, Macmillan.

Warr, D. J., Mann, R., \& Kelaher, M. (2013). "'A lot of the things we do ... people wouldn't recognize as health promotion': Addressing Health Inequalities in Settings of Neighborhood Disadvantage." Critical Public Health 23(1): 95-109.

Waterland, R. A. (2014). "Epigenetic Mechanisms Affecting Regulation of Energy Balance: Many Questions, Few Answers." Annual Review of Nutrition 34: 337-355.

Weatherspoon, D., Oehmke, J., Coleman, M. A., \& Weatherspoon, L. (2014). "Understanding Consumer Preference for Nutritious Foods: Retailing Strategies in a Food Desert." International Food and Agribusiness Management Review 17(A): 6182 .

Weatherspoon, D., Oehmke, J., Dembele, A., Coleman, M., Satimanon, T. \& Weatherspoon, L. (2013). "Price and Expenditure Elasticities for Fresh Fruits in an Urban Food Desert." Urban Studies 50(1): 88-106.

Weatherspoon, D., Oehmke, J., Dembele, A., \& Weatherspoon, L. (2014). "Fresh Vegetable Demand Behavior in an Urban Food Desert." Urban Studies 52(5): 960 979.

Wedick, N., Ma, Y., Olendzki, B., Procter-Gray, E., Cheng, J., Kane, K. J., ...Li, W. (2015). "Access to Healthy Food Stores Modifies Effect of a Dietary Intervention." American Journal of Preventive Medicine 48(3): 309-317.

Wekerle, G. R. (2004). "Food Justice Movements: Policy, Planning, and Networks." Journal of Planning Education and Research 23: 378-386.

Wells, J. C. K. (2006). "The Evolution of Human Fatness and Susceptibility to Obesity: An Ethological Approach." Biological Reviews of the Cambridge Philsophical Society 81(2): 183-205.

Wells, J. C. K. (2012). "The Evolution of Human Adiposity and Obesity: Where Did It All Go Wrong?" Disease Models \& Mechanisms 5: 595-607. 
Westley, R. L. \& May, F. E. B. (2013). "A Twenty-First Century Cancer Epidemic Caused by Obesity: The Involvement of Insulin, Diabetes, and Insulin-Like Growth Factors." International Journal of Endocrinology 2013.

White, J. (2012). "'Hearing the Voices": African American Nutrition Educators Speak about Racism in Dietetics." Journal of Critical Dietetics 1(3): 26-35.

Widener, M. J., Metcalf, S. S., \& Bar-Yam, Y. (2011). "Dynamic Urban Food Environments: A Temporal Analysis of Access to Healthy Foods." American Journal of Preventive Medicine 41(4): 439-441.

Widener, M. J. \& Shannon, J. (2014). "When Are Food Deserts? Integrating Time into Research on Food Accessibility." Health and Place 30: 1-3.

Wiggins, N., Johnson, D., Avila, M., Farquhar, S. A., Michael, Y. L., Rios, T., \& Lopez, A. (2009). "Using Popular Education for Community Empowerment: Perspectives of Community Health Workers in the Poder es Salud/Power for Health Program." Critical Public Health 19(1): 11-22.

Wilde, P. E. \& Llobrera, J. (2009). "Using the Thrifty Food Plan to Assess the Cost of a Nutritious Diet." The Journal of Consumer Affairs 43(2): 274-304.

Wills, W., Backett-Milburn, K., Roberts, M., \& Lawton, J. (2011). "The Framing of Social Class Distinctions through Family Food and Eating Practices." The Sociological Review 59(4): 725-740.

Wilson, W. J. (1987). The Truly Disadvantaged: The Inner City, the Underclass, and Public Policy. Chicago, University of Chicago Press.

Winne, M. (2004). Community Food Security: Promoting Food Security and Building Healthy Food Systems. Portland, Community Food Security Coalition.

Winson, A. (2004). "Bringing Political Economy into the Debate on the Obesity Epidemic." Agriculture and Human Values 21: 299-312.

Wolch, J. (1990). The Shadow State: Government and Voluntary Sector in Transition. New York, NY, Foundation Center.

Woodward-Lopez, G., Kao, J., \& Ritchie, L. (2010). "To What Extent Have Sweetened Beverages Contributed to the Obestiy Epidemic." Public Health Nutrition 14(3): 499509.

Woolford, A. \& Curran, A. (2012). "Community Positions, Neoliberal Dispositions: Managing Nonprofit Social Services within the Bureaucratic Field." Critical Sociology 39(1): 45-63. 
Wrigley, N. (1999). "Market Rules and Spatial Outcomes: Insights from the Corporate Restructuring of U.S. Food Retailing." Geographical Analysis 31(3).

Wrigley, N., Warm, D., Margetts, B., \& Whelan, A. (2002). "Assessing the Impact of Improved Retail Access on Diet in a 'Food Desert': A Preliminary Report." Urban Studies 39(11): 2061-2082.

Young, A. (2015). Oregon Economy: Who Wins? The Skanner. Portland, OR.

Young, D. \& Lecy, J. D. (2014). "Defining the Universe of Social Enterprise: Competing Metaphors." Voluntas 25: 1307-1332.

Young, D. R. (2012). The State of Theory and Research on Social Enterprises. Social Enterprises: An Organizational Perspective. B. Gidron and Y. Hasenfeld. New York, NY, Palgrave MacMillan.

Zachary, D. A., Palmer, A. M., Beckham, S. W., \& Surkan, P. J. (2013). "A Framework for Understanding Grocery Purchasing in a Low-Income Urban Environment." Qualitative Health Research 23(5): 665-678.

Zelizer, V. (1994). The Social Meaning of Money: Pin Money, Paychecks, Poor Relief, and Other Currencies. New York, Basic Books.

Zenk, S. N., Schulz, A. J., Matthews, S. A., Odoms-Young, A., Wilbur, J., Wegrzyn, L, ... Stokes, C. (2011). "Activity Space Environment and Dietary and Physical Activity Behaviors: A Pilot Study." Health \& Place 17: 1150-1161.

Zhang, D., Fu, M., Gao, S., \& Liu, J. (2013). "Curcumin and Diabetes: A Systematic Review." Evidence-Based Complementary and Alternative Medicine 2013.

Zheng, Y. (2013). Families Line Up for Food Boxes. The Oregonian. Portland, OR. 


\section{Appendix A: SAMPLE INTERVIEW QUESTIONS}

\section{Initial Open-ended Questions}

A. Could you describe how you are involved in the Village Market?

B. Tell me about how you got involved in the Village Market.

C. Tell me about how the Village Market got started.

D. Tell me about how Big City Produce came to New Columbia.

E. Could you describe for me your routine for getting groceries?

\section{Intermediate Questions}

A. Tell me about how the Village Market became a Healthy Corner Store.

B. Tell me about how the idea for doing Village Market as a nonprofit came about.

C. Could you talk about what you see as the pluses and minuses of doing the store as a nonprofit?

D. As you look back on the effort to get the Village Market open, what stands out for you?

E. Could you tell me about the business plan and how it has changed as this project has evolved?

F. I'd like to hear about the demographic research that went into planning the store.

G. Talk about the most important lessons you learned through participating in the opening of the Village Market.

H. Could you talk about your experience doing the marketing survey and what you learned from it?

I. I'd like to hear some of your thoughts about food. What is good food to you?

J. Can you share your thoughts about food justice?

$\mathrm{K}$. What does the phrase 'food justice' mean to you?

L. Could you share your thoughts about whether the Village Market has had any effect on food justice?

M. What about health? I'd like to hear about any aspects of you/your family's health that you worry about.

N. Could you share your thoughts about whether the Village Market has had any effect on health?

O. I'd like to hear about the wellness program and how that idea came about.

P. I'd like to hear about what you think of the Village Market.

Q. Could you tell me about the impacts that the Village Market has had on you?

R. As you look back on the presence of Big City Produce at New Columbia, what stands out for you?

S. Do you have any advice or suggestions for the people who are operating the Village Market?

\section{Ending Questions}

A. After having the experience of starting the Village Market, what advice would you give to someone else wanting to do something similar?

B. Is there anything else you think I should know about your food or health concerns? 
C. Is there anything else you think I should know to better understand how you feel about the Village Market?

D. Is there anything else you think I should know to better understand how the importance of the Village Market to the community?

E. Is there anything else you think I should know about Big City Produce and its tenure at New Columbia?

F. Is there anything you would like to ask me? 
Appendix B: FOCUS GROUP OUTLINE - GENERAL

0 . Have people serve themselves some food and come back to the table with it. Next, have them introduce themselves by giving their first name and a favorite food. (10 mins)

\section{Getting Acquainted}

(10 mins)

I'm going to use the phrase "good food" to talk about food that fits the way that you want to eat. I'm guessing this will be a little different for each of you. Let's start by having each of you give a little description of what "good food" is to YOU?

Probes if not mentioned or very little discussion, and time allows:

What are the things about it that make it good?

Where does it come from?

What goes into it?

Who makes it?

Who shares it with you?

What about health? How important is it that your food be healthy?

2. Topic 2: Food and Food Justice

(20 mins)

I'd like to dig a little deeper into the food discussion. I'd like to hear about the things that get in the way of you eating "good food". Remember, "good food" is food that YOU think is good.

Probes if not mentioned or very little discussion and time allows:

What things are hard for you about getting good food?

How hard is it for you to get groceries? Where do you go to get them?

What about cooking? Are there things that make it hard for you to cook?

What about cost? Are there things you would like to be eating that are just too expensive?

Are there things you would like to be better about how you eat? Tell me about those ...

What do you think you have a right to when it comes to food?

\section{Topic 3: The Village Market}

(20 mins)

I'd like to hear what you think about the Village Market ...

Probes if not mentioned or very little discussion, and time allows:

Do they have good food?

Do you ever go there? Why or why not?

What else? Who has a story to share about the Village Market?

Are there ways that it makes your life easier or harder?

What about the things in the store? Are there things that you wish it would have that it doesn't have or things that it has that you wish it wouldn't?

What about the prices?

How has its being there changed the neighborhood?

Break: Activity around life stressors

(15 mins) 
I'm going to give everyone a piece of paper and put some markers on the table. I'd like each of you to take $\mathbf{1 0}$ minutes to draw how important food is to you as compared to all of the other things that you have going on in your life.

\section{Topic 3: Discussion around Life Stressors}

(20 mins)

I'd like to talk more about the things in your life that are difficult for you other than food...

Probes if not mentioned or very little discussion and time allows:

What kinds of things do you worry about?

What things do you have to do that are hard for you?

What about health? Do you have any difficulties with your health?

What about money? Do you have a hard time making ends meet?

What about family? Do you have family responsibilities that sometimes make things difficult for you?

What else? What are some other things that sometimes make life hard for YOU?

5. Wrap up

(15 mins)

I'd like to finish up by asking each of you for any last thoughts that you think would help me understand your perspective on the things we've discussed today ...

\section{Questions}

Do you have any questions for me? 
Appendix C: FOCUS GROUP OUTLINE - IMMIGRANT \& REFUGEE GROUPS

0. Individual Stories Have people serve themselves some food and come back to the table. Have them introduce themselves (if they don't already know each other) and tell a little bit about how they came to this country and how life is different for them here than it was where they came from.

(25 mins)

\section{Food in Your Home}

(15 mins)

I'd like to hear each of you describe a typical meal in your household.

Probes if not mentioned or very little discussion:

Who is eating this meal with you?

What foods are you eating?

Who helps with the food preparation?

What else is important about meals in your household?

\section{Topic 2: Food Justice}

I'd like to hear about any difficulties you have with respect to food in your household.

Probes if not mentioned or very little discussion:

What foods are you not able to get or do you have difficulty getting?

What kinds of difficulties do you have getting enough food?

What challenges do you have with eating the way you want to eat?

Describe any difficulties you have with the American lifestyle when it comes to your family's meals

\section{Topic 3: The Village Market}

(20 mins)

I'd like to hear what you think about the Village Market ...

Probes if not mentioned or very little discussion, and time allows:

Do you ever go there? Why or why not?

What about the things in the store? Are there things that you wish it would have that it doesn't have or things that it has that you wish it wouldn't?

Are there ways that it makes your life easier or harder?

What about the prices?

How about the staff?

What else? Who has a story to share about the Village Market?

How has its being there changed the neighborhood?

\section{Questions}

Do you have any questions for me or the moderator?

(30 mins) 
Appendix D: FOOD REGIMES AND FOOD MOVEMENTS TYPOLOGY

\begin{tabular}{|c|c|c|c|c|}
\hline & \multicolumn{2}{|c|}{ Corporate Food Regime } & \multicolumn{2}{|c|}{ Food Movements } \\
\hline Politics & Neoliberal & Reformist & Progressive & Radical \\
\hline Discourse & Food Enterprise & Food Security & Food Justice & $\begin{array}{l}\text { Food } \\
\text { Sovereignty }\end{array}$ \\
\hline $\begin{array}{l}\text { Main } \\
\text { Institutions }\end{array}$ & $\begin{array}{l}\text { International } \\
\text { Finance } \\
\text { Corporation } \\
\text { (World Bank); } \\
\text { IMF; WTO; } \\
\text { USDA; Global } \\
\text { Food Security } \\
\text { Bill; }\end{array}$ & $\begin{array}{l}\text { International } \\
\text { Bank for } \\
\text { Reconstruction } \\
\text { and } \\
\text { Development } \\
\text { (World Bank); } \\
\text { FAO, } \\
\text { USDA(Merrigan } \\
\text { ); mainstream } \\
\text { fair trade; some } \\
\text { Slow Food } \\
\text { chapters; some } \\
\text { Food Policy } \\
\text { Councils; most } \\
\text { food banks and } \\
\text { food aid } \\
\text { programs }\end{array}$ & $\begin{array}{l}\text { Alternative fair } \\
\text { trade and many } \\
\text { Slow Food } \\
\text { chapters; many } \\
\text { organizations in } \\
\text { the Community } \\
\text { Food Security } \\
\text { Movement; } \\
\text { CSAs; many } \\
\text { Food Policy } \\
\text { Councils and } \\
\text { youth food and } \\
\text { justice } \\
\text { movements; } \\
\text { many } \\
\text { farmworker and } \\
\text { labor } \\
\text { organizations }\end{array}$ & $\begin{array}{l}\text { Via Campesina; } \\
\text { International } \\
\text { Planning } \\
\text { Committee on } \\
\text { Food } \\
\text { Sovereignty; } \\
\text { Global March } \\
\text { for Women; } \\
\text { many food } \\
\text { justice and } \\
\text { rights-based } \\
\text { movements }\end{array}$ \\
\hline Orientation & Corporate & Development & Empowerment & Entitlement \\
\hline Model & & $\begin{array}{l}\text { Niche market } \\
\text { certification } \\
\text { market-led land } \\
\text { reform }\end{array}$ & $\begin{array}{l}\text { Investment in } \\
\text { underserved } \\
\text { communities; } \\
\text { solidarity } \\
\text { economies; land } \\
\text { and food access }\end{array}$ & $\begin{array}{l}\text { Dismantling of } \\
\text { corporate } \\
\text { agrifood } \\
\text { monopolies; } \\
\text { redistributive } \\
\text { land reform; } \\
\text { community seed } \\
\text { and water } \\
\text { rights; } \\
\text { democratization } \\
\text { of the food } \\
\text { system }\end{array}$ \\
\hline
\end{tabular}




\begin{tabular}{|c|c|c|c|c|}
\hline & \multicolumn{2}{|c|}{ Corporate Food Regime } & \multicolumn{2}{|c|}{ Food Movements } \\
\hline $\begin{array}{l}\text { Approach } \\
\text { to the food } \\
\text { crisis }\end{array}$ & $\begin{array}{l}\text { increased } \\
\text { industrial } \\
\text { production; } \\
\text { unregulated } \\
\text { corporate } \\
\text { monopolies; } \\
\text { land grabs; } \\
\text { expansion of } \\
\text { GMOs; public- } \\
\text { private } \\
\text { partnerships; } \\
\text { liberal markets; } \\
\text { microenterprise; } \\
\text { GAFSPF - The } \\
\text { Global } \\
\text { Agriculture and } \\
\text { Food Security } \\
\text { Program }\end{array}$ & $\begin{array}{l}\text { same as } \\
\text { neoliberal but } \\
\text { with increased } \\
\text { middle peasant } \\
\text { production and } \\
\text { some locally- } \\
\text { sourced food aid; } \\
\text { microcredit; } \\
\text { more agricultural } \\
\text { aid, but tied to } \\
\text { GMOs and 'bio- } \\
\text { fortified/climate- } \\
\text { resistant' crops; } \\
\text { Comprehensive } \\
\text { Framework for } \\
\text { Action (CFA) }\end{array}$ & $\begin{array}{l}\text { right to food; } \\
\text { better safety } \\
\text { nets; } \\
\text { sustainably } \\
\text { produced, } \\
\text { locally sourced } \\
\text { food; } \\
\text { Committee on } \\
\text { World Food } \\
\text { Security (CFS) }\end{array}$ & $\begin{array}{l}\text { human right to } \\
\text { food; locally } \\
\text { sourced, } \\
\text { sustainably } \\
\text { produced, } \\
\text { culturally } \\
\text { appropriate, } \\
\text { democratically } \\
\text { controlled; } \\
\text { focus on } \\
\text { UN/FAO } \\
\text { negotiations }\end{array}$ \\
\hline $\begin{array}{l}\text { Guiding } \\
\text { Document }\end{array}$ & $\begin{array}{l}\text { World Bank } \\
2008 \\
\text { Development } \\
\text { Report }\end{array}$ & $\begin{array}{l}\text { World Bank } \\
2008 \\
\text { Development } \\
\text { Report }\end{array}$ & IAASTD & $\begin{array}{l}\text { Declaration of } \\
\text { Nyeleni; } \\
\text { Peoples' } \\
\text { comprehensive } \\
\text { framework for } \\
\text { action to } \\
\text { eradicate } \\
\text { hunger; } \\
\text { ICAARD; UN } \\
\text { Declaration of } \\
\text { Peasant Rights; } \\
\text { IAASTD }\end{array}$ \\
\hline
\end{tabular}

